IDI2 
Published by

Institute for Social Research - Zagreb

Sociology of Science and Technology Network

of ESA (European Sociological Association)

For the publisher

Vlasta Ilišin

Aaro Tupasela

Book editorial board

Aaro Tupasela, Chair

University of Helsinki

Katarina Prpić

Institute for Social Research - Zagreb

Luísa Oliveira

Lisbon University Institute

Sven Hemlin

Gothenburg University

Language revisers

Mark Davies

Stephen Hindlaugh

Book funding

Office for Gender Equality

of the Government of the Republic of Croatia

Ministry of Science, Education and Sports

of the Republic of Croatia

Copyright ( 2009 by Institute for Social Research - Zagreb

Sociology of Science and Technology Network

ISBN 978-953-6218-41-7

The CIP code is available in the electronic catalogue of the National and University Library in Zagreb under number 707731. 


\title{
Women in Science and Technology
}

\author{
Edited by \\ Katarina Prpić \\ Luísa Oliveira \\ Sven Hemlin
}

Institute for Social Research - Zagreb Sociology of Science and Technology Network of the European Sociological Association

Zagreb, 2009 



\section{Contents}

Aaro Tupasela

Foreword

Katarina Prpić

Why another book on women in science and technology?

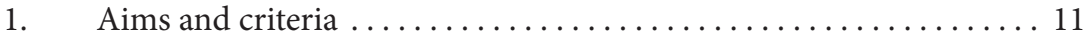

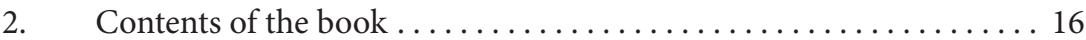

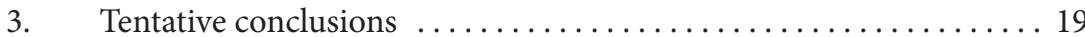

\section{Part I. Multinational comparisons of gender inequality in S\&T}

Luísa Oliveira and Helena Carvalho

The segmentation of the S\&T space and gender discrimination in Europe

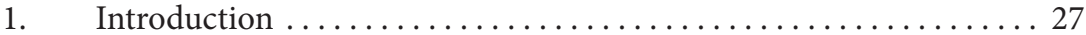

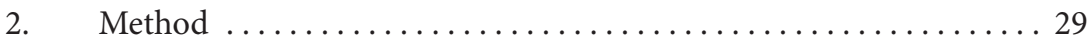

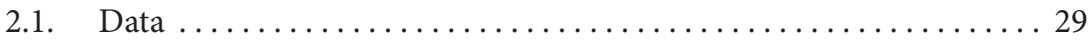

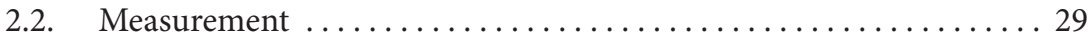

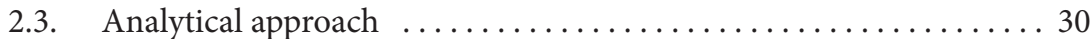

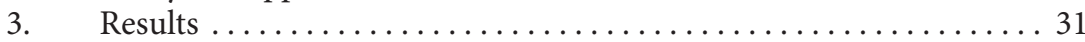

3.1. S\&T European space segmentation $\ldots \ldots \ldots \ldots \ldots \ldots \ldots \ldots \ldots \ldots$

3.2. Trends in gender discrimination by $\mathrm{S} \& \mathrm{~T}$ segment $\ldots \ldots \ldots \ldots \ldots 37$

3.3. Patterns of S\&T gender discrimination in the European Union .... 41

3.4. Segmentation of the S\&T space and gender discrimination

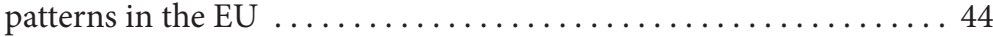

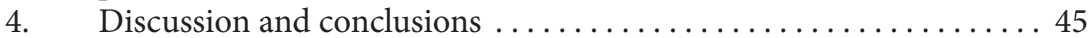

\section{Part II. Women's careers and performance}

Agrita Kiopa, Julia Melkers and Zeynep Esra Tanyildiz

Women in academic science: mentors and career development

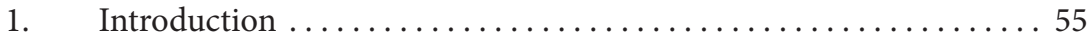

2. Mentoring programmes in STEM fields $\ldots \ldots \ldots \ldots \ldots \ldots \ldots 6$

2.1. Mentoring and career outcomes $\ldots \ldots \ldots \ldots \ldots \ldots \ldots \ldots \ldots \ldots$

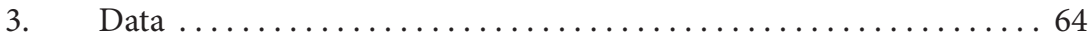

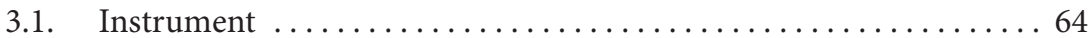




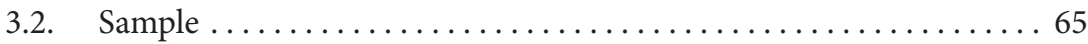

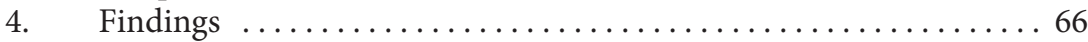

4.1. Do mentors matter? ............................ 66

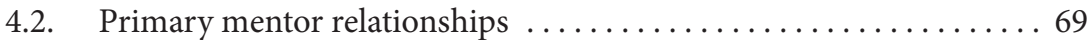

4.3. The contributions of mentors $\ldots \ldots \ldots \ldots \ldots \ldots \ldots \ldots \ldots \ldots \ldots$

4.3.1. Mentors as collaborators .......................... 73

4.3.2. Mentors as advisors ............................. 75

4.4. Moving beyond the primary mentor: Other sources of mentoring advice and interaction $\ldots \ldots \ldots \ldots \ldots \ldots \ldots \ldots \ldots 77$

5. Conclusion and future research $\ldots \ldots \ldots \ldots \ldots \ldots \ldots \ldots \ldots, 78$

Helene Schiffbänker

\section{Gender specific career aspects in science and technology}

1. Introduction .................................. 85

2. Women in science and technology in Austria .............. 86

3. "Career" as a sociological dimension ................... 90

4. Reconciliation of childcare and research ................. 95

4.1. Reconciliation and research ....................... 97

4.2. Reconciliation in Austrian non-university research institutions . . . 98

4.3. Employment structure in non-university research institutions . ... 99

4.4. Career implications and barriers ..................... 101

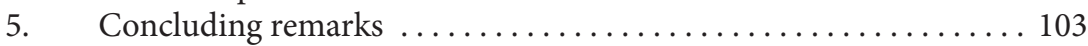

Katarina Prpić, Adrijana Šuljok and Nikola Petrović

Gender differences in the research productivity of natural and social scientists

1. Gender and productivity: puzzling findings or approaches? . . ... 109

2. Research design: a comprehensive comparison of the natural and social sciences ............................. 111

3. Findings: gender differentials in productivity at different

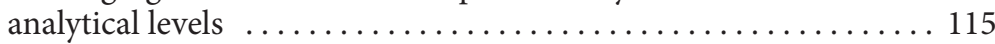

3.1. The socio-professional features of the two scientific populations .. 115

3.2. The first analytical level: visible gender patterns of scientific productivity . ................................. 117

3.3. The second level: trying to explain gender patterns in productivity 128

4. Gender differences in research productivity: dimensions and

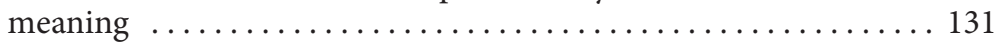

Anitza Geneve, Karen Nelson and Ruth Christie

Women's participation in the Australian Digital Content Industry: initial case study findings

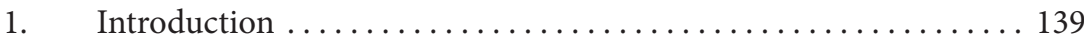

1.1. Research project .................................. 139 
1.2. Research domain .................................. 139

1.3. Agency as a way of understanding participation $\ldots \ldots \ldots \ldots \ldots 141$

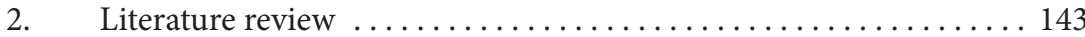

2.1. Previous research ............................... 143

2.2. Theoretical framework $\ldots \ldots \ldots \ldots \ldots \ldots \ldots \ldots \ldots \ldots \ldots \ldots, \ldots \ldots \ldots$

2.2.1. Multiple theories .............................. 145

2.2.2. Social Cognitive Theory ........................... 146

3. Methodology .................................. 147

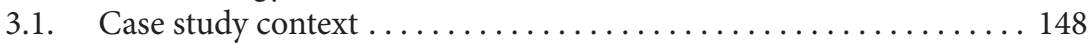

3.2. Data collection and analysis ........................ 150

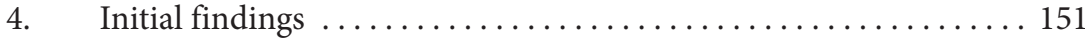

4.1. Context - pathways along a lifespan ................. 152

4.2. Influences - environment and agent .................... 154

4.2.1. Gender ratio . . . . . . . . . . . . . . . . . . . . . . . . . . 154

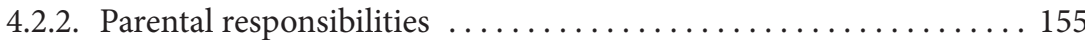

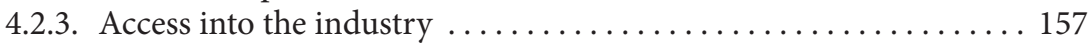

4.3. Processes - mechanisms of interaction $\ldots \ldots \ldots \ldots \ldots \ldots \ldots \ldots . \ldots \ldots$

4.3.1. Gender and occupational stereotypes and agency ............ 158

5. Sphere of Influence - the proposed model $\ldots \ldots \ldots \ldots \ldots \ldots 160$

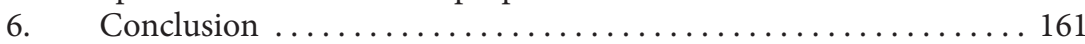

\section{Part III. Policy-relevant research and experiences}

\section{Danica Fink-Hafner}

\section{Changing frameworks for research into factors affecting the role of women in research decision-making}

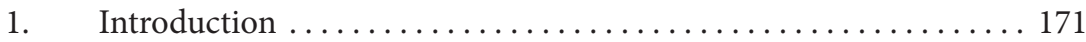

2. Frameworks for studying the role of women in research decision-making ............................... 174

2.1. Main theoretical and conceptual approaches $\ldots \ldots \ldots \ldots \ldots . \ldots 174$

2.2. Modernisation macro view findings ................... 177

2.3. Theories and concepts related to European integration processes and the current status of their research employment ......... 178

2.4. Organisational (cultural) learning $\ldots \ldots \ldots \ldots \ldots \ldots \ldots \ldots \ldots \ldots$

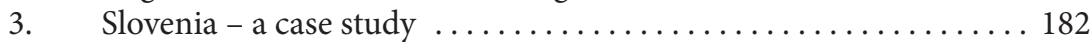

3.1. Macro view (general modernisation theory point of view) . . . . 182

3.1.1. Politics ...................................... 183

3.1.2. Management .................................. 184

3.1.3. Academic environment ........................... 185

3.2. EU pressures and their impacts ..................... 186

3.2.1. Multi-level governance view $\ldots \ldots \ldots \ldots \ldots \ldots \ldots \ldots \ldots \ldots \ldots \ldots$

3.2.2. "European" social constructivism . ................... 187 
3.3. Micro level - the organisational point of view $\ldots \ldots \ldots \ldots \ldots . \ldots 188$

3.3.1. Organisational (cultural) learning of national research funding

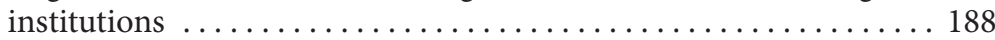

3.3.2. Organisational (cultural) learning of research organisations .... 188

4. Conclusions .................................. 192

Anke Reinhardt

Third party funding agencies and their role in advancing women in science: The case of the DFG in Germany

1. Introduction .................................... 199

2. Gender equality in science policy studies $\ldots \ldots \ldots \ldots \ldots \ldots \ldots . \ldots 201$

3. Equal opportunities as a research policy issue $\ldots \ldots \ldots \ldots \ldots . \ldots 204$

3.1. Research policy players in Germany for women in science ..... 205

3.2. The role of third party funding agencies in promoting gender

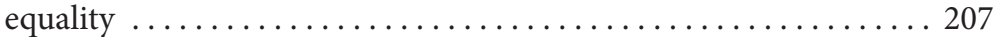

3.3. The DFG and its role in research policy issues ............. 209

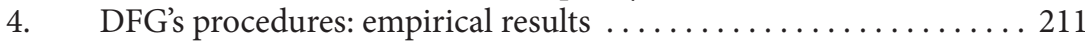

4.1. Functioning of peer review processes ................. 212

4.2. Distribution of resources: applications for and success with research grants ................................... 215

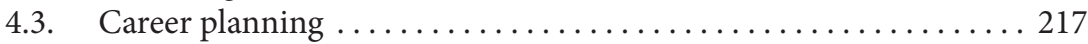

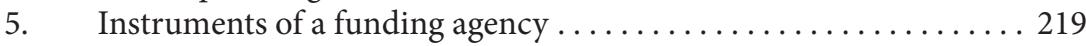

6. Conclusion and future prospects $\ldots \ldots \ldots \ldots \ldots \ldots \ldots \ldots \ldots \ldots \ldots \ldots \ldots \ldots, 222$

\section{Appendix}

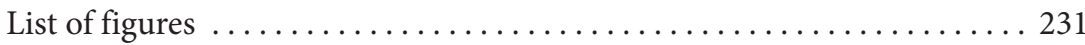

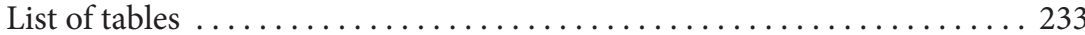

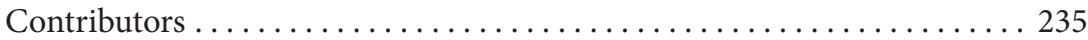




\section{Foreword}

The European Sociological Association's (ESA) Research Network 24 on the Sociology of Science and Technology Network (SSTNET) was founded in 1999 to promote and support the development of a European framework for the study of science and technology. Part of these activities includes the organization of a bi-annual workshop to promote the exchange of ideas and research results among the research community. Over the years the network has been able to broaden its membership base and attract a great deal of attention and interest towards its activities.

In June 2008 the SSTNET organized, in cooperation with the Institute for Social Research of Zagreb, a two day workshop entitled "Women in Science and Technology" in Zagreb, Croatia. The idea and driving force behind the workshop came from our networks co-chair Katarina Prpić who suggested that such a workshop would be timely and attract a host of international researchers to present and discuss the most recent trends and research results in this field. The two-day workshop brought forth the depth and breadth of the state of research concerning women in science and technology and highlighted the need to continue to foster further scientific enquiry into this field, as well as collaboration between researchers. It also provided an excellent opportunity to network and discuss research ideas amongst its participants.

Given the high quality of the presentations that took place it was decided that a book showcasing the best papers of the workshop should be published and contributions were therefore invited from the presenters. The production of this book would not have been possible without the commitment and hard work of its editors Katarina Prpić, Luísa Oliveira and Sven Hemlin. Besides working as members of SSTNET they have also committed themselves to furthering and facilitating the publication of research results, which is one of the goals of the network. We are grateful for their work in bringing this book to fruition. Special thanks should undoubtedly go to all those who participated in the workshop and its discussions, particularly those who have contributed to this valuable volume, including the reviewers who commented on the manuscript. The articles contained within the covers of this book provide an important cross-section of some of the most current research that is taking place in the field today. 
All such undertakings also require funding and it is with gratitude that we extend our thanks to the European Sociological Association and the Croatian Ministry of Science, Education and Sports for funding the workshop and the Institute for Social Research in Zagreb as a co-organiser of the workshop. More importantly, however, we are very grateful to The Office for Gender Equality of the Government of the Republic of Croatia and the Croatian Ministry of Science, Education and Sports for funding this publication. However, without commitment and support of the scientific and technical staff of the Institute of Social Research in Zagreb this publication would not have been possible.

We hope that this volume will serve its reader as a valuable resource and reference source for facilitating and stimulating further research and learning into the field of women in science and technology studies.

Aaro Tupasela

Chair of SSTNET and of Book Editorial Board 


\section{Katarina Prpić}

\section{Why another book on women in science and technology?}

\section{Aims and criteria}

The reasons for publishing this book are both general and particular. The general reasons are related to the overall importance of gender topics in (social) studies of science and technology, and the particular reasons arise from the contribution the book may make to a deeper understanding of the processes, patterns and factors of gender differentiation in research and development (R\&D). We will attempt to identify both in order to show the goals we had in mind with another book in a growing body of research and literature on the position and role of women in science and technology studies (STS).

The claims that this topic is rarely covered in the sociology of science are now obsolete. Merton's school, the most influential in the field at the time, sought to investigate gender differences in science on account of their unwanted influence on the universalism of science. Although the differences found were reduced through their interpretation, the school's interest is considered an exception to the general neglect of the said topic (Delamont, 1987, 1989). However, social constructivist studies of science did face (feminist) criticism for their neglect of the gender aspect (Rose, 1990). The criticism was also confirmed by empirical analyses of the production of four eminent journals of the traditional and new history and sociology of science in the 1980s and one in the 1990s (Delamont, 1987, 2002). However, an increase in the number of articles on women in science, and reviews of the most relevant feminist works were noticed in the latter period (Delamont, 2002).

On the other hand, judging by the 1,793 articles and books published on this topic since 2000, interest in women studies in STS has increased significantly. ${ }^{1}$ In terms of books, feminist science studies

1 The piece of information was obtained by a simple Google Scholar search. In the first round, all publication titles that included the words women and science and that were published between 2000 and 2009 in the social sciences (including economics) were extracted. The word gender was excluded in the search. In the second round, the titles of publications from the same 
stand out among the most frequent types of recent literature in this area (for example, Mayberry, 2001; Pinnick et al., 2003; Harding 2006, 2004; Wyer et al., 2008) as well as historical and encyclopaedic works on women scientists and/or scholars (for example, Oglivie and Harvey, 2000; Haines and Stevens, 2001; Nye, 2003; Sheffield, 2004). However, there are numerous books, usually multi-authored rather than monoauthored or co-authored, that have tried to explain gender differentiation in science with various theoretical approaches and empirical analyses (Etzkowitz et al., 2000; Palomba and Menniti, 2001; Long, 2001; Xie and Shauman, 2003; EC, 2004; Ceci and Williams, 2007). Some of these and similar books contain elaborate recommendations for policies of gender equality in science (EC, 2004; NAS, NAE and IM, 2007). This growing research interest must have been sparked by feminist criticism of science, the increasing presence of women studies at universities, and the expansion of gender equality policies in society and in $\mathrm{R} \& \mathrm{D}$, both at national and international levels, especially within the framework of the European Union.

Such a scientific and social context also encouraged the research network (RN24) of the European Sociological Association (ESA), called the Sociology of Science and Technology Network (SSTNET), to convene a workshop under the title Women in Science and Technology, with the Institute for Social Research - Zagreb as the local organiser, on 5 and 6 June 2008 in Zagreb, Croatia. ${ }^{2}$ The goal of the workshop was to assemble a broad range of researchers to present their recent findings on gender in S\&T and to promote communication between scientists in this field. The presented papers (nineteen of them and two additional circulating papers) made up four topical categories: a) broader comparative and historical analyses of the role of women in science and technology; b) studies of the scientific career and performance of

period and field of science which used the terms gender and science were extracted, while the word women was excluded. Publication titles with all three words (the same period and scientific fields) were extracted in the third round. The data pertain to 16 March 2009, the date when the search was conducted.

2 The workshop received financial support from the ESA and the Croatian Ministry of Science, Education and Sports and was attended by a total of 39 participants from 10 European countries (Austria, Croatia, Finland, Germany, Portugal, Slovenia, Sweden, the Czech Republic, the Netherlands, the UK) and also from the USA and Australia. The members of the Workshop Organising Committee were: Katarina Prpić (Institute for Social Research - IDIZ, Croatia), Aaro Tupasela (University of Helsinki, Finland), Luísa Oliveira (Lisbon University Institute ISCTE, Portugal), Sven Hemlin (University of Gothenburg, Sweden) and Yuwei Lin (University of Manchester, UK). 
women researchers; c) studies of gender and technology; d) analyses of the relations of science policies toward gender equality.

These topics are certainly represented in this book, but the reasons for publication go beyond mere thematic diversity. Through the selection of papers, we have tried to achieve several goals important for the development of research on gender differentiation in science and technology. We could not completely follow the recommendations on achieving the greater visibility and impact of women (scientist) studies in the field of science and technology studies (Delamont, 2002), but we certainly did keep them in mind. Here, we primarily refer to the recommendation for the role of women in science and technology to be observed within the framework of the most important research problems and theoretical insights in STS (Delamont, 2002).

The concept of the book, especially the selection of papers and organisation of chapters, rests on the following scientific goals and criteria:

- the relevance of the presented research questions in studying gender differentiation in science but also in the studies of science and technology in general;

- the thematic diversity and complementarity of papers that make up a certain topical whole related to the role of women in science and technology;

- the theoretical foundation of the research, empirical insights into relevant gender issues, and the methodological diversity of papers;

- gender issues with regard to technoscientific, socio-economic and socio-cultural differences and the specificities of individual countries and wider regions;

- the social importance of the research and the research results, and the potential applicability of individual papers and the whole book in the promotion of gender equality in national and supranational (especially EU) frameworks.

The concept of this book thus aimed at expanding insights into some of the most important, and yet underinvestigated or somewhat contradictory, issues of gender differences in science and technology. This certainly refers to broader, sociologically founded, international comparisons of gender differentiation in research and development (R\&D) based on key statistical indicators. In contrast to valuable EU statistical analyses, both in periodical publications like She figures and 
in specialised editions (see EC, 2008), there have been practically no such comparisons in STS so far. Research on gender differences in mentoring experiences on a national scale is also scarce. The same can be said of comparisons of the scientific production of all scientists, both men's and women's, in the hard and soft sciences.

The situation is similar with comparisons of the career trajectories of men and women researchers in the analytically neglected non-university sector, just as it is with the studying experiences of women working in creative technical roles in information communication technology (ICT). Theoretically grounded research agendas, on whose findings gender policy debates can rely, and the experiences of the German Research Foundation (DFG) - one of the giants in science funding - in the promotion of equal opportunities for women and men scientists are important for gender policy studies and for gender equality policies in science.

These issues are relevant for the broader investigations of science since they touch on the important topics of differentiation of (social) S\&T space, professional socialisation, career patterns, researchers' performance, and science policy. Their importance for gender studies in S\&T arises from the effort to go beyond the mere participation of women in science and technology, and to search for various societal, subsystemic, group and individual impacts on women's roles in that sphere. Due to their complementarity, these issues constitute a certain whole because they include all the important elements of a thematically integrated scientific insight into gender differentiation in S\&T - from the education and recruitment of women, their scientific socialisation, career, productivity and contribution, to social support in achieving gender equality in science. There is no need to stress that a relatively complete, and also empirical, insight has some social importance and provides a scientific platform for an efficient gender policy in science and technology.

Although the majority of papers published in this book are based on empirical studies or at least on the use of secondary sources (statistical data and/or the results of other studies), they develop hypothetical frameworks based on relevant sociological, psychological and political science theories. Thus, the classical sociological concept of career is subjected to feminist criticism, and, by integrating aspects such as the reconciliation of work and family which are neglected but important for women, a better understanding can be gained of the career trajecto- 
ries and the deconstruction of traditional gender roles. It is also shown that the theories of scientific fields (organisations) can contribute to an explanation of different patterns of gender differentiation in the research production of various scientific fields by bringing attention to the differences in the social organisation of individual sciences. The socalled social cognitive theory as a learning theory has also proved to be a suitable theoretical framework to explain the participation of women in the technologically sophisticated sector of multimedia and games production. In an effort to obtain the best possible research findings to serve as the foundation for a more successful gender equality policy in science, especially in the EU, complex theoretical approaches are analysed - the modernisation theory, (social) constructivism, multi-level governance, policy network and organisational theories.

The empirical analyses presented here differ greatly in their methodologies. They use both primary (the researchers' own) and secondary (other) sources of information, and also both qualitative methods of data collection (interviews) and quantitative methods (questionnaire surveys), including bibliometrical data gathering. The analytical level of the papers also differs significantly - ranging from international and multinational comparisons of gender differentiation in S\&T, comprehensive analyses and research at the national level (of individual countries), through to case studies. It is clear that the data processing methods vary from more complex quantitative methods, such as multivariate models and simple quantitative analyses, to permanent comparative analyses of qualitative data with the aim of allowing for theoretically informed interpretation.

Finally, through the selection of these papers, we wanted to present and examine the general similarities as well as the specificities of gender differences in S\&T arising from the disparities in the socio-cultural, economic and technoscientific development of individual (groups of) countries. For this reason, the book includes papers that examine gender differences in various highly developed European and nonEuropean countries, as well as relevant analyses related to the societies of the South of Europe and to post-socialist regions. In fact, comparative sociological and other investigations have already shown that technoscientific development is not linear and uniform. Thus, studies on scientific productivity find or assume its cultural and structural background variables, apart from its common determinants such as economic development (Cole and Phelan, 1999; Teodorescu, 2000; 
Inönü, 2003). Although various effects of the influence of different societies on gender differentiation in science have already been noticed (Etzkowitz et al., 2000; Prpić, 2002; Blagojević, 2004; Lagesen, 2008), it seems that they are not always given enough prominence in the STS literature. Their relevance is seen here primarily in multinational comparisons, but also at the national level of individual analyses when they are put into a wider international context. At the same time, the book also points out the common characteristics of the (more marginal) role of women scientists in different social frameworks, showing that no policy-relevant research can be conducted without knowledge of the supranational factors of gender differentiation.

\section{Contents of the book}

The topic-based organisation of the book arises from its concept. Besides the introduction, the book consists of three thematic units or parts. Although comprising only one paper, the first part, Multinational comparisons of gender inequality in Se $T$, is close to being a general, main overview because it offers international (European) comparisons of the key indicators of gender differentiation in science and technology. The second part is entitled Women's careers and performance, indicating the common denominator of the four chapters included in this part. The third part, Policy-relevant research and experiences, consists of two papers, where one investigates the research bases relevant for the development of gender equality policies in R\&D, and the other sums up the experiences of one of the most powerful actors of such a policy.

- The first chapter of the book is The segmentation of the S\&T space and gender discrimination in Europe by Luísa Oliveira and Helena Carvalho. The authors examine the relation between the patterns of technoscientific development and gender inequality at the multinational level of the EU, applying multivariate data analyses to the key statistical data or indicators of the observed phenomena. They find three patterns of European S\&T development, with the main difference lying between the rich northern and central countries and the poor eastern and southern regions. Three types of gender discrimination are found, differing in intensity and type of discrimination. Women are generally discriminated against in Europe, but a relation between developed S\&T regions and gender discrimination patterns 
is revealed: the most developed countries tend to be more discriminative in the academic conditions for women's scientific careers. However, some gender discrimination indicators cannot be explained simply by S\&T segmentation.

- In the second part of the book, the authors of the first chapter entitled Women in academic science: mentors and career development are Agrita Kiopa, Julia Melkers and Zeynep Esra Tanyildiz. They review key issues in the mentoring process for academic women in (natural) science, technology, engineering and mathematics (STEM). They also present the results of a 2006 national survey on the mentoring experiences of academic (natural) scientists and engineers in research extensive universities in the United States. According to the survey findings, both men and women academics show higher productivity and greater satisfaction when they have a primary mentor. Regarding some observed gender differences, it was found that women who had a primary mentor performed at the same level as their male colleagues. The study suggests that mentoring relationships in academia may be an important indicator for scientific productivity, especially in studies attempting to predict gender differentials in research production.

- The second chapter in this part of the book is Gender specific career aspects in science and technology by Helene Schiffbänker. After describing the analytically neglected Austrian non-university sector, with emphasis on gender differences in career steps, the author questions the gender relevance of classical career concepts. The relevance of feminists' insistence that career theory should include the private sphere is also stressed. The author's survey of researchers from the non-university sector therefore focuses on the reconciliation of child care and research work, since the former is usually considered to be the main determinant of women's less successful careers. A traditional employment structure and traditional gender roles are found: women researchers work part time and do most of the unpaid work, in contrast to men who work full time. Women thus experience dequalification and declining career perspectives. Hence, more pluralistic career paths in research culture become socially desirable.

- Gender differences in the research productivity of natural and social scientists is the third chapter. Its authors - Katarina Prpić, Adrijana Šuljok and Nikola Petrović - present bibliometric research of WoSindexed productivity from 1996 to 2005 of all Croatian natural and so- 
cial scientists who hold a doctorate. Gender differences are significant in the natural sciences, as opposed to the social sciences (which show much smaller WoS production and visibility). When a minimal set of productivity predictors was used, there was no significant impact of gender on publications and citations in the social sciences, and a significant but small impact in the natural fields. In the latter area, the influence of gender disappears when the number of publications is added to the predictors of citations. Consequently, women's publications, whether in the natural or the social sciences, do not have lesser international visibility than men's, which - in line with some other studies - indicates women's scientific achievement since they do not have the same professional advantages as men.

- Anitza Geneve, Karen Nelson and Ruth Christie are the authors of the fourth chapter Women's participation in the Australian Digital Content Industry: initial case study findings. The paper is based on a case study exploring the problem of the low participation of women employed as interactive content creators in the sector of multimedia and games production. An online questionnaire survey and interviews were used in the data collection. Initial findings provide rich descriptive insights into the perceptions and experiences of female DCI professionals. The findings show that women are confronted with negative influences that may discourage their participation in this career and that women who remain in the industry had previously overcome potential barriers or were able to embrace the support available within their environment. Thus, being active agents, women have an element of control over their environment. The analysis and analytic generalisation of the case study findings were guided by Bandura's social cognitive theory (SCT).

- Changing frameworks for research into factors affecting the role of women in research decision-making is the first chapter in the last part of the book. Its author, Danica Fink-Hafner, focuses on the theoretical frameworks of high quality research on gender issues in R\&D which can be a solid basis for policy debates. The main theoretical and conceptual approaches and the empirical studies inspired by them are presented: modernisation theory, theories/concepts explaining European integration processes, and organisational theories. An overview of Slovenian studies related to the mentioned approaches results in the finding that policy relevant research on gender inequality is in general (and not only in Slovenia) insufficiently based on a multidisciplinary, 
systematic, comparative, longitudinal and multi-level research agenda. The author concludes that gender studies in STS should take all economic, social and political aspects of globalisation seriously, that social science theories need to be "gendered", and that additional gender-sensitive theoretical approaches should be developed.

- The last chapter of the book entitled Third party funding agencies and their role in advancing women in science: the case of the DFG in Germany is written by Anke Reinhardt. Since the German Research Foundation (DFG) is one of the key science policy actors in the country, this analysis focuses on DFG's internal mechanisms and on its policies addressing the barriers in a woman's scientific career. The analysis summarises the main research findings on gender inequality in academia relevant to the research policy actors. Data on women in the DFG bodies, in the peer review process, and in the distribution of resources, as well as women's perceptions of these processes, are also presented. Gender equality has become one of DFG's statutory goals and many policies have been adopted, ranging from ensuring the representation of women in review groups and in decision-making bodies, to a system of monitoring the effects of such policies. Since the measures are very recent, their impacts cannot yet be evaluated.

\section{Tentative conclusions}

Is it possible to draw any common, at least tentative, conclusions on the role of women in science and technology from these studies that differ in approach, methods, scope and socio-cultural background? The answer in short is: yes. Indeed, the aim of publishing this book was to provide a sample of a thematic whole through a selection of papers. Moreover, the possible conclusions refer to the research findings as well as to the theoretical and methodological implications of the presented studies and analyses.

First, even though they were limited to European societies and some developed non-European countries, these studies also identify gender differentiation as an undeniably universal phenomenon. This is corroborated primarily by the results of a comparison of statistical indicators at the EU level (see Oliveira and Carvalho, 2009), but also by other studies and analyses presented here. Gender differences are seen not only in women's representation in $\mathrm{R} \& \mathrm{D}$, but also in the obstacles they had to overcome to remain in the sector (Geneve et al., 
2009). The differences are also apparent in the career patterns and performance, and especially in the distribution of power, for example in the participation of women in research decision-making bodies. The universality of gender differences was already noticed in earlier, especially comparative, studies (Etzkowitz et al., 2000; Etzkowitz and Kemelgor, 2001). In our opinion, the contribution of this book is that it can encourage systematic comparisons of gender differentiation patterns, and not only comparisons of individual data or indicators, and that these comparisons may be continuously expanded to cover an increasing number of European and other countries. Certainly, the implications of systematic multinational comparisons are both cognitive (better scientific insights) and policy relevant (efficient gender policies in S\&T).

Second, in the light of these studies, gender inequalities prove to be impregnated with the effects of the given society, its economic, political, technoscientific and socio-cultural specificities. This is most obvious in cross-county comparisons, proving that relations between economic and technoscientific development on one hand, and gender (in)equality on the other, have no simple, regular, or even easily interpretable patterns, as was indicated in earlier comparative sociological studies (Etzkowitz et al., 2000; Etzkowitz and Kemelgor, 2001). European social space, not to mention global space, is highly differentiated in terms of gender inequality, and certain types of European societies can also be identified and can be related to their socio-historical background (the post-socialist societies, for example). This book draws attention to the need for deeper comparative, multidisciplinary research of the differences in types of social development, gender inequality, and their mutual relations.

Third, despite the gender differences in research performance corroborated here, these same differences were also relativised by the findings of two very different scientific and social milieux, with far-reaching cognitive and social implications. Namely, gender differences in the average output of American scientists in the natural and technical disciplines become negligible if women have a primary mentor (Kiopa et al., 2009). Similarly, there are no significant differences among Croatian social scientists, while among natural scientists these differences are significant but small, and gender has no influence on citation rates when the number of publications is taken into account (Prpić et al., 2009). The relevance of these results lies not 
only in their compatibility with the findings of some other studies (EC, 2004), but in their methodological reliability and consequential implicit theoretical "subversiveness". Old explanations of women scientists' professional marginality with their smaller publication output have already been replaced by a search for multi-layered sociological, psychological and multi-disciplinary explanations. These findings imply that simple comparisons of the number and visibility of publications should give way to more complex comparisons and studies on the efficiency and purpose of the publication strategies of men and women scientists, and also to re-examining the evaluation criteria for scientists' production.

Fourth, it has been shown that, in terms of theory and methodology, the application, modification and development of theoretical models created in STS, but also in other social sciences, crucially directs empirical studies of gender differentiation in science and technology, thus enriching them with more relevant empirical insights. Moreover, a separate analysis has proven that the key precondition for creating successful (supra)national gender equality policies in $R \& D$ is the grounding of these studies in the most important and heuristically most fruitful social theories and concepts and in adopting more complex theoretical and methodological approaches (Fink-Hafner, 2009).

Fifth, although this book does not aim to offer a set of immediately applicable results for science and/or gender policy, all of its findings have a socially applicable dimension. This refers to the analysis of gender policy conceived and introduced by a powerful German science funding agency (Reinhardt, 2009) whose experiences go beyond the national level, but also to all other studies from which recommendations for improving women's positions and roles in science and technology can be derived. One of the presented studies, however, includes clear recommendations for establishing better career prospects for women in $\mathrm{R} \& \mathrm{D}$, and advocates concrete changes in career conditions and concepts at the macro social level, at the level of the scientific system, and at the organisational or micro level (Sciffbänker, 2009).

We leave it to colleagues in our field and to the interested wider scientific public to decide if we have met the set goals of this book, and if we have contributed to enriching knowledge about women in science and technology and in affirming the relevance of gender issues for the development of the overall STS area. 


\section{References}

BYSTYDZIENSKI, Jill M., \& BIRD, Sharon R. (2006). Removing barriers: Women in academic science, technology, engineering, and mathematics. Bloomington and Indianapolis: Indiana University Press.

BLAGOJEVIĆ, Marina (2004). Creators, transmitters and users: Women's scientific excellence at the semy-periphery of Europe. In EC. Gender and excellence in the making (pp. 135-145). Brussels: European Commission.

CANEL, Annie, OLDENZIEL, Ruth, \& ZACHMANN, Karin (Eds.) (2000). Crossing boundaries, building bridges: Comparing the history of women engineers, 1870s 1990s. Amsterdam: Harwood Academic Publishers.

CECI, Stephen, \& WILLIAMS, Wendy M. (Eds.) (2007). Why aren't more women in science? Top researchers debate the evidence. Washington, DC: American Psychological Association.

COLE, Stephen, \& PHELAN, Thomas J. (1999). The scientific productivity of nations. Minerva, 37 (1), 1-23.

DELAMONT, Sara (1987). Three blind spots? A comment on the sociology of science by a puzzled outsider. Social Studies of Science, 17 (1), 163-170.

DELAMONT, Sara (1989). Knowledgeable women: Structuralism and the reproduction of elites. London and New York: Routledge.

DELAMONT, Sara (2002). Hypathia's revenge?: Feminist perspectives in S\&TS. Social Studies of Science, 32 (1), 167-174.

EC (2004). Gender and excellence in the making. Brussels: European Commission.

EC (2008). Benchmarking policy measures for gender equality in science. Brussels: European Commission.

ETZKOWITZ, Henry, \& KEMELGOR, Carol (2001). Gender inequality in science: A universal condition? Minerva, 39 (2), 153-174.

ETZKOWITZ, Henry, KEMELGOR, Carol, \& UZZI, Brian, with NEUSCHATZ, Michael, SEYMOUR, Elaine, MULKAY, Lynn ALONZO, Joseph (2000). Athena unbound: The advancement of women in science and technology. Cambridge: Cambridge University Press.

FINK-HAFNER, Danica (2009). Changing frameworks for research into factors affecting the role of women in research decision-making. In K. Prpić, L. Oliveira, S. Hemlin (Eds.), Women in science and technology (pp. 169-198). Zagreb: IDIZ - SSTNET.

FOX, Mary Frank, JOHNSON, Deborah G., \& VILHAUER ROSSER, Sue (Eds.) (2006). Women, gender, and technology. Chicago: University of Illinois Press.

GENEVE, Anitza, NELSON, Karen, \& CHRISTIE, Ruth (2009). Women's participation in the Australian Digital Content Industry: initial case study findings. In K. Prpić, L. Oliveira, \& S. Hemlin (Eds.), Women in science and technology (pp. 139-168). Zagreb: IDIZ - SSTNET.

HAVEN, Kendall (2003). Women at the edge of discovery: 40 true science adventures. Westport, Connecticut - London: Libraries Unlimited.

HAINES, Catharine M. C., \& STEVENS, Helen M. (Eds.) (2001). International women in science: A biographical dictionary to 1950. Santa Barbara, CA: ABC-CLIO. 
INÖNÜ, Erdal (2003). The influence of cultural factors on scientific production. Scientometrics, 56 (1), 137-146.

KIOPA, Agrita, MELKERS, Julia, \& TANYILDIZ, Zeynep Esra (2009). Women in academic science: Mentors and career development. In K. Prpić, L. Oliveira, \& S. Hemlin (Eds.), Women in science and technology (pp. 55-84). Zagreb: IDIZ SSTNET.

LAGESEN, Vivian Anette (2008). A cyberfeminist utopia? Perceptions of gender and computer science among Malaysian women computer science students and faculty. Science, Technology, \& Human Values, 33 (1), 5-27.

LEDERMAN, Muriel, \& BARTSCH, Ingrid (Eds.) (2001). The gender and science reader. London and New York: Routledge.

LONG, J. Scott (Ed.) (2001). From scarcity to visibility: Gender differences in the careers of doctoral scientists and engineers. Washington, D.C.: National Academy Press.

MAYBERRY, Maralee, SUBRAMANIAM, Banu, \& WEASEL, Lisa H. (Eds.) (2001). Feminist science studies: A new generation. London and New York: Routledge.

NAS, NAE and IM (National Academy of Sciences, National Academy of Engineering and Institute of Medicine) (2007). Beyond bias and barriers: Fulfilling the potential of women in academic science and engineering. Washington D.C: The National Academies Press.

NYE, Mary Jo (Ed.) (2003). The Cambridge history of science: The modern physical and mathematical sciences. Cambridge: Cambridge University Press.

OGLIVIE, Marylin \& HARVEY, Joy (Eds.) (2000). The bibographical dictionary of women in science. Pioneering lives from ancient times to the mid-20 th $c e n t u r y$. Vols. 1 and 2. New York and London: Routledge.

OLIVEIRA, Luísa \& CARVALHO, Helena (2009). The segmentation of the S\&T space and gender discrimination in Europe. In K. Prpić, L. Oliveira, \& S. Hemlin (Eds.), Women in science and technology (pp. 27-51). Zagreb: IDIZ - SSTNET.

PALOMBA, Rossella, \& MENNITI, Adele (2001). Minerva's daughters - Filles de Minerve. Rome: Institute for Research on Population and Social Policies.

PRPIĆ, Katarina (2002). Gender and productivity differentials in science. Scientometrics, 55 (1), 27-58.

PRPIĆ, Katarina, ŠULJOK, Adrijana \& PETROVIĆ, Nikola (2009). Gender differences in the research productivity of natural and social scientists. In K. Prpić, L. Oliveira, \& S. Hemlin (Eds.), Women in science and technology (pp. 109-138). Zagreb: IDIZ - SSTNET.

PINNICK, Cassandra L., KOERTGE, Noretta, \& ALMEDER, Robert F. (Eds.) (2003). Scrutinizing feminist epistemology: An examination of gender in science. Piscatawy, NJ: Rutgers University Press.

REINHARDT, Anke (2009). Third party funding agencies and their role in advancing women in science: the case of the DFG in Germany. In K. Prpić, L. Oliveira, \& S. Hemlin (Eds.), Women in science and technology (pp. 199-228). Zagreb: IDIZ - SSTNET.

ROSE, Hilary (1990). Talking about science in three colours: Bernal and gender politics in the social studies of science. Science Studies, 3 (1), 5-19. 
ROSSER, Sue V. (Ed.) (2008). Women, science, and myth: Gender beliefs from antiquity to the present. Santa Barbara, CA: ABC-CLIO.

SCHIFFBÄNKER, Helene (2009). Gender specific career aspects in science and technology. In K. Prpić, L. Oliveira, \& S. Hemlin (Eds.), Women in science and technology (pp. 85-107). Zagreb: IDIZ - SSTNET.

SHEFFIELD, Suzanne Le-May (2004). Women and science: Social impact and interaction. Santa Barbara, CA: ABC-CLIO.

TEODORESCU, Daniel (2000). Correlates of faculty publication productivity: A cross-national analysis. Higher Education, 39 (2), 201-222.

XIE, Yu, \& SHAUMAN, Kimberlee A. (2003). Women in science: Career processes and outcomes. Cambridge MA - London UK: Harvard University Press. 


\section{Part I}

\section{Multinational comparisons of gender inequality in S\&T}





\section{Luísa Oliveira \\ Helena Carvalho}

\section{The segmentation of the S\&T space and gender discrimination in Europe}

\section{Introduction}

This chapter examines the relationship between Science and Technology (S\&T) development and gender discrimination patterns in the EU at a macro level stage, using statistical data. ${ }^{1}$ It aims to explore EU heterogeneity both in S\&T development and gender discrimination in order to obtain a greater understanding of the differences between European regions in these fields. This could open up possible new research directions and also prove useful in policymaking.

Historically, differences are found both in countries' S\&T development and in their technological trajectories (Dosi, 1982, 1983; Perez, 1988). The development level of European countries and their technological dependence relations sustain the presupposition of a stratified European S\&T space ${ }^{2}$ (Oliveira and Carvalho, 2002). Our main hypothesis is that gender discrimination in $\mathrm{S} \& \mathrm{~T}$ is strongly related to the S\&T development of each European region. If this hypothesis is confirmed, European regions with the most developed S\&T systems should be distinct from others by having a more equalitarian gender situation.

This may occur in spite of the changes that are taking place to mitigate differences, such as the attempt to build a European higher education system in the Bologna Declaration. Other structural change factors are being implemented in the European S\&T space, inspired by the well-known triple-helix formula (Etzkowitz and Leysdorf,

\footnotetext{
${ }^{1}$ For a discussion on the problems of cross-national comparisons see, among others, M. Maurice et al. (1986) and M. L. Kohn (1989).

2 The European Science and Technology (S\&T) space is firstly a knowledge-embedded and occupational space that is constructed in interaction with the actors who constitute it, including its institutions, culture, rules and policies. Thus the S\&T space is not synonymous with the S\&T system, because it is a "social construct" that emerges out of the subtlest interactions between collective actors (men and women) and their professional activities, interactions which are then structured and diffused within organisations and institutions (Oliveira, 2008).
} 
1997), largely due to budgeting pressures and the financial crises of the welfare state. With companies co-financing research, academia has opened up to the business world, which will contribute in time to change in both the academic and business cultures in each country. As this is a relatively recent process in Europe, and the conditions of implementation vary from country to country, the inheritance of the culture of the Humboldt University model (Oliveira, 2000) and career procedures postulated by Merton's (1973) regulation of science may continue to be present and to a certain extent may explain the possible gender differences in S\&T nowadays. This is particularly relevant if we consider that even universities in the oldest European democracies are extremely closed institutions, metaphorically comparable to an ivory tower, thus contributing to the maintenance of a certain conservatism (Caplan, 1994; Rhode, 2006). Given that gender discrimination is found across Europe in the most varied areas (Cockburn, 1983; Charles, 1993; Maruani, 2005; McGrayne, 2001), and that there are multiple explanations for this phenomenon, our starting point is that the nature of the political regimes governing post-war Europe and their more or less conservative approach to science for civil purposes has affected the development of their Science and Technology (S\&T) systems as well as societal and organisational socialisation processes. As these effects are long-lasting, they have produced a culture that tends to neutralise discriminatory social practices in specific contexts. This may support the hypothesis that gender discrimination ${ }^{3}$ in S\&T, which has deep-seated cultural roots, reacts distinctly and at different speeds to European gender equality policies (CCE, 2007; RuestArchambault, 2008). In addition, the timing of countries' integration into the EU construction process contributes to this situation, as do their specificities in the transition process to a market economy and democracy (Stark, 2008).

Our first analysis explored the hypothesis of EU S\&T space stratification, identifying the configuration of each of these strata and the countries associated with each of them. The second analysis evaluated to what extent these strata are distinct from each other in relation to gender discrimination indicators. In addition, European S\&T patterns

${ }^{3}$ In this chapter, we use the BIT definition for gender discrimination as "any distinction, exclusion or preference made on the basis ... of sex..., which has the effect of nullifying or impairing equality of opportunity of treatment in employment or occupation..." (BIT, 2007: 9). 
of gender discrimination were identified and described. Finally, the articulation between the S\&T strata and these gender discrimination patterns were mapped.

\section{Method}

\subsection{Data}

For cross-country comparison at the EU level, we examined statistical information derived from data in Eurostat science and technology (S\&T) statistics and in the She figures 2006 report: Women and science statistics and indicators. The data relate to the active population, aged between 15 and 64 for 2003 and 2004 .

\subsection{Measurement}

Three main indictors were used to analyse the segmentation of the S\&T European space (EU 27) from a cross-national perspective:

- the proportion of researchers per thousand labour force (2003); ${ }^{4}$

- the proportion of scientists and engineers in the total labour force (2004);

- the proportion of $\mathrm{R} \& \mathrm{D}$ expenditure in Purchasing Power Standards (PPS) per capita researcher (2003). ${ }^{5}$

The following indicators were used to analyse gender discrimination:

- the proportion of $\mathrm{PhD}$ (ISCED 6) graduates by sex (2003);

- the proportion of researchers by sex (2003);

- the proportion of academic staff total by sex (2004);

- the proportion of women in grade $\mathrm{A}^{6}$ positions among all women in academic staff (2004);

- the proportion of men in grade A positions among all men in academic staff (2004);

- the difference in research funding success rates between women and men (2004);

\footnotetext{
${ }^{4}$ The labour force includes both employed and unemployed people.

${ }^{5}$ Purchasing Power Standard (PPS) is the artificial common currency into which national currencies are converted (Eurostat, 2004).

${ }^{6}$ Grade A is "the single highest grade/post at which research is normally conducted" (EC, 2006: 100).
} 
- the proportion of women and men on scientific boards (2004); $;^{7}$

- the Glass Ceiling Index (2004). ${ }^{8}$

For four indicators (the proportion of $\mathrm{PhD}$ (ISCED 6) graduates, the proportion of researchers, the proportion of the academic staff total, and the proportion on scientific boards), we constructed a new measure - the gap - by computing the difference between the male/ female proportions. Using gaps we are able to include simultaneously both female and male rates and solve the problem of multicollinearity.

\subsection{Analytical approach}

The first stage of our examination of the indicators systematised above involved a vertical analysis within each set of indicators: $S \& T$ segmentation and gender discrimination. This then led to the mapping of countries.

The other vector of analysis was centred on identifying pattern types among the countries for S\&T segmentation and then for gender discrimination. Assuming the multidimensionality of these pattern types, we explored the relationships within each set of indicators using a multivariate method of data analysis: Principal Components Analysis for Categorical Data (CATPCA). This is a non-linear analysis of principal components that allows quantitative variables (S\&T segmentation indicators and gender discrimination indicators) to be combined with qualitative variables, in this case, the country (Van de Geer, 1993a; Van de Geer, 1993b; Gifi 1996; Meulman et al., 2004). By applying CATPCA, profile types were identified that distinguish groups of countries from each other, revealing the existence of different situations among EU countries.

\footnotetext{
7 The reader should be aware that the variables research funding success rates and proportion of women and men on scientific boards, as well as a new measure constructed using the latter, should be interpreted with caution due to potential differences in coverage and definitions in different countries (Cf: She figures 2006: pp. 70-71).

8 The Glass Ceiling Index (GCI) is a ratio between the proportion of women in grade $\mathrm{A}+\mathrm{B}+\mathrm{C}$ and the proportion of women in grade A. The GCI is an indicator that measures "the relative chance for women compared to men of reaching a top position" (EC, 2006: 52). Grade B includes "researchers working in positions not as a senior as top position[s] (A) but more senior than newly qualified PhD holders", and Grade C includes "the first grade/post into which a newly qualified PhD (ISCED 6) graduate would normally be recruited” (EC, 2006: 100).
} 
A clustering analysis was also performed using a hierarchical algorithm (Hair et al., 2006) in order to validate the configuration of the European S\&T space exhibited by CATPCA. Finally, a Correspondence Analysis (CA) (Greenacre and Blasius, 2006; Greenacre, 2008) was implemented to graphically show the contours between S\&T segments and gender discrimination patterns.

\section{Results}

\subsection{S\&T European space segmentation}

Historically, differences are found both in the countries' S\&T systems and in their technological trajectories (Dosi, 1982; Perez, 1988). The development level of European countries and their technological dependence relations sustain the hypothesis of a stratified European S\&T space (Oliveira and Carvalho, 2002; Oliveira, 2008). Using the above-mentioned indicators as development indicators in this field (the proportion of researchers per thousand labour force, the proportion of scientists and engineers in the total labour force, and the proportion of R\&D expenditure in Purchasing Power Standards (PPS) per capita researcher), the data show (Figures 1, 2 and 3) an extremely unequal distribution of human resources and materials in S\&T across the different countries.

Using the EU average as a reference, European countries can be divided into at least two groups: countries below the overall mean and countries above this mean. This shows that the S\&T European space is a dualised space of rich (Central and Northern European countries) and less developed S\&T countries (Eastern and Southern European countries, namely Portugal and Greece). Spain, Italy and Estonia are special cases. Spain is closer to the Northern European countries with a high level of researchers, scientists and engineers, but low S\&T research expenditure per capita. Italy, on the other hand, has low levels of human resources working in S\&T but high S\&T expenditure. Estonia is above the overall mean for research per thousand labour force, but presents very low rates in the two other indicators.

In order to identify stratification segments in the European S\&T space, a Principal Components Analysis for Categorical Data (CATPCA) was carried out, exploring the relationships between the three indicators and matching the countries through their position. 


\section{LUÍSA OLIVEIRA, HELENA CARVALHO}

Figure 1. Proportion of researchers per thousand labour force by country (2003)

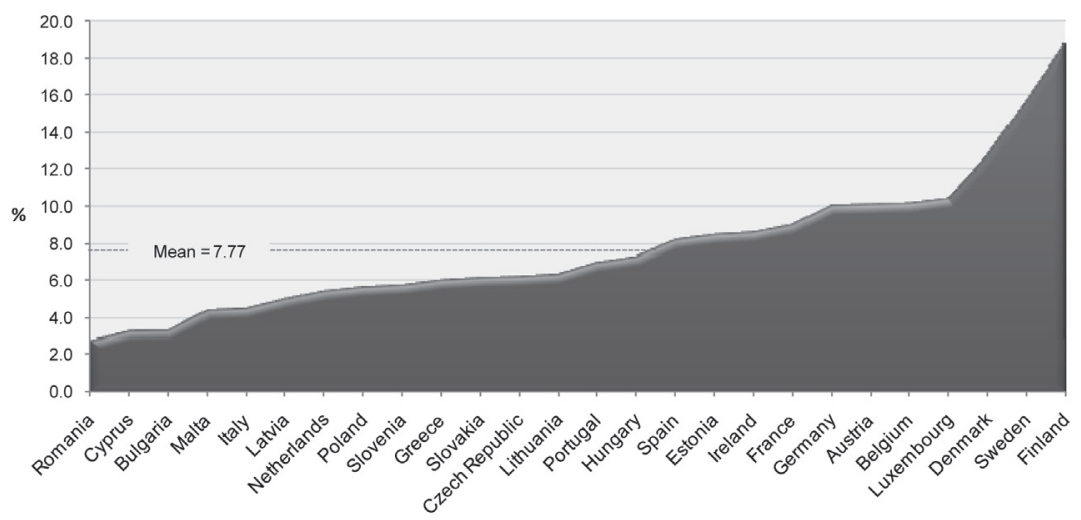

Figure 2. Proportion of scientists and engineers in the total labour force by country (2004)

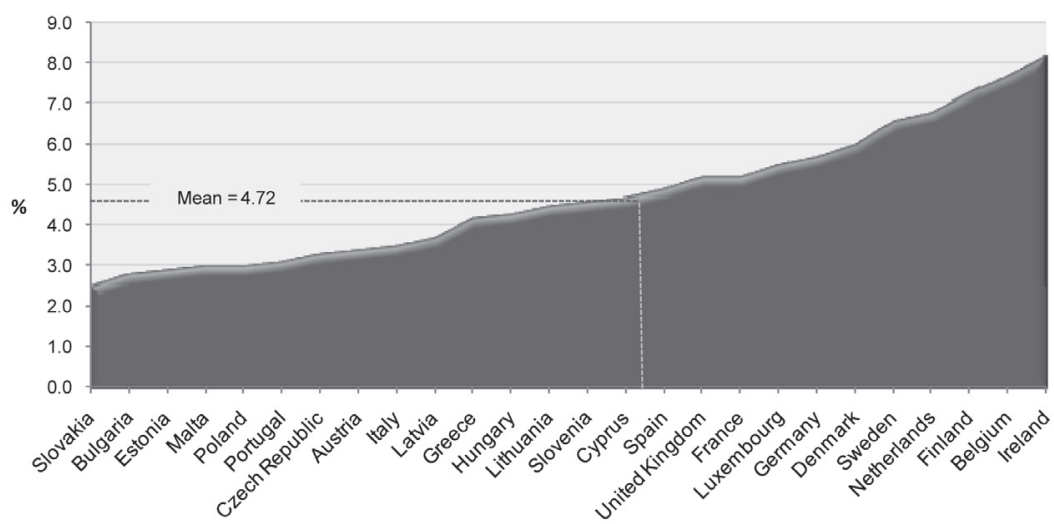


Figure 3. Proportion of R\&D expenditure in purchasing power standards (PPS) per capita researcher by country (2003)

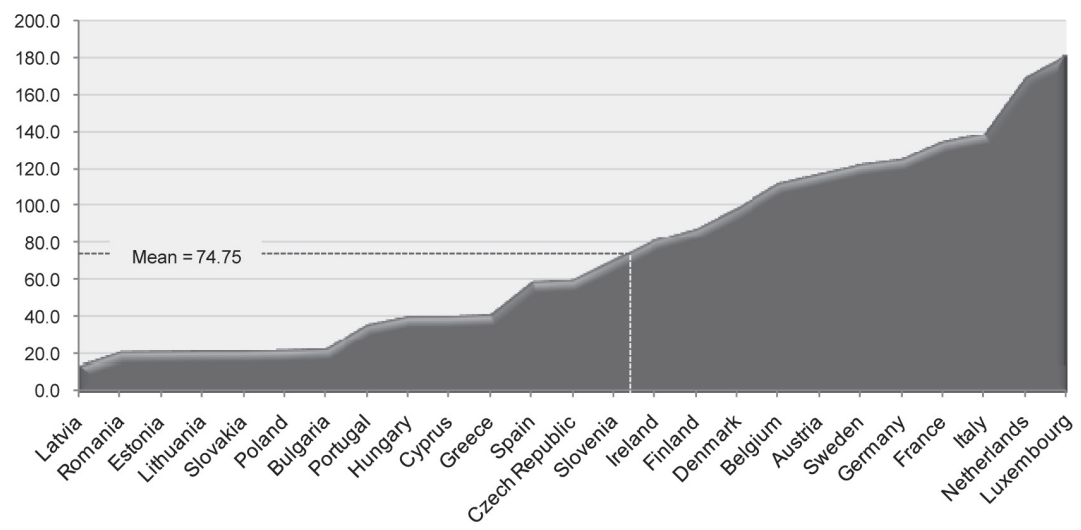

This analysis confirms the dualisation of the S\&T space (Figure 4). Countries with lower rates, i.e. Eastern and Southern European countries (Dimension $1<0$ ), contrast with those which have higher rates in every indicator, i.e. Central and Northern European countries (Dimension $1>0$ ).

However, another feature of Central and Northern European countries is that they have a greater spread than the other group of countries due to the fact that this group is divided into two different segments:

- one is characterised by having both a larger number of scientists and engineers in the total labour force and also researchers per thousand labour force. This segment is a development pattern based on the extent of the high level of qualifications in the labour force, which is typical of northern countries, Ireland and Belgium; ${ }^{9}$

- the other stands out for its higher rates of R\&D expenditure in PPS per capita researcher, which is typical of Central European countries (Luxembourg, France, Austria and Germany). The Netherlands and Italy also belong to this group.

9 The United Kingdom and Malta are not included in this multivariate analysis because data is missing for them in at least one indicator. 
Figure 4. The segmentation of the European S\&T space

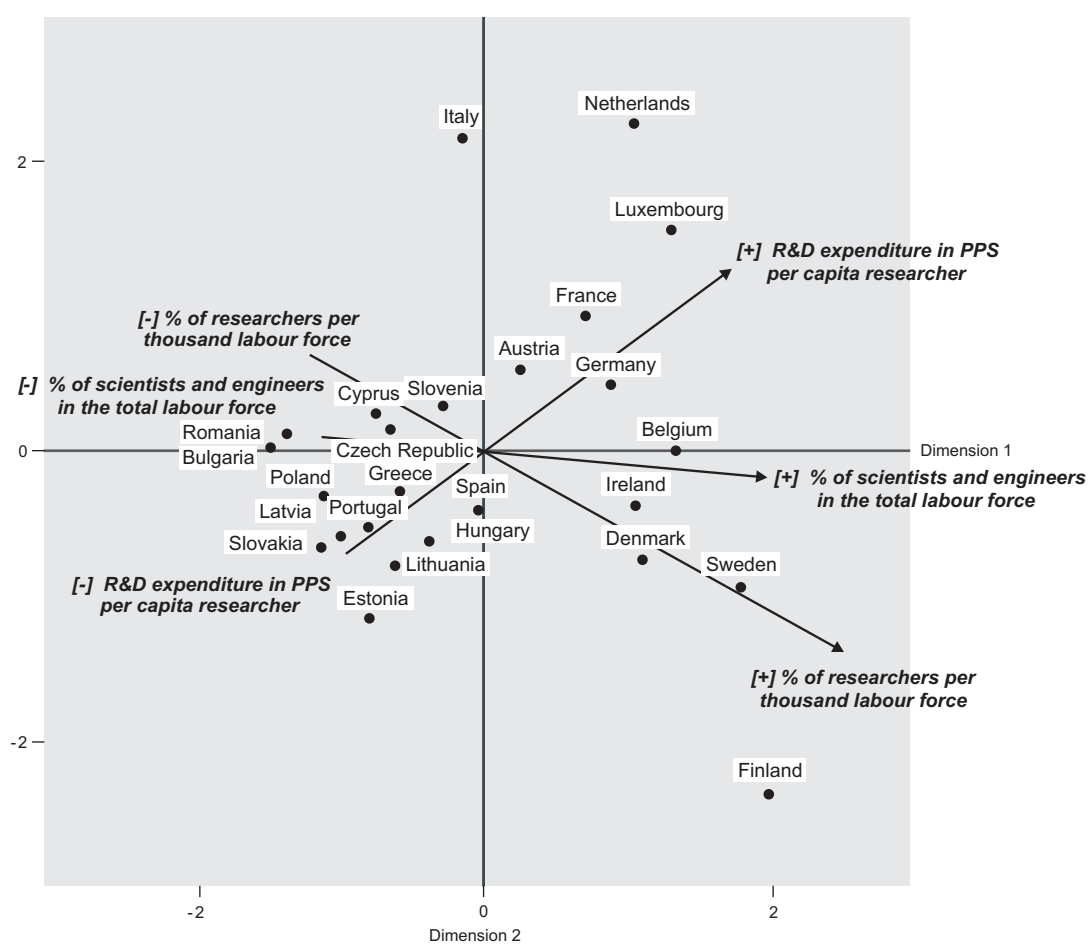

Despite this segmentation of the European S\&T space, the three strata cannot be definitively ranked (Figure 5) because the two segments with the best performance in S\&T development (Northern and Central European countries) exchange their top positions in S\&T indicators. 
Figure 5. Hierarchy of European countries according to S\&T development indicators

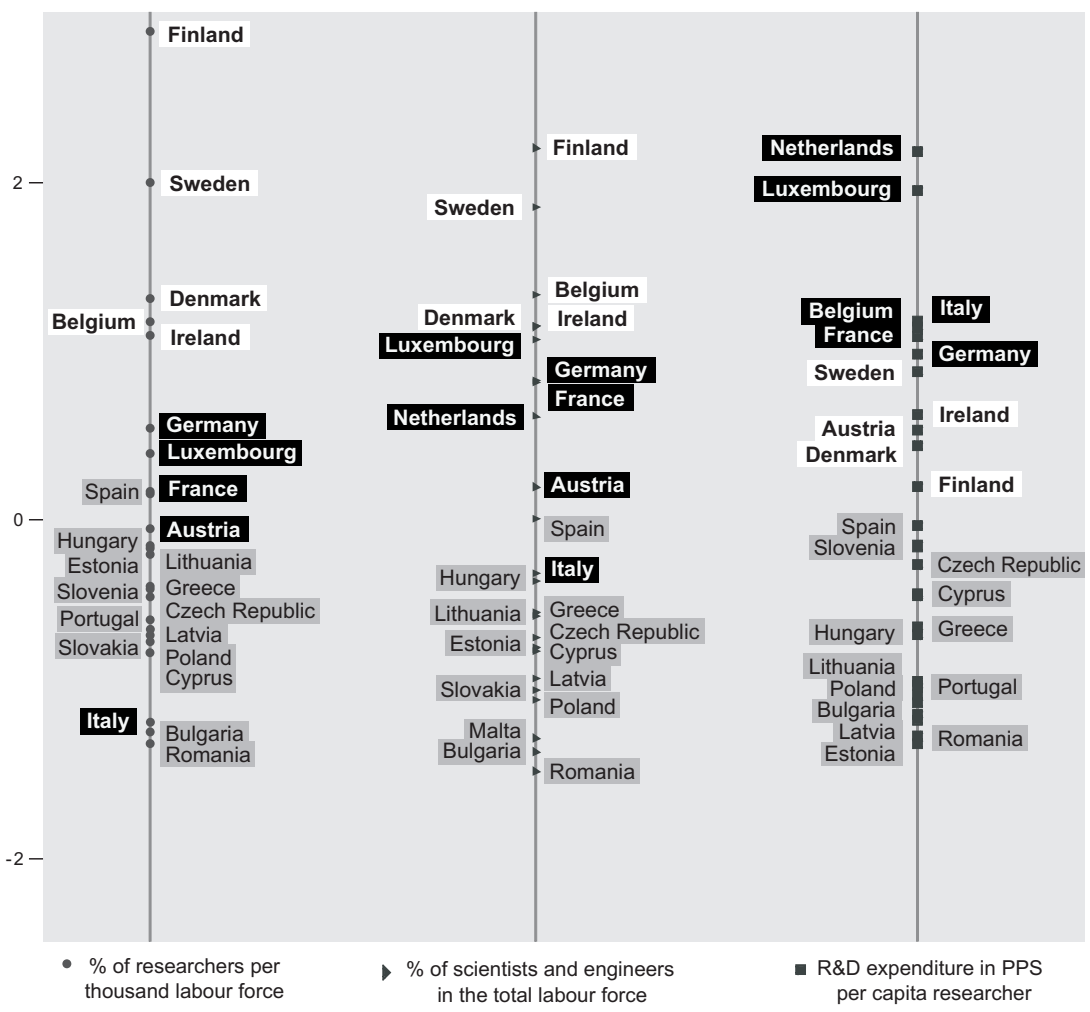

The results of a Hierarchical Cluster Analysis fit well with the threefold nature of European S\&T space segmentation. In accordance with this classification, we have redrawn the segments linking the countries to their cluster (Figure 6). 
Figure 6. Segmentation of the European S\&T space: clustering the countries

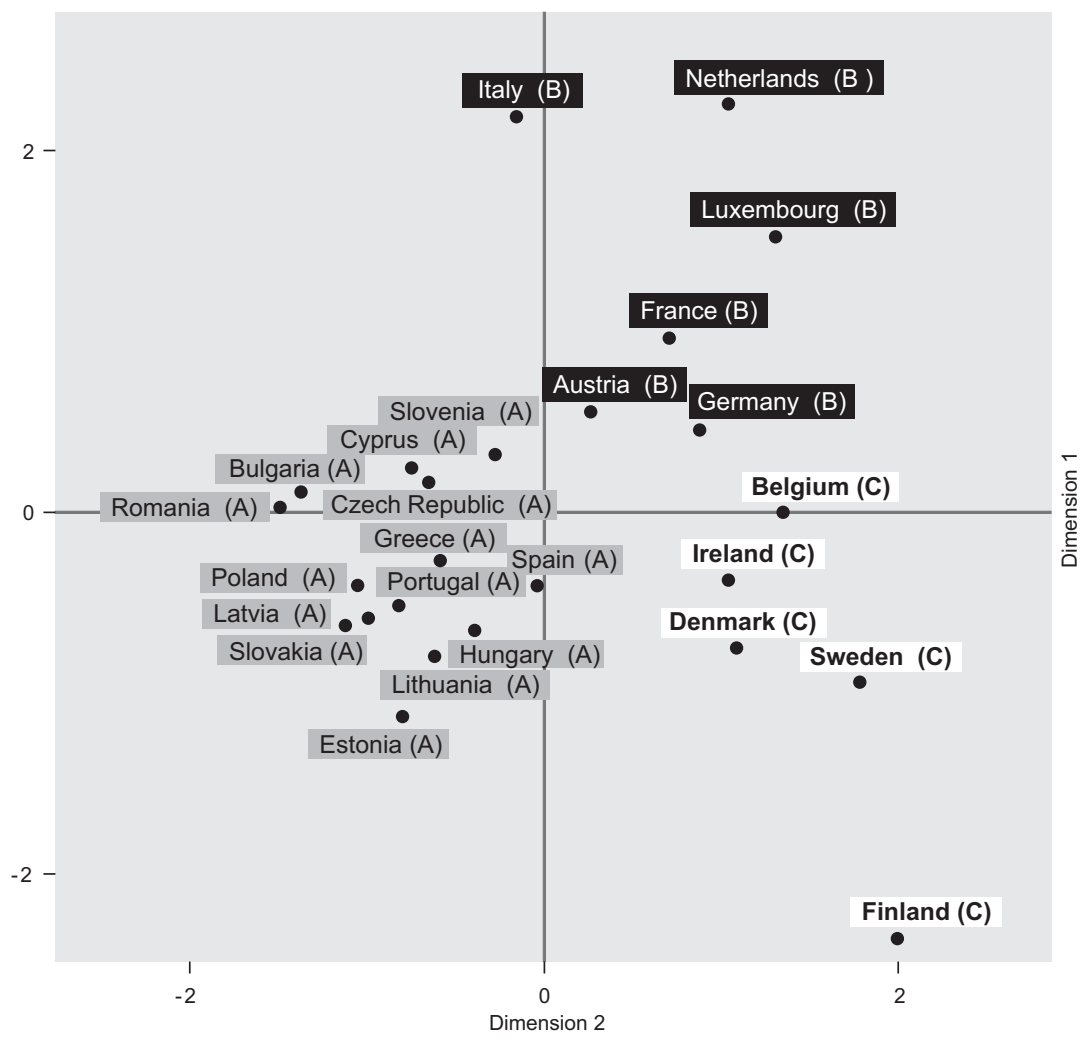

Table 1 shows that the average of S\&T development measures by segment reproduces the profiles found by multivariate analysis. Segment A has the lowest mean in every indicator. Segment B presents the highest mean for R\&D expenditure in PPS per capita researcher and Segment $C$ has the highest mean for indicators concerning the high level of S\&T qualifications of the labour force. It is precisely because of the above-mentioned inversion of the mean in segments B and C that a hierarchy between them is out of the question. 
Table 1. Measures of S\&T segments

\begin{tabular}{lccc}
\hline S\&T segment & $\begin{array}{c}\text { \% of researchers } \\
\text { per thousand } \\
\text { labour force } \\
\text { Mean }\end{array}$ & $\begin{array}{c}\text { \% of scientists and } \\
\text { engineers in the total } \\
\text { labour force } \\
\text { Mean }\end{array}$ & $\begin{array}{c}\text { R\&D expenditure } \\
\text { in PPS per capita } \\
\text { researcher } \\
\text { Mean }\end{array}$ \\
\hline Segment A & 6.07 & 3.73 & 36.54 \\
Segment B & 8.27 & 5.02 & 144.68 \\
Segment C & 13.25 & 7.16 & 100.86 \\
Overall mean & 8.12 & 4.77 & 76.98 \\
\hline
\end{tabular}

A hierarchy exists when the S\&T space is approached as a dual space, and therefore the performance of segments $\mathrm{B}$ and $\mathrm{C}$ is better, but when these two are compared it is found that despite being included in the group of countries with more developed S\&T systems, they have different profiles and their most important S\&T indicators are inverted.

\subsection{Trends in gender discrimination by $S \& T$ segment}

According to the profiles of the three segments in the S\&T European space, and if our main hypothesis holds true, most gender discrimination would be found in segment A (eastern/southern countries) and there would also be some differences in segments B and C, as their S\&T development models are based on different principles: higher rates in $\mathrm{R} \& \mathrm{D}$ expenditure and scientific professions. The question that must be answered is whether and how these different development models are associated with gender discrimination in Science and Technology.

Two analytical dimensions were defined (Table 2) based on gender discrimination indicators. The first refers to the preconditions needed to improve equal gender opportunities in S\&T, and the second refers to the academic conditions for men's/women's career pathways. 
Table 2. S\&T systems and organisational academic culture in gender discrimination

\begin{tabular}{lll}
\hline Dimensions & Indicators & Variables \\
\hline $\begin{array}{l}\text { Preconditions for improving } \\
\text { equal gender opportunities }\end{array}$ & Education & Equal access to research \\
in S\&T & Gap \%M-\%W PhD (ISCED 6) \\
academic conditions to & Access to control and & Gap \%M-\%W researchers \\
promote women's career & power positions & $\begin{array}{l}\text { Percentage of women in } \\
\text { grade A }\end{array}$ \\
pathways & & $\begin{array}{l}\text { Percentage of men in grade A } \\
\text { Gap \%M-\%W on scientific boards }\end{array}$ \\
& & $\begin{array}{l}\text { Research funding success rate } \\
\text { Glass Ceiling Index }\end{array}$ \\
\hline
\end{tabular}

These dimensions were defined in accordance with the above observations on the closed and conservative academic culture, which is an ideal environment in which to analyse gender equality in S\&T. Will there be relevant differences in men's/women's career pathways among S\&T segments or, despite S\&T segmentation, does academia continue to have basically the same cultural gender pattern all over Europe? Despite the differences between countries regarding the level of university autonomy from the State and also recruitment rules and career management, as Musselin (2005) concludes in a comparison of France, Germany and the United States, this question makes sense in that gender discrimination appears to be transversal across organisational models and other national specificities in different fields.

In fact, a vertical analysis per indicator shows gender discrimination throughout EU countries, detailing differences in the distribution of indicators (Annex 1).

In order to find out how far S\&T segmentation could explain the range in the rates, a cross-relation between the segments (A, B and C) and gender discrimination indicators was performed (Figure $7^{10}$ ).

The major differences between segments (Figure 7) are found in the male/female researcher gap, in the male/female academic staff gap,

${ }^{10}$ For this analysis, comparisons are made using the mean of the variables (indicators of gender discrimination) within each segment, because the exploratory analysis reveals a symmetrical distribution for each of them, which means that the representativeness of this statistical measure is guaranteed. 
and in the gap on scientific boards. But despite these differences, and with the exception of $\mathrm{PhD}$ degrees, for which the gap has a negative mean in segment $\mathrm{A},{ }^{11}$ the three groups of countries on average have common features, as all the gender gaps have positive values, which means women are discriminated against in all of them. In fact, more women have a $\mathrm{PhD}$ than men in these countries (Annex 1).

There is no proportional expression of this feature of women's emancipation (Esping-Andersen, 2002 and 2008), which some authors call the women's silent revolution (Ferreira, 1988), in terms of access to scientific professions. Further research would be necessary to determine whether this is due to a discriminative attitude from these institutions or to other professional strategies taken by women who do not wish to enter the academic world or who even leave it because they are dissatisfied (Preston, 1994; Ledin et al., 2007; West, 2007).

On the basis of this data, it appears that women have difficulty in accessing academic and research professions even in countries where there are more women than men with a PhD. Access to these scientific professions seems to be a powerful gender discrimination factor all over Europe, with segment B (predominantly Central European countries) presenting the highest figures.

Figure 7. Indicators of gender discrimination by S\&T segment

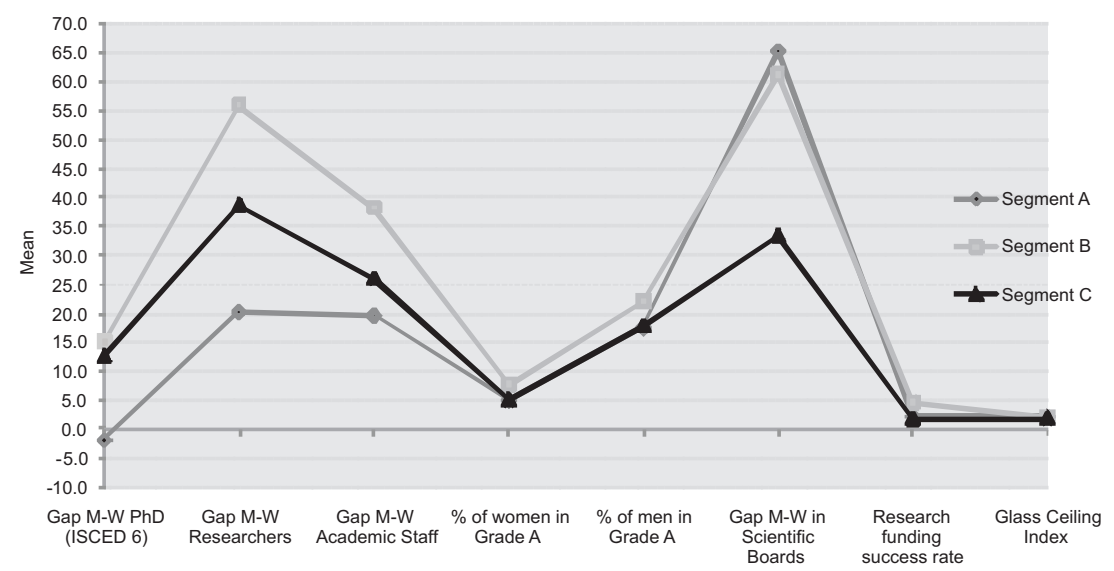

${ }^{11}$ The gap in this indicator is negative in almost all Eastern European countries, except for the Czech Republic and Poland, and Portugal. 
As far as academic careers are concerned, the results show the percentage of women in grade $\mathrm{A}$ is on average lower than the percentage of men in the same position. This gender discrimination feature is particularly high in segment B. As Side and Robbins (2007) point out with regard to the American case, women faculty members continue to encounter a glass ceiling when it comes to achieving the position of full professor. ${ }^{12}$ For EU countries, the Glass Ceiling Index has a narrow range, with Malta as an outlier (Annex 2).

On average, the gap on scientific boards is also very high in each segment, above all in segments A and B. Moreover, segment C (almost all northern countries) is the least discriminative in the dimension of academic conditions to promote women's career pathways. We can also conclude that the widest gap in the dimension of preconditions for improving equal gender opportunities in S\&T is found in segment $B$, in contrast to segment A.

This analysis leads to the conclusion that only a part of the total variation of these indicators could be explained by intersegment differences. In order to reinforce this conclusion, a measurement of association using the eta coefficient and derived effect size ${ }^{13}$ was applied (Table 3).

Table 3. Associations between S\&T segmentation and gender discrimination indicators

\begin{tabular}{lcc}
\hline & \multicolumn{2}{c}{ S\&T segmentation } \\
\cline { 2 - 3 } Gender discrimination indicators & $\eta$ & $\eta^{2}$ \\
\hline Gap M-W PhD (ISCED 6) & 0.462 & 0.213 \\
Gap M-W researchers & 0.796 & 0.633 \\
Gap M-W academic staff & 0.494 & 0.244 \\
\% of women in grade A & 0.303 & 0.092 \\
\% of men in grade A & 0.247 & 0.061 \\
Gap M-W on scientific boards & 0.597 & 0.357 \\
Research funding success rate & 0.236 & 0.055 \\
Glass Ceiling Index & 0.358 & 0.128 \\
\hline
\end{tabular}

12 For the Canadian case, see Side and Robbins (2007).

13 Eta measures the association between S\&T segmentation and gender discrimination indicators, and eta squared - the effect size - quantifies the proportion of variance in the dependent variable (gender discrimination indicators) explained by differences among groups (each S\&T segment). 
As already emphasised, only three indicators (the male/female researcher gap, the male/female academic staff gap, and the scientific board gap) exhibited at least medium coefficients of association (an approximate eta of over 0.5 ) with S\&T segmentation. All the others have lower association coefficients and consequently a weak effect size which ranges from $5.5 \%$ to $21.3 \%$ (Table 3 ). Hence, with the exception of the research funding rate and the Glass Ceiling Index, which have essentially equal means for all three segments (Figure 7), we have differences in intragender discrimination indicators that cannot be explained by S\&T segmentation alone.

In short, it can be said that there is an overall coherence in the most marked features defining EU S\&T segmentation, which gives rise to a certain geographic logic for the configuration of segments A, B and C. There is, however, a certain heterogeneity within these segments/geographic areas in terms of gender discrimination.

Going a step further in this explorative approach, and in order to analyse the heterogeneity within S\&T segments, a new analytical strategy was developed consisting of: 1) the identification of gender discrimination patterns in the EU; 2) an interaction analysis between these gender discrimination patterns and the S\&T segments previously identified.

\subsection{Patterns of S\&T gender discrimination in the European Union}

To identify and describe gender discrimination patterns in the EU, a Principal Components Analysis for Categorical Data (CATPCA) was applied to the gender discrimination indicators, as described above.

Three main patterns were found concerning gender discrimination (Figure 8). ${ }^{14}$ The first (1) includes some of the countries which have a less developed S\&T system, which corresponds with segment A (Portugal, Slovakia, Bulgaria, Estonia, Latvia and Lithuania ${ }^{15}$ ), and which is differentiated from the others because the countries are less gender discriminative in terms of the preconditions for improving gender equality in S\&T systems. That is, they present the smallest gap for the level of PhDs, undertaking research, and entering academic professions. It should be noted that $\mathrm{PhD}$ gaps in these countries are all nega-

\footnotetext{
${ }^{14}$ Luxemburg, Malta and Romania are not included in this multivariate analysis because of missing data.

15 The letter in brackets on the right of the label is the cluster (segment) identification.
} 
tive, which means that women advance further and successfully obtain their PhDs, as mentioned above. These countries also have the smallest gaps for researchers and academic staff.

But while these countries record this configuration in these indicators, with the exception of Portugal and Bulgaria, their proportions in the Glass Ceiling Index are high (even though this indicator has the narrowest range) and the proportion of women in grade $A$ and of men in grade $A$ is low.

It is important to stress that a high proportion of women is always accompanied by a high proportion of men with a huge and positive correlation coefficient $(\mathrm{R}=0.942)$. This means that, generally speaking, these countries have a lower proportion of people in grade $\mathrm{A}$, which is explained by the career constraints that men and women are both subject to as a result of national human resource management policies in S\&T. However, within these constraints, there are differences in every country between men and women that demonstrate women's segregation from grade A.

Figure 8. Patterns of gender discrimination in the European S\&T space

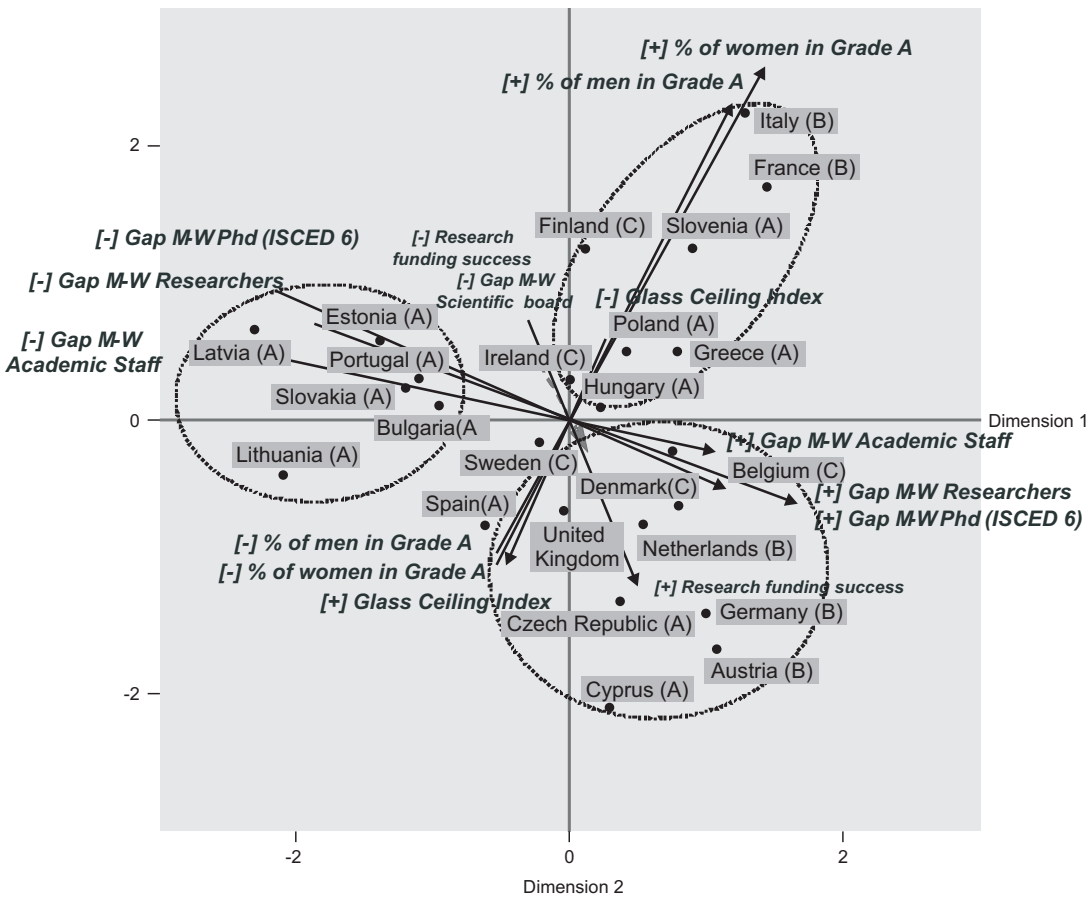


The main problem in these countries seems to be women's career pathways (high proportions for the Glass Ceiling Index ${ }^{16}$ ) within S\&T professions, as Caplan (1994) noted when he stated that academia is traditionally elitist, male and patriarchal in its workplace culture, structure and values. This is also seen, for example, in the astonishing disparity in the number of Nobel Prizes awarded to women (McGrayne, 2001).

The organisational culture and rules of academia is the dimension in this discriminative pattern that has the greatest influence on gender discrimination.

A second pattern (2) associates countries like Hungary, Poland, Greece and Slovenia (also with less developed S\&T systems) which join some countries in segment B (the Central European segment) like France and Italy, and also others from the northern model (Finland and Ireland) in forming a group of countries which is distinct because they display relatively little discriminative behaviour towards women's career pathways. However, they tend to be more discriminative in terms of the preconditions for improving equal gender opportunities in S\&T because they exhibit a trend towards higher values for $\mathrm{PhD}$, researcher and academic staff gaps.

The results indicate that this group is extremely heterogeneous in relation to S\&T development, as it includes countries from the three S\&T segments.

A third pattern (3), in which most of the countries are concentrated, is differentiated from the others because these countries are simultaneously the most discriminative in relation to the preconditions for improving gender equality in S\&T (like pattern 2) and women's career pathways. That is, there are lower percentages of women with $\mathrm{PhDs}$ in these countries and wider gaps within the researcher and academic professions. These are what could be called barriers to entering S\&T professions. If women are able to overcome these barriers to entry in these countries, they will encounter the worst conditions for career development, particularly reaching higher positions within organisa-

\footnotetext{
16 There is an association between the Glass Ceiling Index and the proportion of women in grade $A$ and the proportion of men in grade A indicators. As expected, it is a negative correlation: the higher figures for the Glass Ceiling Index (women are underrepresented in Grade A positions) are close to the lowest values for the proportion of women and men in grade A.

Another strong association occurs between Gap M-W in PhD (ISCED 6) graduates, Gap $\mathrm{M}-\mathrm{W}$ in researchers and Gap M-W in academic staff. In this case, they are positively correlated.
} 
tions. Despite the smaller range of the research funding success indicator, some of the higher rates approach this pattern.

This group (Belgium, the Netherlands, Germany, Denmark, Austria, Sweden, the Czech Republic, the United Kingdom, Spain and Cyprus) is also extremely heterogeneous in terms of S\&T development. This is another pattern that covers countries from the three S\&T segments.

\subsection{Segmentation of the S\&T space and gender discrimination patterns in the EU}

Having concluded the segmentation of the European S\&T space with the identification and description of its three main constitutive segments and also three S\&T gender discrimination patterns, we move to the question of how far these segments are related to the identified gender discrimination patterns. In addition, how do they relate to each other?

A Correspondence Analysis was carried out to answer these questions. The results show (Figure 9) a close relationship between segment A (less developed S\&T countries) and gender discrimination pattern (1), which shows a polarised situation for less segregation in preconditions for improving equal gender opportunities in S\&T and greater segregation for academic conditions to promote women's career pathways. For the two other groups, we find a mix between countries belonging to different segments. Though starting with a situation of generalised S\&T development, segments B and C acquire different patterns for gender discrimination indicators, which means our main hypothesis has only been partially confirmed.

However the dualisation feature of S\&T space still remains across countries, as Eastern and Southern European countries are still on the less developed side of the $\mathrm{S} \& \mathrm{~T}$ divide space (Dimension $>1$ ) and Central and Northern European countries are on the opposite side (Dimension $<1)$, irrespective of the women's discrimination pattern with which they are associated.

This graph demonstrates clearly that all S\&T segments, including segment A, have links with patterns 2 and 3 . However, no rich countries are linked to pattern 1 . When this is combined with the middle-low degree of association (Cramer's $\mathrm{V}=0.382$ ) between the S\&T segmentation and patterns of gender discrimination, the need to include other 
qualitative factors (historical, organisational and cultural) to explain the specificities of these patterns becomes evident.

Figure 9. Correspondence Analysis Map for S\&T segments and patterns of gender discrimination in the European Space

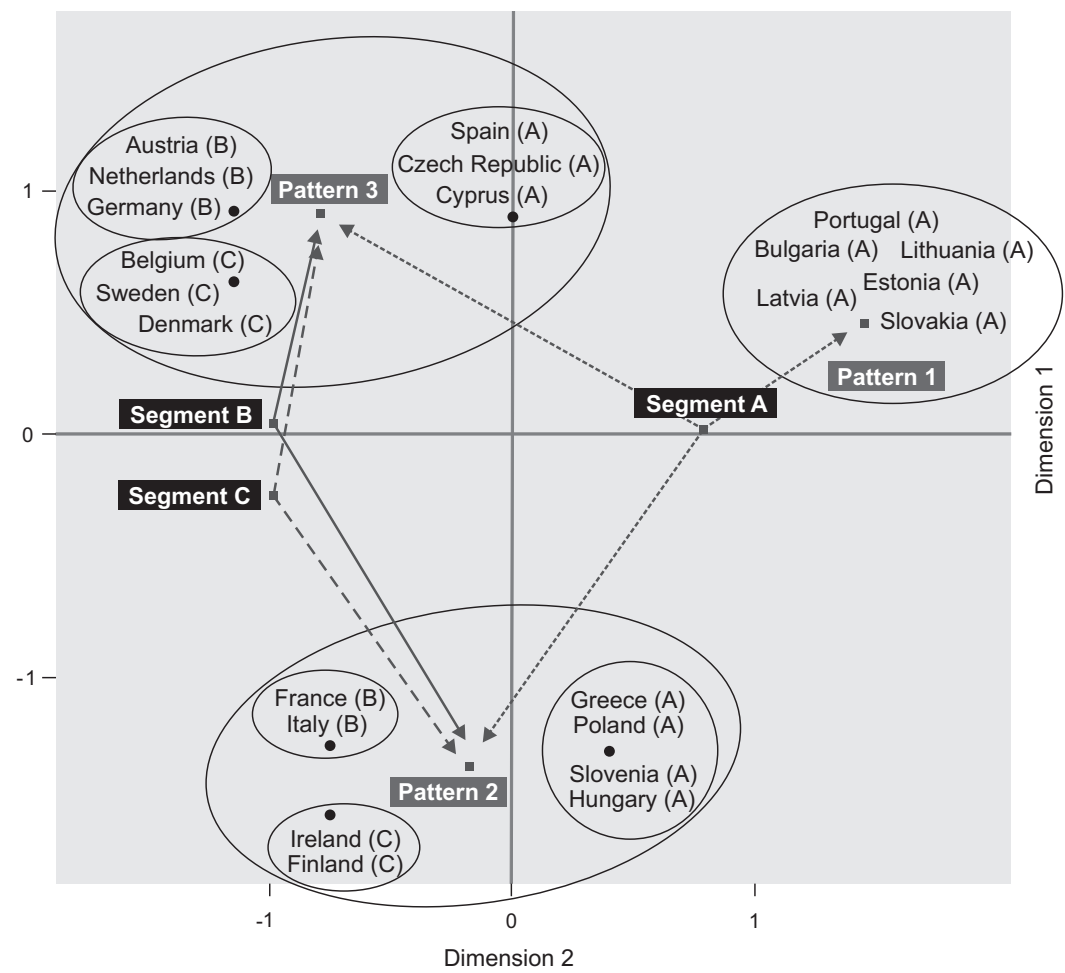

\section{Discussion and conclusions}

The first conclusion is that the European S\&T space is dualised into two opposing strata: S\&T poor (Eastern and Southern European countries) and S\&T rich countries (Central and Northern ones).

Further analysis reveals, however, that the group of S\&T rich countries is also marked by a certain heterogeneity, suggesting there is also a division within these countries. This differentiation expresses two different models of S\&T development. One favours the qualifications of S\&T human resources (northern countries, Ireland and Belgium) while the other is based on high rates of S\&T expenditure (Central European 
countries - Luxembourg, France, Austria and Germany - and also the Netherlands and Italy).

Given this differentiation, it is preferable to talk of the segmentation of the EU S\&T space rather than its stratification.

These three different segments are associated with specific kinds of gender discrimination in S\&T. Thus, the major differences between segments occur in the proportion of male/female researchers, $\mathrm{PhD}$ graduates and academic staff.

Nevertheless, there are common features to the three segments, as women are discriminated against in all analysed indicators with the exception of PhDs, where there are more women than men in certain countries. This is found in the poor segment (A), namely in Portugal and Eastern European countries, with the exception of the Czech Republic and Poland. This does not mean that this segment is less gender discriminative than a first reading of data might suggest. In fact, women's access to the top levels of education may be explained by very different factors ranging from a more democratic and culturally open society, women's will and determination, to labour market needs, i.e. there are not enough highly-qualified men. Only further extensive analysis, at least in some EU countries, can clarify this issue.

The fact that there are more women with PhDs than men in these countries does not mean that men and women enter academic careers in equal proportions. However, it could be interpreted as a discriminative factor in recruitment for these professions, as pointed out by West in the case of California University (West, 2007) or be indicative of women's rejection of such a discriminatory career, as noted by Preston (1994) and Schiffbänker (2009). While these are both situations of gender discrimination, their sociological meaning is quite different.

Although our main hypothesis was not completely confirmed, since the data show that there is a relationship between developed S\&T regions and gender discrimination patterns, it also reveals a much more complex situation as intragender discrimination indicators were detected that cannot be explained simply by S\&T segmentation in the EU space.

Three patterns of gender discrimination in the European S\&T space were found. The first includes Portugal, Slovakia, Bulgaria, Estonia, Latvia and Lithuania and coincides with segment A, described above. In spite of fewer discriminative conditions in the preconditions for improving gender equality in the SeT professions in this segment, it 
is very discriminative in relation to women's academic careers (a high Glass Ceiling Index and segregation of women from Grade A).

A second pattern (2) is a mix of rich and poor countries from the three SerT segments: Hungary, Poland, Greece, Slovenia, France, Italy, Finland and Ireland. This group of countries is differentiated from other groups because it has relatively less discriminative behaviour towards women's career pathways, but it is more discriminative in terms of the preconditions for improving gender equality in S\&T.

A third pattern (3) is formed by a concentration of the majority of countries: Belgium, the Netherlands, Germany, Denmark, Austria, Sweden, the Czech Republic, the United Kingdom, Spain and Cyprus. It is differentiated from the others because it is the most discriminative in relation both to the preconditions for improving gender equality in SerT systems and women's career pathways.

Finally, we can conclude that there is in fact a relationship between gender discrimination and the differentiated development of S\&T regions in Europe, and that to some extent this differentiation has a geographic coherence in which countries in the south and east of Europe contrast with those of Central and Northern Europe.

Meanwhile, the three patterns identified for female discrimination in S\&T professions are more complex when it comes to the typical behaviours of the countries, suggesting the inclusion of other explanatory factors in the analytical model that require further comparative research, including historical and qualitative data, for a deeper understanding of gender discrimination factors in the European S\&T space.

\section{References}

ANERUD, Rebeca, MORRISON, Emory, HOMER, Lori, RUDD, Elizabeth, NERAD, Maresi, \& CERNY, Joseph (2007). Widening the lens on gender and tenure: Looking beyond the academic labour market. NWSA Journal, 19(3), 105-122.

AMÂNCIO, Lígia (2005). Reflections on science as a gendered endeavour: Changes and continuities. Social Science Information, 44(1), 65-83.

BIT (2007). Igualdade no trabalho: enfrentar os desafios, Relatório Global de acompanhamento da Declaração da OIT relativa aos Direitos e Princípios Fundamentais no Trabalho. Genebra: BIT.

BROWNE, Jude (2006). Sex, segregation and inequality in the modern labor market. Policy Press: University of Bristol.

CAPLAN, Paula (1993). Lifting a ton of feathers: A women's guide to surviving in the academic world. Toronto: Toronto University Press. 
CASACA, Sara Falcão (2005). Flexibilidades de emprego, novas temporalidades e relações de género, PhD. dissertation. Lisbon: School of Economics and Management Administration (ISEG).

CCE (2007). Relatório da Comissão ao Conselho, ao Parlamento Europeu, ao Comité Económico e Social Europeu e ao Comité das Regiões, sobre a Igualdade entre Homens e Mulheres, Bruxelas.

CHARLES, Nickie (1993). Gender divisions and social change. Hemel Hempstead: Harvest Wheatsheaf.

COCKBURN, Cynthia (1983). Brothers: Male dominance and technological change. London: Pluto Press.

DOSI, Giovanni (1983). Technological paradigms and technological trajectories. In C. Freeman (Ed.), Long waves in the world economy (pp. 78-101). London: Pinter Publishers.

EC (2006). She figures 2006. Retrieved March 2008 from <http://www.kif.nbi.dk/ She_Figures_2006.pdf.>

ESPING-ANDERSEN, Gosta (2002). A new gender contract. In G. Esping-Andersen \& G. Duncan (Eds.), Why we need a new welfare state (pp. 124-148). Oxford: Oxford University Press.

ESPING-ANDERSEN, Gosta (2008). Famille et révolution du rôle des femmes. In G. Esping-Andersen \& B. Palier (Eds.), Trois leçons sur l'État-providence (pp. 19-58). Paris: Ed. Seuil.

ETZKOWITZ, Henri, \& LEYDESDORF, Leit (Eds.) (1997). Universities and the global knowledge economy, a triple-helix of university-industry-government relations. London: Pinter Publishers.

EUROSTAT (2004). Science \& technology. Retrieved March 2008 from <http://epp. eurostat.ec.europa.eu/>

FERNÉ, Georges (1993). Science, pouvoir et argent, la recherche entre marché et politique. Paris: Ed. Autrement.

FERREIRA, Virgínia (1988). O feminismo na pós-modernidade. Revista Crítica de Ciências Sociais, 24, 93-106.

GEISLER, Cheryl, KANINSKI, Debbie, \& BERKLEY, Robyn (2007). The 13+ club: An index for understanding, documenting and resisting patterns of non promotion to full professor. NWSA Journal, 19(3), 145-162.

GIFI, Albert (1996). Nonlinear multivariate analysis. London: John Wiley \& Sons.

GREENACRE, Michael, \& BLASIUS, Jörgen (Eds.) (2006). Multiple correspondence analysis and related methods. London: Chapman \& Hall/CRC.

GREENACRE, Michael (2007). Correspondence analysis in practice (2nd ed.). London: Chapman \& Hall/CRC.

HAIR, Joseph, ANDERSON, Rolph, TATHAM, Ronald, \& BLACK, William (2006). Multivariate data analysis with readings (4th ed.). New Jersey: Prentice-Hall International.

KOHN, Melvin (Ed.) (1989). Cross-national research in sociology. Newbury Park: Sage.

LEDIN, Anna, BORNMANN, Lutz, GANNON, Frank, \& WALLON, Gerlind (2007). A persistent problem. Traditional gender roles hold back female scientists. EMBO report 8. Retrieved 1 March 2008 from <www.emboreports.org> 
MARUANI, Margaret (Ed.) (2005). Femmes, genre et sociétés, l'état des savoirs. Paris: La Découverte.

MAURICE, Marc, SELLIER, François, \& SILVESTRE, Jean-Jacques (1986). The social foundations of industrial power. Cambridge, Mass: MIT Press.

MERTON, Robert (1973). The sociology of science: Theoretical and empirical investigation. Chicago: University Press.

McGRAYNE, Sharon Bertsch (2001). Nobel prize women in science: Their lives, struggles and momentous discoveries. National Academy of Sciences. Washington, DC: Joseph Henry Press.

MEULMAN, Jacqueline, KOOIJ, Anita, \& HEISER, Willem (2004). Principal components analysis with nonlinear optimal scaling transformations for ordinal and nominal data. In D. Kaplan (Ed.), The Sage handbook of quantitative methodology for the social sciences (pp. 49-70). London: Sage Publications.

MUSSELIN, Christine (2005). Les marchés des universitaires, France, Allemagne, États-Unis. Paris: Presses de la Fondation Nationale des Sciences Politiques.

OLIVEIRA, Luísa (2008). Sociologia da inovação. Lisboa: Celta Editora.

OLIVEIRA, Luísa (2000). Commoditization of science and paradoxes in universities. Science Studies, 13(2), 23-36.

OLIVEIRA, Luísa, \& CARVALHO, Helena (2002). A Segmentação do espaço de inovação na indústria Portuguesa. Sociologia Problemas e Práticas, 39, 39-56.

PALERMO, Simona, GIUFFRA, Elisabetta, ARZENTON, Valeria, \& BUCCHI, Massimilano (2008). Gender and science. EMBO report 9. Science \& Society. Retrieved 1 March 2008 from <www.emboreports.org.>

PEREZ, Carlota (1988). New technologies and development. In C. Freeman \& B. Lundvall (Eds.), Small countries facing the Technological Revolution (pp. 85-97). London: Pinter publishers.

PERISTA, Heloisa, \& SILVA, Alexandra (2004). Science careers in Portugal. Working paper 13. Centre for the Study of Law and Policy in Europe, University of Leeds, 27-42.

PRESTON, A. E. (1994). Why have all the women gone? A study of exit of women from science and engineering professions. America Economic Review, 85, 1146-1462.

RENAUT, Alain (1995). Les révolutions de l'université: Essai sur la modernisation de la culture. Calmann-Lévy: Paris.

RUEST-ARCHAMBAULT, Elyse (2008). Benchmarking policy measures for gender equality in science. European Commission Report. Brussels.

RHODE, Deborah (1989). Justice and gender. Harvard: University Press.

RHODE, Deborah (2006). In pursuit of knowledge: Scholars, status and academic culture. Stanford: University Press.

SALOMON, Jean Jacques, SAGASTI, Francisco, \& SACHS-JEANTET, Céline (Eds.) (1994). La quête incertaine, science, technologie, développement. United Nations: University Press.

SCHIFBÄNKER, Helene (2009). Gender specific career aspects in science and technology. In K. Prpić, L. Oliveira \& S. Hamlin (Eds.), Women in science and technology (pp. 85-107). Zagreb: Institute for Social Research - Sociology of Science and Technology Network of European Sociological Association. 
SIDE, Katherine, \& ROBBINS, Wendy (2007). Institutionalizing inequalities in Canadian universities: The Canada Research Chairs Program. In NWSA Journal, 19(3), 163-181.

STARK, David, \& BRUSZT, László (1998). Postsocialist pathways: Transforming politics and property in East Central Europe. New York and Cambridge: Cambridge University Press.

STOUT, Patricia, STAIGER, Janet, \& JENNINGS, Nancy (2007). Affective stories: Understanding the lack of progress of women faculty. NWSA Journal, 19 (3), 124144.

VAN DE GEER, John (1993a). Multivariate analysis of categorical data: Theory. USA: Sage.

VAN DE GEER, John (1993b). Multivariate analysis of categorical data: Applications. USA: Sage.

VERNET, Jean Pierre, \& BUTERA, Fabrizio (2004). Emancipation féminine et discrimination des féministes: Quelques paradoxes dans les pays démocratiques. In A. Dorna \& P. Georget (Eds.), La démocratie peut-elle survivre au XXI siècle? (pp. 269-285). Paris: Editions Minuit.

WEST, Martha (2007). Unprecedented urgency: Gender discrimination in faculty hiring at the University of California. NWSA Journal, 19(3), 199-211. 
THE SEGMENTATION OF THE S\&T SPACE AND GENDER DISCRIMINATION IN EUROPE
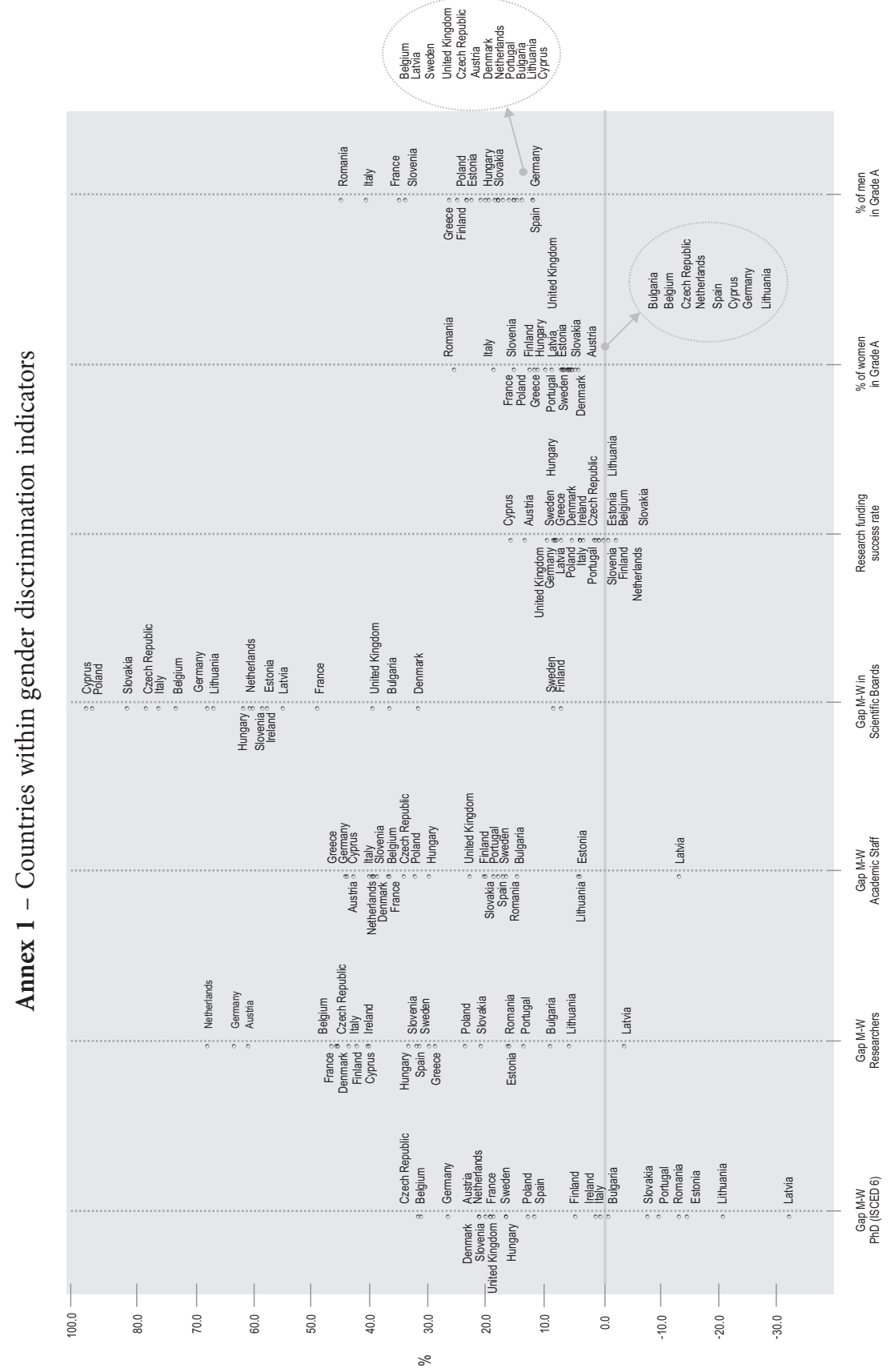



\section{Part II}

\section{Women's careers and performance}





\section{Agrita Kiopa \\ Julia Melkers \\ Zeynep Esra Tanyildiz ${ }^{1}$}

\section{Women in academic science: mentors and career development}

\section{Introduction}

One area where specific resources can be committed to address issues of underrepresentation and attrition of women in science is in the establishment of mentor programmes. "Mentoring is a workplace relationship in which the senior or more experienced person (the mentor) provides career related advice and personal support to a less experienced person (mentee)" (Kram, 1985). These programmes are intended to assist women in career development, navigation of the academic system, and address issues specific to women in the underrepresented fields of science and engineering. They are inspired by evidence that in the academic setting, women in research universities occupy lower academic ranks, are more likely than men to be employed in temporary positions (Long and Fox, 1995; Long, 2003), earn less than comparable men in similar fields and positions (Astin and Cress, 2003; Long, 2003), teach and advise more (Astin and Cress, 2003; Fox, 2003; Shauman and Xie, 2003), and have less time and resources for research (Shauman and Xie, 2003). In the context of academic science, the development of an effective mentoring relationship is expected to yield important outcomes in terms of socialisation to the academic environment, related job satisfaction, career advancement, and productivity.

Some have suggested that a lack of effective mentoring can even be detrimental to the careers of women in science (Riegle, 2006). For example, qualitative research points to substantial qualitative differences with regard to gender differences in mentoring, including differences

1 The authors thank the National Science Foundation for their support in this research and the Sociology of Science and Technology Network for the opportunity to present this work. Data analysed in this proposed research were collected under the auspices of the 2005-08 project, "Women in Science and Engineering: Network Access, Participation, and Career Outcomes" (NETWISE, 2007), a project funded by the National Science Foundation (Grant \# REC-0529642) (co-PI's Dr. Julia Melkers and Dr. Eric Welch). Opinions expressed in this paper are not necessarily shared by the NETWISE 2007 project leadership and/or the University of Illinois at Chicago or the Georgia Institute of Technology. 
in the provision of information about promotion criteria, and the facilitation of external visibility and productivity (Field, 2003). The findings of the few empirical studies that have addressed the effects of gender differences in mentoring on career outcomes are mixed. For women, mentoring has been identified as a success strategy in women's careers (Ragins and Sundstrom, 1989), and evidence suggests that it might be more important and less available than for men (Fox and Fonseca, 2006). Feeney (2006), in her study of public sector employees, found that mentoring helps in career advancement, but not substantially more for women. She found that women in informal mentor relationships report more positive outcomes compared to those in formal programmes.

In this chapter, we review issues in mentoring for women faculty in STEM (science, technology, engineering and mathematics) fields, and provide recent survey research findings on mentoring experiences of faculty in six fields of science and engineering in Research I institutions in the United States.

\section{Mentoring programmes in STEM fields}

In the United States, there is an increasing number of institutions adopting formal mentoring programmes designed to assist in career development, productivity, and satisfaction for individuals. Certainly, individuals develop informal mentoring relationships with colleagues outside of any programmatic framework. However, some individuals may be naturally more strategic or able to form these relationships. For example, the rationale for many formal professional mentoring programmes has been to target underrepresented populations, including women, to help them to retain their positions and advance in organisations (Kram and Hall, 1996). For those who are not able to form such relationships, mentoring programmes can help to bridge the gap. Formal mentoring programmes are often developed in an attempt to enhance and even replicate informal mentoring relationships (Zey, 1985). Here, formal mentor-mentee relationships are defined, and individuals are linked via a programmatic mechanism (Raggins and Cotton, 1999).

In practice, professional associations for scientists, such as the American Chemical Society, have established mentee-mentor matching programmes for women entering and employed in the sciences. These organisations are charged with improving professional opportunities and resources for their members, and mentoring relationships are seen as instrumental in career development processes. Outside of field-specific 
professional associations, there are also numerous initiatives that exceed the boundaries of a single organisation or field and target women in science more generally. For example, the Association for Women in Science (AWIS) has partnered with "MentorNet" (MentorNet, n.d.) to provide an online mentoring programme for women faculty and students in the sciences. MentorNet is designed as an "E-Mentoring Network for Diversity in Engineering and Science", and is described as a multi-institutional "ementoring" programme for students and untenured faculty, primarily women, with mentors, which provides support through "positive, oneon-one, email-based mentoring relationships with mentors from industry, government, and higher education". AWIS also offers specific mentoring resources for members through localised chapter activities. For example, they note that AWIS chapters engage in a variety of activities that involve:

- direct one-on-one mentoring;

- group mentoring in which an "audience" receives advice, via career days, panel discussions, and the like;

- indirect mentoring in which the visibility of a woman scientist encourages aspiring women scientists;

- other activities that teach attendees how to be effective mentors to younger women and/or provide relevant resources (AWIS, n.d.)

An important institutional response to the underrepresentation and attrition of women in science and engineering fields has been the emergence of formal mentoring programmes in universities. In the academic science setting, mentoring has traditionally been an integral part of graduate education. Graduate students are introduced to the conduct of science by their dissertation advisors and relationships between them could potentially develop from mentoring to collegial (De Janasz and Sullivan, 2004). Younger faculty and underrepresented groups have been recognised by many institutions as potentially benefiting from a similar relationship. Thus, universities in the United States are developing formalised mentor programmes for younger faculty, some STEM field specific, others targeted at faculty in general. Overall, these programmes are typically developed with the goal of supporting the integration and retention of targeted groups. They vary, depending on whether they have originated from a women or minority-based initiative or whether they are a broader institutional initiative. For example, universities with an NSF ADVANCE grant targeted to the advancement of women in science may include mentoring as part of that initiative. To illustrate, a brief description and sample of programmes are provided in Table 1. 


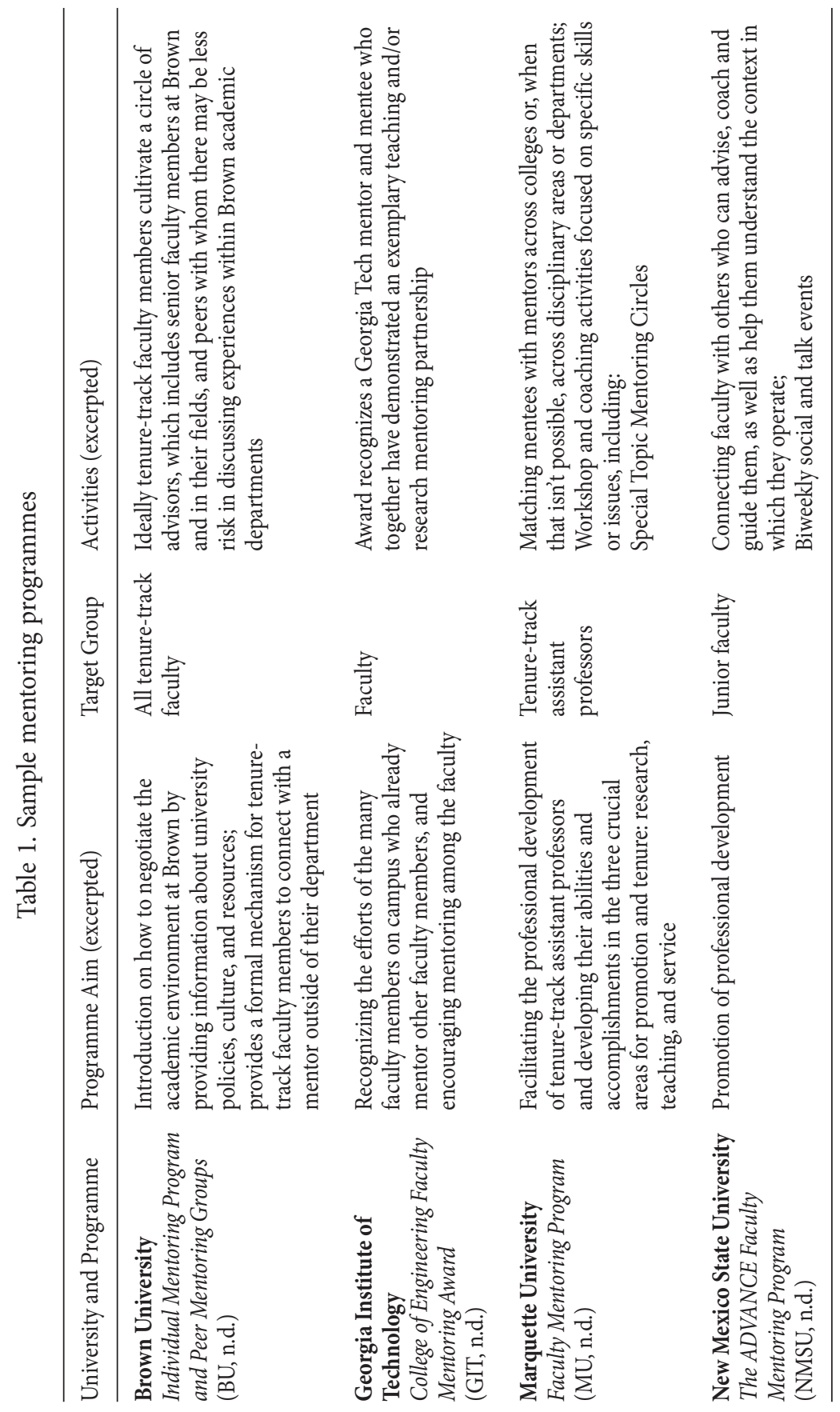




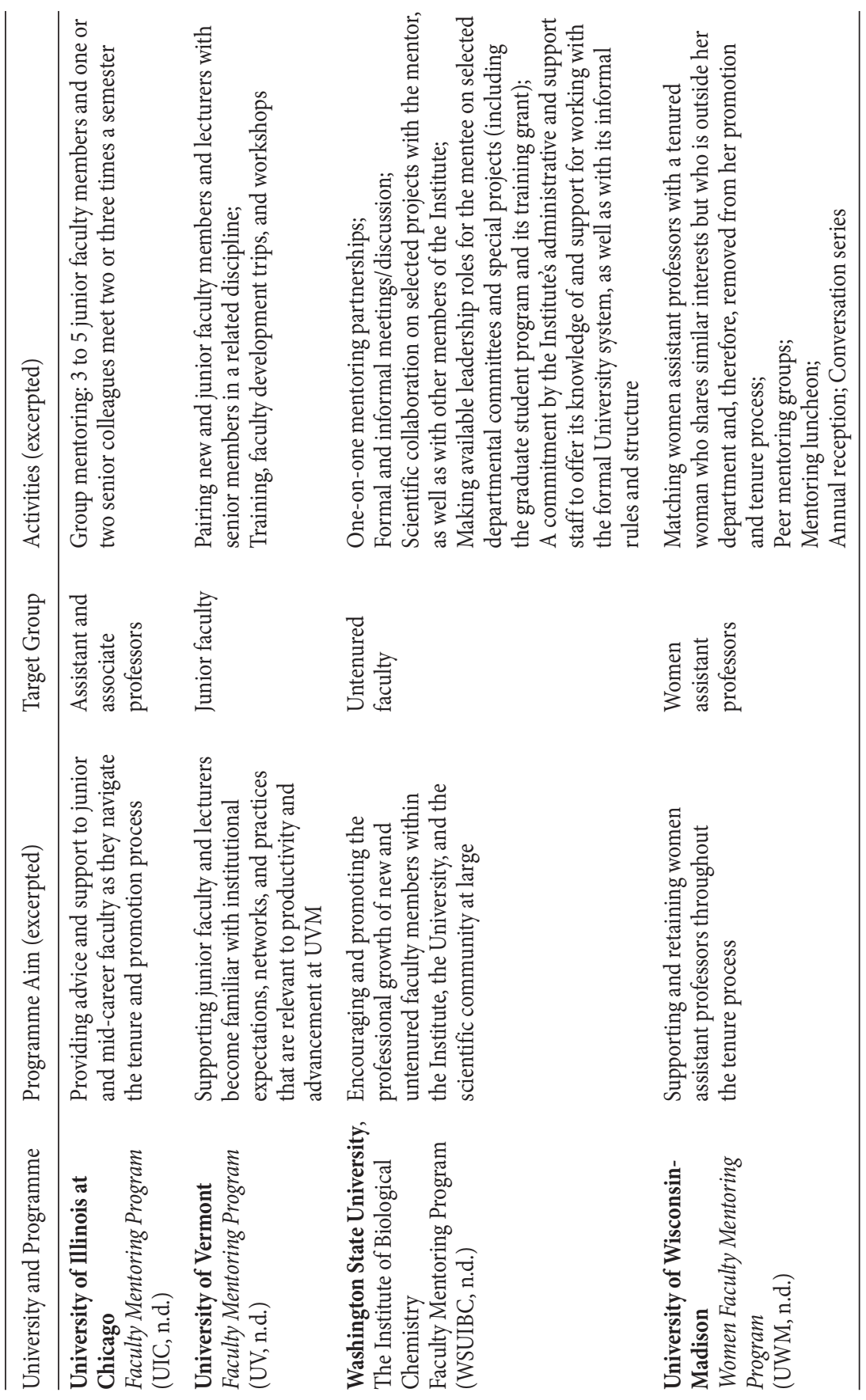


The review of programmes demonstrates that mentoring programmes are often used as training programmes to familiarise faculty with the unique culture of the university or the department, and provide information that will help in understanding how to proceed through the tenure process. These programmes facilitate individuals' professional growth and provide junior faculty with learning and networking opportunities. Typical activities include one-to-one matching of the mentee and mentor, setting up mentoring circles, organising social and professional events and, thus, providing a space for making contacts and interacting. Some of the programmes match mentees with senior individuals outside of their department in an effort to provide access to unbiased feedback and support.

More recently group mentoring programmes have emerged in some universities (e.g. Brown University and University of Illinois at Chicago) where senior faculty mentors are assigned more than one mentee, and mentees are encouraged to develop multiple supportive relationships. Most of the universities reviewed for this chapter have developed mentoring programmes that facilitate access to mentors. Others, such as Georgia Institute of Technology, have established an award that recognises outcomes of the mentoring, specifically exemplary teaching and/or research partnerships.

While the establishment of mentoring programmes appears to be a positive step forward in mitigating barriers to the advancement and retention of women in science, mentoring research suggests that these programmes may have limitations and may not always produce the desired results. For example, formally assigned mentors may or may not have an interest in their mentees' career advancement (Singh, Bains and Vinnicombe, 2002) and their provided mentoring may or may not be a good fit to the needs of the mentee (Bozeman and Feeney, 2006). In self-initiated mentoring, the relationships develop around mutual interest; mentors tend to select individuals that have a certain level of promise as their mentees, and mentees look for mentors with needed competencies. This mutual selection based on shared interests or compatible personalities leads to the high intensity of relationship that benefits both parties (Ragins and Cotton, 1999; Walz and Gardner, 1992). Interestingly, Ragins et al. (2000) suggest that formal programmes should be designed to stimulate informal relationships between the mentor and the mentee. The question remains whether formal programmes are more effective and more ben- 
eficial to women in STEM fields than informal mentor relationships are.

Finally, having a relationship with only one mentor is seen as no longer realistic or feasible for career advancement (De Janasz and Sullivan, 2004). Instead, an individual may develop multiple mentoring or "developmental" relationships, all of which may contribute to career development and overall productivity. This represents an expanded mentor network of sorts that may also retain or specifically include a relationship with one primary mentor as an important node of a workrelated network. Moreover, this suggests the importance of taking a broad view of mentoring relationships.

\subsection{Mentoring and career outcomes}

In general, research on mentoring suggests that it is a positive relationship that brings better outcomes to its recipient. From the social learning perspective, a mentor may help their mentee to develop necessary social and professional competence (Kram, 1985), serve as a role model and help in understanding the workplace culture (Fox and Fonseca, 2006). From this perspective, the relationship between mentoring received and career outcome is likely to be mediated with mentoring qualities that can be conceptualised as mentors' knowledge of organisational politics and culture, knowledge about mentees' career paths, developers' skills, motivation and the opportunity to provide assistance, power and hierarchical placement, and mentors' ability to assess accurately mentees' needs and provide relevant developmental solutions (Dougherty and Dreher, 2007).

Empirical research on mentoring has addressed various mentee outcomes (Noe et al., 2002; Allen et al., 2004; Dougherty and Dreher, 2007). For example, Noe et al. (2002) categorised career outcomes as proximal and distal, where proximal included the mentoring functions (psychosocial, career-related, and role modelling) received, and distal outcomes referred to career success and rewards. They found that mentored individuals, compared to non-mentored ones, are more satisfied, better rewarded and have less intention of leaving. Empirical studies suggest that the most consistent benefit of mentoring is related to work satisfaction. Specifically, studies have found that both career mentoring and psychosocial mentoring have an effect on individuals' satisfaction with their work and career (Allen et al., 2004), and that career men- 
toring has a stronger effect on overall job and career satisfaction than psychosocial mentoring (Chao et al., 1992).

What role does mentoring play in the academic science setting? In the knowledge production process, researchers build upon the resources they access through their networks in ways that would not be possible without having these relationships (Bozeman et al., 2001). From the social capital perspective, a mentor may help his or her mentee to acquire resources that are necessary for research and career advancement. In the academic environment, mentoring may affect productivity in several ways. Research has also provided evidence that men and women's networks differ (Moore, 1990) and that women may not be as effective in creating social capital through network participation (van Emmerik, 2006). Yet, active participation in career-related networks enhances one's opportunities in terms of advancement, salary, and career satisfaction by increasing the amount and quality of resources accrued by the networked individual (Granovetter, 1973; Granovetter, 1983; Burt, 1992; Burt, 2000; Renzulli et al., 2000). In an effective mentor relationship, the mentor may help the mentee to advance human and social capital and acquire necessary research resources, such as new knowledge, or access additional resources that otherwise would not be accessible to the mentee. The mentor may also enhance productivity by helping the mentee to choose and establish her or his research programme, and by enhancing her or his reputation through introductions or opportunities. Reputation and recognition (typically through publications and citations) provide the basis for career advancement and reward (Stephan, 1996). Mentors may be active advisors or collaborators in the academic production process. Mentors may serve as role models, give advice, review articles or proposals before submissions or they may collaborate with their mentees on publications, presentations and proposals.

Thus, the development of an effective mentoring relationship is expected to yield important outcomes in terms of socialisation to the academic environment and related job satisfaction, career advancement, and productivity. We depict this process in Figure 1, based on studies of mentoring as well as the framework of formal mentor programmes in practice. The expectation is that the flow of resources from one's mentor and other colleagues contributes to faculty human and social capital, which in turn affects career outcomes. 
Figure 1. Mentoring and career outcomes

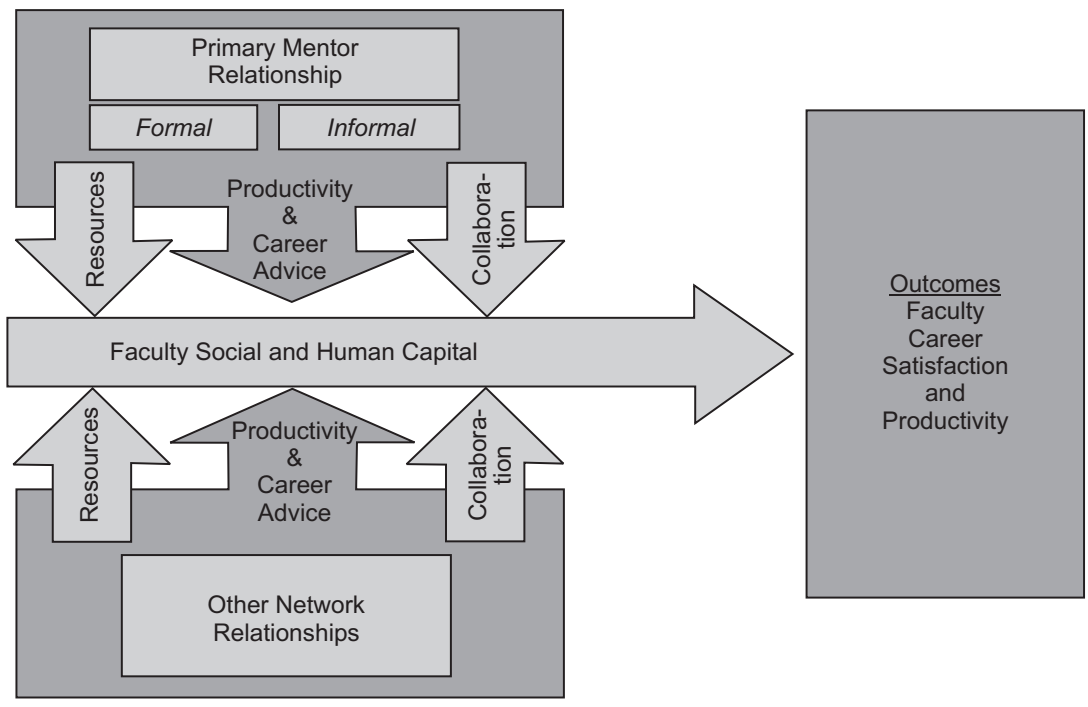

Finally, it is worthwhile noting that not all mentoring relationships are effective, and that mentoring is also likely to be impacted by the nature of the relationship (Long, 1997). Research suggests that the gender composition of the mentor-mentee dyad may impact received mentoring functions and its outcomes (Ragins, 1997; Sosik and Godshlak, 2005). For example, there is some expectation that underrepresented groups are better served with mentors or role models with similar characteristics or life experiences. Non gender-matched mentoring relationships are seen to face various challenges, such as the absence of role modelling, gender stereotyping, and more difficult management (McKeen and Bujaki, 2007). For women in science, identifying a woman mentor can be difficult due to the smaller numbers of women in more senior academic positions in many of these fields (Kulis, et al., 2002). Research suggests that this is problematic. For example, Feeney (2006) found that a gender-matched mentor affects career outcomes for women, suggesting that this gender match may matter in some settings. 


\section{Data}

\subsection{Instrument}

In order to extend our understanding of issues related to mentoring for women in science, we provide findings from a recent survey. The overall framework of the survey is based on the issue of the role of networks for career advancement for women in academic science. Within this framework, we examine the role of mentors as members of the overall career development network. The data for this study comes from a 2006 national survey of academic scientists and engineers in Research Extensive universities in the United States. The study is unique in that it gathers data on network content and knowledge exchange on a national scale. The survey uses an egocentric network design to explore the respondents' relationships with individuals in the respondents' collaborative and advice networks, not the global network of which individuals are members (Wasserman and Faust, 1994). Through the use of detailed survey questions, respondents describe their networks for select activities and their relations with network members (Burt and Minor, 1983). As a result, the survey captures multiple dimensions of collaborative and advice networks that are not accessible through existing data such as bibliometrics. The survey also provides data on individual background, career path, productivity, satisfaction and work environment factors.

To capture the network data, the survey instrument included a series of name generator and name interpreter questions. Respondents (assistant and associate level faculty only) were first provided with a definition of a mentor and asked to indicate whether they had someone that they considered to be their primary mentor. If yes, they were asked to name this individual. Respondents were then asked to write in the names of key collaborators or advisors in research collaboration, as well as advice and support networks, into five name generator questions. These included closest collaborators within their own university, closest collaborators outside their university, individuals with whom "they talk about their research but have never collaborated" and individuals in two types of advice scenario - those with whom they talk about career advice and those with whom they discuss departmental matters. Although the first three (research) networks are mutually exclusive, there is some overlap between the research and advice networks. Once the survey respondent had provided names in each of the five name 
generator questions and the mentor question, they were then asked a series of name interpreter questions about each of the individuals they had named. Name interpreter questions addressed the type of the collaboration undertaken with the collaborator, details about the level of relationship and origin of acquaintance, closeness of research expertise, communication frequency, grant activity, and general demographics. For the purposes of our research on mentor relationships, these additional network members are important in identifying additional mentoring resources across an individual's network.

\subsection{Sample}

The survey was implemented online using Sawtooth Software ${ }^{\circledR}$. In addition to the social network questions, respondents were asked about their research activities, including grant submission and success rate, teaching and committee responsibilities, attitudes about and involvement in interdisciplinary research, their work environment, and detailed demographic and academic background questions. Overall, the survey took between 30 and 45 minutes to complete. The survey sample of 3,677 was randomly drawn from the population of academic scientists and engineers in six disciplines in Carnegie-designated Research Extensive universities (151 universities). The selection of the sample was stratified by gender, rank and discipline. The disciplines (biological sciences, chemistry, computer science, earth and atmospheric sciences, electrical engineering, and physics) were selected based on the level of female representation (low, transitioning, and high). Overall, 1,764 surveys were returned for a $50.1 \%$ response rate and a usable response rate of $47 \% .^{2}$ Responses were fairly evenly distributed across the six fields, gender ( $48 \%$ women) and rank ( $27 \%$ assistant professor, $28 \%$ associate professor, and $45 \%$ full professor). Emeritus and research scientists were not included in the sample. Further, the focus of this paper is on the nature of the information exchange between mentor and mentee. Therefore, in most of this chapter we limit the data only to the assistant and associate level faculty that responded affirmatively that they "had someone whom they considered to be a primary mentor" (421 respondents).

${ }^{2}$ Non responses due to bad addresses were also removed for the calculation of response rate. For example, 136 of the emails were "bounced back" due to a bad email address and 19 were "returned to sender" by the recipients" university email servers. 


\section{Findings}

The findings section is divided into four major sections. First, in order to establish whether there are any distinctions between individuals with a mentor versus those without, we address the differences in productivity and satisfaction for assistant and associate level faculty depending on whether they have an identified "primary mentor".

Second, we address the prevalence of mentoring relationships in the sciences - how common are mentoring relationships in academic science? Here we explore the extent to which assistant and associate level faculty have identified an individual whom they consider to be a primary mentor. As noted earlier, mentoring programmes in the sciences have grown in recent years. Thus, we are also interested in the origin of the mentor relationships. How were they initiated? To what extent have faculty identified their primary mentor through a formal programme? Next, who are the mentors? What are their characteristics? Are they typically senior to the mentee or is there a significant level of peer-to-peer mentoring?

Third, we explore the nature of the mentor-mentee relationship. Here we examine not only the origin and aspects of the relationship, but even more importantly, we provide detailed data on the nature of collaboration, advice, and knowledge exchange and interaction. Descriptive information about the origin and extent of mentor relationships in our sample, the knowledge/advice exchange, as well as other aspects of the relationship that occurs between mentee and mentor are critical to understanding the nature of the relationship.

Fourth, based on developments in mentor literature, we acknowledge the range of mentoring interaction in an individual scientist's career. While many individuals have someone whom they consider to be a primary mentor, they may also receive a spectrum of mentoring advice and assistance from other individuals. This exchange among peers and collaborators is an important aspect of the mentoring process.

\subsection{Do mentors matter?}

Before addressing details of mentoring relationships, it is useful to establish whether there are in fact differences in individuals that have identified primary mentors versus those who have not. In other words, why are mentoring and other developmental relationships important in 
the academic setting? Do individuals with mentors perform differently than those who do not have one?

Table 2. Productivity and work satisfaction for assistant and associate level faculty (difference of means)

\begin{tabular}{|c|c|c|c|c|}
\hline \multirow[b]{2}{*}{ Has a primary mentor } & \multicolumn{2}{|c|}{ Men } & \multicolumn{2}{|c|}{ Women } \\
\hline & $\begin{array}{c}\text { No } \\
(\mathrm{n}=207)\end{array}$ & $\begin{array}{c}\text { Yes } \\
(\mathrm{n}=252)\end{array}$ & $\begin{array}{c}\text { No } \\
(\mathrm{n}=192)\end{array}$ & $\begin{array}{c}\text { Yes } \\
(\mathrm{n}=205)\end{array}$ \\
\hline \multicolumn{5}{|l|}{ Productivity: publications } \\
\hline Average publication (5 yrs) & 3.14 & 3.16 & 2.54 & $3.16^{*}$ \\
\hline Journal articles (2 yrs) & 3.61 & 3.82 & 3.29 & $3.57^{\star}$ \\
\hline Reviewed conference proceedings ( 2 yrs) & 2.56 & $2.94^{\star *}$ & 2.55 & 2.66 \\
\hline Invited conference presentations & 2.29 & 2.32 & 2.22 & 2.24 \\
\hline Other conference presentations & 2.79 & 2.92 & 2.89 & 2.95 \\
\hline \multicolumn{5}{|l|}{ Productivity: grants } \\
\hline Average number of grant proposals (5 yrs) & 2.58 & 2.63 & 2.60 & 2.78 \\
\hline Have been principal or co-principal investigator & & & & \\
\hline on a grant targeted at junior faculty $(0,1)$ & 0.36 & 0.41 & 0.37 & $0.5^{\star *}$ \\
\hline Total dollar amount of successful grants (2 yrs) & $1,742,381$ & $1,067,125$ & $1,091,756$ & 918,017 \\
\hline \multicolumn{5}{|l|}{$\begin{array}{l}\text { Work satisfaction } \\
\text { (1-4, very dissatisfied-very satisfied) }\end{array}$} \\
\hline Recognition as a scholar & 2.61 & $2.80^{* *}$ & 2.59 & $2.79^{* *}$ \\
\hline Salary & 2.41 & 2.82 & 2.53 & 2.75 \\
\hline Support from department chair & 2.76 & $3.00^{* *}$ & 2.78 & 2.90 \\
\hline $\begin{array}{l}\text { Relationships with colleagues in their } \\
\text { department }\end{array}$ & 2.88 & $3.14^{* * *}$ & 2.74 & $2.79^{\star * *}$ \\
\hline The faculty reward system at their institution & 2.29 & $2.58^{* * *}$ & 2.22 & $2.42^{\star *}$ \\
\hline Ability to balance home and work life & 2.62 & 2.63 & 2.48 & 2.37 \\
\hline Quality of research assistants & 2.44 & $2.67^{* * *}$ & 2.58 & 2.63 \\
\hline Courses taught & 3.12 & $3.22^{*}$ & 3.07 & 3.14 \\
\hline
\end{tabular}

${ }^{* * *} \mathrm{p}<0.001,{ }^{* *} \mathrm{p}<0.01,{ }^{*} \mathrm{p}<0.05$, one-tailed t-test

Table 2 presents means of productivity and work satisfaction measures, and one-tailed t-test results of the comparison of means for men and women faculty that have a primary mentor and those who do not. Our findings suggest that mentoring may be having an effect on some aspects of faculty productivity and satisfaction, particularly for women. As shown in Table 2, women with a primary mentor statistically have significantly more publications (past five years) and journal articles (past two years) than women that do not have one. For those that 
do have a primary mentor, their publication rate matches that of men (with or without a mentor). Conversely, women that have not named a primary mentor report lower productivity in terms of average publications and number of journal articles in the past two years. Regarding grants, women that have identified a primary mentor not only exceed the number of grant proposals submitted (for women without primary mentors and for men overall) but have served as principal investigators on grants targeted at junior faculty more often than have either men or women who have not identified a primary mentor. For both men and women, individuals that have identified a primary mentor have a smaller dollar average in terms of total grants received in the last two years as well as the largest grant received. While this may be perplexing, it may also show that individuals that have been particularly successful have not sought mentor relationships. Further research should be done to address this issue.

When mentors provide guidance and information that helps young faculty to socialise in a university setting, they may develop a fuller understanding about norms, expectations, and other aspects of the work environment that may enhance their satisfaction. In terms of work satisfaction, faculty that have identified a primary mentor report higher levels of satisfaction in a number of categories than those who have not identified a primary mentor. Both men and women with mentors report significantly higher satisfaction with their recognition as a scholar, aspects of their work environment and the reward systems in their departments when they have identified a primary mentor. Men that have identified a primary mentor report significantly greater satisfaction with the support that they get from their department chairs, however. Men with primary mentors also report higher satisfaction with the courses they teach and their research and teaching assistants. There are however no significant differences in satisfaction with one's salary based on whether or not a respondent has a primary mentor. While a comparison of these groups does not suggest causality without additional analysis, it can point to the importance of understanding mentor relationships in further detail. Overall our results show that there are distinctions between those who have an identified primary mentor versus those who do not. Both men and women faculty show higher productivity and greater satisfaction in general when they have a primary mentor. We now turn to look more specifically at mentor-mentee relationships and how they 
differ by gender and rank in order to understand the dynamics of the relationships in further detail.

\subsection{Primary mentor relationships}

How prevalent are mentor relationships in academic science? We asked assistant and associate level faculty in our sample, "Do you have someone whom you consider to be a primary mentor?" A mentor was defined as "a more experienced colleague who in one-on-one relationships provides support, direction and feedback regarding career-related and other issues to a junior colleague (mentee)". Our sample is almost evenly split in this regard - 48\% (421 respondents) report this relationship. Not surprisingly, more junior faculty $(62 \%)$ report having a primary mentor than associate-level faculty do (35\%). Within these ranks, men reported having a primary mentor slightly more often than women do (51\% of assistant male professors and $56 \%$ of associate level male professors). Not surprisingly, almost all of our respondents name mentors that are senior to them (96\%). Overall, we observe some field distinction in the identification of mentor relationships. As noted earlier, the disciplines selected for this research include STEM fields with low, transitioning and high representations of women in faculty positions. Interestingly, in the fields of computer science and physics (fields where women are less represented) more men than women report having a primary mentor (Table 3 ).

While organisations have recognised mentoring benefits in adaptation and retention of their employees (Kram, 1985; Allen and Eby, 2007), individual faculty may enter into mentoring relationships for different reasons. Some may seek the guidance of a senior faculty member, others may seek entry to a formal mentoring programme to use institutionalised means of access to university resources, and others may be assigned to such a programme by joining the department. The development of mentor programmes in the sciences has been an important initiative by both individual universities as well as professional societies. The emergence of these programmes suggests that in some cases individual mentoring relationships may not emerge naturally. Further, they are based on the notion that by tailoring and guiding these relationships, faculty (particularly junior faculty) will reap more career development benefits. Thus, how do individuals form mentor relationships? 
Table 3. Identification of and initiation with primary mentor by field

\begin{tabular}{|c|c|c|c|c|c|}
\hline \multirow{2}{*}{$\begin{array}{l}\text { Women's } \\
\text { share }\end{array}$} & \multirow{2}{*}{ Field } & \multicolumn{2}{|c|}{$\begin{array}{l}\text { Respondents with a } \\
\text { "primary mentor" }\end{array}$} & \multicolumn{2}{|c|}{$\begin{array}{l}\text { Respondents that initiated } \\
\text { mentor relationship }\end{array}$} \\
\hline & & $\begin{array}{c}\text { Men } \\
(\mathrm{n}=104)\end{array}$ & $\begin{array}{l}\text { Women } \\
(\mathrm{n}=97)\end{array}$ & $\begin{array}{c}\text { Men } \\
(\mathrm{n}=104)\end{array}$ & $\begin{array}{l}\text { Women } \\
(\mathrm{n}=97)\end{array}$ \\
\hline \multirow[t]{2}{*}{ High } & Biology & $46 \%$ & $50 \%$ & $76 \%$ & $54 \%$ \\
\hline & Chemistry & $46 \%$ & $36 \%$ & $43 \%$ & $68 \%$ \\
\hline \multirow[t]{3}{*}{ Transitioning } & $\begin{array}{l}\text { Earth and } \\
\text { atmospheric }\end{array}$ & & & & \\
\hline & sciences & $51 \%$ & $51 \%$ & $66 \%$ & $55 \%$ \\
\hline & $\begin{array}{l}\text { Electrical } \\
\text { engineering }\end{array}$ & $47 \%$ & $57 \%$ & $38 \%$ & $46 \%$ \\
\hline \multirow[t]{3}{*}{ Low } & Computer science & $50 \%$ & $46 \%$ & $48 \%$ & $48 \%$ \\
\hline & Physics & $55 \%$ & $43 \%$ & $45 \%$ & $41 \%$ \\
\hline & Overall & $45 \%$ & $52 \%$ & $53 \%$ & $53 \%$ \\
\hline
\end{tabular}

To examine how prevalent the relationships are that have been established by an institution, we asked respondents to indicate whether their mentor was "assigned to them through a formal mentoring program". From our results, we found that $40 \%$ of respondents named primary mentors that were assigned through a formal programme. Of these, almost half of assistant professors were engaged through formal mentor programmes, whereas only about one quarter of associate professors had their mentors assigned through formal programmes. Men were more likely ( $45 \%$ of men respondents) to have a mentor that was matched through a formal programme, while only $35 \%$ of women indicated this interaction. This finding demonstrates that mentoring programmes have become an instrument in the U.S. university system. However, given that many of the programmes are established to support integration of women faculty, finding that more men actually engage with their mentors with the help of formal programmes is somewhat surprising and indicates that further research is necessary to understand the dynamics of the formation of mentoring relationships.

If mentors are not assigned through a formal programme, then do other typical academic supervisory relationships coincide with active mentoring relationships? In the doctoral education process, there is some expectation that a dissertation or postdoctoral supervisor may 
play a mentoring role. These supervisors by definition guide individuals through key points in the academic professional development process. Thus, it may be expected that junior faculty (who are closer to their doctoral and postdoctoral experiences) may be more likely to name their dissertation or postdoctoral supervisors as mentors. From our results, we find that this is not the case. Of our respondents whose primary mentor was not assigned through a formal programme, only about $7 \%$ of women faculty and $11 \%$ of men reported their dissertation advisor as their primary mentor. Further, while only $15 \%$ of our respondents overall report that their primary mentor was on their dissertation committee, this was significantly higher for men.

Similarly, while $71 \%$ of assistant and associate level respondents reported having a postdoctoral appointment, almost none of our respondents (men or women) name their postdoctoral adviser as their primary mentor. Overall, these results are somewhat surprising, given the guidance and critical role that dissertation and postdoctoral supervisors play in young faculty career development. It could point to the importance of distinguishing oneself from advisors, or it may also point to a lack of mentoring guidance and resources received from these individuals.

If dissertation advisors and committee members or postdoctoral advisors are not considered to be primary mentors, then how and where do junior faculty meet their mentors? For example, while some faculty may be assigned a mentor through a programme, some faculty may be strategic in affiliating themselves with a mentor. In the development of faculty careers, do women or men faculty tend to be more assertive in developing mentor relationships? We might expect that women seeking to overcome the difficulties of accessing male dominated professional networks (Saloner, 1985) might pursue mentoring relationships more actively than men. Respondents were asked to indicate who had initiated their mentor relationship. Here, faculty were evenly split - about half indicated that they had initiated the mentor relationship themselves, with the remaining half saying it had been initiated by their mentor. Are women less likely to initiate mentor relationships in fields where women are less represented? Examining these data by gender, respondents are almost equally split - men do not initiate mentor relationships at a higher rate than women. For some, professional conferences have been useful in meeting colleagues that can serve a mentoring role. Of the respondents whose mentor was not assigned through a formal 
programme, about $9 \%$ overall met their mentors for the first time at a conference. Interestingly, of those faculty who initiated the relationship themselves, twice as many women (12\%) as men (6\%) met their mentors for the first time at a professional conference. This finding points to the importance of mentors' professional knowledge and expertise above organisational factors.

Given the gender disparities in the sciences, how often do women have women mentors? Are these relationships more effective than non gender-matched mentor relationships? Research suggests that the gender composition of mentor relationships may impact mentoring functions and their outcomes (Ragins, 1997; Sosik and Godshlak, 2000). Studies of women in science and general studies of mentoring have suggested that individuals may be best served by mentors who share their experience (Lawrence, 2008). These studies found that for women, mentoring might be more important and less available than for men (Fox and Fonseca, 2006) and its lack can even be detrimental to the careers of women in science (Riegle, 2006). Our results show one quarter $(25 \%)$ of the women who identified primary mentors have a woman mentor. Men occasionally have women mentors $-6 \%$ of our respondents that have named a primary mentor indicated that this was the case. The naming of women mentors, not surprisingly, is field specific. Overall and not surprisingly we found that very few women mentors were named - only in the fields of computer science and electrical engineering did the percentage of women mentors named in our sample correspond to the overall percentage of women in the discipline. This is not surprising given the number of senior women in these fields.

While similarities of experience can contribute to a close working relationship, other aspects regarding the closeness of the mentor relationship may in fact have important implications for the tailoring and appropriateness of advice and assistance provided by the mentor (Bozeman and Feeney, 2007). In professional networks, close relationships are important for resource acquisition (Gersick et al., 2000). In our results, slightly more than one quarter of respondents (27\%) indicated that their primary mentor is a "close friend". While there was no difference in this rating for men and women at the assistant level (both slightly more than one quarter), $45 \%$ of male associate respondents, as compared to $35 \%$ of women associate faculty, indicated that their primary mentor is a "close friend". In any trusted relationship, close- 
ness develops over time. On average, assistant professors have known their mentors less than six years, and associate professors more than six years. This may also explain why associate level faculty are more likely to call their mentors "close friends". Maintaining close relationships, as well as providing opportunities for interaction, depends on active interaction (Lewicki and Bunker, 1996). From our results we find that half of faculty meet with their mentors about once a week, and assistant professors meet with their professors more often than associate ones. Finally, women, especially women assistant professors, meet with their mentors less often than men. This may be important in understanding how close the contact is between women faculty and their mentors and may suggest a less close relationship than that between male faculty and their mentors.

\subsection{The contributions of mentors}

What resources are provided through mentor interactions? Mentor relationships are based on the expectation of and actual exchange of career relevant information, support and resources (Bozeman and Feeney, 2007), and are defined as a process of work and career-related knowledge and social capital transmission. Kram (1985) defined two types of related mentoring functions - career and psychosocial, which refer to the provision of sponsorship, exposure, visibility and protection, as well as role modelling, friendship and recognition. In the academic setting, mentor resources may range from tangible collaborative interaction, assistance in reviewing papers or proposals, to less tangible information on organisational or institutional norms, collegial interactions, and other career relevant information.

\subsubsection{Mentors as collaborators}

Collaborative relationships drive the productivity of faculty. How intertwined are mentor relationships with collaborative relationships? How often do mentees collaborate with their mentor? We asked our respondents whether they have collaborated with their mentor, as shown in Table 4. From our results, we find that almost half of respondents (48\%) named primary mentors with whom they have also actively collaborated. More specifically, $35 \%$ of assistant and $43 \%$ of associate professors have collaborated with their mentors on research grant propos- 
als, $27 \%$ of assistant and $32 \%$ of associate professors report collaboration on unpublished working or conference papers, and $20 \%$ of assistant and $35 \%$ of associate professors report collaboration on academic journal articles/book chapters.

Table 4. Types of collaboration with primary mentor (past two years) (mean responses by rank and gender: $0=$ no, $1=$ yes)

\begin{tabular}{lcccccc}
\hline & \multicolumn{3}{c}{ Assistant faculty } & \multicolumn{3}{c}{ Associate faculty } \\
\cline { 2 - 7 } & $\begin{array}{c}\text { All } \\
(\mathrm{n}=216)\end{array}$ & $\begin{array}{c}\text { Men } \\
(\mathrm{n}=114)\end{array}$ & $\begin{array}{c}\text { Women } \\
(\mathrm{n}=102)\end{array}$ & $\begin{array}{c}\text { All } \\
(\mathrm{n}=132)\end{array}$ & $\begin{array}{c}\text { Men } \\
(\mathrm{n}=68)\end{array}$ & $\begin{array}{c}\text { Women } \\
(\mathrm{n}=68)\end{array}$ \\
\hline $\begin{array}{l}\text { Research grant proposal } \\
\begin{array}{l}\text { Unpublished working or } \\
\text { conference paper }\end{array}\end{array}$ & 0.35 & 0.40 & $0.29^{*}$ & 0.43 & 0.47 & 0.38 \\
$\begin{array}{l}\text { Academic journal article/ } \\
\text { book chapter }\end{array}$ & 0.27 & 0.31 & 0.23 & 0.32 & 0.34 & 0.29 \\
$\begin{array}{l}\text { Product development } \\
\text { Patent application }\end{array}$ & 0.20 & 0.25 & $0.15^{*}$ & $0.35^{* * *}$ & 0.32 & 0.38 \\
\hline
\end{tabular}

${ }^{* * *} \mathrm{p}<0.001,{ }^{* *} \mathrm{p}<0.01,{ }^{*} \mathrm{p}<0.01$, one-tailed t-test

Few respondents reported collaborating with their primary mentor on industry-specific collaborations, such as product development or patent applications. Overall, there are some important distinctions in the results when examined by gender and rank. Men assistant professors collaborated significantly more often with their primary mentors on grant proposals and journal articles than did women. This is particularly important because production at this time is directly related to the ability to gain tenure. If men are more advantaged in their collaborative and mentor relationships, this has implications for career advancement. Not surprisingly, associate faculty overall collaborate significantly more with primary mentors on journal articles. Here, there is no significant difference between men and women. This may indicate a more developed collaborative relationship, rather than one where the mentor is actively engaged with their mentee for career development purposes prior to tenure. However, the engagement of women faculty with their mentors in journal articles increases at the associate-level. There were no differences between groups for collaboration on unpublished conference presentations or papers. 


\subsubsection{Mentors as advisors}

To assess the actual contribution of mentors as a source of knowledge, we asked respondents to indicate the type of advice and other resources that they sought and received from their primary mentor (Table 5). Here, the results show that mentors serve as an important source of basic career navigation advice. Specifically, the majority $(85 \%)$ of our respondents indicated that they go to their primary mentor for advice on overall career development strategies, with another $71 \%$ indicating that they seek advice from their mentor on interactions with colleagues. About one third (33\%) of our respondents reported going to their mentors for advice on work-family balance. Slightly more associate professors (36\%) and slightly more men than women have sought this type of advice, but the differences between the groups are not significant.

Table 5. Advice sought and resources received from primary mentor and other workplace relationships (mean responses: $0=$ no, $1=$ yes)

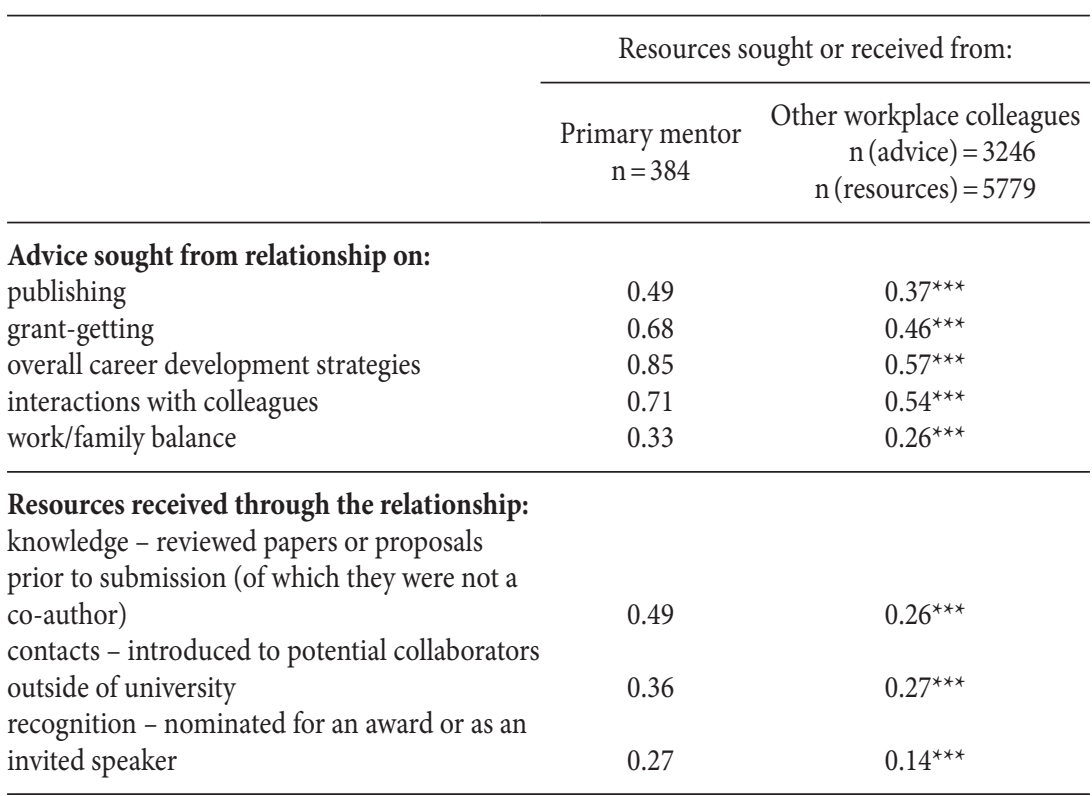

${ }^{* * *} \mathrm{p}<0.001,{ }^{* *} \mathrm{p}<0.01,{ }^{*} \mathrm{p}<0.05$, one-tailed t-test

While an important component of mentor interactions is based on advice and related support regarding career development, in the aca- 
demic setting mentors may also provide valuable tangible assistance to their mentees in terms of contributions to productivity. From our results, we found this to be the case $-68 \%$ of our respondents reported going to their primary mentor for advice on grant-getting, and about half (49\%) report seeking advice on publishing strategies. While not shown here due to space limitations, significantly more assistant professors (74\%) than associate professors (60\%) sought advice on grantgetting, and especially assistant men (77\%) compared to associate men (56\%). However, some mentor relationships play an even more active role in this regard. For example, on average, $49 \%$ of the respondents report their mentors reviewed their papers or proposals (of which they were not co-authors) prior to submission.

Mentors may also provide important access to opportunities and networks that further individual productivity, reputation or other opportunities. The academic promotion process is based on productivity in terms of publication and grantsmanship. Since the knowledge production process in science increasingly relies on collaboration, an important resource that mentors can be instrumental in providing is access to individuals that will enhance the actual productivity of their mentees. From our results, we found that slightly more than one third (36\%) of respondents report that their mentors have introduced them to potential collaborators outside of their universities, thereby expanding individual professional networks. Perhaps not surprisingly, we find some variation here based on mentee rank (not shown here). More associate $(43 \%)$ than assistant (31\%) professors, both men and women, report that their mentors introduced them to potential collaborators.

Building one's professional reputation in terms of recognition is also important in the academic world (Stephan, 1996). In this light, mentor nominations can be valuable resources, as they provide entrance to the established scientific community. Kirchmeyer (2005) argues that mentors impact the advancement of their mentees by connecting them with the social system, and signalling their capacity, reputation, and organisational fit. Slightly more than one quarter $(27 \%)$ of our respondents report that their mentors had nominated them for an award or as an invited speaker. As individuals progress in their careers, their opportunities also increase. From our results, we see that significantly more associate (37\%) than assistant (21\%) professors report their mentors nominating them for an award, as do more women (30\%) than men (24\%). Interestingly, $41 \%$ of women associate professors report that 
mentors nominated them for an award or as an invited speaker, in other words, provided them with recognition. This finding suggests that even in mid-career, women faculty might have to rely on closer relationships in order to be able to access the established science community.

\subsection{Moving beyond the primary mentor: Other sources of mentoring advice and interaction}

While additional research and analysis must be done to uncover the causal relationships between specific mentoring exchanges, mentor relationship types, and career advancement and productivity, our analysis shows important mentor interactions in the academic science environment. What our review thus far does not reveal is the richer mentor-like interaction that faculty experience with other colleagues beyond the dyadic relationship with their mentor. As the academic environment has evolved to be more collaborative, having a relationship with only one mentor is seen as no longer realistic or feasible for career advancement (De Janasz and Sullivan, 2004). As a result, individuals may seek multiple developmental relationships across numerous activities (De Janasz and Sullivan, 2004). This represents an expanded mentor network, where the relationship with one primary mentor still exists as an important node of a work-related network, but is complemented by other professional relationships and resources.

To assess this, we asked individuals to indicate the types of mentor-like exchange they had with other members of their professional networks (Table 5). Specifically, we asked individuals to first name individuals from whom they sought advice about a range of professional issues and with whom they discussed important departmental matters. Further, we asked respondents to indicate whether individuals they had named as close collaborators (both inside and outside of their institution) provided active mentoring support in the form of nominations, introductions to other collaborators, or the review of papers or proposals of which they were not a co-author. Do individuals gain more mentoring exchange from their collective network or from their primary mentor?

Our results show (Table 5) that on average, mentees have sought significantly more advice overall from their mentors than from their other workplace relationships, particularly regarding career development strategies, grant-getting, and interactions with colleagues. This suggests that mentors may play a significant and distinct role for 
younger faculty members. When asked about more tangible exchange of resources in terms of active involvement in productivity capacity, mentors again provide more resources. Respondents' mentors have reviewed papers or proposals prior to submission when they are not a co-author more often than other colleagues. This shows an important tangible resource that is not provided to the same extent by one's own network. While these differences are important in understanding the real contribution of a primary mentor, areas where mentors and network members provide a similar level of advice and resources are also important. While mentors are sought out more often for advice on publishing and personal interactions, it is only slightly more often than individuals seek the same from other network members. In terms of resources received, there is little difference in the extent to which introductions to potential collaborators is provided by mentors versus other colleagues. Similarly, while mentors are reported as nominating individuals for an award or as an invited speaker more often than other network members, the differences are small. Overall, these results show that even though individuals may gain important career support (mentorship) from a range of colleagues, the resources received from one's primary mentor can exceed those other sources. It also underscores the importance of looking beyond the primary mentor for developmental resources in the study of faculty development in the sciences.

\section{Conclusion and future research}

The development of a mentoring relationship can provide important resources, support, and other assistance important for career advancement for women in the sciences. In fields where women are underrepresented, this can be an important factor in bridging gaps and overcoming barriers to advancement faced by women in these fields. As noted, mentoring can take a number of forms and provide a range of resources. The mentor may provide advice, support, protection, promotion, and sponsorship, thereby increasing an individual's capacity via the development of social capital (Kram, 1985; Kram and Isabella, 1985; Noe, 1988; Ragins, 1989; Bozeman and Feeney, 2007). It is also seen as a developmental type of relationship that may involve the exchange of psychological and emotional support, and more tangible exchange of knowledge, links to resources, and active collaboration (Burke, 1984; Kram, 1985; Noe, 1988). 
Overall, the descriptive findings presented in this chapter suggest that mentoring is an important part of workplace relationships in the academic science environment. While our findings are descriptive, they do demonstrate some important differences in productivity for junior faculty, particularly women, when a primary mentor is identified as part of their network. Our results quantify some earlier conceptual work on mentoring relationships (Long, 1997; van Emmerik, 2006) and provide additional support for some other empirical work (Noe et al., 2002; Dougherty and Dreher, 2007). We provide outcome differences for men and women on seventeen different productivity and psychosocial measures. Overall, these findings are in line with earlier work. However, the differences in significant measures for men and women are worth noting. Another interesting contribution of these results is the identification of the areas in which mentor and mentee are likely to actively collaborate. Earlier work points to the benefits of active collaboration in career advancement (Burke, 1984; Kram, 1985; Noe, 1988). We find slightly favourable results for men in terms of collaboration opportunities with their mentor, which provokes further investigation into understanding the reasons. Finally, we build on the argument that peer networks and mentors simultaneously influence individual careers (De Janasz and Sullivan, 2004). While we find evidence that both interactions occur, we specify that advice sought from mentors constitutes a significant portion of individuals' resources.

Our results show that both men and women faculty show higher productivity and greater satisfaction in general when they have a primary mentor. For women faculty, the differences in several of the data presented in this chapter show them performing at the same level as men faculty when they have a primary mentor. These preliminary descriptive results suggest that mentorship may in fact have important potential impacts for women in science. The importance of findings for women could be realised at two levels. First, this study provides support for previous work suggesting that mentors could play a positive role in women's academic careers. Women in science could initiate mentoring relationships where formal programmes do not exist. Second, and more importantly, this study could initiate an attempt to understand the circumstances that create different environments for men and women in the academic world. However, the descriptive results are limited, as they do not show causality or additional details regarding the mentor-mentee exchange that are important in drawing more substantial and useful conclusions regarding 
mentorship in the academic sciences. Nevertheless, these findings are critical in laying the groundwork for explanatory research in this area. Our findings suggest that mentoring relationships may be an important parameter in estimating academic productivity, especially in research attempting to predict differences by gender. Furthermore, the components of our study would provide useful insights in developing path analyses in academic careers. For example, future studies addressing job satisfaction in academia would not only acknowledge the difference in having a mentor, but also realise how men and women achieve different types of satisfaction in the presence of a mentor.

The question remains - why do these differences exist? Are individuals who are more strategic and focused aligning themselves with individuals who can assist in career development, or do mentors make a difference? If mentoring does make a difference, which aspects of the mentoring resource exchange that occurs for women in science are most important? As mentoring programmes are institutionalised and individual informal mentoring relationships are encouraged as part of faculty service, a better understanding of the exchange and outcomes of these relationships can lead to the better crafting and conceptualising of these relationships. For women in underrepresented fields of science, this is particularly important. Our future research will attempt to address many of these issues.

\section{References}

ALLEN, Tammy D., EBY, Lillian, POTEET, Mark L., LENTZ, Elizabeth, \& LIMA, Lizzette (2004). Career benefits associated with mentoring for protégés: A metaanalysis. Journal of Applied Psychology, 89(1), 127-36.

ALLEN, Tammy D., \& EBY, Lillian T. (2007). The Blackwell handbook of mentoring: A multiple perspectives approach. Wiley-Blackwell

ASTIN, Helen S., \& CRESS, Christine M. (2003). A national profile of academic women in research universities. In L. S. Hornig (Ed.), Equal rites, unequal outcomes: Women in American research universities (pp. 53-88). New York: Kluwer Academic/Plenum Publishers.

AWIS (n.d.). Association for Women in Science. Retrieved 9 January 2009 from $<$ http://www.awis.org/careers/mentoring.html>

BOZEMAN, Barry, DIETZ, James S., \& GAUGHAN, Monica (2001). Scientific and technical human capital: An alternative model for research evaluation. International Journal of Technology Management, 22(7/8), 716-740.

BOZEMAN, Barry, \& FEENEY, Mary K. (2007). Toward a useful theory of mentoring: A conceptual analysis and critique. Administration \& Society, 39(6), 719-739. 
BU (n.d.). Brown University Mentoring Program. Retrieved 9 January 2009 from $<$ http://www.brown.edu/Administration/Provost/Advance/development.html>

BURKE, Ronald J. (1984). Mentors in organizations. Group \& Organization Management, 9(3), 353-372.

BURT, Ronald S. (1992). Structural holes versus the social structure of competition. Cambridge, MA: Harvard University Press.

BURT, Ronald S. (2000). Creating careers: Women's paths through entrepreneurship. Working paper. University of Chicago and Institute Européen d'Administration d'Affaires (INSEAD). Retrieved 9 January 2009 from <http://faculty.chicagobooth.edu/ronald.burt/research/GSBAS7.pdf>

BURT, Ronald, \& MINOR, Michael J. (1983). Applied network analysis: A methodological introduction. Beverly Hills: Sage Publications.

CHAO, Georgia T., WALZ, Pat M., \& GARDNER, Philip D. (1992). Formal and informal mentorships: A comparison on mentoring functions and contrast with nonmentored counterparts. Personnel Psychology, 45, 619-636

DE JANASZ, Suzanne C., \& SULLIVAN, Sherry E. (2004). Multiple mentoring in academe: Developing the professorial network. Journal of Vocational Behavior, 64(2), 263-283.

DOUGHERTY, Thomas W., \& DREHER, George F. (2007). Mentoring and career outcomes: Conceptual and methodological issues in an emerging literature. In B. R. Ragins \& K. E. Kram (Eds.), The handbook of mentoring at work: Theory, research and practice (pp. 51-93). Thousand Oaks, CA: Sage.

FEENEY, Mary K. (2006). Mentoring women in the public sector: Expectations and realities. International Journal of Learning and Change, 1(4), 381-406.

FIELD, John (2003). Social capital. London and New York: Routledge.

FOX, Mary Frank (1996). Women, academia, and careers in science and engineering. In C. S. Davis, A. Ginorio, C. Hollenshead, B. Lazarus, and P. Rayman (Eds.), The equity equation: Fostering the advancement of women in science, mathematics, and engineering (pp. 96-121). San Francisco, CA: Jossey-Bass.

FOX, Mary F. (2003). Gender, faculty, and doctoral education. In L. S. Hornig (Ed.), Equal rites, unequal outcomes: Women in American research universities (pp. 91109). New York: Kluwer Academic/Plenum Publishers.

FOX, Mary F., \& FONSECA, Carolyn (2006). Gender and mentoring of faculty in science and engineering: Individual and organisational factors. International Journal of Learning and Change, 1(4), 460-483.

(GIT, n.d.), Georgia Institute of Technology College of Engineering Faculty Mentoring Award, Retrieved 9 January 2009 from <http://www.gtdiversity.gatech.edu/ faculty/>

GERSICK, Connie, BARTUNEK, Jean, \& DUTTON, Jane (2000). Learning from academia: The importance of relationships in professional life. Academy of Management Journal, 43(6), 1026-1044.

GRANOVETTER, Mark (1973). The strength of weak ties. American Journal of Sociology, 78(6), 1360-1380. 
GRANOVETTER, Mark (1983). The strength of weak ties: A network theory revisited. Sociological Theory, 1, 201-233.

KIRCHMEYER, Catherine (2005). The effects of mentoring on academic careers over time: Testing performance and political perspectives. Human Relations, 58(5), 637-660.

KRAM, Kathy E. (1985). Mentoring at work: Developmental relationships in organizational life. Glenville, IL: Scott, Foresman.

KRAM, Kathy E., \& HALL, Douglas T. (1996). Mentoring in a context of diversity and turbulence. In S. Lobel \& E. E. Kossek (Eds.), Human resource strategies for managing diversity. London, UK: Blackwell Publishers.

KRAM, Kathy E., \& ISABELLA, Lynn A. (1985). Mentoring alternatives: The role of peer relationships in career development. The Academy of Management Journal, 28(1), 110-132.

KULIS, Stephen, SICOTTE, Diane, \& COLLINS, Shawn (2002). More than a pipeline problem: Labor supply constraints and gender stratification across academic science disciplines. Research in Higher Education, 43(6), 657-691.

LAWRENCE, Ron (2008). Executive mentoring: Turning knowledge into wisdom. Business Strategy Series, 9(3) 126-131.

LEWICKI, Roy J., \& BUNKER, Barbara B. (1996). Developing and maintaining trust in work relationships. In R. M. Kramer \& T. R. Tyler (Eds.),Trust in organizations: Frontiers of theory and research (pp. 114-139). Thousand Oaks, CA: Sage.

LONG, Janette (1997). The dark side of mentoring. Australian Educational Researcher, 24, 115-33.

LONG, John S. (2003). The presence and participation of women in academic science and engineering: 1973-1995. In L. S. Hornig (Ed.), Equal rites, unequal outcomes: Women in American research universities (pp. 145-74) New York: Kluwer Academic/Plenum Publishers.

LONG, John, \& FOX, Mary F. (1995). Scientific careers: Universalism and particularism. Annual Reviews in Sociology, 21(1), 45-71.

McKEEN, Carol A., \& BUJAKI, Merridee (2007). Gender and mentoring: Issues, effects, and opportunities. In B. R. Ragins \& K. E. Kram (Eds.), The handbook of mentoring at work: Theory, research and practice (pp. 197-222). Thousand Oaks, CA: Sage.

MENTORNET (n.d.). Retrieved 9 January 2009 from <http://www.mentornet.net/>

MOORE, Gwen (1990). Structural determinants of men's and women's personal networks. American Sociological Review, 55(5), 726-735.

MU (n.d.). Marquette University Faculty Mentoring Program. Retrieved 9 January 2009 from <http://www.marquette.edu/fmp>

NOE, Raymond (1988). An investigation of the determinants of successful assigned mentoring relationships. Personnel Psychology, 41(3), 457-479.

NOE, Raymond, GREENBERGER, David, \& WANG, Sheng (2002). Mentoring: What we know and where we might go. Research in personnel and human resources management, 21, 129-174. 
NMSU (n.d.). New Mexico State University ADVANCE Faculty Mentoring Program. Retrieved 9 January 2009 from < http://www.advance.nmsu.edu/Events/Initiatives/ Mentoring/index.html>

RAGINS, Belle R. (1989). Barriers to mentoring: The female manager's dilemma. Human Relations, 42(1), 1-22.

RAGINS, Belle R. (1997). Antecedents of diversified mentoring relationships. Journal of Vocational Behavior, 51(1), 90-109.

RAGINS, Belle R., \& COTTON, John L. (1999). Mentor functions and outcomes: A comparison of men and women in formal and informal mentoring relationships. Journal of Applied Psychology, 84, 529-550.

RAGINS, Belle, COTTON, John L., \& MILLER, Janice S. (2000). Marginal mentoring: The effects of type of mentor, quality of relationship, and program design on work and career attitudes. Academy of Management Journal, 43(6), 1177-1194.

RAGINS, Belle R., \& SUNDSTROM, Eric (1989). Gender and power in organizations: A longitudinal perspective. Psychological Bulletin, 105(1), 51-88.

RIEGLE, Stephanie (2006). Mentoring and socialisation: Senior female faculty and mentoring practices. International Journal of Learning and Change, 1(4), 446459.

RENZULLI, Linda A., ALDRICH, Howard, \& MOODY, James (2000). Family matters: Gender, networks, and entrepreneurial outcomes. Social Forces, 79(2), 523-546.

SALONER, Garth (1985). Old boy networks as screening mechanisms. Journal of Labor Economics, 3(3), 255-267.

SHAUMAN, Kimberlee A., \& XIE, Yu (2003). Explaining sex differences in publication productivity among postsecondary faculty. In L. S. Hornig (Ed.), Equal rites, unequal outcomes: Women in American research universities (pp. 175-208). New York: Kluwer Academic/Plenum Publishers.

SINGH, Val , BAINS, Divindra, \& VINNICOMBE, Susan (2002). Informal mentoring as an organisational resource. Long Range Planning, 35(4), 389-405.

SOSIK, John J., \& GODSHALK, Veronica M. (2000). The role of gender in mentoring: Implications for diversified and homogenous mentoring relationships. Journal of Vocational Behavior, 57(1), 102-122.

STEPHAN, Paula E. (1996). An essay on the economics of science. Journal of Economic Literature, 34(3), 1191-1235.

UIC (n.d.). University of Illinois at Chicago Faculty Mentoring Program. Retrieved 9 January 2009 from <http://www.uic.edu/depts/oaa/faculty/facment.html>

UV (n.d.). University of Vermont Faculty Mentoring Program. Retrieved 9 January 2009 from <http://www.uvm.edu/ mentor/>

UWM (n.d.). University of Wisconsin-Madison Women Faculty Mentoring Program. Retrieved 9 January 2009 from <http://www.secfac.wisc.edu/wfmp/resources3b. htm >

VAN EMMERIK, Hetty I. J., EUWEMA, Martin C., GESCHIERE, Myrthe, \& SCHOUTEN, Marieke F. A. G. (2006). Networking your way through the organization. Women in Management Review, 21(1), 54-66. 
WSUIBC (n.d.). Washington State University Institute of Biological Chemistry, Faculty Mentoring Program. Retrieved 9 January 2009 from $<$ http://provost.wsu. edu/faculty_mentoring/biochem.html>

WASSERMAN, Stanley, \& FAUST, Katherine (1994). Social network analysis: Methods and applications. Cambridge: Cambridge University Press.

ZEY, Michael G. (1985). Mentor programs: Making the right moves. Personnel Journal, 64(2) 53-57. 


\section{Helene Schiffbänker}

\section{Gender specific career aspects in science and technology}

\section{Introduction}

The "career" concept is widely used in management literature, but it also has an interesting sociological dimension, especially in relation to gender issues. Recently, career aspects have become increasingly relevant when talking about gender issues in science and technology (S\&T). Because of the Lisbon Strategy, the participation of women in S\&T has become an important political goal. Policymakers at both the European and national level intend to promote women in science and technology in a quantitative (more women) and qualitative way (more women in leading positions and better frameworks for their career advancement).

To make the field more attractive and to get a greater number of women into S\&T, more women are needed at all levels of the innovation system. So far, it is noticeable that women have greatly succeeded at student level but not at entering the research labour market. In Austria, industrial research in particular and also non-university research institutions attract few women. More research is needed on factors influencing the choice of discipline at school and university level and on barriers when starting and continuing a research career. Doing this from a gender-theoretical position, we need to look at both genus groups, women and men, as well as at structural dimensions.

There is a general insufficiency of empirical research on women in S\&T in Austria, but in particular there is a lack of data on female and male researchers in non-university research institutions and in industrial research. In the first section of this chapter, the Austrian S\&T sector in general and the non-university-research sector are described, focusing on different career steps.

The second part of the chapter is a theoretical discussion on "career" as an analytical dimension in a sociological context, seeking a definition of career and possible gender implications. It describes "career" as a link between individual acting and social systems. It also 
enquires into the gender relevance of classical career concepts and introduces useful ideas of feminist researchers for better conceptualising career theory, arguing for a greater integration of the private sphere into career theory.

The third section discusses some of my own empirical research, located at the interface between research work and the private sphere. In Austria, the difficulty in reconciling childcare and research work is seen as the main factor in the less successful careers of female scientists compared to their male counterparts. As both childcare and research work make great demands on time, being a successful researcher seems to make it impossible to be a good mother. However, as being a good mother is culturally seen as being important, a lack of time for research, both in terms of quality and quantity, seems to be the reality for female researchers.

Consequently, we have asked female and male researchers with children who are active in the field for their reconciliation pattern and how they combine work and childcare, and what their coping strategies are. Possible differences between male and female researchers with children are then analysed.

\section{Women in science and technology in Austria}

In Austria, women are still marginalised in S\&T. Only $25 \%{ }^{1}$ of all $\mathrm{R} \& \mathrm{D}$ personnel are women (Table 1). However, there are considerable differences between different sectors. The private non-profit sector and the government sector employ the highest percentage of female researchers, but the total number employed in these sectors in Austria is marginal.

The two sectors with the most significant employment numbers are more sex segregated in their employment structure. 35\% of all researchers in the higher education sector are women, which makes university the most important employment field for female researchers (in terms of absolute numbers) in Austria. But in the largest sector, the business enterprise sector with its increasing employment potential, just $14 \%$ of all researchers are female. This is of specific relevance, as in terms of the Lisbon goals this sector will be in particular need of more highly qualified human resources.

\footnotetext{
1 Headcounts are used because women more often work part-time.
} 
Table 1. R\&D in Austria - employment by sector and $\operatorname{sex}^{2}$

\begin{tabular}{lccccc}
\hline & \multicolumn{5}{c}{ Research and development (R\&D) 2006 } \\
\cline { 2 - 6 } & $\begin{array}{c}\text { Higher } \\
\text { education } \\
\text { sector } \\
\text { HES }\end{array}$ & $\begin{array}{c}\text { Government } \\
\text { sector }\end{array}$ & $\begin{array}{c}\text { Private } \\
\text { non-profit } \\
\text { sector } \\
\text { GOV }\end{array}$ & $\begin{array}{c}\text { Business } \\
\text { enterprise } \\
\text { sector } \\
\text { PNP }\end{array}$ & Total \\
Total & 23,609 & 2,789 & 284 & 22,915 & 49,597 \\
Women & 8,190 & 1,095 & 147 & 3,109 & 12,541 \\
Men & 15,419 & 1,694 & 137 & 19,806 & 37,056 \\
Share of women & $35 \%$ & $39 \%$ & $52 \%$ & $14 \%$ & $25 \%$ \\
\hline
\end{tabular}

Source: Statistics Austria, 2009

As Figure 1 illustrates, the share of women has been slowly increasing in all sectors over recent years.

Figure 1. Male and female scientific personnel by sector 1998-2006

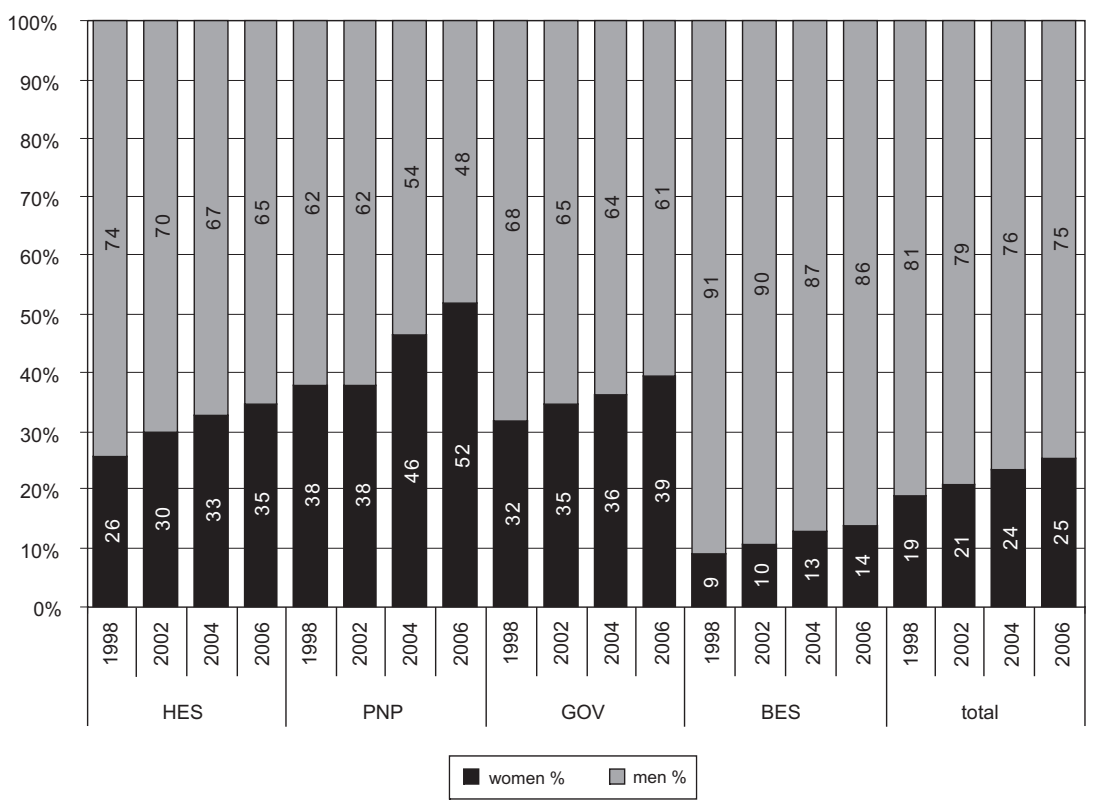

\footnotetext{
2 Based on headcounts.
} 
From the cross-national perspective, the share of female researchers in Austria is below the EU average. In the business enterprise sector, Austria is at the bottom end (EC, 2006).

To analyse the career prospects that women and men face, the Glass Ceiling Index (GCI) is used. This indicator measures the relative chance of women reaching a top position compared to men (Table 2). The She figures 2006 publication compares ${ }^{3}$ women in Grade A positions (equivalent to full professors in most countries) to the proportion of women in academia, indicating the opportunity, or lack thereof, for women to move up the hierarchical structure in their profession.

Table 2. Glass Ceiling Index in selected countries

\begin{tabular}{ll}
\hline EU 25 & 2.1 \\
Austria & 2.7 \\
France & 2.0 \\
Germany & 1.9 \\
Finland & 1.8 \\
\hline
\end{tabular}

Source: EC, 2006: 59

This ranking shows that it is quite difficult for female researchers in academia to succeed on the career ladder. When discussing career paths at universities, the "leaky pipeline" approach is widely used to describe the fact that the higher the position, the fewer women there are (Figure 2).

It is also noticeable that women do not get to the top, even when the majority of graduates in a specific discipline are women, e.g. in humanities. However, in this chapter the main focus is not on academia, but on the non-university research sector. In Austria, this research field is part of the business enterprise sector, together with industrial research. Compared to the higher education sector, these two sectors have hardly been analysed empirically. More relevant data, which is supposed to be the basis for political intervention, would be especially fruitful, as these sectors are supposed to have the specific basic conditions for both male and female career trajectories. As no sex-segregated data of the employ-

\footnotetext{
3 Values run from 0 to infinity. A GCI of 1 indicates that there is no difference between women and men being promoted. A score of less than 1 means that women are overrepresented and a GCI score of more than 1 indicates a glass ceiling effect showing that women are underrepresented in grade A positions. In other words, the interpretation of the GCI is that the higher the value, the thicker the glass ceiling and the more difficult it is for women to move into a higher position (EC, 2006).
} 
ment structure in non-university research organisations were available, FEMtech ${ }^{4}$ started gender-monitoring in all non-university research organisations in 2003 (Table 3).

Figure 2. Researchers by position in all Austrian universities

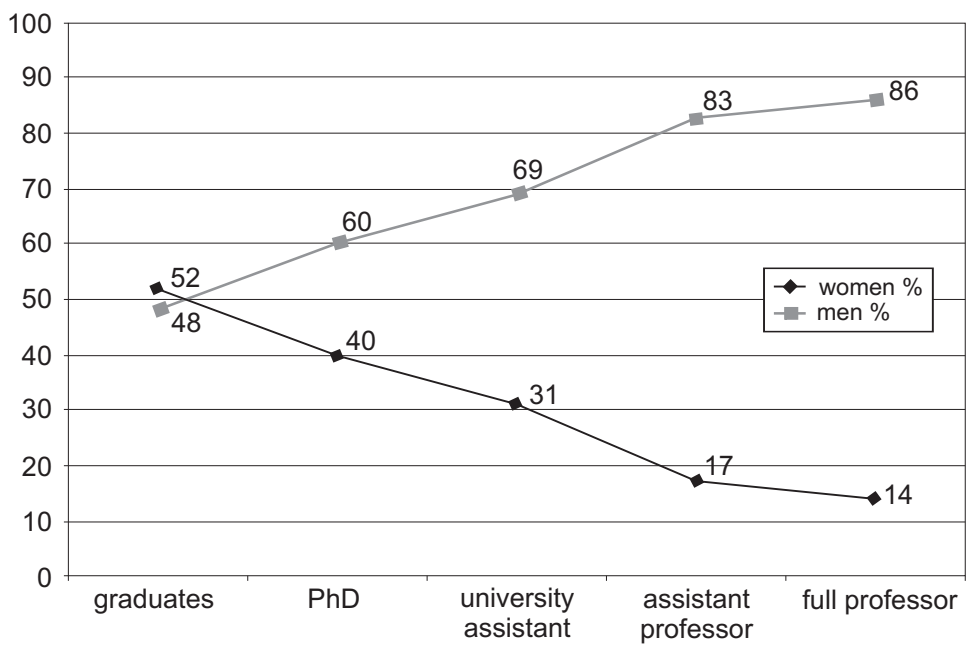

Table 3. Employment structure in non-university research institutions in Austria

\begin{tabular}{ll}
\hline Total & 2,391 \\
Women & 430 \\
Men & 1,961 \\
Share of women & $18 \%$ \\
\hline
\end{tabular}

Source: BMVIT, 2006: 18

In contrast to academia, the non-university research sector does not offer institutionalised career paths. Additionally, the hierarchy is primarily flat, not allowing too many "career steps". This means that the metaphor of the "leaky pipeline" is inappropriate.

Looking at the "career ladder" again, it can be seen how male dominated the management level is in the field. Table 4 shows the broad marginalisation of women in decision-making bodies, as only $7 \%$ of all

${ }^{4}$ FEMtech is a Federal Ministry of Transport, Innovation and Technology (BMVIT) funding programme for women in research and technology. 
management positions in non-university research institutions are held by women. On management and executive boards, less than $6 \%$ of the positions are held by women, while on scientific boards, only one out of ten members is a female researcher.

Table 4. Researchers in management positions and on boards at non-university research institutions in Austria, 2006

\begin{tabular}{lcc}
\hline & Women & Men \\
\hline Management & $7.1 \%$ & $92.9 \%$ \\
Management/executive boards & $5.7 \%$ & $94.3 \%$ \\
Scientific boards & $9.8 \%$ & $90.2 \%$ \\
\hline
\end{tabular}

Source: BMVIT, 2007: 27

Before looking for reasons at the empirical level, a few theoretical remarks on the notion of "career" seem necessary to clear up what we are examining.

\section{3. "Career" as a sociological dimension}

What do we mean when we talk about "career"? What does "career" mean in general, in sociology, and from a gender-perspective?

In everyday language, at least in a German-speaking context, the term "career" is related to hierarchical advancement or leading positions. A career is visible, meaning a better job, more income or a special position. "Career" is a common term. We read about careers in newspapers, and career prospects are already important when children or their parents choose a certain educational institution, as they are already thinking of specific career options.

However, at the individual level the significance of the term may differ considerably from the common definition, with the concept being based on personal decisions, and individual preferences, priorities and goals in professional and private development.

Finally, what do sociologists mean by "career"? How is the concept of "career" rooted in sociology? I will point out a few selected aspects that seem relevant to understanding better women's careers compared to men's in science and technology.

Looking back to early sociologists, we find Max Weber's wellknown definition of a bureaucratic career. Regarding it through "gen- 
der-glasses", it is basically a male concept with the husband at work and his wife at home. By the 1940s, the Chicago School of Sociology was focusing on careers both theoretically and empirically. Everett Hughes and his colleagues defined "career" according to four dimensions:

- Careers are janus-headed. They have an objective dimension, for example the way people participate in institutions like the labour market, and a subjective dimension that depends on subjective career experiences and the relevance of a career in one's personal life.

- Careers are organised in different stages. Different status-passages enable the individual to take over different social roles.

- Careers enable the individual to take part in the "proportion of collectives": a career is what is seen as a career in a specific social setting.

- Careers are a link between institutions and the individual. The objective and the subjective aspects of a career, according to Gofmann (1961) and Bailyn (1996), consist in the distinction between "external career" and "internal career". The first is visible from the outside, while the second is not observable, but is based on personal motivation structure and therefore "internal".

Giddens' structuration theory (1984) describes careers as interaction processes between institutions and individuals that are defined by career scripts. These career scripts incorporate interpretation patterns, resources and norms that are defined in different specific contexts.

Martin Kohli's (1985) concept of the "institutionalisation of the life course" is a theoretical concept that is closely linked to the discussion of career paths and career motivations. Kohli argues that, while the process of individualisation is ongoing (see for example Beck, 1986), there might be new orders for structuring individual lives. The "life course as an institution" describes the individual's specific and personal way of organising his/her life and indicates a new form of institutional order. Historically, at the socio-structural level, this concept was rooted in a period of stable economic growth, full employment and an expanding welfare state. At the individual level, it was based on the "Normalarbeitsbiographie" (standard working career) with constant and full employment typical for most male employees. Women at this time either worked part-time or did not re-enter the labour market after childbearing. Economically, they depended on their husbands, the socalled "male breadwinners". This indicates that the concept of the "in- 
stitutionalisation of the life course" is mainly structured by an employment system only giving women a marginal position in paid work.

Figure 3. Career scripts as a link between social institutions and individual acting

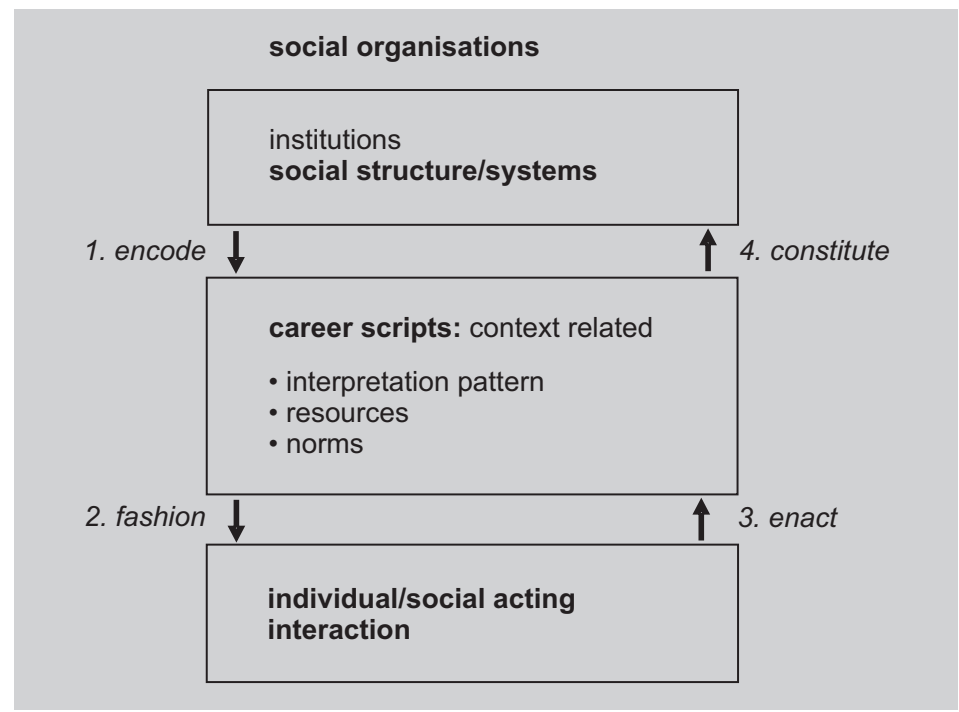

Source: Barley (1996), adapted by the author

As the socio-structural framework had changed remarkably over the following two decades, Kohli (2001) reconsidered his concept in favour of a tendency towards de-institutionalisation. A process of destandardisation and deregulation can be seen in the pluralisation of life forms. At the employment and family level, heterogeneous life paths and patchwork biographies exist. The individual actively organises the life course or, as Sennett (1998) points out, is even forced into a greater level of flexibility. Based on this theoretical concept, heterogeneous career forms are possible that may differ from classical understanding and give more room for the live realities of men and women.

Gender in this context is a dimension of inequality. Today, women are better educated and better integrated in the labour market, yet they still do not succeed in their careers, at the level of income and leading positions, in the same way that men do. Their investments in their careers are not equally rewarding. A typical female 
life course, with more employment interruptions, more part-time work, and thus less professional advancement, does not correspond to this life course concept as well as the male one, which is strongly employment-oriented. And as women are doubly integrated into society (doppelte Vergesellschaftung, Becker-Schmidt, 1987) by both profession and family, this divergence is reflected in their subjective motivation structure. Women tend to be more oriented to the family and to their partner's employment integration. So when a wife and husband (or partner) organise their "related life courses" (Born and Krüger, 2001), women's decisions are usually more related to men's than the other way round. As a result, women's life courses are directly related to men's and less self-contained.

Feminist researchers have already formulated critiques of this "male" employment concept in classical career theory. The dominance of the male life course ignores the differences in female life orientation both in terms of career path as well as family. Feminist theorists argue for new theoretical approaches that better integrate female career aspects in career theory by paying more attention to female life specifics such as the private sphere, female values or female ways of acting. Gallos (1996) focuses on differences in female personal development. These differences illustrate the need for a new career theory that concerns not only the professional sphere, but that equally integrates aspects of private/family life. The often used definition of "career" as the "success of a person in his (!) self selected profession" 5 is not broad enough to describe diverse (female) career paths that could also be attractive for men. As a result, Gallos (1996) suggests a new feminist career theory offering alternative career orientation for women (and men):

Career can no longer be limited to occupational choice and ignore lifestyle issues ... We need more ways of describing ... careers and career choices that reflect the experiences of today's women (and an increasing number of men) who acknowledge the importance of professional work but choose to fashion lives that combine both productive and nurturing roles over time. We neither have adequate language, models, nor illustrative teaching cases to talk about what does a career look like that is simultaneously high on achievement and high on relationship.

(Gallos 1996: 124)

${ }^{5}$ Merrian-Webster (1974). 
Women's life course perspectives might reconcile strong professional ambition with social needs (children, family), planned in accordance with a long-term life perspective that is personally satisfying. This seems different from a male career concept, which is characterised by long-lasting business commitments or life decisions that put professional success first.

These differences have to be recognised in order to avoid the general use of male career concepts as the norm, making women's careers seem like deviant exceptions. Gallos argues that typical female career management is not accepted as "female", but is always compared to the male model and thus characterised by deviation. It is described in terms of shortcomings, career-backlash or quitting the one and only (male) career path. It could also be described as involving less job commitment and less career ambition, and being less career focused. At the same time (as Gallos shows empirically), some women in successful organisational positions quit in favour of better life quality. They "opt-out" to "gain back their sovereignty over life-time". For Gallos, career preparation, societal opportunities, subjective values and perspectives (especially having children), timing and age must be considered as indispensable components of a female career theory; hence the need for more information on female career paths, career patterns and career images.

Another difference-based theoretical approach has been developed by Marshall (1996), who argues that women and men have different basic human qualities and potential human characteristics. Professional success and what is seen as a "career" is dominated by male values (like acting straightforwardly), while female values are seen as being less important. Therefore, a theoretical re-framing should integrate female aspects better. It seems obvious nowadays that the traditional linear male career concept is obsolete, and careers are organised more in sequential stages based on personal experiences. This "phasing" is open to steady change thus producing different and plural career paths. A career is not to be defined as the result or final achievement of a person's professional development, but rather in terms of the quality of the process or the personal satisfaction it brings in each phase.

Theses concepts stress significant dimensions that need to be taken into account when talking about women's careers in general and those in science and technology in particular. They demonstrate that the theoretical concept of "career" for a long time was mainly focused on male realities, widely ignoring female aspects. They may also point 
to certain dimensions of difference between men and women in their career trajectories.

At the same time as focusing on differences between genus groups, we need to focus on differences within the groups as well as on similarities between male and female career trajectories that are based on dimensions other than sex. Having or not having children, partner arrangements, type of work contract, etc. may have more influence on career trajectories and career orientations than sex. Talking in terms of the careers of women and men may re-establish gender stereotypes and also career stereotypes. Therefore, theoretical concepts based on the social construction of gender roles, such as doing and undoing gender, could help insights to be obtained more efficiently and the structural dimension to be better integrated.

For my own empirical work, this basically means that in analysing the career aspects of female and male researchers, not only does public sphere paid work have to be integrated, but also private sphere unpaid work. Dimensions more relevant for women (in traditional gender roles), such as the reconciliation of work and family, have to be integrated. They may in fact have an important impact on career orientations and career trajectories. At the same time, it is necessary to integrate men into the analysis to be better able to deconstruct traditional gender roles.

\section{Reconciliation of childcare and research}

As mentioned above, the reconciliation of (research) work and childcare is important when looking at gender specific career aspects. In public, politics and also in enterprises it is said to be the main reason for a woman's "career slump" and less successful career advancement. This argument is based on two opposite positions. The first mentions the lack of childcare facilities as the main barrier to the better career advancement of women, while the other refers to the freedom of choice to care for children at home and re-enter a career at a later time. Nevertheless there is strong evidence that political regulation ${ }^{6}$ has had a hindering effect on career advancement (Riesenfelder et al., 2006). At the same time, in Austria it is highly valued socially for mothers to stay at home and care for their children themselves. Other factors that

${ }^{6}$ In fact, it is possible for mothers to stay at home on maternity leave for 30 months, while fathers may take another 6 months. 
make reconciliation an important gender specific career aspect include ongoing employment patterns like job interruptions, part-time work or a woman's orientation towards her partner's/husband's career.

In addition, an internal career, defined in terms of personal motivation aspects, plays a crucial role in choosing an individual reconciliation pattern. The same can be said about the division between paid and unpaid work, as both are greatly influenced by personal values incorporated in role models.

Reconciliation is related to both the employment and private sphere. The decision on how long a woman stays at home after maternity leave and to what extent she re-enters the labour-market is of great relevance to her career prospects. This decision depends on her personal preferences and motivation structure and also on institutions and role arrangements. It also depends on the welfare state, which (in combination with the market) offers money and regulations concerning time off as well as public childcare.

The reconciliation of work and childcare has been widely discussed in Austria, and consequently in the last few years has also become more relevant in research. The Lisbon Strategy and other political goals are trying to bring more women into research and ask why they are underrepresented. "Having children" is often mentioned as the first (and sometimes only) explanation, and with this, the reconciliation issue comes up. Reconciliation is often discussed exclusively as a female matter, but it has to be said that this is not so. Do only women have children and thus something to reconcile, or men too? Why do more and more women neglect personal goals and refrain from having children? And does being childless mean women having the same career options as men?

Reconciling work and childcare, with the focus on women and children, has been discussed for decades. Lately a new focus has been put on the work-life-balance, switching from children and women to both sexes and to a balanced relationship between the professional and private spheres, and between working time and leisure time. This seems an increasing challenge as the borders between working time and private time become more and more blurred (for a discussion on delimitation, see Gottschall and Voß, 2003). This approach is interesting but not specifically relevant to the current research questions. For gender specific career advancement, the fact that women are biologically able to become pregnant and so potentially be absent from the 
labour market ${ }^{7}$ is significant, and thus (potential) reconciliation with childcare becomes an issue.

\subsection{Reconciliation and research}

Doing research successfully while having children at the same time seems difficult, at least for women. This is argued from the point of view of the "male scientific ethos" that proclaims that science needs one's total presence, ${ }^{8}$ which is impossible for people with childcare responsibilities. As far back as 1985, Helga Nowotny identified the "myth of non-reconciliation" in the scientific system, based on a (potential) lack of time. This is confirmed at the empirical level. Looking at the university system first (where more data are available), we can see that a high proportion of female professors, who can be seen as being at the top of a research career, have no children. Looked at from a crossnational perspective, remarkable differences can be clearly seen. This indicates that national and/or cultural factors are of special relevance in the reconciliation of research work and children.

Figure 4. Share of female professors without children

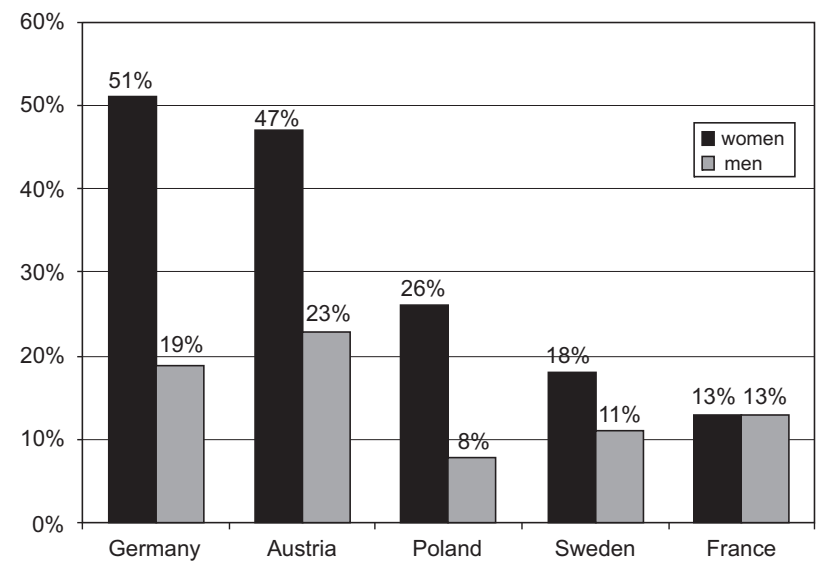

Source: Majcher (2007)

7 Potential absence may be anticipated by human resource managers, which creates potential disadvantages for all women (both those with and without children).

8 Recently, the discussion has focused more on social factors, asking how professional roles in science are socially constructed (Beaufays, 2003). 
These cultural factors are incorporated in the national institutional framework that defines an individual's career acting (Figure 3). The legal institutional framework in Austria concerning reconciliation matters may be described as "conservative". As there is a lack of childcare facilities and regulations concerning leave for longer periods, a large number of women work part-time. Lewis and Ostner (1994) classified Austria as a country with a "strong breadwinner model". In the meantime, the Austrian welfare state has introduced a few improvements to give more "free choice" to women, to enable them to stay at home or to re-enter the labour market earlier. In 2008, a new childcare allowance was established that enables parents to choose between three different leave options $(18,24$ or 36 months for both partners), with corresponding financial support from about EUR 440 to 800 with the less time off, the more money per month. By the second half of the 1990s, some small attempts had been made to encourage more fathers into care work and to contribute to a change in the traditional division of labour. This has not been very effective so far, as only $4 \%$ of all carers are fathers.

\subsection{Reconciliation in Austrian non-university research institutions}

As there were no data available on researchers with children in non-academic research institutions, these data have been collected in the human-resource departments of all Austrian non-university research institutions (Table 5). These provided institutional data on their male and female researchers' children.

Table 5. Researchers in Austrian non-university research institutions

\begin{tabular}{lccc}
\hline & All & Women & Men \\
\hline $\begin{array}{l}\text { Researchers in Austrian non-university research institutions } \\
\begin{array}{l}\text { Researchers in Austrian non-university research institutions } \\
\text { with children }\end{array}\end{array}$ & 2,905 & 582 & 2,323 \\
\hline
\end{tabular}

Source: BMVIT, 2007: 8

In a second survey, all male and female researchers in non-university research institutions in Austria (with children under 16 years of age) were asked about their personal arrangements for managing care work and research activities. The main research questions were: 
- Which working-(time)-patterns exist for female and male researchers with children?

- Which implications for scientific careers can be identified?

- Which barriers can be identified at the personal and structural level?

- In which way is unpaid and paid work organised within parenthood?

- Which implications for policies can be identified?

From the gender perspective, it was crucial to ask both female and male researchers ${ }^{9}$ for their reconciliation patterns and barriers in order to avoid gender stereotypes by assuming the widespread understanding of care obligations as a female issue.

The survey was carried out in spring 2007 by email. Of the 565 researchers with children, 238 returned the questionnaire. This quite high return rate of $42 \%$ may illustrate that the subject is a high priority one and of interest to researchers.

Analysing reconciliation in terms of gender specific career aspects means looking at paid work as well as unpaid work for both sexes.

\subsection{Employment structure in non-university research institutions}

The employment structure of fathers and mothers in research in non-university research institutions is highly segregated in terms of sex. Only $17 \%$ of female researchers with children under 16 work full-time (Table 6). Consequently, the dominant employment form for mothers in research is part-time. $83 \%$ of all mothers engaged in research work part-time, depending on the children's age (under 3: 91\%; 3-6: 83\%; 6-16: 72\%).

An interesting finding can be observed for men/fathers employed in research: fewer male researchers with children work part-time than male researchers in general. Just $12 \%$ of all male researchers with children work part-time, while $15 \%$ of all male researchers in non-academic research institutions work part-time. This result illustrates clearly that part-time is not a reconciliation pattern for men, but is used more for other reasons. It also shows that it is not impossible for male researchers to work part-time, as is often argued (see below).

${ }^{9}$ With this definition, we include only people who have children and are actively employed in research (not people on maternity leave or those who have not re-entered the labour-market). 
Table 6. Form of employment in non-university research institutions in Austria

\begin{tabular}{lcccc}
\hline & \multicolumn{2}{c}{ Parents with children under 16 } & \multicolumn{2}{c}{ All researchers } \\
$\mathrm{N}=238$ & & \multicolumn{2}{c}{ N 2888} \\
\cline { 2 - 5 } & Women & Men & Women & Men \\
\hline Full-time & $17 \%$ & $88 \%$ & $65 \%$ & $85 \%$ \\
Part-time & $83 \%$ & $12 \%$ & $35 \%$ & $15 \%$ \\
\hline
\end{tabular}

Source: BMVIT, 2007: 11

This gender-specific employment structure underlines the traditional division of paid labour that makes paid work the domain of men (the male breadwinner) and unpaid work the domain of women. The latter do paid work, mostly part-time, in addition to their household and care obligations.

For career prospects, the integration of the private sphere is of specific relevance when we want to improve women's career chances and look for equal career prospects for female and male researchers. Feminist theorists argue that this is an attempt to improve the classical career concept towards a more female-related life concept. As far as the gender-specific division of unpaid labour is concerned, mothers engaged in research work 58 hours unpaid per week, while fathers do only 35 hours. As fathers do more paid work and have less time for unpaid work, this may mainly be caused by the time required for paid work. To check this, only male and female researchers with part-time work were compared. This revealed a significant difference: mothers employed in research on a part-time basis work another 61.7 hours unpaid per week, while fathers with part-time jobs work only 37.6 hours unpaid. Mothers engaged in research do a lot more unpaid reproduction work than their male colleagues who also work part-time.

This traditional labour division in the Austrian research sector reflects traditional gender roles in Austria. To describe this division of paid and unpaid work in terms of partnerships, the term "gender arrangement" is used. Gender arrangements describe different forms of labour division, from the breadwinner model (one partner earns, one partner cares) to the egalitarian model (income and care are equally divided). Our data (Table 7) show that most mothers employed in research live in a household with a partner who is the main earner, her income is additional (from part-time work) and she cares for the child(ren). $62 \%$ of 
all mothers employed in research belong to this moderate breadwinner model. In contrast, $45 \%$ of all male researchers with children are moderate breadwinners. Another $31 \%$ of male researchers live in a traditional breadwinner model household, being the only one with an income, while the wife does care work at home or has only a little income.

Table 7. Gender arrangement of researchers with children under 16

\begin{tabular}{lrr}
\hline & Women & \multicolumn{1}{c}{ Men } \\
\hline Strong breadwinner model & ---- & $31 \%$ \\
Modified breadwinner model & earner: $2 \%$ & earner: $45 \%$ \\
& carer: $63 \%$ & carer: $3 \%$ \\
Egalitarian model & $23 \%$ & $19 \%$ \\
Solitaire model & $12 \%$ & $2 \%$ \\
\hline
\end{tabular}

Source: BMVIT, 2007: 13

Approximately every fifth researcher with children under 16 lives in a partner arrangement that offers equal responsibility for income and care: $23 \%$ of female researchers and $19 \%$ of male researchers practise an egalitarian arrangement, mostly with both working part-time for about 30 hours per week.

\subsection{Career implications and barriers}

As we have already seen, women do not have the same careers that man have, and female researchers with children under 16 work mainly part-time, while $88 \%$ of male researchers in the same situation work full-time. These facts may already indicate that the amount of time in paid work has a significant impact on career prospects. Therefore, female and male researchers were asked about the main career implication of childbirth on their careers (Table 8). Women describe employment interruption after childbirth and maternity leave as the main effect on their career. This is often linked with a remarkable reduction in working time and some years in part-time employment. Less promotion in their career is the consequence. One out of four women has changed job because of individual or structural reasons. Men do more work at home, which is the main consequence for them. Less than one man out of ten takes paternity leave, while $16 \%$ reduce their working hours, whether slightly or considerably. 
Table 8. Effects on career after childbirth (multiple responses)

\begin{tabular}{lcc}
\hline & Women & Men \\
\hline Parental leave interruption & $80 \%$ & $9 \%$ \\
Part-time, working hours reduction & $74 \%$ & $16 \%$ \\
More working at home & $50 \%$ & $57 \%$ \\
Less promotion & $50 \%$ & $11 \%$ \\
Job change & $25 \%$ & $5 \%$ \\
Other & $18 \%$ & $8 \%$ \\
None & $17 \%$ & $25 \%$ \\
\hline
\end{tabular}

${ }^{*}$ less income, de-qualified jobs, more stress

Consequences at the personal level are mostly gender-specific (Table 9). When asked ${ }^{10}$ about the main barriers when reconciling work and care, ${ }^{11}$ female researchers mainly see career disadvantages. Working part-time is seen as the main reason for professional de-qualification, which in turn leads to worse career prospects. When having older children, women at a personal level mainly face personal pressure, stress and a permanent lack of time. Lack of time is also the greatest barrier to fathers employed in research. They talk about time management becoming more difficult, little personal flexibility and a lack of part-time jobs available (for men).

Table 9. Reconciliation barriers (open question, answers ranked)

\begin{tabular}{rll}
\hline & Women & Men \\
\hline 1. & Part-time as de-qualification & No flexible working hours \\
2. & Less career prospects & Meetings outside regular working time \\
3. & More stress & Time management \\
4. & No flexible working hours & Little individual flexibility \\
5. & Lack of childcare & Constant work pressure \\
\hline
\end{tabular}

Source: BMVIT, 2007: 15

Individual reconciliation experiences are summed up positively. More than four out of ten researchers say that good personal organisation allows them to manage both tasks, while only two out of ten describe reconciliation as difficult (women: 19\%; men: 17\%). It therefore

\footnotetext{
10 This was an open question.

11 While children are younger than six years old.
} 
seems that individuals already have well developed coping strategies that enable them to practise their preferred reconciliation pattern.

At the motivational level (Table 10), two dimensions are interesting: $21 \%$ of all female researchers with children and $7 \%$ of male researchers with children like the job more than they did before becoming a parent.

Table 10. Motivation aspects after childbirth

\begin{tabular}{lcc}
\hline & Women & Men \\
\hline I like the job better than before. & $21 \%$ & $7 \%$ \\
Career is not as important any more. & $24 \%$ & $20 \%$ \\
\hline
\end{tabular}

Besides this "empowering" effect, the career motivation of every fifth researcher has decreased since childbirth. Interestingly, there is a strong similarity between mothers and fathers employed in research.

\section{Concluding remarks}

The focus of this chapter is on career aspects in S\&T in relation to gender. Better career prospects for female researchers have become of increasing political interest as we head towards Lisbon targets. For more qualified human resources and a competitive European Research Area more women are needed. But, as national data on Austria illustrate, the S\&T field is still a male dominated sector, as just one out of five researchers is female. Careers in leading positions are also "male", as just $14 \%$ of professors and $7 \%$ of management in non-university research institutions are women. The field holds little attraction for women and/ or has a strong exclusion mechanism.

For a better understanding of differences in career trajectories between male and female researchers, we have looked at the impact of having children on the careers of female and male researchers in non-university research institutions in Austria. The reconciliation of research work and childcare is an interesting and important aspect for careers. First, having children is seen as the main reason why female researchers do not succeed in the way that their male counterparts do. Second, at a theoretical level, feminist researchers argue for an improvement in the classic career concept. This is termed "gender blind", as it is based on a classical male career trajectory (linear oc- 
cupations, no interruptions, full-time employment). They argue for a better integration of the private sphere and aspects typical of female (research) careers (interruption/s, part-time employment, career loops).

Reconciliation, particularly the pattern that female and male researchers with children under 16 use for combining their research work with family/care duties is of great interest, as it concerns both public (work) and private (care) spheres.

Empirical results show a traditional employment structure and traditional gender roles. Men with children mainly work full-time, while just $17 \%$ of all female researchers with children under 16 work full-time. Taking into account the high level of qualifications of the target group, the return on investment seems to be small, as women are not able to fully apply their abilities and competencies in their careers. Female researchers work part-time and do most of the unpaid work, while their male colleagues work full-time and so have better career prospects. Female researchers therefore experience de-qualification and bleaker career prospects. As a result, gender arrangements are also quite traditional in the non-university research field.

These results may be surprising, as personnel in science in some way are supposed to be open-minded and orientated towards equality. In fact, a commitment to gender equality can often been heard in daily discourse. However, at present, there is a remarkable difference between practice and discourse. As Wetterer (2008) points out, "rhetorical" gender equality goes hand in hand with practical differentiation.

As far as political intervention is concerned, our data show that a start could be made at the individual level by empowering women and enhancing their individual careers. But as careers can be seen as links between individual researchers and institutions, this has to be addressed too. Political intervention can play an important role by changing role stereotypes and providing a model for more gender balance. Regulations like the $40 \%$ quota for women in leading positions in Norway are examples of effective political intervention.

At a theoretical level, trying to modify the definition of "career" and integrating specific female career aspects into careers might help women (and men) to develop more realistic images of careers that are better related to their personal life context. Careers of male and female researchers have become more heterogeneous, putting more focus on the quality of life and less on hierarchical steps. As a consequence, poli- 
cymakers and organisations will need to change research culture towards more pluralistic and heterogeneous career paths.

At the structural level, the low participation of women researchers in management and decision-making bodies and the high amount of unpaid reproduction work still done by female researchers (compared to male ones) indicate a traditional labour division as the basis underlying the unequal career prospects for female researchers. A change in research culture is needed that defines success not by output and/or researchers' presence in the office, but more by performance in relation to working hours.

At the institutional level, research institutions need to offer more qualified part-time work to reduce the risk of de-qualification, and more flexible working hours to reduce the pressure on women in science and technology. At this point, it has to be mentioned that from a gender-specific point of view, part-time work is difficult as it regenders the division of labour between women and men. As long as only women work part-time and men work full-time, a gender-specific work-division is kept alive. This indicates the need for new role models to change the traditional division of labour in the non-university research field. Research institutions have to show interest and flexibility in these matters to show that the reconciliation of research and childcare is not an individual but an organisational concern. This might motivate more women to enter and stay in the research field. Organisations could then obtain and keep both the best females and males.

At the political level, efforts have also been strengthened over recent years in non-university research institutions and industrial research. While the promotion of women in Austrian academia was launched as far back as the mid-1970s (Wroblewsky et al., 2007), funding programmes for equal opportunities in research and development (R\&D) have started only during the last five years. In 2003, when She figures showed that the proportion of female researchers in industrial research was 9\% in Austria and thus lower than in any other European country, the FEMtech initiative started. FEMtech is one of four pillars in the fFORTE ("Frauen in Forschung und Technologie" - Women in Research and Technology) umbrella-programme that provides intervention at different levels: funding, research, awareness, etc. Hopefully, it will soon, together with other measures, contribute to an improvement in the situation of female researchers. 


\section{References}

BARLEY, Stephen (1996). Careers, identities, and institutions: The legacy of the Chicago School of Sociology. In M. Arthur, D. Hall, \& B. Lawrence (Eds.), Handbook of career theory (pp. 41-65). Cambridge: Cambridge University Press.

BEAUFAYS, Sandra (2003). Wie werden Wissenschafter gemacht? Bielefeld: Transcript Verlag.

BECK, Ulrich (1986). Die Risikogesellschaft. Frankfurt a.M.: Suhrkamp.

BECKER-SCHMIDT, Regina (1987). Die doppelte Vergesellschaftung - die doppelte Unterdrückung: Besonderheiten der Frauenforschung in den Sozialwissenschaften. In L. Unterkircher \& I. Wagner (Eds.), Die andere Hälfte der Gesellschaft. Österreichischer Soziologentag 1985 (pp. 10-25). Wien: Verl. d. Österreich. Gewerkschaftsbundes.

BMVIT (Ed.) (2007). Gender Booklet außeruniversitäre Forschung 2006. Wien: BMVIT.

BORN, Claudia, \& KRÜGER, Helga (Eds.) (1993). Erwerbsverläufe von Ehepartnern und Modernisierung weiblicher Lebensläufe. Weinheim: Deutscher Studienverlag.

BORN, Claudia, \& KRÜGER, Helga (Eds.) (2001). Individualisierung und Verflechtung. Geschlecht und Generation im deutschen Lebenslaufregime. Weinheim: Juventa.

EC (2003). She figures 2003. Luxemburg: European Commission.

EC (2003b). Women in industrial research. A wake up call for European industry. Luxemburg: European Commission.

EC (2004). Gender and excellence in the making. Luxemburg: European Commission.

EC (2005). Women and science: Excellence and innovation - Gender equality in science. Luxemburg: European Commission.

EC (2006). She figures 2006. Luxemburg: European Commission.

FRASER, Nancy (1994). After the family wage. Gender equity and the welfare state. Political Theory. 22(4), 591-618.

GALLOS, Joan (1996). Exploring women's development. Implications for career theory, practice and research. In M. Arthur, D. Hall, \& B. Lawrence (Eds.), Handbook of career theory (pp.110-132). Cambridge: Cambridge University Press.

GIDDENS, Anthony (1984). The constitution of society. Berkeley: University of California Press.

GOFMANN, Erving (1961). Asylums. Essays on the social situation of mental patients and other inmates. New York: Anchor Books.

GOTTSCHALL, Karin, \& VOSS, Günter (Eds.) (2003). Entgrenzung von Arbeit und Leben. Zum Wandel der Beziehung von Erwerbstätigkeit und Privatsphäre im Alltag. München: Mering.

HOFF, Ernst (2006). Work-Life-Balance. Zum Wandel des Verhältnisses von Berufsund Privatleben bei Frauen und Männern. Fundiert. Wissenschaftsmagazin der Freien Universität Berlin. <http://www.elfenbeinturm.net/archiv/2006/09.html>

KOHLI, Martin, \& WOODWARD, A. (Eds.) (2001). Inclusions and exclusions in European societies. London: Routledge. 
KOHLI, Martin (1985). Die Institutionalisierung des Lebenslaufs: historische Befunde und theoretische Argumente. Kölner Zeitschrift für Soziologie und Sozialpsychologie (37), 1-29.

LEWIS, Jane, \& OSTNER, Ilona (1994). Gender and the evolution of European social policies. Working paper no. 4/94. Bremen: Centre for Social Policy Research, University of Bremen.

LEWIS, Jane (1992). Gender and the development of welfare regimes. Journal of European Social Policy. 2(3), 159-173.

LUTZ, Hedwig (2003). Auswirkungen der Kindergeldregelung auf die Beschäftigung von Frauen mit Kleinkindern. Wien: WIFO-Monatsberichte 3/2003.

MAJCHER, Agnieszka (2007). Seeking the guilty - Academics between career and family in Poland and Germany. In R. Siemienska \& A. Zimmer (Eds.), Gendered career trajectories in academia in cross-national perspective (pp. 298-321). Warsaw, Poland: Wydawnictwo Naukowe Scholar Sp. z o.o.

MARSHALL, Judi (1996). Re-visioning career concepts. A feminist invitation. In M. B. Arthur et al., Handbook of career theory (pp. 275-291). Cambridge: Cambridge University Press.

MERRIAM-WEBSTER (1974). Merriam-Webster dictionary. Springfield: MerriamWebster.

NOWOTNY, Helga (1985). Does it only need good men to do good science? In M. Gibbons \& B. Wittrock (Eds.), Science as Commodity (pp. 143-155). London: Cartermill International Longman.

RIESENFELDER, Andreas, SORGER, Claudia, WETZEL, Petra, \& WILLSBERGER, Barbara (2006). Evaluierung der Einführung des Kinderbetreuungsgeldesr. Wien: L\&R Sozialforschung. <http://www.lrsocialresearch.at/files/Endbericht_Eval_ KBG_L\&R_Sozialforschung.pdf>

SCHIEBINGER, Londa (2007). Gendered innovations in science. Keynote speech. Gender Issues in Research - Innovation through Gender Equality. Konferenz im Rahmen der Deutschen Ratspräsidentschaft 18-19 April, Berlin. <http://www. cews.org/konferenz-innovation/files/47/en/londa_en.pdf>

SENNETT, Richard (1998). The corrosion of character. New York: Norton.

STATISTICS AUSTRIA (2009).Beschäftige in ForschungundexperimentellerEntwicklung (F\&E) in Kopfzahlen und in Vollzeitäquivalenten 2006 nach Durchführungssektoren/ Erhebungsbereichen, Beschäftigtenkategorien und Geschlecht, available at: http:// www.statistik.at/web_de/statistiken/forschung_und_innovation/f_und_e_in_ allen_volkswirtschaftlichen_sektoren/index.html (26 January 2009).

WETTERER, Angelika (2008). Geschlechterwissen \& soziale Praxis. Theoretische Zugänge - empirische Erträge. Frankfurt a.M.: Helmer.

WROBLEWSKI, Angela, GINDL, Michaela, LEITNER, Andrea, PELLERT, Ada, \& WOITECH, Birgit (2007). Wirkungsanalyse frauenfördernder Maßnahmen im $b m . b w k$. Materialien zur Förderung von Frauen in der Wissenschaft 21. Wien: Verlag Österreich. 



\section{Katarina Prpić Adrijana Šuljok Nikola Petrović}

\section{Gender differences in the research productivity of natural and social scientists}

\section{Gender and productivity: puzzling findings or approaches?}

The importance of the scientific investigation of the publication productivity of women and men scientists arises from the vital role, both cognitive and social, that publishing plays in science. This process has an impact on the professional differentiation of scientists, but, at the same time, also depends on it (Fox, 2005). Thus, studying the quantity, quality and factors of men's and women's research productivity is relevant for a deeper understanding of gender differentiation in science.

The findings of numerous studies do not sustain the well-known conclusions of Cole and Zuckerman (1984) that women scientists publish only slightly more than half the publications of their male colleagues, and that these differences have not changed for decades. However, their conclusions mostly refer to certain segments of the American academic community in the third quarter of the previous century. Other, also partial, investigations in the US either have not shown such big differences in productivity between the genders, or the differences were not constant during the scientists' entire career (Reskin, 1978; Long, 1990; 1992; Long and Fox, 1995).

Furthermore, surveys of representative samples of American university professors found a significant decrease in gender differences in productivity over time (Astin, 1984). The women-to-men productivity ratio increased from $60 \%$ to $75 \%-80 \%$ in the period between the end of the 1960s and the beginning of the 1990s (Xie and Shauman, 1998). It seems that during roughly the same period the gender differences between unproductive, lowly productive and medium productive scientists decreased, but that the gap between the most productive scientists remained unchanged (Sax et al., 2002).

The significant gender differentiation in scientific productivity was also empirically found in other socio-cultural milieux and scien- 
tific communities, but was not as vast as Cole and Zuckerman report. In certain European countries, the average number of publications of women scientists reached at least two-thirds, and sometimes even more that three-quarters of the publication production of men scientists (Luukkonen-Gronow and Stolte-Heiskanen, 1983; Kyvik, 1990; Prpić, 1990; Thagaard, 1991; Haraszthy, 1991). In addition, some recent studies have not established any significant differences in the productivity of men and women in observed scientific fields, for example in the field of natural resources and chemistry (Bordons et al., 2003), or found that the differentiation disappeared within the same academic rank, as in materials science (Mauleón and Bordons, 2006). The lack of any significant influence of gender on both the career and five-year productivity of eminent Croatian scientists was of a similar nature (Prpić, 1996).

The gender gap in scientific productivity in developing countries also varies. The productivity of Venezuelan women researchers was two-thirds of the average productivity of men researchers (Lemoine, 1992a). In contrast, no significant gender differentiation was found in the publication productivity of Brazilian astronomers, immunologists and oceanographers (Leta and Lewison, 2003), and only minimal gender variations were established in the productivity of 14,328 of the most productive Mexican scientists (Gonzales-Brambila and Veloso, 2007). The average productivity of Indian female and male scientists in the physical sciences, biology and engineering sciences was not significantly different (Lemoine, 1992b; Gupta et al., 1999), but in the same country male psychologists considerably outperformed female psychologists in productivity (Goel, 2002). In addition, no noticeable gender differentiation was found either in the international visibility of the publications of researchers in Ghana, Kenya and the Indian State of Kerala (Shrum, 1997), or in other indicators of their productivity (Campion and Shrum, 2004).

The findings on gender differentiation in the quality of publications, measured by visibility or citations, are also ambiguous. On one hand, some findings show that men scientists are more cited than women scientists (Cole and Cole, [1973] 1981; J. Cole, 1987; Davenport and Snyder, 1995). Yet, if the number of publications is taken into account, significant differences in citations either disappear (Reskin, 1977; J. Cole and Zuckerman, 1984), or women's publications receive even more citations than those of male scientists (Long, 1992; Sonnert, 1995). Some studies used less reliable indicators of visibility or sci- 
entific quality - the impact factor of the journals in which men and women publish their papers. They did not find any significant gender differentiation in astronomy, immunology or oceanography (Leta and Lewison, 2003), natural resources and chemistry (Bordons et al., 2003) or in materials science (Mauleon and Bordons, 2006). Where men, on average, publish more scientific papers than women, their papers are not necessarily cited more frequently (Sánches Peňas and Willett, 2006), or published in more prominent international journals (Palomba and Menniti, 2001).

Consequently, gender differences in scientific productivity are not constant or stable, but rather tend to decrease over time when (para) longitudinally monitored. It also seems that socio-cultural and disciplinary influences are reflected in the depth and size of gender differentiation in the research productivity of different countries and scientific areas. Therefore, the real challenge still lies in examining the social and professional processes and mechanisms that produce gender differentiation in research productivity, and their wider or socio-cultural, and narrower or inter-scientific, particularities.

\section{Research design: a comprehensive comparison of the natural and social sciences}

The discrepancy and diversification of the overall empirical picture of gender differences found in different countries, in different samples, and in different scientific fields, are manifested and affirmed by the specificity of the Croatian social framework. Previous studies based on self-reported data concerning scientists' productivity show the following tendencies.

1. In the 1970s and at the beginning of the 1980s, lowly productive or medium productive authors were over-represented among Croatian female scientists, while authors who showed medium or high productivity were more numerous among male researchers (Previšić, 1975; Prpić 1983). With (higher) academic degree and (older) age, (male) gender was the only other significant predictor of career-long scientific productivity, meaning that gender independently contributed to the explanation of the variability in respondents' productivity (Prpić, 1983).

2. During the second half of the 80 s, significant gender differences were also visible in the five-year productivity of the research population, and the average number of scientific publications of women reached 
$71.7 \%$ of men's publications. The ratio was much more unfavourable in professional publications - women's productivity reached barely $53.2 \%$ of men's professional publications (Prpić, 1990: 119). ${ }^{1}$ However, while using a large predictor set of 26 socio-demographic, socialisational and structural variables, no significant impact of gender on researchers' scientific productivity was established, although gender did significantly contribute to the variance of respondents' professional production (Prpić, 1991). Furthermore, the contribution of gender to the explanation of scientific productivity was completely lost at the level of each of the six scientific fields when the same predictor variables were used. Gender was found to be a relevant factor only in professional publication productivity in the technical, biotechnical and social sciences (Prpić, 1991).

3. For the first time, there were no statistically significant differences found in the productivity of women and men researchers at the turn of the millennium. In the five-year period that preceded the survey, women produced $90.0 \%$ of the average number of scientific publications of their male colleagues. The applied regression analyses using a set of 25 socio-demographic, socialisational and structural predictors did not show any independent influence of gender on researchers' fiveyear scientific productivity, either at the level of the entire sample, or at the level of the subsamples of natural and social scientists. Therefore, gender once again does not significantly contribute to variability in Croatian researchers' publication productivity.

Although these findings are compatible with the results of studies which have assumed and corroborated the crucial importance of the structural factors of gender differentiation for scientific productivity (Xie and Shauman, 1989; 2003; Etzkowitz et al, 2000; Palomba and Menniti, 2001; Long, 2001; Prpić, 2002; Rothausen-Vange et al., 2005; Fox and Mohapatra, 2007), there are still methodological doubts concerning their reliability.

A well-founded critique of the majority of studies of gender differentiation in science, especially those on productivity, claims that generalisations and firm conclusions cannot be based on the selec-

${ }^{1}$ Professional publications do not include original scientific papers, but rather the by-products of scientific research such as book reviews, bibliographies, descriptive reviews of scientific results for non-scientific specialists, publications popularising science, etc. A smaller share of these publications in their research production could be a signal of women's higher selectivity and of their focus on original scientific publications that are the most important in a scientific career. 
tive, unrepresentative samples which have been prevalently used (Xie and Shauman, 2003). This is also the main methodological problem of Croatian studies on scientific productivity which have not been based on representative samples of the research population. Selectivity can be completely avoided if the whole research population in certain scientific fields is used, which is much easier to do in a small scientific community.

Therefore, we decided to conduct comprehensive bibliometric research of the ten-year Web of Science (WoS) indexed production of all natural and social scientists holding a doctoral degree. There are three reasons for this decision. Firstly, so far in Croatia there has been no comprehensive bibliometric research of the WoS production of any scientific area, so all the former bibliometric insights into research production have necessarily been partial. Secondly, a simultaneous study of all scientific fields would demand too much funding and time, so at the starting point we chose to analyse two scientific areas as paradigmatic examples of the hard and soft sciences. The natural sciences and social sciences are areas that considerably, even sharply, differ in their intellectual and social organisation (Whitley, 1984; Fuchs, 1992; Becher and Trowler, 2003), yet not in the share of women in their research personnel in Croatia. Thirdly, a ten year period is long enough to neutralise the effect of short-term irregularities and variations in the number of publications, especially so in the social sciences where publishing in journals indexed in WoS databases is a far less practised publication pattern and strategy.

The goal of the study was to establish the quantity, visibility and the most basic socio-demographic and contextual factors of gender differences in the publication productivity of natural and social scientists indexed in the WoS bibliographic and citation databases. Research conceived in such a way may show whether the gender patterns observed in average scientific productivity in the (sub)samples of the research population will also appear in the most selective and internationally most visible production of natural and social scientists. Although this is the most elite scientific production, it is to be expected that gender differences, if found, will decrease or even disappear under the influence of other, gender-related characteristics of the researchers and their scientific contexts.

It is clear that this study omits a large part of production in the social sciences - primarily books and articles in national periodicals, but 
also papers in foreign and/or international books and less visible journals. In other words, while the research production indexed in WoS databases makes up the major, or the most important, part of publication productivity in the natural sciences, a considerable (perhaps the largest) portion of important social research productivity remains outside the scope of these most selective international bases (Nederhof et al., 1989; Hicks, 1999; Nederhof, 2006). However, an insight into gender differentiation in scientific production has special relevance in the social sciences considering their minimal presence in these bases in the (pre) transitional period (Klaić, 1998). The general internationalisation of the social sciences, especially in post-socialist countries (Hicks, 1999), will inevitably have an impact on Croatian scientific production as well. It is also expected that Croatian science policy will increasingly stimulate and reward this type of research productivity, just as EU Member States and other countries do (Butler, 2003; Debackere and Glänzel, 2004; Weingart, 2005). This could even increase gender differentiation in the social sciences.

All natural and social scientists holding a doctoral degree and employed in registered scientific institutions in Croatia were included in this study. ${ }^{2}$ The data were provided by the Ministry of Science, Education and Sports of the Republic of Croatia, reflecting the state of affairs in June 2004, and referred to 1,938 researchers. They were grouped in 9 social science fields - psychology, pedagogy, law, economics, political science, sociology, defectology, kinesiology, and information science - and 6 fields of the natural sciences - mathematics, chemistry, physics, biology, geography and geology. The research of scientific productivity and its visibility or received citations was preformed by searching the ISI (Institute for Scientific Information) / Thomson Web of Science (WoS) bibliographic and citation bases - Science Citation Index Expanded and Social Science Citation Index (SCI \& SSCI) - for the period from 1996 to $2005 .^{3}$

Since the research population was known and registered, the most reliable procedure was to search by the surname and by the forename

${ }^{2}$ Doctoral degree holders that are not employed in registered scientific institutions but who work in non-scientific organisations were not on the list of scientists and researchers included in the study.

${ }^{3}$ Research was done by Maja Jokić, senior research fellow of the National and University Library, an associate on the project Social Actors of Scientific and Technological Development which is carried out at the Institute for Social Research in Zagreb and led by Katarina Prpić. 
or initial of each researcher listed. Equal authorship was assigned to each of the authors in multi-authored publications, irrespective of their place in the list of authors. Therefore, the same paper was assigned to each of the co-authors. Since the software used did not offer a reliable option of isolating types of publications, abstracts of conference papers and letters were included in addition to articles. However, when categorising articles, the WoS is ambiguous, since professional papers were often classified as articles or scientific papers. The data on the number of citations refer only to the publications that the authors published in the period 1996-2005. The citation counts were taken from the WoS, based on their options to automatically assign citations and citation counts to a publication. Due to time pressure, self-citations were not excluded from the independent citations because the option offered for excluding self-citations, when tested, did not produce reliable results. The database search was done in one week (July 2007) since the WoS is renewed once a week and the data in the bases are the same only within that time frame.

The SPSS was used for data processing (version 15.0). In accordance with the goals and the main hypothesis of the study, t-tests, chisquare tests, analyses of variance with post hoc tests, as well as multiple linear regression analyses, were applied.

\section{Findings: gender differentials in productivity at different analytical levels}

\subsection{The socio-professional features of the two scientific populations}

Before presenting the research results on the gender differences in WoS productivity, we will briefly comment on the observed sociodemographic, organisational and disciplinary composition of the Croatian natural and social scientific populations. Unfortunately, the only data available for both areas were gender, age structure, and the organisational and disciplinary context, namely the type of scientific institution and scientific field (see Table A in the appendix).

Although men in both scientific fields make up the majority of the researchers, the gender composition is different. In the natural sciences, the proportion of women is significantly larger than in the social sciences (Table A in the appendix) where the feminisation of the re- 
search personnel has been slower, in spite of the high portion of women among university graduates in this area. ${ }^{4}$ The highly differentiated institutional structure of these two scientific areas has clearly contributed to the gender differences there. Members of faculty, who are relatively more numerous in the social than in the natural sciences, are clearly less inclined to recruit (young) women than are researchers engaged in institutes, who are much more highly represented in the natural than in the social fields (same table).

The gender composition of individual scientific fields within a natural or social scientific area is also significantly different, as the data in the aforementioned table show. Only chemistry and biology in the natural sciences have a high portion of female scientists, while in physics, the geosciences and to a lesser extent mathematics men traditionally predominate. However, in the social sciences only psychology stands out in its prevalent proportion of women, while pedagogical and information sciences tend towards a gender equilibrium. In contrast, sociology, economics and especially law and political science have a considerably lower percentage of women in their research personnel. A comparison of the graduates of the respective faculties shows that the base for recruiting women scientists is much bigger than their actual share in the individual scientific fields, ${ }^{5}$ indicating the crucial influence of various mechanisms of social selection on the gender structure of scientists. Unfortunately, space in this paper does not allow us to discuss these mechanisms and long-term trends of Croatian women entering science, which is done elsewhere (Prpić, 2002a; 2002b).

The age structure of researchers in both areas, primarily in the social sciences, confirms the view that deeper changes in the gender structure are of a more recent date, since women are relatively more numerous in younger age groups than in older ones (Table A in the ap-

\footnotetext{
${ }^{4}$ For example, in 2005 women made up $68 \%$ of the natural sciences faculty graduates and $69 \%$ of the social sciences faculty graduates. Source: Gender Equality Ombudsperson of the Republic of Croatia: Annual Report for 2006, Zagreb PDF, p. 134. Retrieved on 8 May 2008 from <http://www.prs.hr/docs/RH_PRS_izvjesce_o_radu_za_2006_godinu.pdf $>$

5 The percentage of women is high for graduates of life sciences $(81.8 \%)$, mathematics and statistics (73.6\%), and above half for the physical sciences (55.6\%). The share of women is also high among graduate students of some social sciences - educational sciences (72.7\%), social and behavioural sciences $(76.0 \%)$, business and administration (68.2\%), law (69.2\%). Source: Women and men in Croatia 2007, Zagreb: Central Bureau of Statistics, PDF, p. 31. Retrieved on 8 May 2008 from $<$ http://www.dzs.hr $>$
} 
pendix). This is also reflected in the fact that they have a younger average age than men, and significant differences were found through an analysis of variance. ${ }^{6}$ Furthermore, post hoc tests show that: female social scientists are significantly younger than their male colleagues both in the same area and in the natural sciences as well; that female natural scientists are also younger than men in both areas; that male social scientists are significantly older than male natural scientists; and that only between the women of both areas is there no significant age difference. ${ }^{7}$ The different age structure of the male and female research population is often neglected when comparing their productivity, although it can have a decisive role, especially due to its association with the structure of the academic ranks of both sexes.

Consequently, the social and professional composition of male and female scientists differs, especially with respect to age and discipline. Just how important this interrelation is for gender differentiation in productivity will be shown later.

\subsection{The first analytical level: visible gender patterns of scientific productivity}

The first level of analysis of gender patterns in research production and its visibility in the natural and social sciences is limited to establishing the significance of gender differentiation among the scientific areas, and in the fields within the same area. Not until the next, deeper analytical level will we examine whether the differences found continue to exist after the available socio-demographic and socio-cognitive productivity predictors are introduced.

Therefore, we present the results of the t-tests that compare the research production of men and women in the natural and social sciences indexed in (WoS) bibliographic and citation bases (SCI Expanded and SSCI) - the average number (mean) of their publications, and citations to their papers in the period from 1996 to 2005. The number of citations per publication for both sexes in both fields is also included (Table 1).

\footnotetext{
${ }^{6}$ In the analysis, the following four groups were used: a) female natural scientists; b) male natural scientists; c) female social scientists; d) male social scientists.

7 With the exception of that last insignificant difference, all other differences were significant at the level $\mathrm{p}<0.001$.
} 
Table 1. Researcher's publications and citations (means and standard deviations) in the natural and social sciences from 1996 to 2005 (with t-tests results)

\begin{tabular}{|c|c|c|c|c|c|c|c|}
\hline \multirow{2}{*}{$\begin{array}{l}\text { Publications and } \\
\text { citations (WoS) }\end{array}$} & \multirow{2}{*}{ Scientific area } & \multicolumn{2}{|c|}{ Men } & \multicolumn{2}{|c|}{ Women } & \multirow{2}{*}{$\mathrm{t}$} & \multirow{2}{*}{$\mathrm{p}$} \\
\hline & & M & SD & M & SD & & \\
\hline \multirow[t]{2}{*}{ Publications } & Natural sciences & 11.3 & 13.9 & 9.6 & 9.9 & 2.334 & 0.020 \\
\hline & Social sciences & 0.9 & 3.0 & 1.2 & 2.5 & 1.232 & 0.218 \\
\hline \multirow[t]{2}{*}{ Citations } & Natural sciences & 77.6 & 164.5 & 52.6 & 70.4 & 3.402 & 0.001 \\
\hline & Social sciences & 1.8 & 8.9 & 3.2 & 17.3 & 1.476 & 0.140 \\
\hline \multirow{2}{*}{$\begin{array}{l}\text { Citations per } \\
\text { publication }\end{array}$} & Natural sciences & \multicolumn{2}{|c|}{6.9} & \multicolumn{2}{|c|}{5.5} & & \\
\hline & Social sciences & \multicolumn{2}{|c|}{1.9} & \multicolumn{2}{|c|}{2.7} & & \\
\hline
\end{tabular}

The differences in the quantity and visibility of natural and social scientists' WOS publications are, as expected, high and necessarily significant. In the Croatian academic community, they can be even greater than in countries where social scientists are less locally/nationally oriented in their publication practices. While the majority of natural scientists (88.4\%) publish in journals indexed in WoS, only slightly more than one quarter of social scientists (27\%) do so. A previous study found that Croatian natural scientists were not much behind the world average, and that in some scientific fields they even show above average results. At the same time, a Croatian social scientist's publication on average receives 2.3 citations, which is quite below the known world average for the social sciences of 3.4 citations per publication (Jokić and Šuljok, 2009: 155).

However, our primary interest lies in gender differentiation in productivity. The results of the t-test show significant gender differences in the average number of publications and citations in the natural sciences, while in the social sciences there is no statistically significant differentiation between women and men in the quantity and visibility of their production. Still, men's greater production in the natural sciences and women's in the social sciences should be viewed bearing in mind that women in both areas are, on average, younger than men. ${ }^{8}$

8 In the natural sciences, women produced $85 \%$ of the average number of publications of men, and in the social sciences men produced $75 \%$ of women's publications. At the same time, the percentages calculated on the bases of such small means, although often used, are in fact not the best indicators of the relative relations in average productivity. 
The difference in the number of publications, although significant, is not great in the natural sciences, but the citations per scientist are considerably smaller for women, who receive two-thirds $(67.8 \%)$ of the citations received by men. In the social sciences, women receive, on average, more citations than men, yet the difference is not significant, possibly due to a larger dispersion. However, when considering citations per publication, female natural scientists have on average 1.4 fewer citations per paper, and female social scientists have 0.8 citations per paper more than their male counterparts. In brief, women's considerable lagging behind men in the average number of citations in the natural sciences substantially decreases when their citations per publication are compared.

The higher achievement of Croatian female social scientists cannot be reliably explained without further research. Still, a tentative explanation can be found in assuming that their research is more highly specialised than men's, since, generally speaking, the weaker specialisation of women scientists seems to be the missing link in explaining productivity differentiation (Leahey, 2006). The aforementioned thesis on the specialisation of women in the social sciences is supported by partial data. In analysing doctoral dissertations in the field of sociology, it has been established that women considerably and significantly more often than men wrote doctoral theses in subfields of sociology and based them on empirical research. ${ }^{9}$ If other female social scientists were more oriented towards specialised empirical papers and less towards theoretical and "essayistic" papers, then this could have made it easier for them to publish in international periodicals and increase the chances of being cited.

For a more complete analysis of gender and productivity, it is important to establish the gender differences in the groups of unproductive or silent researchers and among the most productive ones in both areas. We found that $9.9 \%$ of women and $13.0 \%$ of men belong to the group of silent natural scientists who did not publish a single paper in the journals indexed in WoS in a ten year period. The difference is not statistically significant. In the social sciences, $67.0 \%$ of women compared to $76.6 \%$ of men belong to the category of unproductive scientists.

9 The analyses included the period from the mid 1960s to the end of the 1980s, and it also showed that female sociologists cited Marxist literature significantly less often in their dissertations than male sociologists (Lažnjak, 1990). 
The difference here is significant (chi-square $=8.979 ; \mathrm{df}=1 ; \mathrm{p}<0.01$ ). Therefore, the higher proportion of women among silent researchers found in the Croatian scientific population at the beginning of the 1970s and in the 1980s does not characterise the natural and social scientists' productivity today. These findings partially indicate decreased gender differences in research productivity during the past thirty years, which has also been found in other studies. Moreover, it should be kept in mind that these elite, internationally visible publications were, during the previous periods, less numerous even in the natural sciences, and extremely rare in the social sciences.

While comparing the gender differentials for the most productive (and lowly productive) scientists, we were (in principle) led by Lotka's law, or rather its modification, which postulates that $10 \%$ to $15 \%$ of scientists produce approximately half of scientific literature in any scientific (sub)field (Cole, 1987). Therefore the group of highly productive scientists included those who authored the greatest number of papers published in WoS journals and whose production in total encompasses approximately half of all WoS publications in the scientific area. All the other researchers were treated as lowly productive, including those without papers published in WoS periodicals.

Table 2 shows the basic indicators of productivity, for both groups in both fields, as well as for both sexes: the average number of publications and the average number of citations with t-test results. The data are supplemented with the number of citations per publication as an important indicator of the dimension and the depth of the gender gap in the visibility of scientists' research production.

This leads to the conclusion that productivity in the natural sciences really does act according to Lotka's law, since $16.1 \%$ of scientists produce $48.2 \%$ of all the publications in this area. Social science production does not strictly follow this law, because just $4.5 \%$ of researchers have $48.6 \%$ of all their papers published in periodicals indexed in WoS. Such extremely elite scientific production is not surprising, since most of the social scientists do not even have WoS publications. It is clear that women scientists contribute relatively more than men scientists to that production. Yet, it cannot be expected that their relative contribution will remain as high after a larger portion of Croatian social scientists, under the pressure of scientific policy, start to publish in WoS journals. 
Table 2. Comparison between lowly productive and highly productive men and women in the natural and social sciences - key indicators

\begin{tabular}{lrrrr}
\hline & \multicolumn{2}{c}{$\begin{array}{c}\text { Lowly productive } \\
\text { scientists }\end{array}$} & \multicolumn{2}{c}{$\begin{array}{c}\text { Highly productive } \\
\text { scientists }\end{array}$} \\
\cline { 2 - 5 } & Men & Women & Men & Women \\
\hline NATURAL SCIENTISTS $^{10}$ & & & & \\
\% within (fe)male gender & 81.9 & 86.3 & 18.1 & 13.7 \\
Publications per scientist & 6.5 & 6.5 & 33.1 & 29.2 \\
Citations per scientist & 34.0 & 32.9 & 275.0 & 176.5 \\
Citations per publication & 5.2 & 5.0 & 8.3 & 6.0 \\
\hline SOCIAL SCIENTISTS & & & & \\
\% within (fe)male gender & 95.8 & 95.1 & 4.2 & 4.9 \\
Publications per scientist & 0.4 & 0.7 & 12.1 & 9.9 \\
Citations per scientist & 0.7 & 1.0 & 26.8 & 45.3 \\
Citations per publication & 1.6 & 1.4 & 2.2 & 4.6 \\
\hline
\end{tabular}

Within the natural sciences, among the lowly productive, there are no gender differences, which appear only when it comes to citations to the publications of the highly productive natural scientists. These results are similar to the findings of other studies indicating the same pattern of differing visibility of the production of men and women. However, when the number of publications is considered, gender variations are considerably reduced, which is shown by the number of citations per publication received by female and male natural scientists.

Before introducing new socio-demographic and socio-professional variables into the productivity analysis, it is important to gain an insight into gender differentiation in research productivity in individual natural and social sciences (Figures 1 and 2).

10 The t-test results showed that the gender differences found in the quantity of WoS publications in the natural sciences are significant neither for lowly productive nor highly productive researchers. Regarding the average number of citations, the only significant difference is the great one in favour of men among highly productive scientists $(t=3.201 ; \mathrm{p}<$ $0.01)$.

${ }^{11}$ In the social sciences, the only significant difference was in the average number of publications by lowly productive scientists, which favoured women $(t=2.984 ; \mathrm{p}<0.01)$. A considerably greater citation average received by highly productive women is not statistically significant, presumably due to its large dispersion. 
Figure 1. The average number of publications by natural scientists according to their gender and scientific field ${ }^{12}$

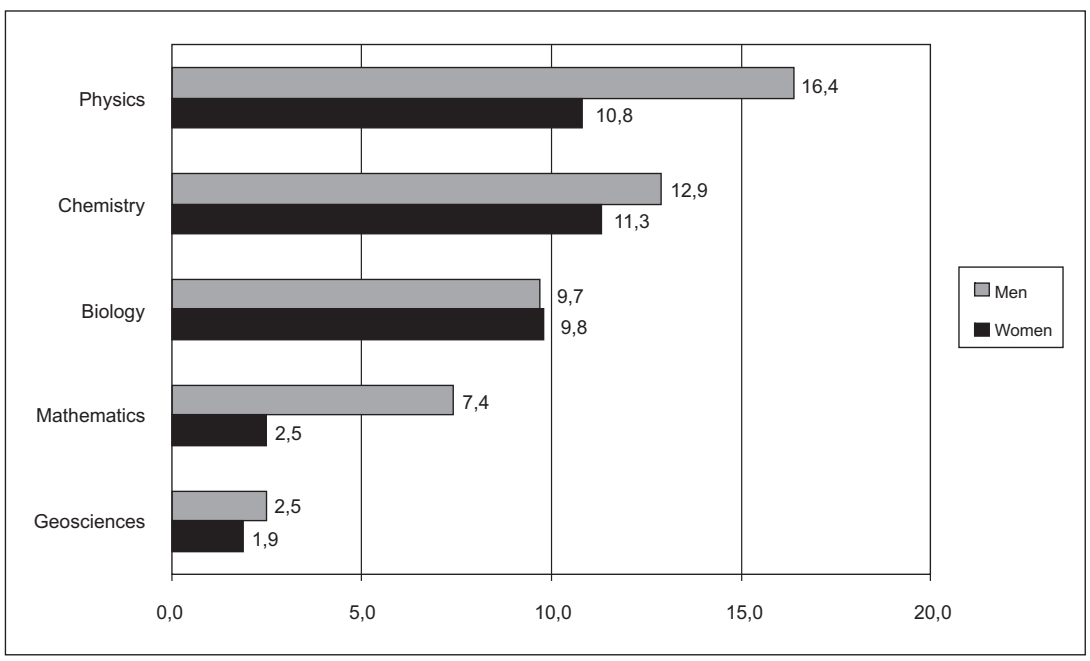

Figure 2. The average number of citations received by natural scientists according to their gender and scientific field

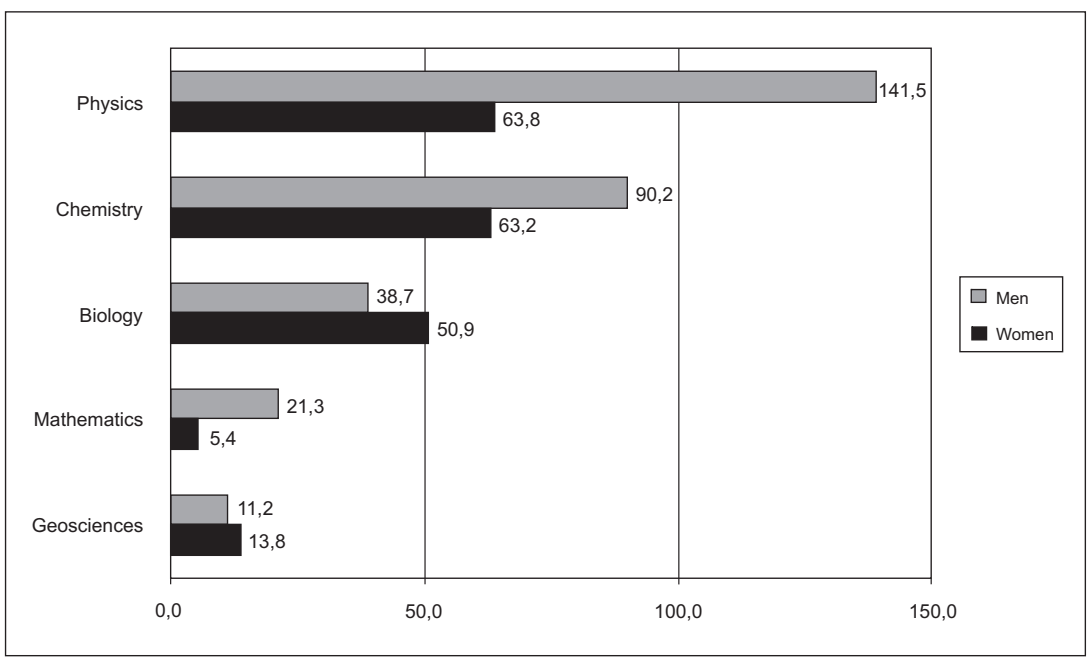

12 For methodological reasons, or for the sake of the correct application of statistical methods, geography, with a sparse research personnel, and geology, with a substantially more numerous research potential, have been fused together into a single field of geosciences. 
Figure 1 clearly shows that gender differentiation in the number of publications is the greatest in physics and mathematics, while in other fields it is much smaller, although in biology the gender differentiation is slightly in favour of women. The results of the t-tests confirm the first impression, because the differences are significant only among men and women physicists $(\mathrm{t}=3.223 ; \mathrm{p}<0.01)$ and male and female mathematicians $(\mathrm{t}=2.495 ; \mathrm{p}<0.05)$.

Similar to this is the variation in the average number of citations received by men and women (Figure 2). Gender differences in the number of citations per scientist are significant and are also the biggest in physics $(\mathrm{t}=3.696 ; \mathrm{p}<0.001)$, chemistry $(\mathrm{t}=2.254 ; \mathrm{p}<0.05)$ and mathematics $(t=2.951 ; p<0.01)$. However, smaller differences in citations in favour of women in biology and geosciences are not statistically significant.

If the study of research productivity ended at this level of analysis, the inevitable conclusion would be that the traditional gender patterns in researchers' scientific interests and accomplishments appear once again. Namely, Croatian natural scientists are most successful (visible) in the very scientific fields with the greatest gender differences in the international visibility of publications (physics, mathematics, chemistry), while in biology, where women are more cited, they lag behind the world average (Jokić and Šuljok, 2009). Yet the picture of gender differences within the scientific fields drastically changes if the number of citations per publication is taken into consideration (Figure 3).

In physics, women gain $45.1 \%$ of the average number of men's citations, but their papers reach $68.6 \%$ of the citation average of men's publications. Female chemists receive $70 \%$ of the citations of male chemists, but their publications receive $80 \%$ of the number of men's citations per paper. A comparison of citations per scientist and per publication shows the highest jump for female mathematicians who come very close to the men's citation average and are not far from the world average of 2.6 citations per publication (Jokić and Šuljok, 2009: 166). While the same gender pattern continues in biology in both types of citations, in geosciences the difference in favour of women in the international visibility of their publications increases strongly. With their average of 7.2 citations per paper, female scientists approach the world average for geosciences of 7.5 citations per paper (Jokić and Šuljok, 2009: 167), while men are considerably below that average. Therefore, in the 
natural sciences, the amount and the international visibility of the production of female researchers vary substantially in particular fields. Further research is required here in terms of gender differentiation and international comparisons.

Figure 3. Number of citations per publication according to the gender and field of natural scientists

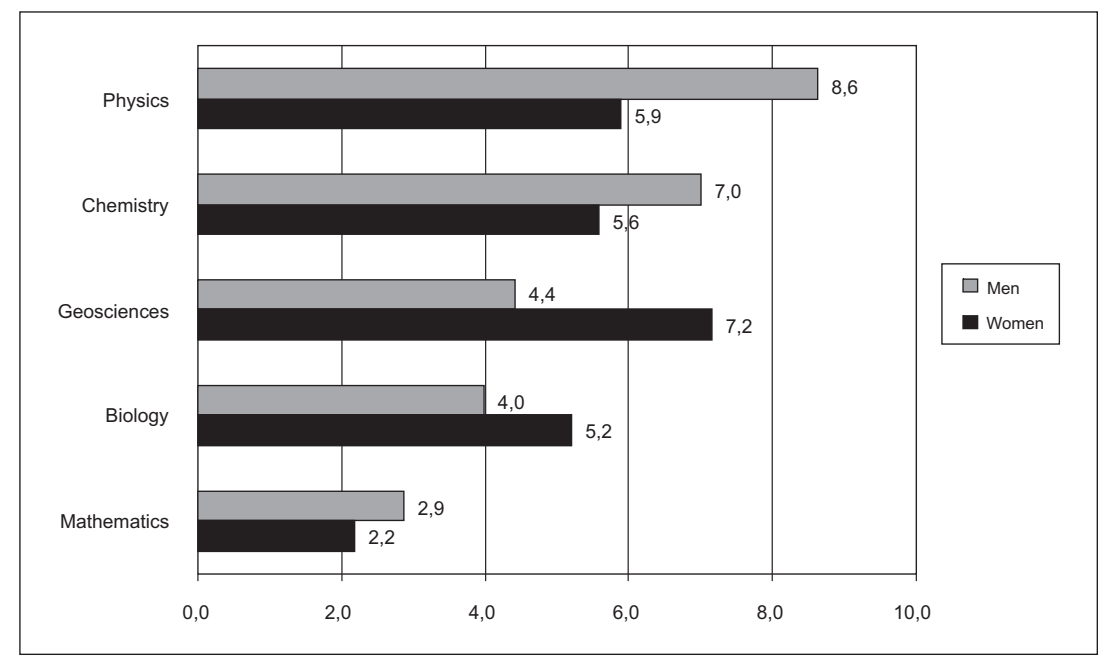

In addition to investigating the structural factors of the differentials in the productivity of male and female researchers in various scientific areas, certain studies have focused on analysing the organisational climate and scientific culture in the natural sciences as possible sources of gender differences in that scientific area. When interviewed, female physicists emphasised that even a slight increase in the number of women in their field improved the social atmosphere at work which became less aggressive and competitive (Viefers et al., 2006). In another interview study, Swedish female physicists and chemists gave similar critiques of the culture of science due to its emphasis on competitiveness and its values and measuring systems (Benckert and Staberg, 2001). An empirical study of a working climate that can stimulate or reduce the effectiveness and performance of women scientists at university departments found the difference between the natural and social sciences to be significant. While female natural scientists more frequently reported sexual harassment 
and a sexist working climate in their departments, women social scientists perceived the climate to be more positive and stimulating (Settles et al., 2006). However, these are only partial studies and their findings should not be generalised. More attention should be given to the value and organisational factors of gender differentiation, especially on account of the differences in the social organisation of the natural and social sciences.

The next two figures show the relations between the quantity and the visibility of the production of male and female social scientists in individual scientific fields. The first (Figure 4) presents a comparison of the average number of WoS publications, revealing a gender pattern very similar to that in the natural sciences, but at a much lower level of productivity.

Figure 4 . The average number of publications by social scientists according to their gender and scientific field ${ }^{13}$

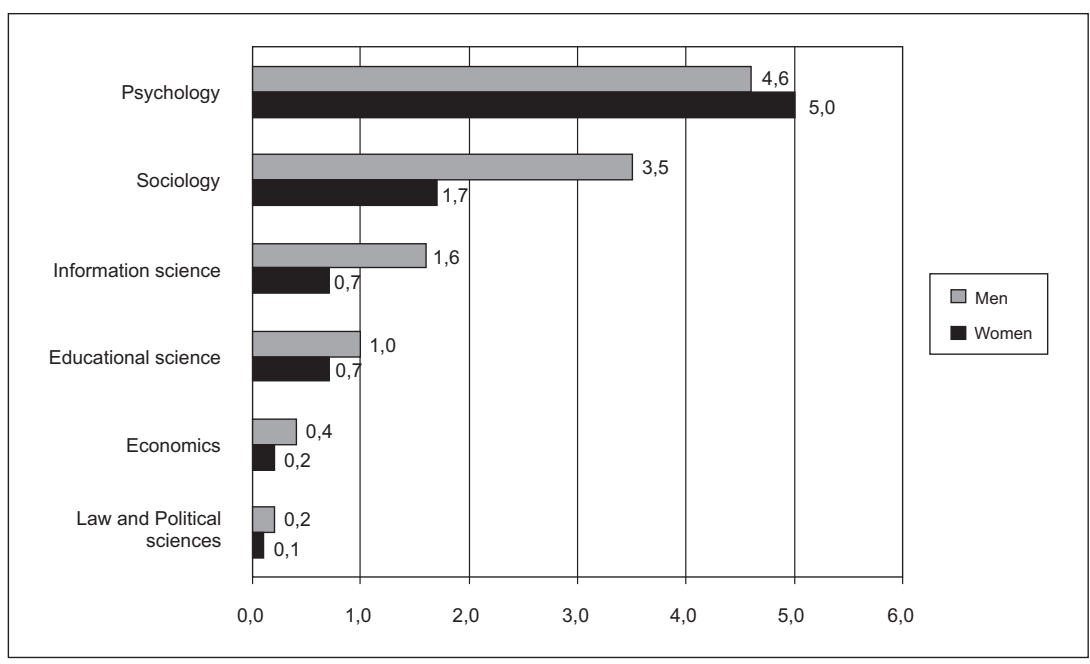

This gender pattern shows that women lag behind men in the average number of publications, with the exception of psychologists at the

${ }^{13}$ For methodological reasons, it was necessary to fuse scientific fields with a small number of scientists with those that have a more numerous potential in the social sciences. The relatedness of the fields, as well as the similarity of their publication patterns and gender structure, was kept in mind. Therefore, pedagogy, kinaesiology and defectology were combined into educational sciences, and political science was grouped with law. 
top of the productivity ladder, and lawyers and political scientists at the bottom. Yet, all the differences, whether in favour of men or women, are not statistically significant, except between male and female sociologists $(\mathrm{t}=2.083, \mathrm{p}<0.05)$. Production in this field is largely published in the Croatian language in a journal that is indexed in WoS. Therefore, the fact that male sociologists have twice the number of publications and slightly more citations than female sociologists indicates that women might publish more often in foreign publications and in a foreign language (Figure 5).

Figure 5. The average number of citations received by social scientists according to their gender and scientific field

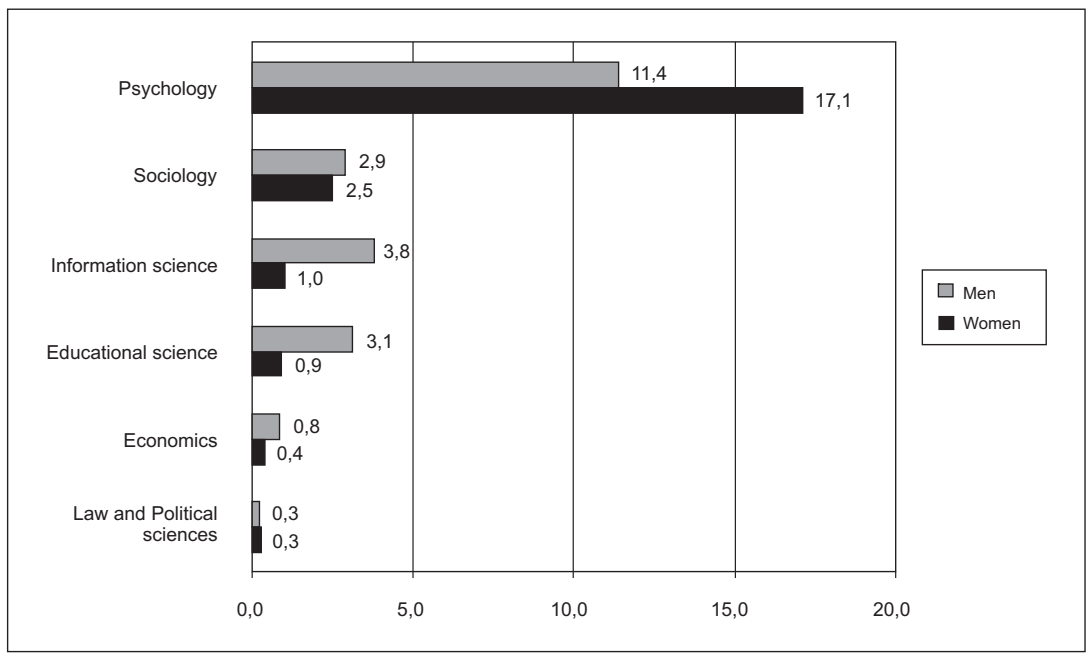

Women do not considerably lag behind men in the average number of citations - the differences in all the fields are not significant and in most cases are small (Figure 5). The exception is in psychology where men have two-thirds (66.7\%) of women's citations, while female information scientists achieve only $26.3 \%$ of the citations of their male counterparts (the large dispersions in these fields must have led to the ttest results being insignificant). However, this picture will change once the number of citations that women and men receive per publication is compared (Figure 6). 
Figure 6. Number of citations per publication according to the gender and field of social scientists

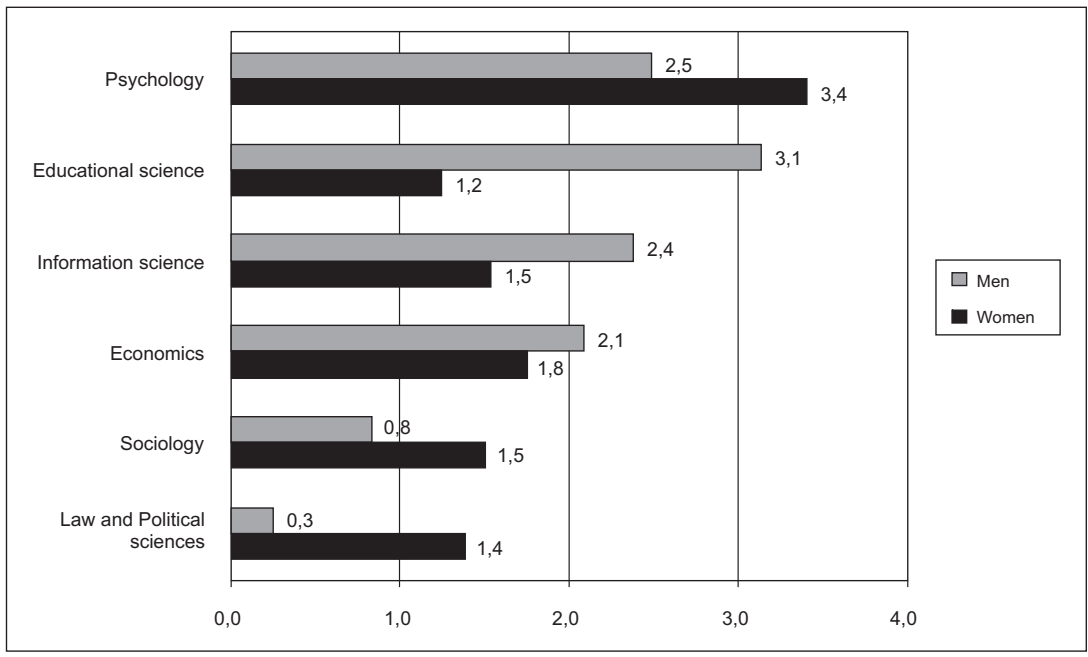

The gender differences diminish in psychology and information science. The male psychologists receive $26.5 \%$ fewer citations per paper than women. Female information scientists achieve $62 \%$ of men's citations per publication. In sociology, men receive $46.7 \%$ of women's citations per paper, which further corroborates the assumption of the different patterns in their publication productivity regarding the broader international nature of the women's production compared with the local orientation of the men's. Figure 6 reveals a very different picture of gender differentiation in publication visibility in other social fields, too. While in economics women gain only $14.3 \%$ fewer citations per paper than men, in educational sciences they receive $61.3 \%$ fewer citations. However, in law and political science, men have only $21.7 \%$ of women's citations per paper.

It is by no means possible to generalise on these results, not only because of the lack of comparable data for other scientific communities and countries, but also because of the insufficient internationalisation of the Croatian social scientists' production. In the social sciences, the publication patterns and international visibility of papers could profoundly change with the inevitable intensification of the social scientist's orientation towards the international community.

Still, we can conclude from the analysis thus far that gender differentiation in both the natural and social sciences radically changes, even 
at the descriptive level, once we introduce the indicator of productivity which relativises the different quantity of men's and women's publications.

\subsection{The second level: trying to explain gender patterns in productivity}

A deeper level of analysis of gender differentiation in research productivity certainly means searching for its explanations. Unfortunately, only four characteristics of the whole population of natural and social scientists registered by the Croatian Ministry of Science Education and Sport were available to us: gender, age, scientific field and type of scientific institution or organisation. ${ }^{14}$

Therefore, these four characteristics of scientists and their organisational-disciplinary contexts were the only ones that could have been considered as possible factors of the quantity and visibility of research production. Since many other relevant socialisational, structural, and organisational characteristics of scientists were not available, our predictors could not be expected to explain to a great extent research productivity in the natural and social sciences. Knowing that a deeper analysis of gender differentiation requires a more complex structure of predictors, we were primarily interested in establishing the contribution of the scientist's gender to predicting production quantity and visibility. This primarily predictive research goal was the main methodological argument in favour of using a stepwise regression analysis rather than a hierarchical regression procedure which should be used in theory testing.

Tables 3 and 4 present the results of three multiple linear regressions for each scientific area. The gender, age, type of institution and the scientific field of scientists were treated as predictors, while the dependent or criteria variables were successively the quantity of publications indexed in WoS and the citations that the publications received in the observed ten-year period. In the third regression, the predictor set additionally included the scientists' publications in order to examine to what extent the respondents' gender contributes to the citations they received independently of the size of their WoS production.

${ }^{14}$ The last category is grouped into three types: institutions of higher education, public scientific institutes, and other institutions which include a wide spectrum of organisational entities - from the Academy of Sciences and Arts, the Meteorological and Hydrological Service, health facilities (clinics), to research institutes and units in the business sector. 
In the natural sciences, irrespective of the organisational context and the contributions of individual scientific disciplines, gender appears as a significant, but not powerful, predictor of the quantity of publications and of the citations received. If we could have considered other important productivity factors, the impact of gender on the quantity of publications in the natural sciences would have most probably been lost, as happened in the surveys of 1990 and 2004 when it was indeed not found (Prpić, 1990, 1991). The disciplinary contributions, especially by physics, to the quantity and visibility of research production in the natural sciences are greater than those of other significant predictors gender and type of scientific institution. Regarding the latter predictor, scientists at public institutes, who prevail in the research personnel of non-academic institutions, are producers of a larger amount of (more visible) publications than academic (university) scientists (Table 3).

Table 3. Significant predictors of the quantity and visibility of natural scientists' productivity

\begin{tabular}{|c|c|c|c|c|c|c|}
\hline \multirow{3}{*}{ Predictors } & \multicolumn{6}{|c|}{ Research productivity 1996-2005 } \\
\hline & \multicolumn{2}{|c|}{ Publications } & \multicolumn{2}{|c|}{ Citations } & \multicolumn{2}{|c|}{ Citations } \\
\hline & Beta & $\mathrm{p}$ & Beta & $\mathrm{p}$ & Beta & $\mathrm{p}$ \\
\hline Gender (female - male) & 0.090 & 0.003 & 0.089 & 0.003 & ---- & ---- \\
\hline Age (year of birth) & ----- & ----- & ---- & ----- & 0.042 & 0.047 \\
\hline Institution (academic - other) & 0.072 & 0.018 & 0.078 & 0.011 & ----- & ----- \\
\hline Physics - other fields & -0.148 & 0.000 & -0.309 & 0.000 & -0.094 & 0.000 \\
\hline Chemistry - other fields & -0.080 & 0.031 & -0.215 & 0.000 & ----- & ---- \\
\hline Geosciences - other fields & 0.188 & 0.000 & ---- & ---- & ---- & $-\cdots$ \\
\hline Mathematics - other fields & 0.091 & 0.010 & ---- & ---- & ---- & ---- \\
\hline Biology - other fields & ---- & ---- & -0.102 & 0.009 & ---- & ---- \\
\hline Publication counts & & & & & 0.682 & 0.000 \\
\hline $\mathrm{R}$ & \multicolumn{2}{|c|}{0.323} & \multicolumn{2}{|c|}{0.302} & \multicolumn{2}{|c|}{0.706} \\
\hline $\mathrm{R}^{2}$ & \multicolumn{2}{|c|}{0.104} & \multicolumn{2}{|c|}{0.091} & \multicolumn{2}{|c|}{0.498} \\
\hline $\mathrm{F}$ & \multicolumn{2}{|c|}{21.844} & \multicolumn{2}{|c|}{22.499} & \multicolumn{2}{|c|}{372.339} \\
\hline F significance & \multicolumn{2}{|c|}{0.000} & \multicolumn{2}{|c|}{0.000} & \multicolumn{2}{|c|}{0.000} \\
\hline
\end{tabular}

By far the most interesting finding is the impact of gender on the scientists' visibility, which is an issue that has not been analysed until now. When the number of the natural scientists' WoS publications was introduced into the regression analysis as a potentially powerful pre- 
dictor, the independent contribution of gender to citations disappeared, the disciplinary influence decreased, and the very small contribution of age appeared. There is no significant impact of gender on natural scientists' visibility (citations received), irrespective of the quantity of their publications (Table 3).

The results for the social scientists show the absence of the impact of socio-demographic variables on research productivity (Table 4). Just like age, gender does not appear as a significant factor of variability in the social scientists' publication productivity and visibility. Yet there are significant contributions of non-academic research personnel and psychologists to both dimensions of productivity, as well as the contribution of sociologists to the quantity but not quality of social science production. As expected, the strongest predictor of visibility was the quantity of scientific production.

Table 4. Significant predictors of the quantity and visibility of social scientists' productivity

\begin{tabular}{|c|c|c|c|c|c|c|}
\hline & \multicolumn{6}{|c|}{ Research productivity 1996-2005 } \\
\hline & \multicolumn{2}{|c|}{ Publications } & \multicolumn{2}{|c|}{ Citations } & \multicolumn{2}{|c|}{ Citations } \\
\hline & Beta & $\mathrm{p}$ & Beta & $\mathrm{p}$ & Beta & $\mathrm{p}$ \\
\hline Institution (academic - other) & 0.158 & 0.000 & 0.136 & 0.000 & ---- & ---- \\
\hline Psychology - other fields & -0.447 & 0.000 & -0.300 & 0.000 & ---- & ---- \\
\hline Sociology - other fields & -0.206 & 0.000 & ---- & ---- & 0.109 & 0.000 \\
\hline Educational sciences - other fields & -0.087 & 0.006 & ----- & ----- & ----- & ---- \\
\hline Information science - other fields & -0.066 & 0.033 & ----- & ---- & ---- & ---- \\
\hline Publication counts & & & & & 0.646 & 0.000 \\
\hline $\mathrm{R}$ & \multicolumn{2}{|c|}{0.323} & \multicolumn{2}{|c|}{0.302} & \multicolumn{2}{|c|}{0.706} \\
\hline $\mathrm{R}^{2}$ & \multicolumn{2}{|c|}{0.104} & \multicolumn{2}{|c|}{0.091} & \multicolumn{2}{|c|}{0.498} \\
\hline $\mathrm{F}$ & \multicolumn{2}{|c|}{21.844} & \multicolumn{2}{|c|}{22.499} & \multicolumn{2}{|c|}{372.339} \\
\hline F significance & \multicolumn{2}{|c|}{0.000} & \multicolumn{2}{|c|}{0.000} & \multicolumn{2}{|c|}{0.000} \\
\hline
\end{tabular}

Therefore, in the social sciences, gender does not prove to be significant, even in a minimal set of potential predictors of the quantity and visibility of scientists' publications. On the other hand, in natural fields, gender plays a small role in the narrowest set of contextual predictors, and by widening that set, the significant impact of gender on publication visibility is lost. The fact that gender patterns of productiv- 
ity in any complex analysis change and disappear confirms that their weakening is not only a matter of historical development and change, but also of the approach and methodology applied.

\section{Gender differences in research productivity: dimensions and meaning}

In summary, the basic results of the first comprehensive bibliometric comparison of the research productivity of Croatian natural and social scientists shows the following characteristics of gender differentiation in the observed scientific areas.

First, no considerable gender gap in research productivity was found either in the natural or the social sciences. The gender difference in favour of men established in the natural sciences is statistically significant, yet smaller in the quantity than in the visibility of scientific production. However, the discrepancy in the visibility of men's and women's research productivity in these sciences decreases once citations per publication are considered. In the social sciences, which have a far smaller WoS publication production and visibility than the natural sciences, gender differences are generally insignificant, but according to quantity and the visibility of publication, women are ahead of men.

In both areas, women are relatively less represented among the silent researchers, which can be understood as a sort of indicator of their scientific efficiency. In the group of highly productive scientists, women do not significantly lag behind men in the quantity of papers, but in the natural fields they fall behind in visibility, although the gap narrows once citations per publication are introduced. Therefore, instead of a gender gap, we could speak about gender differences that are systematically to the advantage of men to a certain extent in the natural sciences, and in some social sciences.

Since the manifested differences diminish when a relative indicator is used - citations per publication - our findings at the first analytical level are already closer to the results of the aforementioned studies that either did not establish significant gender differentiation in scientific productivity or found small differences. Although gender differentials in scientific productivity are not big, they still exist. Due to the cumulative nature of productivity, and the accumulative professional advantages in the social organisation of science, it is important to note that 
even insignificant or small differences should be kept in mind while studying gender in science (Long, 1990).

Second, socio-cognitive differences between scientific fields are usually reflected in publication patterns and strategies (Prpić and Brajdić Vuković, 2009). Consequently, gender differentiation in productivity is also to be expected among them. In the natural sciences, gender differentiation is generally greater in most fields, especially in laboratory sciences and mathematics, while it is less expressed in the social sciences and is insignificant in individual fields. Even when gender differentiation in research production is greater, the picture of its visibility changes once the citations per publication are analysed. It is hard to foresee whether women's accomplishments in producing elite scientific publications in some social fields will be maintained. Some changes will presumably occur with the broader internationalisation of the social sciences that will most certainly be encouraged by Croatian scientific policy, in the same way that it has been stimulated by the policies of techno-economically and scientifically more developed countries.

Third, gender differences in the natural or hard sciences that are bigger than in the social or soft sciences suggest that due to the specific features of their social and intellectual organisation, and thus the type of knowledge production (Whitley, 1984; Fuchs, 1992; Becher and Trowler, 2001), the performance of researchers can also be gendered to a different degree. Although in Croatia the inflow of women has been relatively stronger in the natural than in the social sciences, in the more competitive, hierarchical and centralised social organisation of the hard sciences with a more rigid cognitive style, women may enjoy less stimulating conditions to maximise scientific performance. In contrast, in the socially (and cognitively) less hierarchical and more decentralised, fragmentised and looser social sciences, it could be socially easier for women to attain equal scientific efficiency. These differences in social organisation between the hard and soft sciences can be seen as the main generator of the differences in achievement between the two genders.

Fourth, in spite of the minimal set of productivity predictors available, the contribution of gender to the variability of productivity is completely insignificant in the social sciences, or is significant but small in the natural sciences. In the latter area, it disappears when the number of publications is introduced among the predictors of citations. 
Furthermore, if data on academic ranks and other relevant features of the researchers' position and role in scientific institutions and communities were available, significant differences in the natural sciences would most likely further diminish or even disappear. The crucial effect of structural and organisational factors on gender differentiation in productivity has been confirmed in several studies, as well as in the Croatian ones.

During the last two decades, trends of diminishing gender differences in productivity have been observed in the Croatian research population. This was probably stimulated by a new competitive scientific system that makes permanent scientific employment conditional on academic promotion and, indirectly, publication productivity. Another tentative explanation of these trends could be attributed to the continuous career pattern of women scientists originating in the socialist period. This pattern includes maternity leave for all employed women, but a longer disruption of career and part-time employment (of women) practically do not exist in science. Such a pattern increases the cumulative effect on the publication productivity of female researchers, which, in return, can cause smaller gender differences in productivity.

Fifth, the implications of this study, in our opinion, can be both theoretical and methodological. The latter implications refer to the advantages of the complete inclusion of the research population, or at least its larger segments, in bibliometric studies of gender differences in productivity. The main advantage is obtaining a reliable picture of scientists' most esteemed and rewarded research production. WoS publications make up the majority of knowledge output in the natural sciences, especially in some fields. Although this kind of publication productivity does not have such a prominent role in the social sciences, its importance has been increasing and therefore should also be studied.

The essential finding shows that women, either in the natural or social sciences, even if they publish less than male scientists, do not gain lesser visibility for their publications in the international scientific community. This result is in accordance with some other cited studies, and actually indicates the above-average professional success of female scientists since they do not have the same professional advantages as male scientists (Palomba and Menniti, 2001; Long, 2001; Xie and Shauman, 2003; EC, 2004; Prpić, 2004). The professional advantages also include social capital which is an important determinant of publication productivity (Etzkowitz et al., 2000). Moreover, citations are not 
just a measure of intrinsic scientific quality, but also the product of a wider collegial network (Feller, 2004).

Our finding thus implies that an approximately similar level of publication visibility for both sexes is an indirect confirmation of the scientific achievement and efficient publication strategy of female natural scientists and of the internationally most visible female social scientists. However, the starting point of studies on gender differentiation in publication productivity still remains open. This is the issue of the referent values with which the research productivity of women scientists is to be compared and assessed. Should the referent values necessarily be the productivity measures of the most productive male scientists?

\section{References}

ASTIN, Helen S. (1984). Academic scholarship and its rewards. In P. Maehr \& M. W. Steinkamp (Eds.), Advances in motivation and achievement (pp. 259-279). Volume 2. Greenwich: JAI Press.

BECHER, Tony, \& TROWLER, Paul R. (2001). Academic tribes and territories: Intellectual enquiry and the culture of disciplines. Buckingham - Philadelphia: The Society for Research into Higher Education \& Open University Press.

BENCKERT, Sylvia, \& STABERG, Else-Marie (2001). Women in science: Can they be disturbing elements? NORA, 9(3), 162-171.

BORDONS, María, MORILLO, Fernanda, FERNÁNDEZ, Theresa M., \& GÓMEZ, Isabel (2003). One step further in the production of bibliometric indicators at the micro level: Differences by gender and professional category of scientists. Scientometrics, 57(2), 159-173.

BUTLER, Linda (2003). Modifying publication practices in response to funding formulas. Research evaluation, 12(1), 39-46.

CAMPION, Patricia, \& SHRUM, Wesley (2004). Gender and science in development: Women scientists in Ghana, Kenya and India. Science, Technology \& Human Values, 29(4), 459-485.

COLE, Jonathan R. (1987). Women in science. In Douglas N. Jackson \& Philippe Rushton (Eds.), Scientific excellence. Origins and assessment (pp. 359-375). Newbury Park - Beverly Hills - London - New Delhi: Sage.

COLE, Jonathan R., \& COLE Stephen ([1973] 1981). Social stratification in science. Chicago - London: The University of Chicago Press.

COLE, Jonathan R., \& ZUCKERMAN, Harriet (1984). The productivity puzzle: Persistence and change in patterns of publication of men and women scientists. In P. Maehr \& M. W. Steinkamp (Eds.), Advances in motivation and achievement (pp. 217-258). Volume 2. Greenwich: JAI Press.

DAVENPORT, Elisabeth, \& SNYDER, H. (1995). Who cites women? Whom do women cite? An exploration of gender and scholarly citation in sociology. Journal of Documentation, 51(4), 404-410. 
DEBACKERE, Koenraad, \& GLÄNZEL, Wolfgang (2004). Using a bibliometric approach to support research policy making: The case of the Flemish BOF-key. Scientometrics, 59(2), 253-276.

EC (2004). Gender and excellence. Brussels: European Commission.

ETZKOWITZ, Henry, KEMELGOR, Carol, UZZI, Brian, NEUSCHATZ, Michael, SEYMOUR, Elaine, MULKAY, Lynn, \& ALONZO, Joseph (2000). Athena unbound: The advancement of women in science and technology. Cambridge: Cambridge University Press.

FELLER, Irwin (2004). Measurement of scientific performance and gender bias. In: Gender and Excellence (pp. 35-38). Brussels: European Commission.

FOX, Mary Frank (2005). Gender, family characteristics, and publication productivity among scientists. Social Studies of Science, 35(1), 131-150.

FOX, Mary Frank, \& MOHAPATRA, Sushanta (2007). Socio-organizational characteristics of work and publication productivity among academic scientists in doctoral-granting departments. The Journal of Higher Education, 78(5), 542-571.

FUCHS, Stephan (1992). The professional quest for truth: A social theory of science and knowledge. Albany: State University of New York Press.

GOEL, Kamlesh (2002). Gender differences in publication productivity in psychology in India. Scientometrics, 55(2), 243-258.

GONZALES-BRAMBILA, Claudia, \& VELOSO, Francisco M. (2007). The determinants of research output and impact: A study of Mexican researchers. Research Policy, 36(7), 1035-1051.

GUPTA, B. M., KUMAR, Suresh, \& AGGARWAL, B. S. (1999). A comparison of productivity of male and female scientists of CSIR. Scientometrics, 45(2), 269-289.

HARASZTHY, Agnes (1991). Equal opportunities for women? Women in science in Hungary (pp. 193-198). In V. Stolte-Heiskanen, F. Acar, N. Ananieva, D. Gaudart, $\&$ R. First-Dilić (Eds.), Women in science: Token women or gender equality. Oxford - New York: Berg Publishers.

HICKS, Diana (1999). The difficulty of achieving full coverage of international social science literature and the bibliometric consequences. Scientometrics, 44(2), $193-$ 215.

JOKIĆ, Maja, \& ŠULJOK, Adrijana (2009). Productivity and its impact in the ISI and Scopus citation databases from 1996 to 2005 period (pp. 143-172). In K. Prpić, (Ed.), Beyond the myths about the natural and social sciences: A sociological view. Zagreb: Institut za društvena istraživanja u Zagrebu.

KLAIĆ, Branimir (1998). Scientometrija ili peer review? [Scientometrics or peer review?] In Darko Polšek (Ed.), Vidljiva i nevidlivia akademija: mogućnosti društvene procjene znanosti u Hrvatskoj [Visible and invisible academy. Social assessment of science and scientists in Croatia] (pp. 85-96). Zagreb: Institut društvenih znanosti Ivo Pilar.

KYVIK, Svein (1990). Motherhood and scientific productivity. Social Studies of Science, 20(1), 149-160.

LAŽNJAK, Jasminka (1990). Znanstvena usmjerenost i opremljenost doktorata iz sociologije [Scientific characteristics of doctoral dissertations in sociology]. Revija za sociologiju, 21(3), 467-475. 
LEAHEY, E. (2006). Gender differences in productivity: Research specialization as a missing link. Gender \& Society, 20(6), 754-780.

LEMOINE, W. (1992a). Productivity patterns of men and women scientists in Venezuela. Scientometrics, 24(2), 281-295.

LEMOINE, W. (1992b). The frequency distribution of research papers and patents according to sex. The case of CSIR, India. Scientometrics, 24(2), 449-469.

LETA, Jacqueline, \& LEWISON, Grant (2003). The contribution of women in Brazilian science: A case study in astronomy, immunology and oceanography. Scientometrics, 57(3), 339-353.

LONG, J. Scott (1990). The origins of sex differences in science. Social Forces, 68(4), 1297-1315.

LONG, J. Scott (1992). Measures of sex differences in scientific productivity. Social Forces, 71(1), 159-178.

LONG, J. Scott (Ed.) (2001). From scarcity to visibility: Gender differences in the careers of doctoral scientists and engineers. Washington, D.C.: National Academy Press.

LONG, J. Scott, \& FOX, Mary Frank (1995). Scientific careers: Universalism and particularism. Annual Review of Sociology, 21(1), 45-71.

LUUKKONEN-GRONOW, Terttu, \& STOLTE-HEISKANEN, Veronica (1983). Myths and realities of role incompatibility of women scientists. Acta Sociologica, 26(34), 267-280.

MAULEÓN, Elba, \& BORDONS, María (2006). Productivity, impact and publication habits by gender in the area of materials science. Scientometrics, 66(1), 199-218.

NEDERHOF, Anton (2006). Bibliometric monitoring of research performance in the social sciences and the humanities: A review. Scientometrics, 66(1), 81-100.

NEDERHOF, A., ZWAAN, R. A., De BRUIN, R. E., \& DEKKER, P. J. (1988). Assessing the usefulness of bibliometric indicators for the humanities and the social and behavioural sciences: A comparative study. Scientometrics, 15(5/6), 423-435.

PALOMBA, Rossella, \& MENNITI, Adele (2001). Minerva's daughters - Filles de Minerve. Rome: Institute for Research on Population and Social Policies.

PREVIŠIĆ, Jozo (1975). Znanstveni kadar u SR Hrvatskoj [Croatian Scientific Personnel]. Zagreb: Institut za društvena istraživanja Sveučilišta u Zagrebu.

PRPIĆ, Katarina (1984). Kadrovski potencijal znanosti: rezultati istraživanja provedena u SR Hrvatskoj u 1983. godini [Scientific personnel: The results of an investigation carried out in Croatia in 1983]. Zagreb: Institut za društvena istraživanja Sveučilišta u Zagrebu.

PRPIĆ, Katarina (1990). Znanstvena produktivnost istraživača između minimalizma i maksimalizma [Scientific productivity between minimalism and maximalism]. In K. Prpić \& B. Golub. Znanstvena produktivnost i potencijalni egzodus istraživača Hrvatske [Scientific productivity and the potential exodus of Croatian researchers] (pp. 1-61, 107-128). Zagreb: Institut za društvena istraživanja Sveučilišta u Zagrebu.

PRPIĆ, Katarina (1991). Odrednice znanstvene produktivnosti [Scientific productivity determinants]. Zagreb: Institut za društvena istraživanja Sveučilišta u Zagrebu.

PRPIĆ, Katarina (1996). Characteristics and determinants of eminent scientists' productivity. Scientometrics, 36(2), 185-206. 
PRPIĆ, Katarina (2002a). Gender and productivity differentials in science. Scientometrics, 55(1), 27-58.

PRPIĆ, Katarina (2002b). Size, structure and dynamics of research and development personnel. In N. Švob-Đokić (Ed.), Research and development policies in the Southeast European countries in transition: Republic of Croatia (pp. 46-73). Zagreb: Institut za međunarodne odnose.

PRPIĆ, Katarina (2004). Sociološki portret mladih znanstvenika [A sociological portrait of young scientists]. Zagreb: Institut za društvena istraživanja u Zagrebu.

PRPIĆ, Katarina, \& BRAJDIĆ VUKOVIĆ, Marija (2009). Self-reported research productivity: patterns and factors. In K. Prpić (Ed.), Beyond the myths about the natural and social sciences: A sociological view (pp. 89-142). Zagreb: Institut za društvena istraživanja u Zagrebu.

RESKIN, Barbara F. (1977). Scientific productivity and the reward structure of science. American Sociological Review, 42(3), 491-504.

RESKIN, Barbara F. (1978). Scientific productivity, sex, and location in the institution of science. American Journal of Sociology, 83(5), 1235-1243.

ROTHAUSEN-VANGE, Theresa J., MARLER, Janet H., \& WRIGHT, Patrick M. (2005). Research productivity, gender, family, and tenure in organization science careers. Sex Roles, 53(9/10), 727-738.

SÁNCHES PEÑAS, Celia, \& WILLETT, Peter (2006). Brief communication: Gender differences in publication and citation counts in librarianship and information science research. Journal of Information Science, 32(5), 480-485.

SAX, Linda J., SERRA HAGEDORN, Linda, ARREDONDO, Marisol, \& DICRISI III, Frank A. (2002). Faculty research productivity: Exploring the role of gender and family-related factors. Research in Higher Education, 43(4), 423-446.

SETTLES, Isis A., CORTINA, Lilia M., MALlEY, Janet, \& STEWART, Abigail J. (2006). The climate for women in academic science: The good, the bad, and the changeable. Psychology of Women Quarterly, 30(1), 47-58.

SHRUM, Wesley (1997). View from afar: 'Visible' productivity of scientists in the developing world. Scientometrics, 40(2), 215-235.

SONNERT, Gerhard (1995). What makes a good scientist? Determinants of peer evaluation among biologists. Social Studies of Science, 25(1), 35-55.

THAGAARD, Tove (1991). Research environment, motivation and publication productivity. Science Studies, 4(1), 5-18.

VIEFERS, Susanne F., CHRISTIE, Michael F., \& FERDOS, Fariba (2006). Gender equity in higher education: Why and how? A case study of gender issues in a science faculty. European Journal of Engineering Education, 31(1), 5-22.

WEINGART, Peter (2005). Impact of bibliometrics upon science system: Inadvertent consequences? Scientometrics, 62(1), 117-131.

WHITLEY, Richard (1984). The intellectual and social organization of the sciences. Oxford: Clarendon Press.

XIE, Yu, \& SHAUMAN, Kimberlee A. (1998). Sex differences in research productivity: New evidence about an old puzzle. American Sociological Review, 63(6), 847-870.

XIE, Yu, \& SHAUMAN, Kimberlee A. (2003). Women in science: Career processes and outcomes. Cambridge MA - London UK: Harvard University Press. 


\section{Appendix}

Table A. Social and professional structure of Croatian natural and social scientists (in \%)

\begin{tabular}{lcccc}
\hline & \multicolumn{2}{c}{ Natural scientists } & \multicolumn{2}{c}{ Social scientists } \\
\cline { 2 - 5 } & Men & Women & Men & Women \\
\cline { 2 - 5 } & $\mathrm{N}=614$ & $\mathrm{~N}=517$ & $\mathrm{~N}=501$ & $\mathrm{~N}=306$ \\
\hline GENDER & 54.3 & 45.7 & 62.1 & 37.9 \\
\hline Chi-square = 11.708, df $=1 ; \mathrm{p}<0.01$ & & & & \\
\hline AGE & & & & \\
$31-40$ & 9.4 & 17.2 & 3.8 & 12.1 \\
$41-50$ & 26.1 & 26.1 & 20.8 & 37.3 \\
$51-60$ & 31.3 & 30.9 & 32.3 & 35.0 \\
$60>$ & 33.2 & 25.7 & 43.1 & 15.7 \\
\hline Average age (in years) & 54.7 & 52.2 & 58.0 & 50.8 \\
F $=44.252 ; \mathrm{p}<0.001^{*}$ & & & & \\
\hline TYPE OF INSTITUTION & & & & \\
Universities & 53.3 & 43.7 & 88.6 & 85.0 \\
Public institutes & 37.6 & 42.6 & 8.6 & 10.5 \\
Other institutions & 9.1 & 13.7 & 2.8 & 4.6 \\
\hline
\end{tabular}

Chi-square $($ natural $)=12.258, \mathrm{df}=2 ; \mathrm{p}<0.01$

Chi-square $($ social $)=2.746 ; \mathrm{df}=2 ; \mathrm{p}>0.05$

\begin{tabular}{lllll}
\hline NATURAL SCIENCES & & & & \\
Biology & 34.6 & 65.4 & --- & --- \\
Chemistry & 42.9 & 57.1 & --- & --- \\
Geosciences & 75.2 & 24.8 & --- & --- \\
Mathematics & 70.1 & 29.9 & --- & --- \\
Physics & 77.2 & 22.8 & --- & --- \\
\hline
\end{tabular}

Chi-square $=141.102, \mathrm{df}=4 ; \mathrm{p}<0.001$

\section{SOCIAL SCIENCES}

Economics

Educational sciences

Information science

Law and political science

Psychology

Sociology

Chi-square $=44.229, \mathrm{df}=5 ; \mathrm{p}<0.001$

* The analysis of variance included these four groups (see footnote 6 ). 


\section{Anitza Geneve \\ Karen Nelson \\ Ruth Christie}

\section{Women's participation in the Australian Digital Content Industry: initial case study findings}

\section{Introduction}

\subsection{Research project}

An exploratory case study which seeks to better understand the problem of low participation rates of women in Information Communication Technology (ICT) is currently being conducted in Queensland, Australia. Contextualised within the Digital Content Industry (DCI) multimedia and games production sectors, the emphasis is on women employed as interactive content creators rather than as users of the technologies. Initial findings provide rich descriptive insights into the perceptions and experiences of female DCI professionals. Influences on participation such as: existing gender ratios, gender and occupational stereotypes, access into the industry and future parental responsibilities have emerged from the data. Bandura's (1999) Social Cognitive Theory (SCT) is used as a "scaffold" (Walsham, 1995: 76) to guide data analysis and assist analytic generalisation of the case study findings. We propose that the lens of human agency and theories such SCT assist in explaining how influences are manifested and effect women's agency and ultimately participation in the DCI. The Sphere of Influence conceptual model (Geneve et al., 2008), which emerges from the data and underpinning theory, is proposed as a heuristic framework to further explore influences on women's participation in the DCI industry context.

\subsection{Research domain}

Over the previous few decades, numerous researchers have asked: "why are there lower rates of participation of women in comparison to men within industries directly associated with computing?" Researchers seeking answers have included authors in Australia (Trauth et al., 2003); the United Kingdom (Panteli et al., 1999; Moore et al., 
2005); the United States, (Trauth, 2002; Ahuja, 2002); and non-western countries such as Malaysia (Othman and Noordin, 2005). Most of this previous research has focused on the Information Technology (IT) and Information Systems (IS) sectors of the Information Communication Technologies (ICT) professions.

The Digital Content Industry (DCI) has been identified as an important emerging industry within the Australian economy, and one where there is an identified skills shortage (DCITA, 2005). However the number of women working (including entry numbers and ongoing retention) in the DCI, both in Australia and internationally, is significantly lower than that of men, which may indicate that the quality of participation differs for women. The Australian Bureau of Statistics (ABS, 2008a) identified 1,188 males and 137 females employed fulltime in the games industry in 2006-07. An international industry survey by the International Games Developer Association (IGDA, 2005) suggests $11.5 \%$ of the respondents were female. Our own investigations (Geneve et al., 2008) indicate a rate of less than $10 \%$ of women working in technical roles, and in some instances the actual rates were even lower. For example, in one local studio of an international games development company, only 2 of the 50 staff were women.

Acknowledging there may be some unique characteristics in the new and emerging DCI context (Pratt, 2000; Leadbeter and Oakley, 1999; Gill, 2002; Flores and Gray, 2000), such as changing work patterns, we locate the DCI sectors of multimedia and games content development as components of the overall ICT umbrella for a number of reasons.

Firstly, definitions by Denning (1998) and Houghton (2001) suggest that the DCI multimedia and games production sectors have traditionally been associated with the ICT context. Secondly, the DCI role of interactive content creator ${ }^{2}$ (ABS, 2008b) is strongly associated with IT hardware and software technologies such as computers, peripherals and programming in C++, HTML scripting and other similar languages, together with software tools such as 3D modellers. Thirdly, the DCI has been described as being situated between traditional creative industries and the ICT industry (Figure 1), spanning the applications and services components of the ICT industry on the one side and the

1 The Australian Department of Communications, Information Technology and the Arts (DCITA).

${ }^{2}$ As defined by the Australian Bureau of Statistics Australian Culture and Leisure Classification occupation of "interactive content creation" (class 267). 
traditional film, entertainment and cultural industries on the other, and overlapping key areas of both (DCITA, 2005). Finally, investigating DCI within a broader ICT context allows us to draw on an existing body of research surrounding studies of "gender in ICT".

Figure 1. Positioning the Digital Content Industry (DCI) sectors

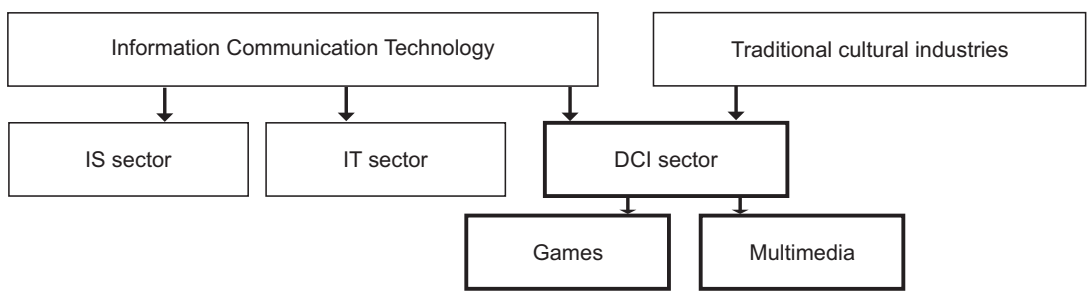

This research aims to identify ways to encourage more women into the DCI industry. If successful, our study may also contribute to resolving some of the social issues associated with the "digital divide" (Castells, 1996). More women in content creator professions may not only shape the world they live in, through their personal agency and as agents of social change (for example as role models), but also the world we live in through their involvement in designing digital products such as websites and digital games. As Wajcman (2000) suggests, these women may shape the digital products that shape society, where technology is a dimension of social change.

\subsection{Agency as a way of understanding participation}

Academic research highlights "a documented need to study the gender imbalance" in IT, suggesting it is both "under-studied" and "under-theorised" (Trauth, 2002: 98). As a response to the paucity of studies focusing on the DCI context, particularly within an interpretative paradigm, the initial research findings reported in this paper explore the perceptions and experiences of female DCI professionals. The hermeneutic approach underpinning the case study focuses on the meanings the women ascribe to the influences on their participation, acknowledging a participant's active phenomenological role in processing environmental influences.

Rowlands (2005: 87 citing Klein and Myers, 2001) recommends that empirical interpretivist research needs to be "guided (or at least 
informed) by one or more social theories", as social theories can better situate the application and findings of research. As such, this case study draws on existing literature, including social theories, for guidance in moving it from being a descriptive to an explanatory study. Although multiple theories are referred to, Bandura's (1999) Social Cognitive Theory (SCT) is the primary "scaffold" (Walsham, 1995: 76).

It is proposed that the lens of human agency and theories such as SCT provide ways to explain how influences on participation are manifested and why they are important in influencing women's agency. When considering women's capability to work in the ICT industry, we are focusing on agency to move our thinking from a deterministic stance towards a potentialistic approach. This conception of agency helps us to understand how the environment influences a woman's belief in her capability and her desire or motivation to pursue a particular path. In this way, the concept of agency can bridge the constructivist and essentialist polemics common to the discussion of "gender in ICT".

In this study, women are considered to be agents having the potential to change the impact of those influences, rather than being victims of circumstance. Agency, be it personal, proxy, collective or moral (Bandura, 2001), or most likely a combination of these, may assist in overcoming potentially negative influences such as gender stereotypes. For women working in the ICT industries, these acts of "human agency or praxis as transformative negation of the given" (Bhaskar, 1994: 93) can comprise: confidence to enter the industry; to challenge and ultimately transform influences such as gender stereotypes; and to maintain their desire to participate in the face of such deterrents. Human characteristics, through which personal agency is exercised include: forethought (goals); motivation (rewards); reactiveness; coping strategies; feedback; and reflection (Bandura, 1997, 2000). These mechanisms of agency may explain how women develop and maintain this passion over their lifetime.

Much previous research focuses on what may be described as "barriers" (for example Newmarch et al., 2000) or negative influences on participation arising from the environment. Ramsey and McCorduck (2005, para. 1) suggest that for women in IT, the environment presents deterrents where "circumstances almost seem designed to wedge them from the work they love". However, similar to previous research in the DCI (Gill, 2007) and IT context (Griffiths et al., 2005) the women ap- 
proached to participate in this study seemed passionate about their occupations. Therefore our research seeks to explore those influences perceived by participants to have a positive impact, as well as "negative" influences, so we can identify what has supported the women's participation along their career path.

In summary, the key contributions of this paper are:

1. the sharing of insights from women working in the DCI (an area where there is currently little empirical research) of the factors they identify as influencing participation;

2. an explanation of the findings utilising a theoretical scaffold, primarily Social Cognitive Theory;

3. the presentation of the proposed "Sphere of Influence" conceptual model, which provides a heuristic framework for further exploring influences.

\section{Literature review}

An overview of the previous academic research within the "gender in IT" domain, including several social theories, follows in the section below. In particular, a discussion about the usefulness of Social Cognitive Theory in guiding our data collection and analysis is presented. The nature of interpretative research means that other key literature is drawn out in the analysis of findings section.

\subsection{Previous research}

There is a significant body of academic research on the declining participation rate of women across both ICT education and career pathways (see the review by Ahuja, 2002 and by Sorenson, 2002). However, there is a paucity of studies focusing on the experience of new media workers in the emerging Digital Content Industry (DCI) sectors. Of notable exception in the European DCI context are Gill's (2002) investigation of gender and Perrons' (2003) exploration of work-life balance. In the United States, Batt et al. (2001) and Pratt (2000) identify the new media worker's need for social interaction.

The studies mentioned above have identified a plethora of factors, such as gender and occupation stereotyping and also the lack of role models (Coohon and Aspray, 2006) which may affect women's participation in the ICT industries. However as Adam et al. (2004) highlight, there has been little research concerning the low participation of wom- 
en in IT that explores women's actual experiences and utilises theory to explain findings. A meta-analysis of empirically derived models from the "gender in IT" literature (enumerated in Table 1) suggests some common themes surrounding influences such as:

- individual - including: behaviours, personality traits and perceptions;

- social - including: cultural, historical context, media and family influence;

- structural or environmental - including: access to equipment, and industry characteristics (long hours).

Table 1. Summary of empirical research explaining influences on women's participation in ICT

\begin{tabular}{lll}
\hline Name & Author/year & Country \\
\hline $\begin{array}{l}\text { Individual Differences } \\
\text { Theory }\end{array}$ & Trauth et al. (2004) & United States of America \\
--- & Adya and Kaiser (2005) & United States of America \\
Stage-model of barriers & Ahuja (2002) & United States of America \\
PRECEDE model & Teague (1997) & Australia \\
& Webb and Young (2005) & Australia \\
& Othman and Noordin (2005) & Malaysia \\
\hline
\end{tabular}

The existing literature has revealed two key theories as being useful in providing some theoretical explanation of women's participation. Both theories emphasise the relationship between the person and their environment. The first is Structuration Theory (ST), specifically the work of Giddens $(1979,1984,1989)$. ST has been utilised by Beekhuyzen et al. (2003) for empirical research in the Australian "gender in IT" context. There have been criticisms of ST though, including Ramsey and McCorduck (2005: 20), who suggest that ST is "promising" but "not mature enough to build a program of action upon". This reference to "maturity" may be a reflection of the limitations in utilising grand theories in empirical studies, where ST is, according to Giddens (in Gregor, 2006: 8), a meta-theory: a very high level of abstraction providing a way of thinking about other theories. The second theory is Individual Differences Theory (IDT), proposed by Trauth et al. (2004). Described as a "complex but fascinating emerging theory" (Adya and Kasier, 2005: 239), this is a theory still under development. Trauth et al. (2004: 114-115), state that the theory "focuses on individual 
differences among women", making the "case for an alternative theory to occupy the space between essentialism and social construction".

\subsection{Theoretical framework}

\subsubsection{Multiple theories}

Trauth et al. (2004: 114) state that "one of the research challenges in studying the underrepresentation of women in the IT field is the lack of sufficient theory to provide a basis for understanding and explanation about this gender imbalance". Concurring with their view, a range of theoretical frameworks were considered for their suitability to interpret data arising from our research which, like other complex, socially contextualised research problems, could present opportunities for multiple interpretations.

Table 2. Summary of the "types" of theory used as a scaffold for analytic generalisability

\begin{tabular}{|c|c|c|}
\hline Type of theory & Specific theory & Application to this study \\
\hline \multirow[t]{3}{*}{ Meta theory } & $\begin{array}{l}\text { Social Construction of Reality } \\
\text { (Berger and Luckman) }\end{array}$ & $\begin{array}{l}\text { Background to sensitise researcher to } \\
\text { the "social construction" approach. }\end{array}$ \\
\hline & $\begin{array}{l}\text { Social Capital Theory (Bourdieu, } \\
\text { Putnam) }\end{array}$ & Emphasis is placed on social relations. \\
\hline & Structuration Theory (Giddens) & $\begin{array}{l}\text { Refers to the "duality of structure", the } \\
\text { discursive and recursive interaction } \\
\text { between society and the individual } \\
\text { over time and space. }\end{array}$ \\
\hline Critical & Social Theory of Gender (Connell) & $\begin{array}{l}\text { Sensitises researcher to a particular } \\
\text { perspective e.g. emancipation of } \\
\text { women, which is an axiological } \\
\text { consideration. }\end{array}$ \\
\hline \multirow[t]{3}{*}{$\begin{array}{l}\text { Middle range } \\
\text { theory }\end{array}$} & Social Cognitive Theory (Bandura) & $\begin{array}{l}\text { Helps to move the case study from } \\
\text { descriptive to explanatory. }\end{array}$ \\
\hline & $\begin{array}{l}\text { Individual Differences Theory } \\
\text { (Trauth) }\end{array}$ & $\begin{array}{l}\text { Provides insights into previous } \\
\text { empirical research in the ICT context. }\end{array}$ \\
\hline & $\begin{array}{l}\text { Theory of Vocational Choice } \\
\text { (Super, 1992) }\end{array}$ & $\begin{array}{l}\text { Relevant to the organisational context, } \\
\text { and also identifies a lifespan concept. }\end{array}$ \\
\hline Operational & $\begin{array}{l}\text { Social Cognitive Career Theory } \\
\text { (Lent, Brown and Hackett) }\end{array}$ & $\begin{array}{l}\text { Operationalises SCT variables such as } \\
\text { "self-efficacy". }\end{array}$ \\
\hline Model building & $\begin{array}{l}\text { Pettigrew (1985) } \\
\text { Ecological Systems Theory } \\
\text { (Bronfenbrenner) }\end{array}$ & $\begin{array}{l}\text { Models from other domains used as a } \\
\text { conceptual tool. }\end{array}$ \\
\hline
\end{tabular}


Several social theories were identified as appropriate for guiding data collection, analysis and explanation. Bourdieu's (1986) Social Capital Theory may be useful when considering the women's social environment. Connell's (2002) Social Theory of Gender provides a critical approach to interpreting both literature and data. Bronfenbrenner's (2004) Bioecological Systems Theory is of value where the emphasis is on exploring the multiple levels of environment (or structure) from a macro to micro perspective. As previously mentioned, a research focus on agency, specifically the interaction between the environment and the individual, leads to theories such as Structuration Theory (ST), in particular Giddens' version $(1979,1984)$ and also Bandura's $(1999,2001)$ Social Cognitive Theory (SCT) as being useful in understanding the data.

\subsubsection{Social Cognitive Theory}

Bandura's (1999) Social Cognitive Theory (SCT) has been selected as a "middle range theory" (Merton, 1968) or "scaffold" (Walsham, 1995) in this research. As a middle range theory, SCT can link the theoretical research contribution with pragmatic outcomes (where the findings that arise may assist in developing new strategies to encourage women into the industry).

Bandura's model (Figure 2) and theory suggest a reciprocal triadic relationship exists between the environment (E), the person (P) and their behaviour (B). Therefore according to SCT, environmental circumstances present influences, and a sense of agency (personal, proxy, moral and collective) may in turn influence the environment (or the person) through various cognitive mechanisms such as coping strategies and reflection.

Figure 2. SCT model (Bandura, 2001)

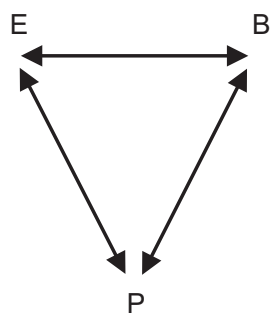

Key: E-environment, B-behaviour, P-person 
SCT provides a unified framework to explore human agency without treating the concept of gender in an essentialist manner. Importantly for this exploratory interpretative study, SCT is not a fixed model providing a static description but rather a framework for understanding dynamic "emergent interactive agency" (Bandura, 2001).

Support for the selection of SCT as a theoretical scaffold is provided by Bhaskar (1979: 40-41), who suggests a suitable sociological approach should provide "a system of concepts designating the "point of contact' between human agency and social structure". Furthermore in the ICT and gender context, Ahuja (2002: 22) suggests "...it is crucial that interactions among these factors [such as the social and structural] be considered". Consequently, this study considers both the person (P) and environment (E) influences and the relationships between them, "not only the P-E but the dash" (Savickas, 2005). These relationships, in most but not all cases, involve direct social contact with other people. Therefore, aligned with Social Capital Theory (Putman, 1993; Bourdieu, 1986), we particularly focus on the process of socialisation which encompass gender because, as Connell suggests, "gender is, above all, a matter of the social relations within which individuals and groups act" (2002: 9).

In utilising the various mechanisms of human agency that Bandura proposes within SCT, such as self-efficacy and vicarious learning from role models, we may begin to explain how women overcome negative influences and develop and maintain their passion towards their DCI careers. Importantly, Bandura's notion of agency incorporates proxy, collective and moral agency as well as personal. The notion of collective agency may be particularly relevant to ICT industries such as the DCI where, as Contu (2005) identifies, labour is often organised in teams.

\section{Methodology}

The research problem is complex, as sociological concerns usually are. Therefore, a methodological stance favouring an interpretive and qualitative approach was required, that is, an approach concerned with discovering phenomena, constructs, and propositions (LeCompte and Preissle, 1993). An exploratory case study was selected as the most suitable method for this investigation because, as Benbasat et al. (1987: 370) argue, a case study "examines a phe- 
nomenon in its natural setting, employing multiple methods of data collection to gather information from one or a few entities (people, groups, or organizations)".

Criticisms of the case study approach are recognised, including scepticism of explanation from case studies (Craib, 1992), and concerns regarding generalisability (see Baskerville and Lee, 1999). In response, the study follows a number of established guidelines, including the principles proposed by Klein and Myers (1999) for interpretative case study research. Reliability was improved through a number of techniques including "bracketing" (Ahern, 1999) of acknowledged biases from the analytic process. Although analytical generalisation is also improved, by following Yin's (1994) recommendation to generalise to a theory, and the use of complementary theories and "scaffolds" as suggested by Walsham (1995), the researcher was aware of not becoming too fixed on the theory or viewing the data in too narrow a manner. As Dobson suggests, theory offers not only a way of seeing but also "not-seeing" (Dobson, 2001: 285), and acknowledging an alternative perspective would aid any theory building.

\subsection{Case study context}

The exploratory case study involves gaining insights from female DCI professionals, specifically women who have been employed in the games and multimedia production sectors for less than five years. Webb and Young (2005: 148) suggest a "woman has been considered to be working in an ICT role if the work she does contributes to or supports the use of a computer system". In this study, we have considered a woman to be in a DCI role if she is employed in the Australian Culture and Leisure Classifications (ACLC) "interactive content creation" class 267 (Australian Bureau of Statistics, 2008), where employment is in core production (creation of digital content is the core business of the organisation) rather than embedded production (the development of digital content to support the organisation's primary business) "e.g. web pages or advertising material for a law firm" (DCITA, 2005: 6). Consequently, our participants are in technical production roles, rather than being technology enabled users (see Figure 3). 
Figure 3. Authors' concept to illustrate women's range of participation in the $\mathrm{DCI}^{3}$

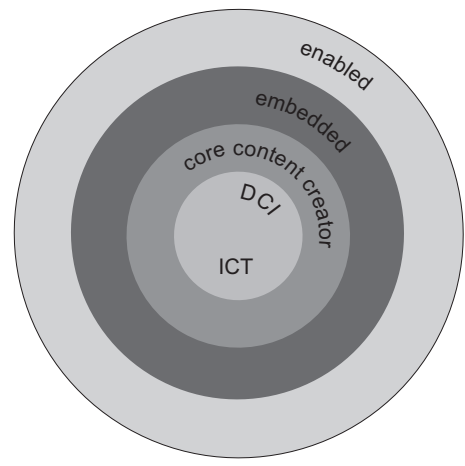

Although it has been identified by industry organisations such as the IGDA (2005) that "male workers heavily dominate most of the core content creation roles", in this study, targeting women who are content creators addresses conceptions that "men in general are more likely to be seen as the designers, developers and managers of systems whereas women are seen as the users of these systems" (Grundy, 1996), and contrasts previous research where the focus is on women as technology users (for example, see Venkatesh and Morris, 2000). The women in our study are in their early careers, and it is hoped that their experiences will provide a lifespan perspective: a bridge between those influences affecting childhood and schooling, their current workplace context, and future influences surrounding career progression.

The participants in phase 1 of the case study were twelve women aged between 22 and 34 . These women came from a variety of cultural backgrounds, and included Asian, Eastern European and Canadian immigrants together with women born in Australia. The participants were employed within a diverse range of DCI organisations, including local studios of large multinational games development companies, public organisations and small family-run web development start-ups. Their core DCI production occupations included: animation prop builder, artificial intelligence (AI) games programmer, assistant games

${ }^{3}$ Women's participation in the DCI ranges from core interactive content creator in the DCI; embedded content creator in other industries and through to enabled user of digital content. 
producer, games designer, web developer, web designer and interactive media producer.

\subsection{Data collection and analysis}

Two methods were used to collect qualitative data in this first phase: an online questionnaire and semi-structured interviews. The questionnaire and interview questions asked participants about the influences they perceived they, or other women, had experienced. Respondents reported taking 10 to 20 minutes to complete the questionnaire. The semi-structured interviews were guided by several probe questions which contributed to the chain of evidence and were documented in the case protocol (Stake, 1994). Each interview took 45 to 120 minutes (the actual time governed by the participant's availability). Audio recordings of the interviews were made on digital video and subsequently transcribed and verified for accuracy of content with the interviewees.

The theories and models identified in the initial literature review sensitised the researchers to the "women in IT" context. Data analysis followed an iterative cycle of thematic mapping for data reduction and display until a point of "saturation" was achieved. Several key themes, such as structure and agency emerged from each individual's responses and between the responses.

At this point, the theories and models previously explored in the literature review were revisited to identify aspects of theory (or of multiple theories) that would further assist analysis and also improve the ability to develop analytical generalisations from the case study data.

The theoretically informed data interpretation involved a constant comparative analysis of the data (see Gibbs and Taylor, 2005; Bogdan and Biklen, 1992; Strauss and Corbin, 1990 for types of phenomena to code). The process of pattern matching (Campbell, 1975; Yin, 1994) looked for similarity and variation in the data sets. Patterns were identified in: influences; conceptual relationships; chronologies; typology of environment; language and non verbal cues (from the digital recordings). This matching requires of the researcher an analytical dualism in exploring ontologically different aspects of a complex social phenomenon, to retain participants' meanings, which are often couched in an informal conversation, and to match established academic research 
models and theories. As Reed (1997) suggests, the nature of the structure/agency debate raises ontological, analytical and methodological dilemmas.

\section{Initial findings}

Initial analysis of phase 1 data provided rich descriptive accounts of the influences on women's participation in the DCI. A number of themes emerged such as: type of influence (in the environment or person as agent); contextual factors (characteristics of the environment); and the processes or relationship between the person and environment. Figure 4 shows these themes as enhancements to Bandura's (1986) model. Table 3 indicates how the different aspects of the modified model assist in answering the research questions.

Figure 4. The initial areas of interest emerging from the data as relevant to Bandura's model

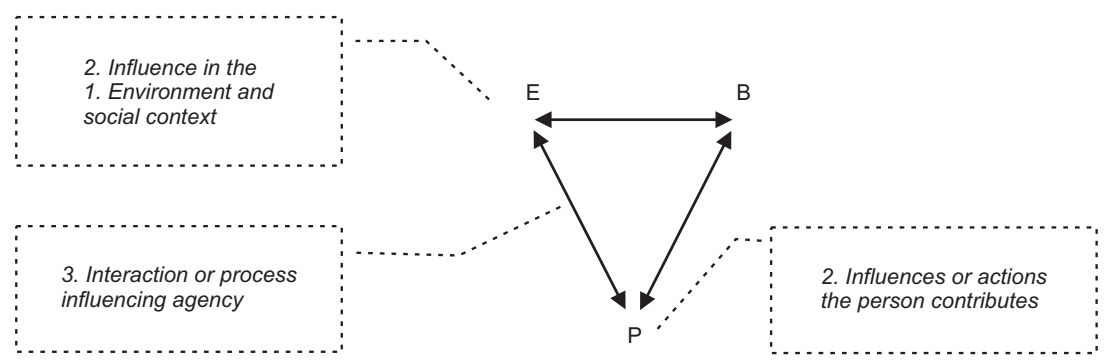

Table 3. How initial research findings help answer the research questions

\begin{tabular}{lll}
\hline Model aspect & Research questions & Evidence \\
\hline Context & $\begin{array}{l}\text { What is the context? (This includes } \\
\text { structural, social, historical, and } \\
\text { cultural.) }\end{array}$ & $\begin{array}{l}\text { The participants identified characteristics } \\
\text { of the environment and social context } \\
\text { along a lifespan/pathway. }\end{array}$ \\
Influences & $\begin{array}{l}\text { What are the influences? (Are these } \\
\text { similar to previous research or is } \\
\text { there variation?) }\end{array}$ & $\begin{array}{l}\text { Participants identified a range of } \\
\text { influences. (e.g. stereotypes, maternity } \\
\text { leave). }\end{array}$ \\
Processes & $\begin{array}{l}\text { How are influences manifested and } \\
\text { why do they influence agency? }\end{array}$ & $\begin{array}{l}\text { The data illustrated the interaction or } \\
\text { processes between the environment and } \\
\text { the agentic person. Mechanisms of SCT } \\
\text { could be used to explain this interaction. }\end{array}$ \\
& &
\end{tabular}


A discussion of these initial findings follows below. Data analysis and synthesis is supported by direct quotes from participants and the support found in the literature. Commencing with a description of the participants' contexts from a "pathways along a lifespan" perspective, the discussion then illustrates how Bandura's theory can help explain the influences on agency and participation. Several influences, such as existing gender ratios, parental responsibilities and access into the games industry, are described. The process of interaction, or relationship, between the person and the context is subsequently illustrated by a specific influence, that of gender and occupational stereotypes.

\subsection{Context - pathways along a lifespan}

At the outset, the case study aimed to understand the context of DCI organisations as experienced by women. However it became evident early in the interview process that participants perceived that influences are manifested over a "lifespan", including childhood, educational and workplace contexts. Gürer and Camp (1997, para. 1), presenting the "shrinking pipeline" metaphor, suggest women are a minority in the ICT workplace due to a gradual decline of participation rates within such contexts. The research findings indicate that this pipeline can be interpreted as a "pathways along a lifespan" concept, where the influence of factors varies over a lifespan and each woman responds differently, creating her own pathway as she responds to influences. Similar lifespan concepts have also been identified in other domains, such as career development theories (Gottfredson, 1981; Super, 1990; Lent et al., 1994), and more recently in the ICT domain (Moore et al., 2006). For this study, the lifespan approach is utilised "as a perspective rather than a theory" (Baltes and Reese, 1984) providing a general orientation for research.

A "pathways along a lifespan" approach suggests that as a person travels through the different stages of their life, they are exposed to certain environments and influenced by social agents within those environments. Study participants consistently identified that in their childhood, the social agents of greatest influence were parents and at the late education stage friends or peers. Although a family, education, and work pathway may be typical in certain cultures, the pathway does not suggest there is a fixed progression through social contexts. This has particular relevance for interpreting our findings where the industry context has unique characteristics, for example the lack of computing 
qualifications of a significant number of ICT professionals (Wardle and Burton, 2002). Furthermore, DCI sectors may challenge a traditional lifespan notion where, although age may mean seniority in the workplace, in the games industry it is not uncommon for a forty-year-old to be retraining to enter the industry while an eighteen-year-old already has five years' experience and is in an upper management role or is even, as one participant described, a "garage CEO". ${ }^{4}$ Therefore it is important to recognise that although there may be some similarity of influences along a "typical" pathway, there are what Trauth et al. (2004) term "individual differences".

How an influence may vary during a lifetime was evident when participants discussed gender stereotypes associated with ICT. They suggested that although gender stereotyping may adversely influence younger girls, there would be less of an influence on women working in the industry. Previous research also suggests young girls are more likely to choose career paths (or interests) that are gender appropriate (Miller and Budd, 1999; O'Connor and Goodwin, 2004) rather than those "traditionally performed by the opposite sex" (Francis, 2002; Miller and Hayward, 2006). There was evidence that stereotypes became less of an influence as the women developed a sense of personal agency through mechanisms such as gaining confidence from direct industry experience.

Even though that years after starting in the workplace, retrospectively I can go, oh, I wasstillreallylackingconfidence, itwasbuildingup. Ithinkalotoftheexperiencessince workingprofessionally havebeen really positive, veryfewsetbacks.

Several participants reflected how surprised they felt when they realised "it wasn't as hard as they thought" and that "they just picked it up" (in reference to computing skills). Bandura's Social Cognitive Theory may ascribe these views to mastery experiences and receiving positive feedback or reinforcement, which strengthens a sense of self-efficacy. Trauth (2002: 109) identifies similar themes in her study

\footnotetext{
${ }^{4}$ A garage CEO is a person who has given themselves the title of Chief Executive Officer of a company they operate from a home or a garage. The term can suggest illusions of grandeur but also has some credibility as several successful business people in IT started their own business in this manner.

${ }^{5}$ Explanation of the coding of participants' comments, for example, g1 indicates the first interviewee is from the games industry or $\mathrm{m} 3$ indicates the third interviewee from the multimedia industry.
} 
of women working in IT, where a "personal characteristic that is consistently represented in the respondents' personal life-histories is their strength and self-confidence".

\subsection{Influences - environment and agent}

Influences identified in the initial research findings aligned with many of those previously cited in the key "gender in IT" literature, in particular those that can be described as social and structural influences, including stereotypes perpetuated by the media (Gill, 2002) and the "long hours" associated with certain occupational roles in the DCI. Additionally, there were a number of interesting variations that occurred as a consequence of the person's or agent's actions, for example, a study participant who chose not to work those long hours. The nature of some of the influences arising from the data and identified by participants as significant for them, such as existing gender ratios, parental responsibilities and access into the industry, are presented below.

\subsubsection{Gender ratio}

It is important to note that current ratio imbalances, where women are in the minority in the workplace context, may lead to female DCI professionals often being evaluated first by gender and then by their ability (Valian, 1999). As Webster and Whitmeyer (1999) suggest, this evaluation is not only by those around them but also by the women themselves. Therefore stereotypes such as "women aren't interested in computing" can challenge women to conform to or transform such negative influences. As Oswald (2008: 197) suggests, "situations that heighten self-relevant stereotypes, both positive and negative, can result in a target assimilating to the stereotyped role". Participants stated that when such gendered stereotypes are triggered, maintaining confidence in their ability, or as Bandura might suggest, their self-efficacy, and acknowledgment from their peers of those skills were seen as an important way to remain feeling valued in workplace teams. As one participant noted, although her technical ability was intrinsically "gratifying", she felt it was important for her to "prove" her technical credibility to her male colleagues. Her emphasis was firstly on being perceived as a valued and skilled member of the team, and then "as a by-line" she could add "and I'm a girl!" (g2). When asked how establishing her technical proficiency had been an in- 
fluence within the workplace context, she noted it made the males "more comfortable in an environment where slowly bit by bit more females are starting to join the industry". Furthermore, this example may illustrate the need for the participant to maintain their credibility within what Bandura (2000b, 2001) describes as "collective" agency.

For Bandura (1999: 35), agency not only suggests that people are "partly the products of their environments", but by selecting, creating, and transforming their environmental circumstances they are creators of environments. Participants displayed a self-awareness of the need to be active in responding to those environmental circumstances which made them feel "different", marginalised or like the "odd girl out" (Trauth, 2002). The women in one games company instigated "ladies lunches" in response to the low number of women employed in the organisation and also to the distribution of the women in the work environment. These lunch events were held on a regular basis and provided an opportunity to informally network with other women in the company. This initiative was seen as important by the participants, as the company's rapid growth had lead it to becoming "so big all the girls had sort of been scattered around" and that they might not "even pass each other in the corridor", which led them to feeling they were in a "minority" (g1). This type of social support may enable both proxy and collective agency in a number of ways, but more simply it assists women to identify with "a collective" within the workplace.

\subsubsection{Parental responsibilities}

Maternity leave is a specific example of how parental responsibilities can influence participation. Firstly, it is evident that the current male to female ratio seems to have influenced work practices. As one participant noted, the games production organisations have not "had to think about maternity leave" (g1), as no one at her company had taken maternity leave. "Like [this company] is fantastic with paternity leave but there's no such thing as maternity leave. I'm pretty sure I'll be one of the first to get maternity leave". Similarly, another participant commented there wasn't "... any kind of maternity pay or anything like that. And you know they probably don't have to because they're all men working in the industry" (g6).

Even if the issue of maternity leave was to be clarified, many of the women did not believe that they could have children and continue work- 
ing in the DCI. A number of reasons were provided such as: the lack of role models, little or no option to work part-time or to have flexibility, and the long hours expected in some situations. The majority of participants could not identify a female role model who was continuing with her career and managing family commitments. One participant, who has a degree in computer science and several years' experience as an artificial intelligence programmer, spoke of leaving the industry when she was ready to have children because she believed there was little chance of part-time work. "And I'd love to do that, but try telling a games company that you're only going to work four days a week ..." (g9).

The long hours, or perception of long hours, within the ICT industries has been cited as one of the "barriers" to women's participation in ICT (Whitehouse and Diamond, 2005; Clayton and Beekhuyzen, 2004; Ahuja, 2002). Participants identified that there was a "long hours" culture in some organisations. They also highlighted how their commitment or "passion" for work has the potential to be compromised by the industry setting up unsustainable expectations of working long hours.

It's a cycle in that you know everyone is passionate about work to put in these hours, so then it's expected, and so then it becomes the norm and then everyone else has to put in. It's a labour of love. And that's the same sort of people you get to work ridiculous hours.

Several participants challenged the "norm" by actively choosing to not work longer than they believed to be reasonable. The data also suggests that this choice was role dependant, differed between types of organisation (public and private), and was heavily influenced by project lifecycles.

The data seems to indicate that industry demands may not only directly influence women's immediate decisions to participate but also their future decisions. This seemed particularly evident where, due to a perceived incompatibility with their workplace roles and a future "gendered burden of care" (Liff and Ward, 2001), the participants suggested they would leave the industry. Bandura (1997) might describe this as participants "selecting" themselves out of the industry. Interestingly, this perception of incompatibility was not based on direct experience (as many did not yet have children or know of women who did), but rather vicarious experience where the women had observed the impact of industry demands on their male colleagues who were trying to manage their family commitments. 
In this industry, I would be concerned about having a family just because seeing the guys at work who are just there all the time and I know they've got babies at home that they should be spending time with, and they don't have the opportunity because we're on deadlines.

The issue of future family responsibilities exposed a need to consider the desire to participate over a lifespan. It was not only past and current experiences that seemed to be influencing agency but also the participants' future desire to have a work-life balance and a family. None of the participants from the games sectors had children and only one participant from the multimedia industry had recently become a parent. This may be indicative of an industry which is comprised of a young workforce whose current priorities may not include parenting. The following comment from a participant who holds a $\mathrm{PhD}$ and works as a games designer raises workforce concerns for the games industry, as it suggests a perceived future incompatibility between work and family for women currently working in the sector.

I guess it's usually a really young industry so there's a lot of people in their twenties that don't have kids and aren't married, aren't really thinking of having kids at the moment. I guess I haven't really thought about it, like I'm working on my career first, and I imagine that it would pretty much come to a halt if I did decide ...

\subsubsection{Access into the industry}

Participants who had made an explicit decision to pursue pathways to work in the DCI industry found initial entry one of the most difficult barriers to overcome, noting that social relationships and connections were a positive influence in gaining access. They reported that these connections or "informal networks" (Gill, 2002) could occur in unlikely places, for example "having friends who are involved in the industry is a good way to start" (m5). Only a few of the women reported having applied for their current positions through an advertisement. Instead, they had heard of the position through social acquaintances such as roommates. Several others had formally applied for positions and had had many rejections. Therefore, there was, for many of the participants, an element of luck or "serendipity" (Webb and Young, 2005) or "fortuity" (Bandura 2006: 166) in knowing someone, more often than not 
a male, who had already gained employment in the sector, and who could facilitate access through "proxy agency" (Bandura, 2000). One particular example involved a woman who, whilst working in a café, became friends with the "guys" from a nearby games company who came in regularly for coffee. She said, "I heard a lot about how work was going, what kind of hours they were working, all the social kind of things" (g7). Although she had "loved" playing on a computer as a child (with her brother) and "spent a lot time, messing around with DOS and all that sort of thing", and in her university days formed an "Atari fan club", it was not until she had an insight into the conditions of working in a games company that she even considered it as a career.

The women who responded that they had actively sought information about entering the industry said that the internet was a key source of information, primarily the websites of games companies. However, the lack of credible information about roles in the industry was identified by participants as a key negative influence.

\subsection{Processes - mechanisms of interaction}

There is evidence that the theoretical framework offered by Bandura can help us begin to identify influences and the context in which they occur, as well as provide explanation about how the influences are manifested and why this may affect women's agency and, ultimately, participation. Participants utilised terms and concepts similar to those presented in Bandura's theory, such as the influence of "role models", negative "feedback" or reinforcement, and mastery experiences. One particular influence identified by participants, that of "gender and occupational stereotypes", can be explored further using the SCT scaffold.

\subsubsection{Gender and occupational stereotypes and agency}

Stereotypes have been widely cited as a negative influence on women's participation in the ICT industry (see Gürer and Camp, 2002; Joshi and Kuhn, 2001; Clayton and Beekhuyzen, 2004). Beyond what one participant (who was a programmer) identified as an overt example, where "a small minority of men hold stereotypes against women" (g3), manifestation of "stereotyping" was described by participants as including: rolemodelling in childhood, under- and misrepresentation of women in the media, gendered and occupational norms within the organisational culture, and even the perpetuation of stereotypes by the women themselves. 
When discussing a potential relationship between stereotyping and a sense of agency, it must be noted that, as Ramsey and McCorduck (2005) suggest, it is difficult for researchers to describe aspects of culture such as "systemic stereotyping, dualism, and devaluation". Indeed, participant responses varied when they were asked to describe the manifestation of stereotypes in their various organisational environments. Although a majority of participants suggested there were not many negative influences, they did describe what Webb and Young (2005) might identify as "subtle" factors. One participant in the games industry replied that she "was sort of racking [her] brain to try to think of a negative in that context" (g2) that she had personally experienced. She described feeling awkward in her "immediate sphere of daily life" when her colleagues seemed to refrain from swearing in front of her, apologising if they accidentally did so. She felt frustrated that, even after "being together for so many years" and "feeling comfortable working", the apology came because she was "one of the only women they see in their day". Insightfully, the participant suggested that her colleagues' actions were not malicious. However, she described how the actions triggered her gender stereotypes against herself, making her feel like a "girl". She asked herself "what else did they think" and how else did they modify their behaviour around her? "Are they doing other things to accommodate this woman in their presence ... and how far does it go ... the way they consider the women in our company?" (g2). Although identified as a "minor thing", another participant felt that if the males couldn't swear freely, "if they couldn't interact with each other in that natural way because there's a women present", then "suddenly that would introduce gender problems" (g7). This triggering of gender stereotypes seemed to not only influence participants self-belief or personal agency, but highlighted their need to fit into the team and not to be treated any differently to the male workers, fostering what Bandura (2000: 76) describes as a "group's capability operating as a whole" or "collective agency".

We can further refine our understanding about how stereotypes influence agency or participation by asking: what, where, how and why sub-questions. If participants identified experiencing negative gender stereotypes in their youth (in relation to a women's capacity to work with computers), this would identify what the influence is, i.e. gender stereotypes. How the factor is an influence is explained when participants describe their experiences of "verbal persuasion" (see Bussey and Bandura, 1999) by teachers and peers, and a lack of positive female role models. Participants may also identify the context by specifying where 
the influence manifested itself e.g. at school or other social settings. In recounting how this lowered their "self-efficacy" (see Bandura, 2000) towards using computers, leading them to refrain from joining in certain activities because of their desire to fit into the collective's normative expectations, they provide an explanation of why it influenced their agency. However, when participants provide an account of how they built up their low confidence over time, from the negative influence earlier in their lifespan through positive or mastery experiences in the workplace, they provide an account of how their actions (or the mechanisms of agency) have aided their participation.

\section{Sphere of Influence - the proposed model}

The conceptual Sphere of Influence model has emerged from the analysis of the participants' descriptions and the theoretical framework. As Figure 5 illustrates, the initial model (Figure 4) has evolved to provide a way to organise and understand the emergent data. The key categories are the influences within the environment and within the person or agent, and the processes identified in the "emergent interaction".

Figure 5. An early representation of the "Sphere of Influence" model

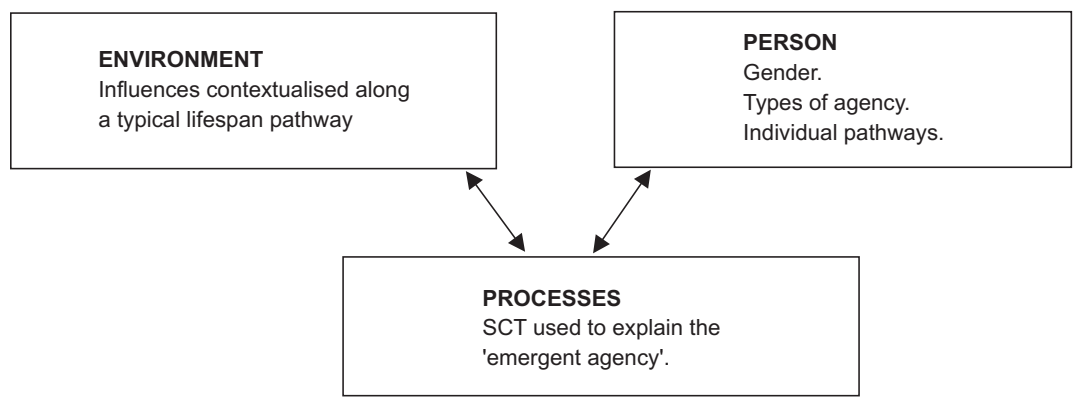

During data analysis, several themes or categories were identified that might not only be illuminated by SCT but could also build on aspects of Bandura's SCT triadic model (2001). In particular, at this stage they might provide a level of granularity to the environment category. Figure 6 illustrates that participants identified the characteristics of the environment or context as being:

1. cultural

2. mediated 
3. socialisation contexts (family, education, work and communities of practice) and social agents (parents, friends, peers, teachers, colleagues, employers)

4. available resources

Figure 6. An expansion of the "environment" category from the "Sphere of Influence" model

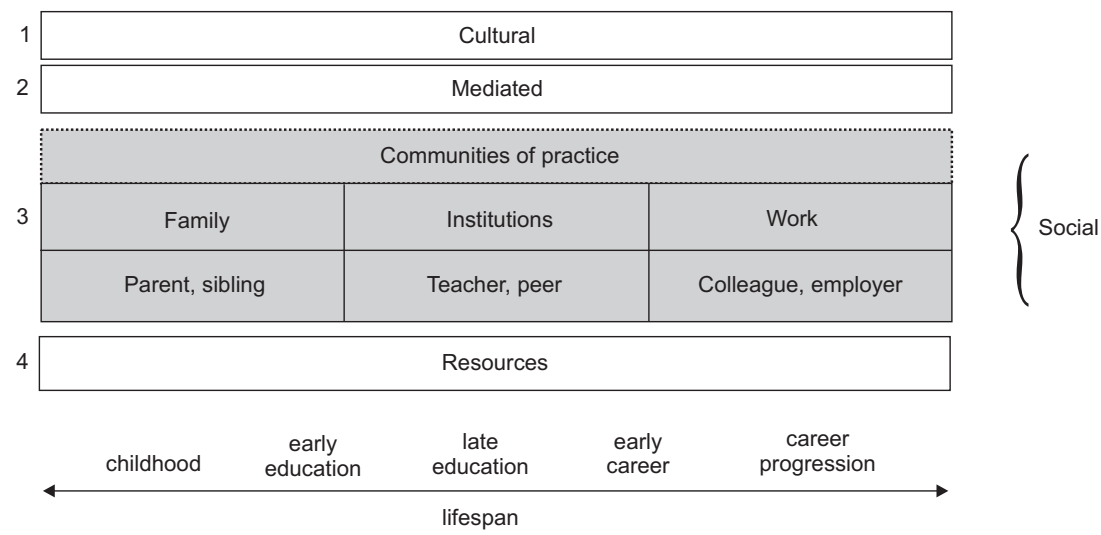

As Figure 6 suggests, influences appear to be manifested in the environment as: (1) cultural phenomena, formed by historical, sociocultural, economic, legal or political influences. These macro level distal "cultural" norms are mediated or perpetuated by the (2) media in its various forms such as literature, television and via technologies such as the internet. Furthermore, proximal influences such as (4) resources, including learning resources, or simply access to technology, can be an influence. The (3) social category encompasses socialisation agents where mechanisms, such as verbal persuasion and role-modelling, across a number of lifespan contexts, such as family, institution, workplace and communities of practice, may influence the individual.

\section{Conclusion}

This case study initially began with a focus on identifying the influences on participation, in DCI organisations, as perceived by women working in technical roles in the sector. However it became evident from the data that influences have manifested themselves over a lifespan for these women. Experiences from their childhood, education, the indus- 
try itself, and future considerations such as beginning a family, all appear to exert influence on a cumulative decision to participate.

The findings of this study support previous research that women are confronted with negative influences that may discourage their participation in an ICT career pathway. This research also highlights that women who remain in the industry have encountered negative influences and importantly, they are able to identify the ways in which they responded to overcome potential barriers or were able to embrace the support available within their environment. Therefore the research adds understanding to what is at times presented as a list of barriers. Harnessing the theory of human agency, our data suggests that in being active agents, women exert an element of control over their environment. Importantly, we find that women participating in the DCI context are not entirely responsible for their circumstances. For example, they are not responsible for barriers such as other people's sexist attitudes. Rather, understanding what fosters their sense of agency identifies how these barriers were overcome.

In addition to providing rich descriptive insights into the experiences of women in the DCI sectors, this paper has described the suitability of SCT as a theoretical framework with which to explain a participant's sense of agency and therefore participation. The Sphere of Influence model is proposed as a framework to explore the complex, socially situated participation of women in the DCI by identifying the influences, contexts and processes involved. The findings to date provide an initial enhancement to Bandura's SCT model in adding a level of granularity to the environment category. This interpretive study has allowed "unique and individual experiences" to be conveyed for the "person" category, maintaining a balance between describing individual differences and providing generalisation in a non-essentialist manner. The next phase of the exploratory case study will involve data collection from the organisational context through interviews with female DCI professionals, their colleagues and employers, and an analysis of secondary sources of data. It is hoped the Sphere of Influence model will be further developed.

\section{References}

ADAM, Alison, HOWCROFT, Debra, \& RICHARDSON, Helen (2004). A decade of neglect: Reflecting on gender and IS. New Technology Work and Employment, 19(3). 
ADYA, Monica, \& KAISER, Kate M. (2005). Early determinants of women in the IT workforce: A model of girls' career choices. Information Technology and People, 18, 230-259.

AHERN, Kathryn (1999). Ten tips for reflexive bracketing. Qualitative Health Research, 9(3), 407-411.

AHUJA, Manju K. (2002). Women in the information technology profession: A literature review, synthesis and research agenda. European Journal of Information Systems, 11, 20-34.

ABS (2008a). Australian Culture and Leisure Classifications. (No. 4902.0). Canberra: Australian Bureau of Statistics. Australia. Retrieved on 10 October 2008 from <http://www.abs.gov.au/AUSSTATS/abs@.nsf/DetailsPage/4902.02008\%20 (Second\%20Edition)?OpenDocument>

ABS (2008b). Digital game development services (No. 8515.0). Canberra: Australian Bureau of Statistics. Australia. Retrieved on 10 October 2008 from $<$ http://www. abs.gov.au/>

BALTES, Paul B., \& REESE, Hayne W. (1984). The life-span perspective in developmental psychology. In M. H. Bornstein \& M. E. Lamb (Eds.), Developmental psychology: An advanced textbook (pp. 493-531).

BANDURA, Albert (1986). Social Foundations of Thought and Action: A Social Cognitive Theory. Englewood Cliffs, N.J.: Prentice-Hall

BANDURA, Albert (1997). Self-efficacy: The exercise of control. New York: W. H. Freeman.

BANDURA, Albert (1999). Social cognitive theory: An agentic perspective. Asian Journal of Social Psychology, 2, 21-4.

BANDURA, Albert (2000). Self-efficacy: The foundation of agency. In W. J. Perrig \& A. Grob (Eds.), Control of human behaviour, mental processes and consciousness (pp. 17-33). Mahwak, NJ: Erlbaum.

BANDURA, Albert (2000b). Exercise of human agency through collective efficacy. Current Directions in Psychological Science, 9, 77-80.

BANDURA, Albert (2001). Social cognitive theory: An agentic perspective. Annual Review of Psychology, 52, 1-26.

BANDURA, Albert (2002). Social cognitive theory in cultural context. Applied Psychology: An International Review, 151, 269-290.

BANDURA, Albert (2006). Toward a psychology of human agency. Perspectives on Psychological Science, 1, 164-180.

BASKERVILLE, Richard, \& LEE, Allen S. (1999). Distinctions among different types of generalizing in Information Systems research. In O. Ngwenyama \& J. I. Degross (Eds.), New information technologies in organizational processes: Field studies and theoretical reflections on the future of work (pp. 33-54). Boston: Kluwer Academic.

BATT, Rosemary, CHRISTOPHERSON, Susan, RIGHTOR, Ned, \& JAARSVELD, Danielle V. (2001). Net working: Work patterns and workforce policies for the new media industry. Washington DC: Economic Policy Institute.

BEEKHUYZEN, Jenine, NIELSEN, Susan, \& VON HELLENS, Liisa (2003). Challenging the dualisms in female perceptions of IT work. The Australian 
Journal of Information Systems, 10(2), 105-114. Retrieved on 2 August 2007 from <http://hdl.handle.net/10072/5963>

BENBASAT, Izak, GOLDSTEIN, David K., \& MEAD, Melissa (1987). The case research strategy in studies of information systems. MIS Quarterly, 11(3), 369-386.

BERGER, Peter, \& LUCKMAN, Thomas (1966). The social construction of reality: A treatise in the sociology of knowledge. Garden City, New York: Anchor Books.

BHASKAR, Roy (1979). The possibility of naturalism. Brighton: Harvester Press.

BHASKAR, Roy (1994). Plato etc. London: Verso.

BOGDAN, Robert, \& BIKLEN, Sarah (1992). Qualitative research for education: An introduction to theory and methods. Needham Heights MA: Allyn and Bacon.

BOURDIEU, Pierre (1986). The forms of capital. In J. G. Richardson (Ed.), Handbook for theory and research for the sociology of education (pp. 241-258).

BRONFENBRENNER, Urie (2004). Making human beings human: Bioecological perspectives on human development. Sage Publications.

BUSSEY, Kay, \& BANDURA, Albert (1999). Social cognitive theory of gender development and differentiation. Psychological Review, 106, 676-713.

CAMPBELL, Donald (1975). Degrees of freedom and the case study. Comparative Political Studies, 8, 178-185.

CASTELLS, Manuel (1996). The rise of the network society. Cambridge: MA Blackwell Publishers.

CLAYTON, Kaylene, \& BEEKHUYZEN, Jenine (2004). Changing ICT career perceptions: Not so geeky? 1st International Conference on Research on Women in Information and Communication Technology. 28-30 July, Kuala Lumpur, Malaysia.

COHOON, Joanne M., \& ASPRAY, William (Eds.). (2006). Women in information technology: Research on underrepresentation. Cambridge, MA: MIT Press.

CONNELL, Robert W. (2002). Gender. Cambridge: Polity Press.

CONTU, Alessia (2005). Professionals in love, or the cool, creative and entrepreneurial subjects of new media production. 4th International Critical Management Studies. 4-6 July, University of Cambridge.

CRAIB, Ian (1992). Modern social theory: From Parsons to Habermas. Hemel Hempstead: Harvester Wheatsheaf.

DCITA (2005). Australian digital content industry futures plan. Prepared for The Department of Communications, Information Technology and the Arts (DCITA) by the Centre for International Economics, March 2005. Retrieved on 19 September 2006 from <http://www.dcita.gov.au/__data/assets/pdf_file/37474/ Appendix_C.2_Australian_digital_content_futures.pdf $>$

DENNING, Peter (1998). Information technology: Developing the profession. Unpublished discussion document. United States: George Mason University.

DOBSON, Philip J. (2001). Longitudinal case research: A critical realist perspective. Systemic. Practice and Action Research, 14(3), 283-296.

FLORES, Fernand, \& GRAY, John (2000). Entrepreneurship and the wired life: Work in the wake of careers. London: Demos. 
FRANCIS, Becky (2002). Is the future really female? The impact and implications of gender for 14-16 year olds' career choices. Journal of Education and Work, 15(1), 75-87.

GENEVE, Anitza, NELSON, Karen, \& CHRISTIE, Ruth (2008). Passion, women and the games industry: Influences on women's participation in the Australian digital content industry. Women in Games Conference, 10-12 September, Warwick University. United Kingdom.

GIBBS, Graham, \& TAYLOR, Celia (2005). How and what to code. Online QDA. Retrieved on 6 May 2008 from <http://onlineqda.hud.ac.uk/Intro_QDA/how_ what_to_code.php>

GIDDENS, Anthony (1979). Central problems in social theory. Berkeley: University of California Press.

GIDDENS, Anthony (1984). The constitution of society. Cambridge: Polity.

GIDDENS, Anthony (1989). Sociology. United Kingdom: Polity Press.

GILL, Rosalind (2002). Cool, creative and egalitarian? Exploring gender in projectbased new media work in Europe. Information, Communication and Society, 5(1), 70-89.

GILL, Rosalind (2007). Technobohemians or the new cybertariat? Understanding contemporary new media work. Amsterdam: Institute of Network Cultures.

GOTTFREDSON, Linda S. (1981). Circumscription and compromise: A developmental theory of occupational aspirations. Journal of Counseling Psychology, 28, 545579.

GREGOR, Shirley (2006). The nature of theory in information systems. MIS Quarterly, 30(3), 611-642.

GRIFFITHS, Marie, KEOGH, Claire, MOORE, Karenza, TATTERSALL, Angela, \& RICHARDSON, Helen (2005). Managing diversity or valuing diversity?: Gender and the IT labour market. In F. Neiderman \& T. Ferratt (Eds.), IT workers: Human capital issues in a knowledge-based environment. Hershey, PA, USA: Information Science Publishing(pp. 303-330).

GRUNDY, Anna F. (1996). Women and computers. Exeter: Intellect Books.

GÜRER, Denise, \& CAMP, Tracy (2002). Investigating the incredible shrinking pipeline for women in computer science (Final report). National Science Foundation Project 9812016. Retrieved on 6 May 2006 from <www.acm.org/women/ pipeline-finalreport_ver_2.doc>

HOUGHTON, John (2001). Impact of the ICT industry in Australia. Report for Australian Computer Society. Retrieved 17 September 2006 from <http://www. acs.org.au/notices/itcimpact.pdf>

IGDA (2005). Game developer demographics: An exploration of workforce diversity. International Games Developer Association. Retrieved on 20 April 2008 from <http://www.igda.org/diversity/IGDA_DeveloperDemographics_Oct05.pdf>

JONES, Melinda. (1991). Gender stereotyping in advertisements. Teaching of Psychology, 18, 231-233.

JOSHI, Kshiti D., \& KUHN, Kristine (2001). Gender differences in IS career choice: Examine the role of attitudes and social norms in selecting IS profession. Proceedings of the ACM SIGCPR Conference, 121-124. San Diego, California. 
KLEIN, Heinz K., \& MYERS, Michael D. (1999). A set of principles for conducting and evaluating interpretive field studies in information systems. MIS Quarterly, Special Issue on Intensive Research, 23(1), 67-93.

LEADBETER, Charles, \& OAKLEY, Kate (1999). The independents: Britain's new cultural entrepreneurs. London: Demos.

LECOMPTE, Margaret D., \& PREISSLE, Judith (1993). (2nd ed.) Ethnography and qualitative design in educational research. San Diego: Academic Press.

LENT, Robert W., BROWN, Steven D., \& HACKETT, Gail (1994). Monograph: Toward a unifying social cognitive theory of career and academic interest, choice, and performance. Journal of Vocational Behavior, 45, 79-122.

LIFF, Sonia, \& WARD, Kate (2001). Distorted views through the glass ceiling: The construction of women's understandings of promotion and senior management positions. Gender, Work and Organisation, 8(1), 19-36.

MERTON, Robert K. (1968). Social theory and social structure. New York: The Free Press.

MILLER,Linda, \&HAYWARD, Rowena (2006). New jobs, old occupational stereotypes: gender and jobs in the new economy. Journal of Education and Work, 19(1), 67-93. Retrieved January 2008 from <http://dx.doi.org/10.1080/13639080500523000>

MILLER, Linda, \& BUDD, Jacqueline (1999). The development of occupational sexrole stereotypes, occupational preferences and academic subject preferences in children at ages 8, 12 and 16. Educational Psychology, 19(1), 17-35.

MOORE, Karenza, GRIFFITHS, Marie, KEOGH, Claire, RICHARDSON, Helen, \& TATTERSALL, Angela (2006). Inclusion through the ages? Gender, ICT workplaces, and life stage experiences. In E. Trauth, D. Howcroft, T. Butler, B. Fitzgerald \& J. D. Gross (Eds.), Social inclusion: Societal and organisational implications for information systems. Springer, New York (pp. 153-168).

MOORE, Karenza, GRIFFITHS, Marie, \& RICHARDSON, Helen (2005). Gender on the agenda: Flexible working and work-life balance in the UK ICT industry. 6th International Women in Computing (WIC) Conference, 14-15 July 2005, University of Greenwich London UK.

NEWMARCH, Eileen, TAYLOR-STEELE, Sandra, \& CUMPSTON, Andrew (2000). Women in IT - What are the barriers? Network of Women in Further Education Conference "Net Gains: Women, Information Technology and Emerging Issues", March 22, Department of Education, Science and Training. Australia.

O'CONNOR, Henrietta, \& GOODWIN, John (2004). Girl's perceptions of adulthood in the 1960s. Chapter 4 in J. Pilcher, C. Pole, \& J. Williams (Eds.), Young people in transition. Becoming citizens? London: Palgrave.

OSWALD, Debra L. (2008). Gender stereotypes and women's reports of liking and ability in traditionally masculine and feminine occupations. Psychology of Women Quarterly, 32, 196-203. Retrieved on 22 May 2008 from <http://www. ingentaconnect.com/>

OTHMAN, Roslina, \& NOORDIN, Mohamad F. (2005). A general framework for collecting and interpreting gender disaggregated data with special reference to women pursuing ICT as a career. International Conference on Reaching Out, Norway, August 2005. 
PANTELI, Niki, STACK, Janet, ATKINSON, Malcolm, \& RAMSAY, Harvie (1999). The status of women in the UK IT industry: an empirical study. European Journal of Information System, 8, 170-82.

PERRONS, Diane (2003). The new economy and the work-life balance: Conceptual explorations and a case study of new media gender. Work \& Organization. 10(1), 65-93.

PETTIGREW, Andrew M. (1985). Contextualist research and the study of organizational change processes. In E. Mumford, R. Hirschheim, G. Fitzgerald, \& A. T. Wood-Harper (Eds.), Research Methods in Information Systems. North Holland, Amsterdam.

PRATT, Andy C. (2000). New media, the new economy and new spaces. Geoforum, 31, 425-436.

PUTNAM, Robert D. (1993). The prosperous community: social capital and public life. In American Prospect, 4(13).

RAMSEY, Nancy, \& McCORDUCK, Pamela (2005). Where are the women in information technology? Report of literature search and interviews. Prepared by the Anita Borg Institute for Women and Technology (www.anitaborg.org) for the National Center for Women \& Information Technology. National Science Foundation under Grant No. 0413538. Retrieved on 2 August 2006 from <http://www.anitaborg.org/news/publications/wherearethe_women.pdf>

REED, Michael I. (1997). In praise of duality and dualism: Rethinking agency and structure in organisational analysis. Organisation Studies, 18(1), 21-42.

ROWLANDS, Bruce (2005). Grounded in practice: Using interpretive research to build theory. The Electronic Journal of Business Research Methodology, 3(1), 8192. Retrieved on 19 September 2006 from <http://www.ejbrm.com/vol3/v3-i1/ v3-i1-art7-rowlands.pdf>

SAVICKAS, Mark L. (2005). The theory and practice of career construction. In S. D. Brown \& R. W. Lent (Eds.), Career development and counseling: Putting theory and research to work. New York: Wiley.

SORENSON, Knut H. (2002). Love, duty and the s-curve. Retrieved on 20 May 2008 from <http://www.rcss.ed.ac.uk/sigis/public/deliverables/D02/1>

STAKE, Robert E. (1994). In N. K. Denzin \& Y. S. Lincoln (Eds.), Handbook of Qualitative Research. London: Sage.

STRAUSS, Anselm, \& CORBIN, Juliet (1990). Basics of qualitative research: Grounded theory procedures and techniques. Newbury Park, CA: Sage Publications.

SUPER, Donald E. (1990). A life-span, life-space approach to career development. In D. Brown, L. Brooks et al. (Eds.), Career choice and development: Applying contemporary theories to practice (2nd ed.) (pp. 197-261). San Francisco: JosseyBass.

SUPER, Donald E. (1992). Toward a comprehensive theory of career development. In D. Montross \& C. Shinkman (Eds.), Career development: theory and practice (pp. 35-64). Springfield, IL: Charles C. Thomas.

TEAGUE, Joy (1997). Structured review of reasons for the underrepresentation of women in computing. Proceedings of the Second Australasian Conference on Computer Science Education, University of Melbourne, Australia, 2-4 July. 
TRAUTH, Eileen M. (2002). Odd girl out: An individual differences perspective on women in the IT profession. Information Technology \& People, 15(2), 98-118.

TRAUTH, Eileen M., QUESENBERRY, Jeria L., \& MORGAN, Allison J. (2004). Understanding the under representation of women in IT: Toward a theory of individual differences. Proceedings of the ACM SIGMIS Computer Personnel Research Conference: Careers, culture, and ethics in a networked environment, SIGMIS'04, 2004, April 22-24. Tucson. AZ. ACM Press: USA. Retrieved on 2 August 2005 from the ACM Portal from The ACM Digital Library Database.

TRAUTH, Eileen M., NIELSEN, Susan H., \& VON HELlENS, Liisa A. (2003). Explaining the IT gender gap: Australian stories for the new millennium. Journal of Research and Practice in Information Technology, 35(1), 7-20. Retrieved on 2 August 2005 from the ACM Portal from the ACM Digital Library database.

VALIAN, Virginia (1999). Why so slow? The advancement of women. Cambridge, MA: The MIT Press.

VENKATESH, Viswanath \& MORRIS, Michael (2000). Why don't men ever stop to ask for directions? Gender, social influence, and their role in technology acceptance and usage behavior. MIS Quarterly, 24(1), 115-139.

WAJCMAN, Judy (2000). Reflections on gender and technology studies. In what state is the art? Social Studies of Science, 30(3), 447-64. Retrieved on 8 May 2008 from <http://sss.sagepub.com.ezp02.library.qut.edu.au/cgi/reprint/30/3/447>

WALSHAM, Geoff (1995). Interpretive case studies in information systems research: Nature and method. European Journal of Information Systems, 4, 74-81.

WALSHAM, Geoff (2005). Systems, signs \& actions. An international journal on communication. Information Technology and Work, 1(1), 6-18. Retrieved on 19 September 2007 from <http://www.sysiac.org/>

WARDLE, Caroline, \& BURTON, Lawrence (2002). Programmatic efforts encouraging women to enter the information technology workforce. SIGCSE Bull, 34(2), 27-31. DOI: <http://doi.acm.org/10.1145/543812.543824>

WEBB, Phyl, \& YOUNG, Judy (2005). Perhaps it's time for a fresh approach to ICT gender research? Journal of Research and Practice in Information Technology, 37(2), 147-160. Retrieved on 17 September 2006 from <http://www.jrpit.acs.org. au/jrpit/JRPITVolumes/JRPIT37/JRPIT37.2.147.pdf >

WEBSTER, Murray, \& WHITMEYER, Joseph (1999). A theory of second-order expectations and behaviour. Social Psychology Quarterly, 62(1), 17-31.

WHITEHOUSE, Gillian, \& DIAMOND, Chris (2005). Reproducing gender inequality: Segregation and career paths in information technology jobs in Australia. Keynote address to the 19th Annual Conference of the Association of Industrial Relations Academics of Australia and New Zealand (AIRAANZ), 10 February 2005, University of Sydney, Sydney.

YIN, Robert (1994). Case study research: Design and methods (2nd ed.). Beverly Hills, CA: Sage Publishing. 


\section{Part III}

\section{Policy-relevant research and experiences}





\section{Danica Fink-Hafner}

\section{Changing frameworks for research into factors affecting the role of women in research decision-making}

\section{Introduction ${ }^{1}$}

Social phenomena and social problems have taken on a new dimension in the context of the most recent wave of globalisation processes. ${ }^{2}$ Against this background, gender imbalance problems have ceased to be, to a greater or lesser extent, a matter of national politics or policy. This is why a more complex research strategy also needs to be developed.

The factors underlying women's marginal role in research and technology (R\&T) decision-making have been uncovered in many aspects of social life. While many of these are rooted in the structural and cultural characteristics of every society (such as the expected social roles of women in the family and other social organisations), recently a growing awareness of other factors can be detected. Besides local and national political (institutional and political-cultural) factors, there are transnational and supranational (global) economic, social and political factors which have taken on an increasingly significant role. Unlike the predominant thinking that there are various forms of state intervention in gender equality politics which can make a key difference in society and its subsystems, recent global economic trends have revealed the opposite. It is globalised economic factors which have proved to be most prominent in the relatively quick growth in the proportion of women in leading positions in firms with headquarters in the developed part of the world (see e.g. Cappelli and Hamori, 2004), and it is economic

\footnotetext{
1 This paper is partly based on the author's work within the framework of the Women in Research Decision Making expert group (WIRDEM) of the Directorate General for Research of the EU Commission. The WIRDEM report "Mapping the Maze: Getting More Women to the Top in Research" is also available as a printed publication at: http://ec.europa.eu/research/ science-society/document_library/pdf_06/mapping-the-maze-getting-more-women-to-thetop-in-research_en.pdf.

${ }^{2}$ Globalisation is understood as the ever broader, deeper and quicker linking of societies and states.
} 
(global market) competition which may bring about the "better use of all available human resources" - possibly also including a more genderbalanced occupation of positions in research decision-making.

Reference to the EU's place in world economic and scientific competition is found in the Lisbon Strategy in which EU member state governments and EU institutions commit themselves to improving the EU's ability to catch up with the world's leading economies. Within this framework, the improvement of opportunities for women in science ${ }^{3}$ has become a policy goal. Unlike the American example of firms directly adapting to world competition, at the EU level political initiatives have been undertaken to translate global economic competition pressures into a policy of creating fairer opportunities for women's access to R\&T, including access to R\&T decision-making.

Research into supranational phenomena (especially at the EU level) and interaction in the context of multi-level governance (especially policy-making and the monitoring of EU policy implementation in EU member and accession states) needs to be incorporated into policy-relevant research. In the context of growing network governance (Jones, Hesterly and Borgatti, 1997), social networking also contributes to the development of common perceptions, values and policy directions. It is thereby possible to reveal social construction through multi-level interactions of governmental and non-governmental policy actors having an impact on policy-making, as well as the implementation of policies at various levels of political authority. It is the current historically unique context of the interplay between the nation-state, the supranational political system of the European Union and the global supranational sphere which has opened up these new opportunity structures. It is precisely in the supranational sphere where various governmental, intergovernmental (such as the United Nations, the Council of the European Union, the Council of Europe) and non-governmental actors' activities

${ }^{3}$ On 27 May 2007, Commissioner Janez Potočnik urged the representatives of member states to report on the implementation of the Council's invitation of April 2005 to member states "to formulate ambitious targets for the participation of women in science, focusing on areas where women are seriously under-represented, and in particular, increase significantly the number of women in leading positions." In his letter, he pointed to the WIRDEM report, which is, among others, also based on the argument that the inclusion of women in science, including leading positions, is essential to stop European research falling behind in terms of international economic competition. In 2008, the Commission presented a report on "Benchmarking National Policies on Gender Equality in Science" (available at http://ec.europa.eu/research/science-society/document_library/pdf_06/benchmarking-policy-measures_en.pdf). 
are taking place in spite of the global "institutional void" (Hajer, 2003). Here governments are neither the sole actors in terms of intervening in policy-making nor the main driving force of social change. However, they remain important factors in governing the territory of (nation) states even when they are integrated into supranational systems. They may disseminate policy values and models or even serve as examples of "soft-law-making" (as in the case of certain Scandinavian countries in the gender equality field) and are obliged to take responsibility for the implementation of supranationally agreed policy orientations (e.g. those defined by the United Nations or the European Union) in domestic environments. Nevertheless, policy implementation chains - either when looking at intergovernmental policy directions adopted within the framework of the United Nations or at the EU level - are relatively long, and give many opportunities for other factors to prevent the formation of more gender-balanced decision-making structures and processes. This is why a new direction in the study of gender inequalities (both in general and specifically in R\&T decision-making) should not exclude previous research efforts, but instead integrate and upgrade them with new ones.

So far, research into gender differentiation in various fields (including academia and R\&D) seems to have chiefly focused on either: a) national case studies; b) comparing certain characteristics of countries; or c) looking at organisations (e.g. enterprises and research organisations). Research also seems to have been quite closed off within specific academic disciplines, including sociology, political science and organisational sciences. In the context of the most recent wave of globalisation (especially European integration processes), merely looking at individual countries (their social characteristics and policies, and their impact on the gender balance in various fields) and research units within the nation-state (individual social and political institutions, political communities at various levels of organisation, and enterprises) can no longer either sufficiently capture the complexity of all the important factors causing gender differentiation or identify policy mechanisms for reducing problematic social differentiation. The growing complexity of gender differentiation phenomena demands not only: a) a more complex sketching of all relevant interacting social and political layers from which gender inequalities are generated (micro, meso and macro levels); but also b) closer interdisciplinary collaboration; and c) the transcendence of national borders in research. 
The focus of this chapter is the new direction in interdisciplinary research. In order to capture new gender-related phenomena (as well as other social, economic and political phenomena) and to enhance policy debate on high quality research findings, it is important to take advantage of the a) various approaches and b) levels of analysis, as well as to c) upgrade research into the indigenous frameworks of nation-states/ societies by taking into account supranational social, economic and political phenomena and their mutual interplay.

This chapter contains three main sections. First, the new direction in research is presented. Second, an overview of existing research in relation to the new research direction in the case of Slovenia is analysed. Third, in the concluding remarks, some grey spots in research practices generally, and in Slovenia in particular, are identified, together with suggestions for a future research agenda.

\section{Frameworks for studying the role of women in research decision-making}

\subsection{Main theoretical and conceptual approaches}

Several main clusters of factors should be taken into account when trying to explain the existing situation of women's under-involvement in research decision-making. These can be explained through the following theoretical approaches and concepts: modernisation theory (macro level); multi-level governance; (social) constructivism; organisational cultural learning (micro level); and social capital (micro networking) (Table 1).

Modernisation theory (for an overview, see e.g. Turner, 1990; Baykan, 1990; van Vuht Tijssen, 1990) focuses on (relatively Eurocentric) historical social change involving the process of rationalisation and a change in the social world - the differentiation of various spheres of the life-world, the separation of the household and the economy, the creation of the institution of motherhood in the $19^{\text {th }}$ century, industrialisation, urbanisation, the bureaucratisation of economic, political and military practices, secularisation and the growing monetarisation of values. Ideally, modernisation processes within the national social system are expected to bring about changes in favour of more genderbalanced social roles and positions for women as they enter various social spheres by gaining access to the market, education and politics. Nevertheless, the modernisation approach must face the fact that equal rights between women and men are not self-evident and that formal 
gender equality is not automatically spilling over into a predominant culture and practice of gender equality in various social spheres. It goes as far as to recognise additional cultural and ideological factors which can stimulate or arrest social developments, but even in its post-modern variation, modernisation theory cannot fully explain the variations in achieving gender equality in otherwise similarly modernised societies or the specific timing of change towards a more gender-balanced distribution of decision-making positions, power and officially recognised honours (awards) in various fields, including research and technology.

Table 1. Theories, concepts and levels of analysis

\begin{tabular}{lll}
\hline Theories & Level of analysis & Main research focus \\
\hline Modernisation theory & macro & $\begin{array}{l}\text { social structures, values, norms, } \\
\text { social roles, usually researched } \\
\text { within the framework of } \\
\text { nation-states }\end{array}$
\end{tabular}

Theories and concepts explaining European integration processes

$\begin{array}{lll}\text { - (social) constructivism } & \begin{array}{l}\text { macro and meso } \\ - \text { multi-level interactions } \\ \text { between organisations } \\ \text { and/or individuals }\end{array} & \begin{array}{l}\text { the development of shared } \\ \text { conceptions of identity or } \\ \text { role which further influences } \\ \text { the creation of preferences } \\ \text { for further co-operation and } \\ \text { integration }\end{array} \\ & & \begin{array}{l}\text { EU policy-making and } \\ \text { implementation of EU policies }\end{array} \\ \text { - multi-level governance } & \text { meso } & \text { in EU member and accession } \\ \text { - policy networks } & \text { - policy processes } & \text { interaction among policy } \\ \text { actors in policy processes } & \text { countries } \\ \text { Organisational theories } & \text { micro } & \begin{array}{l}\text { organisational cultural learning, } \\ \text { social networking, social capital }\end{array}\end{array}$

Multi-level governance (e.g. Marks, 1996; Hooghe and Marks, $2001 \mathrm{a}$ and 2001b) is usually defined as a middle-range theory/concept of European integration processes that is helpful for understanding EU policy-making, and in which the implementation of common European policies gives an insight into policy processes which go beyond the traditional two-level game (national and supranational) and, in fact, portray governance more like a marble cake. It is a result of a complex web of interrelated decision-making arenas with multiple actors operating at different levels (van der Vleuten, 2007). International 
networking of (female) researchers ${ }^{4}$ and decision-makers at various levels, including those in national (para) state funding institutions have a positive impact on the development of sensitivity to gender issues (implying at least the continuous monitoring of the situation at various levels), the building of the social capital of the researchers involved, as well as the transmission of policy principles and values from more advanced countries and institutions to "laggards". Supranational actors and policies may not only put informal pressure on national level actors and policies, but may even be quite formal and use intervention. There have been cases where pressure "from above", the Commission and the European Court of Justice with its obligatory ruling for EU member states, has led to significant change in EU member states in some areas of gender equality policy, such as equal pay involving direct and indirect discrimination, equal treatment (also related to the use of masculine and feminine gender in job advertisements) and social security (see e.g. Mazey, 1988). This may be most efficient when combined with pressure "from below".

Social constructivism has developed as one of the so-called grand theories of European integration processes (e.g. Diez, 1999; the 1999 special issue of the Journal of European Public Policy on the social construction of Europe, edited by Christiansen, Jørgensen and Wiener; the 2000 special issue of the Journal of European Public Policy on women, power and public policy in Europe, edited by Sonia Mazey; Risse, 2004). The main thesis in explaining European integration processes is that interaction with other states, organisations, groups or individuals leads to shared conceptions of identity or roles which further influence the creation of preferences for further co-operation and integration. This quite recent research trend focuses on the transformative impact on the European state system and its constituent units while investigating

the impact of constitutive norms and rules; the role of ideas and communicative action; the uses of language and deliberative processes; the interplay of routinised practices, socialisation, symbolism and institutional interaction; and the interplay between agent identity and interests.

(Chryssochoouet al., 2003: 56)

${ }^{4}$ This not only includes networking through professional mobility, collaboration within international (e.g. European) research areas, and professional networks, but also networking via non-governmental professional organisations/lobbies and expert groups nominated by governmental institutions (such as the European Commission). 
This approach is considered capable of explaining variation in politics and policy, looking at variables which are usually left out when taking other approaches - the impact of intersubjectivity and social context (see e.g. the case study by Elgström, 2000). Phenomena like the creation of the EU's "soft law" (including the use of the open method of co-ordination in order to reduce women's under-representation in research and technology decision-making positions) as well as implementation processes of EU directives related to gender mainstreaming cannot be fully understood without this approach.

Organisational micro-level cultural learning and social capital (micro networking) approach (for an overview of key literature, see e.g. Dahlerup, 1988; Kanjuo-Mrčela, 2000; Harvard business review on women in business, 2005; Schmidt, 2005). Even when all three mentioned clusters of variables are active, it is at the micro-level (organisational level) where day-to-day problem-solving takes place. At least to some extent, this is an autonomous part of the broader social environment where organisational culture, organisational learning, employees' internal social networking and the formal and informal distribution of power do matter. What is especially important for understanding the field of research and technology is that women encounter many problems as a minority in male-dominated organisations. The consequences of being in the minority in an organisation, and which are mostly shared by others in a minority position, include (as noted by Dahlerup, 1988: 279): high visibility in terms of symbolising the entire sex (group) and stereotypes related to that group; role conflict (e.g. too feminine or too masculine); a lack of allies in the organisation; exclusion from informal networks; a lack of knowledge of the informal power structure and the recruitment process; a lack of personal power; a higher dropout rate; a lower rate of promotion; less efficiency; feeling uncomfortable in the dominant culture of the organisation; over-accommodation; sexual harassment; a lack of legitimate authority; no consideration of family obligations by the organisation; and exposure to double standards.

\subsection{Modernisation macro view findings}

Modernisation processes, especially the pace of cultural change, are mediated by the religious legacies, historical traditions and institutional structures of each country (Inglehart and Norris, 2003). These authors also stress research findings from the World Value Surveys 
1995-2001 showing that the move from the industrial to the post-industrial phase is not only bringing about a shift towards greater opportunities for women in university (tertiary) education, but also in cultural attitudes giving women a greater opportunity to move further up the career ladder within both professions and management. The biggest gap is seen between traditional agrarian societies and egalitarian post-industrial societies. In addition, results based on national-level data from the 43 societies included in the 1990 World Value Survey reveal that cultural change is a necessary but not a sufficient condition for the consolidation of gender equality across all major dimensions of life. The differences among advanced industrial nations (e.g. between Scandinavian countries, France, the United States and Canada) underline the fact that changes in the roles and statuses of women are not automatic and inevitable. Here, Inglehart and Norris (2003) stress that "top-down" policy initiatives adopted by the government can even "overcome" prevalent public opinion (paradoxically, giving examples of gender quotas in policies implemented by communist regimes). In addition, it is critical to bear in mind that women and men share the predominant attitudes, values and beliefs about the appropriate division of sex roles within any society (Norris, 2004: 184). In social contexts, with prevalent traditional values, women are limited by both the opportunities determined in societies and by their choice to limit themselves. Many UN- and EU-funded reports (e.g. She figures, ENWISE and WIRDEM reports), publications emerging out of EU-funded networks such as reports within the framework of the first social science ERA-net NORFACE, and the research and training network "Women in European Universities” (Siemieńska and Zimmer, Eds., 2007) provide many valuable statistics and other data describing national idiosyncrasies together with cross-country comparisons.

\subsection{Theories and concepts related to European integration processes and the current status of their research employment}

Since modernisation does not automatically spill over into all social fields, social constructivism theory and the concept of multi-level governance in the European Union (including a clear gender-mainstreaming policy principle) may be helpful in research at least: a) for transferring/disseminating/implementing new kinds of policies as the legal norms (public policies) of still modernising societies in candidate 
and member states; ${ }^{5}$ and b) in forming supranational policies and supranational policy instruments with a goal to reducing gender inequalities in various social fields (including research and development).

The meso level of policy research: multi-level governance and policy networks. Looking at the EU's multi-level governance (Marks, 1996; Hooghe and Marks, 2001a and 2001b) goes beyond looking at gender imbalances across nations. This is generally a political science concept that helps in the understanding of the functioning of a unique regional political system (the political system of the European Union) involving local, regional (where they exist), national and supranational authorities, complex networking and the activities of governmental and non-governmental actors in both policy-making and multiply-chained policy implementation. Due to the multi-level networking and interchange between various public and private actors, their relationship is changing (relative to the modern nation-state model). Only recently has research been published based on the employment of the multi-level governance approach for explaining the gendered impact of globalisation and contingent international processes from a multidimensional perspective, such as the impacts of a complex web of interrelated decision-making arenas with multiple actors operating at different levels (e.g. Van der Vleuten, 2007 - albeit not explicitly in the field of research and development). However, research policy in the EU has recently not only led to the creation of European research areas but also towards the use of the open method of co-ordination in the search for mechanisms to achieve the better inclusion of women at all levels of research, including leading positions in research decision-making. It has clearly found its place in an EU system which

at times offers women opportunities to improve their position, because its multi-tired structure empowers non-state actors and "sandwiches" state governments. It does not radically transform gender relations, because the underlying power relations are not altered to such an extent that the system becomes an "open" system with non-hierarchical tiers. Although the EU remains a political system characterised by power asymmetries, state and non-state actors pursuing power, ideas and interests do interact and produce outcomes that generally reflect a mixture of conflicting ideas and unintended consequences.

(Van der Vleuten, 2007: 189)

5 The EU has already had an impact on post-socialist EU candidate and accession states by introducing the gender-mainstreaming agenda into these countries and prompting these countries to comply with EU and international requirements (Galligan, Clavero and Calloni, 2007). 
The policy network concept, as developed in national frameworks (van Waarden, 1992), has also become useful for investigating an important functional role in EU governance by bringing together the interests of a variety of different actors in a highly differentiated polity marked by the fragmentation of policies and politics (Rhodes, 2003: 7). In line with the widespread belief held by social science scholars (see e.g. Börzel, 1997; Peterson and Bomberg, 1999; Kohler-Koch, 2002), a central role in the development and implementation of EU public policies and programmes is played by policy networks. These emerge when specific policy tasks can only be achieved through the exchange of information and resources possessed by a range of actors (Peterson, 1995: 76). In this context, policy-making is a collective exercise. The links between the various actors is a "game" in which all participants seek an advantage. Each uses its resources - legal, organisational, financial, political, or informational - to maximise their influence over outcomes while trying to avoid becoming dependent on other actors (Rhodes, Bache and George, 1996: 368). This concept has so far not been systematically applied when analysing policy-making and policy implementation relating to gender inequality in R\&T.

The theory of "European" social constructivism. The main research focus of this theoretical approach is on the social construction of Europe (the main authors here include Thomas Diez, J. T. Checkel and Thomas Risse). European integration processes are explained by the creation of shared conceptions of identity or role. Social constructivism (especially when combined with meso-level analysis - such as social and policy networks) can help us understand learning processes and policy transfers via social networking. While studies of the EU have paid increased attention to the role of identity, community, legitimacy and changing state sovereignty, gender dimensions (both generally and in the specific field of gender issues in research and development) remain relatively under-researched (Hansen, 2000). As many authors have recognised the need to employ this theoretical approach (as noted in the previous section), some case studies have started to appear that look specifically at gender issues in research and technology (see e.g. Pollack, and Hafner-Burton, 2000). Hoskyns (2004) points to certain research in the context of EU enlargement which provides a striking case for the salience of gender perspectives not only for EU newcomers, but also for older EU members. Since the constructivist approach is relatively recent, the usual research waves (identifying gender discrimi- 
nation in research and development; generating material on the formation and implementation of gender policies in the field; the challenging of old concepts and policies deriving from them; re-conceptualisation and constructing theories) are still quite underdeveloped or delayed, as is their level of feeding practical policy-making and implementation.

\subsection{Organisational (cultural) learning}

In the organisational literature, two previously developed paradigms (the discrimination-and-fairness paradigm and the access-andlegitimacy paradigm) have recently been amended by a third one: the organisation-beneficial-learning paradigm (Thomas and Ely, 2005). This last one was revealed as a result of empirical research into the changing attributes and careers of corporate executives under the pressure of growing global market competition (Cappelli, and Hamori, 2004). In the context of stronger demand for talent, "the hidden brain drain" (Hewlett, Luce and Southwell, 2005) of highly qualified female managers and would-be managers has become a problem for the (global) competitiveness of individual enterprises, including the most stable and biggest American corporations. It has been an economic force driving more research into possible organisational mechanisms which could enable enterprises to maximise the use of all talented employees (including females) at all organisation levels (including higher level management). The advice emerging from the field here includes "life-friendly policies" based on ending the Zero-Sum Game philosophy (Friedman, Christensen and Degroot, 2005) and the defining of pre-conditions for making the paradigm shift. Thomas and Ely (2005: 143-145) determined the following eight pre-conditions for this qualitative change:

1. the leadership must understand that a diverse workforce will embody different perspectives and approaches to work, and must truly value a variety of opinion and insight; 2 . the leadership must recognise both learning opportunities and the challenges that the expression of different perspectives presents for an organisation; 3. the organisational culture must create an expectation of high standards of performance from anyone; 4 . the organisational culture must stimulate personal development; 5. the organisational culture must encourage openness; 6 . the culture must make workers feel valued; 7. the organisation must have a well-articulated and widely understood mission; and 8 . the organisation must have a relatively egalitarian, nonbureaucratic structure. 
Although, at least in the USA, research into factors of gender (im) balance in top managing positions has gained momentum at the beginning of the $21^{\text {st }}$ century, it seems that such research is lagging behind not only geographically (e.g. in Europe), but also in the non-profit sector (including research organisations and higher education). While the state cannot interfere much in internal organisational policy, it seems that in the public sector the state can (and in some cases) does so to a greater extent. So far, cases of nation-state policy mechanisms encouraging organisational units such as universities to pay more attention to the gender balance in academic career-making (e.g. in Sweden) still do not seem to have been systematically studied, and neither have EU policy mechanisms (e.g. Marie Curie stipends) nor corporations' mechanisms to promote female scientists (e.g. L' Oreal Women in Science Fellowships) been studied. Contrary to the American experience, some research has been undertaken at the level of enterprises (including in Slovenia) as part of an EU (public!) programme. These include EQUAL 2005-2007 (see e.g. Kanjuo-Mrčela and Černigoj-Sadar, Eds., 2007) and in some way also PROMETEA - "Empowering Women Engineers in Industrial and Academic Research", which compare various research organisations (industrial, academic and governmental). EU funding as part of EU research policy places such research more within the EU multi-level governance research point of view.

\section{Slovenia - a case study}

Slovenia is a good case for considering the research approaches used and research findings available so far. The revelation of the unequal research efforts and parallelism in current research aims at triggering a broader social science discussion on a future strategy for more integrated interdisciplinary research projects within nationstates (including Slovenia) as well as beyond nation-state boundaries. In the following sections, an overview of research streams in Slovenia is presented, sketching out a situation referring to various research levels.

\subsection{Macro view (general modernisation theory point of view)}

Previous evaluations of the role of women in the research field (e.g. She figures, Enwise report, Norface report) revealed that in some 
respects the status of female researchers in Slovenia may be a little better than in some other post-socialist countries where multiple social transitions also included a decline in research funding. At the same time, the current situation is not keeping pace with examples of certain more developed states with a more advanced sensitivity to and a culture of gender balance (e.g. certain Scandinavian countries). When looked at statically, this gap may be evaluated negatively. However, a more long-term, historical view reveals some changes in the last few decades. Some of them (e.g. the growing proportion of women in higher education) are at least partly the result of a policy encouraging a higher proportion of high school graduates to continue studying at university. Mass university study started in Slovenia in the 1990s and opened up opportunities for more university teachers, including a greater share of female university staff ${ }^{6}$ (see e.g. Komac, 2000). Nevertheless, the growing proportions of female students and university graduates do not automatically and immediately translate into a more visible growth in the proportion of female researchers with higher academic titles or in leading research decision-making positions at various levels (heads of organisational units, university leadership, decision-making bodies within research organisations, and within the national research decision-making system).

\subsubsection{Politics}

In many social aspects, traditionalism and modernism mix together in Slovenia, while certain elements of post-modern society can also be found (see e.g. Inglehart and Norris, 2003; Ramet and Fink-Hafner, Eds., 2006). When it comes to decision-making in Slovenia, women are clearly under-represented in politics where, for example, the proportion of female MPs has not exceeded $19 \%$ since the change in the old political system (which had provided a one-third "female quota") (see e.g. Antić G., 1991; Fink-Hafner and Krašovec, 2004). Empirical research (Krašovec and Fink-Hafner, 2004) has revealed that the predominant political culture of male and female voters in Slovenia is discriminatory against women. While discrimination is primarily based on the fact that voters prefer candidates with more previous political experi-

${ }^{6}$ According to Komac (2000), the share of female university teachers at the University of Ljubljana grew from 26\% in 1990 and 1991 to 30\% in 1996, and 38\% in 1999. 
ence (with female candidates automatically having less political capital in this regard), older respondents even openly say that a candidate's gender is important for their electoral choice (male candidates are preferred over female candidates).

\subsubsection{Management}

When searching for data on the share of female decision-makers in non-political fields, problems are even encountered in obtaining full and accurate numbers. The available figures (e.g. data gathered by the Chamber of Commerce and Industry in 1996 and the Office for Women's Politics - Urad za žensko politiko - in 1999, and reported by Kanjuo-Mrčela, 2000: 56) show that the proportion of female managers remains relatively small (an average of 9\%) but is still highest in small enterprises (14\%) and lowest in large enterprises (7\%). The increase in the proportion of female managers from $8.04 \%$ in 1986 to $21.5 \%$ in 1996 had been due to the frequent establishment of small enterprises (SORS, 1998; Kanjuo-Mrčela, 2000: 56-57). A survey of managers in Slovenia (Kanjuo-Mrčela, 1996) revealed that although family life and managerial work are not mutually exclusive $(80 \%$ of female managers were married and on average had two children), male managers (100\% married!) worked under quite different circumstances. As a result, even women in top managerial positions in Slovenia carry the dual burden of both managerial and domestic/household duties, unlike their male colleagues who simply focus on their jobs. Besides this, female managers confirmed that they are always aware of their gender. Their perception was that they had to work much harder to achieve the same as their male colleagues. The same survey also revealed male managers' open expression of traditional stereotyped views of women's social roles (including their employment), along with negative views of women taking over managerial positions (Kanjuo-Mrčela, 2000: 72). In spite of some estimates that women in Slovenian management are in a better position than their female colleagues in e.g. the United Kingdom (it seems that female managers in Slovenia usually do not decide to leave managerial positions due to aggressiveness, rudeness or isolation in their micro environment), it is still the case that they have to cope with a relatively male-centred culture, especially characterised by patronising behaviour and an extra need to "prove themselves" in relation to the other sex. 


\subsubsection{Academic environment}

In line with modernisation theory, one can observe a growing trend of women entering the education system in Slovenia - recently quite dynamically at undergraduate level as well as for master's, doctoral and post-doctoral studies. While the average proportion of females among $\mathrm{PhD}$ holders in the $1945-2000$ period was $26.9 \%$, in more recent years (2000-2004) it rose to $42.9 \%$. However, the growing amount and level of women's education have so far not brought about a significant spill-over leading to a change in various academic/research roles and positions. Although women make up about $64 \%$ of all university graduates, women represent only $25.4 \%$ of researchers, $11.1 \%$ of full professors, and just $17.2 \%$ of members of Slovenian university and academy councils (see OEO, 2005).

Jogan (2001: 91) described the process of women entering the public sphere as the de-domestification of women according to the following formula: "traditional + new role". This is valid even for those with the highest education levels. A 1996 survey of female assistants and assistant professors at the University of Ljubljana and the University of Maribor conducted by Maca Jogan revealed that those interviewed predominantly took care of communication with external family institutions, mostly looked after their children when they were sick, and still faced open prejudice in their work environments in the form of comments such as "beautiful women - stupid heads", "women cannot truly be scientists because they look after a family", "women are less capable in physics", they are "intellectually inferior", "technical professions are reserved for men", "women are less competent, are unreliable, and misuse their sex" (Jogan, 2001: 101-103). Even the conducting of research into the status, social roles and academic careers of women is still perceived, even in the academic environment, as being inferior to other research fields. It is something "serious researchers don't decide to do research in" (Jogan, 2001; personal experiences of the author).

The described aspects of the status and role of women in Slovenia help us understand why not only the situation in the mentioned research field but also gender differences in salaries in Slovenia between better paid male and worse paid female employees (including in the field of R\&T) exist in spite of the official policy of non-discrimination, a policy even based on an article in the Slovenian Constitution of 1991 
that guarantees no discrimination on the basis of gender (or any other "personal circumstances").

\subsection{EU pressures and their impacts}

The top-down implementation view seems to have been studied to a certain extent, while the bottom-up view still needs to attract more research interest. In Slovenia, the policy of gender equality was recently specified by transferring the EU policy of gender mainstreaming into several national legal norms. ${ }^{7}$ Yet their actual implementation is much more critical. A recent survey (conducted in 2005) among: a) leading public administration employees at three key ministries (the Ministry of Higher Education, Science and Technology; the Ministry of Education and Sport; the Ministry of Work, Family and Social Affairs) and several governmental bodies at the national level; b) leading representatives of the mass media; and c) leading research representatives provides some insights into implementation problems (Mladenić, Ed., 2006). The most telling findings include: a) a divergence in opinions on the status of women in science; b) the lack of qualifications of staff working at state institutions in the area of implementing equal opportunity policies for men and women in science and research; c) the lack of collaboration between state institutions with responsibilities in this field; d) poor communication between state actors, non-governmental organisations, research organisations and the mass media; and e) the relatively low level of dissemination to the mass media of knowledge even about the formal legal norms already adopted by Slovenian political institutions. Although it is probably no surprise that in state institutions the reported inclination towards change is quite visible, the lack of it at the highest (ministerial) levels (Jogan, 2006) is astonishing. More research is needed to reveal all the complex problems of the relatively long EU policy implementation chain (including the national, sub-national and organisational levels) along with the practical effects at the end of the chain.

7 These include: the Law on Equal Opportunities for Women and Men (Ur.l. RS 59/02); Resolution on the National Programme of Equal Opportunities for Women and Men 20052013 adopted by Parliament in 2005 (Ur.l. Republike Slovenije 100/05); Resolution on the National Research Developmental Programme for the Period 2006-2010; and Periodical Plan for Implementation of the National Programme in 2006 and 2007, adopted by the Slovenian Council of Ministers in April 2006. 


\subsubsection{Multi-level governance view}

For countries like Slovenia, integration with the EU has so far predominantly meant the transfer of political and policy principles as well as specific policies. During negotiations with the EU, the acquis was "given" to candidate states, which were then basically in a position to "take it or leave it". As a full EU member, Slovenia (like all other member states) must in practice implement formally adopted legal norms and, as a very recent new member, it has been undergoing careful policy monitoring by the European Commission. In the multi-level political system of the European Union, member states are responsible for putting laws into practice and may do so with respect to their own traditions and culture, and by means of an acceptable selection of policy instruments. But there is also a variety of bottom-up and top-down channels and means (available to state and non-state actors) to bring pressure to bear on the responsible actors to make enough effort to ensure efficient implementation. EU-level actors and institutions can play an important role as "external" factors empowering domestic actors and/or communicating with national decision-makers. Unfortunately, there is a lack of research into the practice of social and political actors' activities as well as into multi-level processes and their impacts.

\subsection{2. "European" social constructivism}

At the European level, it appears that there is a lack of research. In the case of Slovenia, it is not only the social networking of researchers and feminist activists that is important, but also governmental the Slovenian Research Agency - networking with research agencies within the framework of Norface (the first social science ERA-net). ${ }^{8}$ It needs to be investigated whether, to what extent and how, horizontal (para-state) networking has brought about an awareness of higher standards, including in terms of the gender-balanced research policies of some Norface countries. These have received the status of a benchmark to be followed in all Norface member research agencies (states). More research is needed to find out how social constructing takes place at several levels (at the level of researchers' networking, the international networking of research institutions, government, and funding para-state institutions) and what difference it makes.

\footnotetext{
${ }^{8}$ For more, see http://www.norface.org/.
} 


\subsection{Micro level - the organisational point of view}

An insight based on certain participant observation and research by several Slovenian authors points out at least two organisational levels: organisations as agencies at the national level and organisations as units where work (including research) takes place.

\subsubsection{Organisational (cultural) learning of national research funding institutions}

One critical question of institutional learning is the basic readiness to at least monitor the gender situation in research and development. Although sporadically the National Research Agency and the Ministry of Higher Education, Science and Technology in Slovenia do collaborate when gathering data on the proportion of women in various positions and activities in the research field (e.g. in the context of Norface comparative analysis, and collaboration in the process of preparing national reports for EU-supported comparative analysis), there is no clear inclination to continuously monitor the implementation of laws concerning equal opportunities for women and men in the research field and to publish them. The factors influencing national institutional (as well as political and administrative elite) learning still need to be analysed more thoroughly.

\subsubsection{Organisational (cultural) learning of research organisations}

The most obvious finding when looking at this type of environment is the lack of data or even readiness to continuously collect gendersensitive data. After investing certain efforts into data gathering and summarising, the picture of the available data is not unexpected - the proportion of women drops as we move from the lowest to the highest decision-making positions, at least within Slovenian universities, although we currently have an idiosyncratic situation at the rector level. The first two female rectors in Slovenia recently took up their positions and in special circumstances. While at the University of Ljubljana (established in 1919), the current and at the same time first female rector had to face several reforms at once (the introduction of the so-called Bologna process, transforming an extremely decentralised institution into a university with many new centrally co-ordinated activities, and direct dealings with governmental and para-state institutions in 
the fields of education and research), at the University of Primorska a former female minister of science and technology led the establishment of this new university and also became its first rector. When looking at the quite atypical (social science) environment of the Faculty of Social Sciences at the University of Ljubljana, a decreasing trend in the proportion of women in leading positions can be noticed. Among the heads of research centres there are 5 women out of $16(31 \%)$ and, among the heads of research programmes (the biggest and longest national research projects) there were 4 women out of 13 (30.8\%) in the 19992003 period, though slightly more in the 2004-2008 period - 4 out of $12(33 \%)$. While no systematic research has so far been conducted at the national level, a pilot study at the Faculty of Social Sciences of the University of Ljubljana (Luthar and Šadl, 2002) revealed a perception that female academic staff get broader access to (selected) leading positions when these positions become less rewarding in terms of their honour and symbolic and real political power. Typically, this happens with positions where the workload is growing, while this is not the case with various related kinds of rewards. The authors talk about a correlation between the social position and politics of honour in the academic environment, as shown on a wall full of exclusively male faces - the pictures of deans from the first four decades of the Faculty of Social Sciences (even the more extensive "wall of honour" at the University of Ljubljana looks the same).

In order to keep up with their academic careers, even younger generations of female academics/researchers in Slovenia cope with a dual role based on a mixture of traditional and modern images of women's social roles. For example, most assistant professors (85\%) and half of the assistants (52.1\%) interviewed at the University of Ljubljana and the University of Maribor in 1996 reported that (in order to remain on their academic career path), they had to give up many things that would fit within the perception of "a normal life", such as leisure time, enjoying culture, sports, hobbies and meeting with friends, and replace them with a "Spartan" lifestyle (Jogan, 2001: 101). Besides the remains of the traditional role of women in relation to their domestic roles (family, household, the division of labour between partners/parents), traditionalism is also still visible in the academic environment, as in their career paths female academics seem to go along with a tendency towards "a gender-biased division of labour". According to research by Luthar and Šadl (2002), female academics tend not to subvert 
any duties and tasks while their male colleagues rebel either openly (in a conflictive way) or in a positive functional way when they are pushed into duties and tasks that are more administrative and less or not at all linked to their teaching or research. Jogan (2001) noticed that this practice could take on "a velvet form" when especially male but also female professors are happy to transfer their administrative tasks to female assistants. This is in line with Luthar's and Šadl's (2002) finding that, while male interviewees disclosed feelings of deprivation in relation to academic generations (the principle of seniority), female interviewees stressed their two-fold deprivation: generational- and genderbiased. Similar findings are reported in research by Jogan (1990 and 2001) and Kump (2001).

Since Slovenia belongs to the Central and Eastern European tradition of universities with strong and quite independent faculties, it is important to look at the faculty level when analysing power relations. While national research into the internal characteristics of universities is lacking, I report some of the findings based on a survey conducted by Podmenik, Kump and Kramberger in 1999 at the University of Ljubljana. The survey highlights the relatively hierarchical character of the university. There are quite significant differences in perceptions of the scope of the available information and the opportunities to influence decision-making at the faculty level. Besides the prevalence of the multiplicity of academic disciplines culture (various sciences) over the common university academic culture, a further two-fold discrimination was found (Kump, 2001): a) generational discrimination (younger researchers estimate they have less information and fewer opportunities to participate in decision-making than older academically-established members); and b) gender discrimination (female interviewees reported a negative evaluation in terms of their access to information and opportunities to participate in decision-making even more frequently than their male colleagues).

The marginalisation of female researchers in terms of their being predominantly excluded from information and decision-making networks also translates into pay gaps. Analysis of data on salaries and additional earnings in the public research sector (Novak, 2006) shows characteristic gender discrimination in favour of male researchers. On average, women receive gross salaries without supplements that are $0.7 \%$ to $11.7 \%$ lower than men's salaries. As a rule, men also receive higher average "functional allowances" than women because they are 
more frequently nominated to leading positions and are nominated to better paid positions. However, Novak finds that women even receive lower "functional allowances" than men in the same positions. The pay gap is biggest when looking at the salaries (including all allowances) of male and female researchers with the highest academic titles.

The elements of organisational culture that make female academics experience the "glass ceiling" (see e.g. research by Luthar and Šadl, 2002; Jogan, 2001) are very similar to those revealed in research among male and female managers in Slovenian enterprises (Kanjuo-Mrčela, 2000), such as stereotyped views of social roles related to gender (concerns about women's ability to work "properly" when having children) and patronising behaviour by their male colleagues. Like Slovenian managers (as reported in the cited research by Kanjuo-Mrčela, 2000), female academics often feel they have to work much harder to achieve the same promotion as their male colleagues, but their male colleagues usually do not notice this. The middle generation can still remember the not-so-distant times when arguments for promotion to a full professorship were read at faculty meetings. Arguments in favour of female candidates for full professorship on the grounds that they were "diligent" could be heard, whereas a male's full professorship was approved on the basis of the loud praise for their expert achievements.

Generational change. Very open gender discrimination seems to have become a relatively rare phenomenon linked to the older generation, at least in the social sciences. Like in politics, where only the oldest openly say in public opinion research that women do not make appropriate candidates for political roles (see e.g. Krašovec and FinkHafner, 2002), only a few academics would openly stick to gender stereotypes, e.g. giving priority to a man when they have to choose between two equally distinguished academics of different genders for a better paid job (in line with the stereotype that "it is the man who is the head of the family and supposed to earn more in order to feed them"). This seems to go hand in hand with a more recently and informally expressed male "fear of emancipated, bold, professionally excellent female academics".

Social networking. Interestingly enough, in spite of the pattern revealed above, female academics do not seem to develop social networks with clear goals to change the described pattern in the academic microenvironment. Whenever an individual female academic experiences feelings of deprivation or unfair treatment, she seems to remain 
"lonely" or isolated and even lacks a clear institutional (legal) path to achieve a satisfactory solution. Emotional reactions to this situation in the form of "an outburst" only add fuel to the stereotyped views of gender differences, creating perceptions of women as "hysterical" or "people with hormone problems". According to Luthar and Šadl (2002: $190)$, these emotions are complemented by female academics' exaggerated self-criticism and their self-declared dependence on moral support from their private relationship (partners). On the contrary, joining the predominately male networks within research institutions is seen as a means to more straightforward promotion and assimilation into a male-like culture (Šadl, 2006). This strategy is based on recognition of the "invisible academy" constructed of male networks (Šadl, 2006). According to Šadl's findings, these networks are perceived as spheres of "linking, mutual recognition of statuses and business profits". Typically, female interviewees in a study of university teachers aged between 35 and 45 working at the Faculty of Social Sciences in 2001 did not report characteristics of "old boy networks" (since they were not part of them). Šadl stresses that all these findings do not mean that male researchers do not have negative experiences in their academic careers, but that female researchers encounter special problems that are characteristic for them in academic institutions due to their lack of social and professional linkages.

All in all, we can say that the various social science disciplines and approaches in Slovenia have so far provided many valuable research findings. However, many grey spots and a lack of interrelations between the research can be noticed. A more thorough analysis of these is presented in the concluding section.

\section{Conclusions}

In general, as well as in Slovenia, there have been many scattered attempts to look at the various factors of gender inequality in R\&T, which have so far produced many islands of research but not very well integrated data. Partial approaches result in partial pictures, usually completely leaving out globalised economic, social and political factors.

In spite of the fact that in Slovenia and more generally there have been many valuable research achievements in various social science disciplines related to research into other issues of gender inequalities, re- 
search into gender inequalities in the field of research and development seems to be lagging behind. Additionally, the existing rather isolated disciplinary research cannot fully capture the researched phenomena which have become even more complex in the most recent wave of globalisation (especially European integration processes).

An overview of research experience in Slovenia (Table 2) indicates the following conclusions which seem to correspond with general findings on current research achievements:

- there is a "patchwork" of unequally developed islands of research into gender inequalities including gender inequalities in research and development;

- a lack of interdisciplinary research can be observed;

- a lack of a systematic integration of research into various levels of gender-related social phenomena may be noticed;

- a lack of systematic comparative longitudinal research goes hand in hand with a lack of systematic cross-national comparative research;

- the least developed research streams seem to include research integrating multidisciplinary and multi-level approaches (especially taking into account the most recent wave of globalisation, especially European integration processes).

Due to the very blurred line between applied expertise and academically sound research, there is a lack of bold research findings on which policy advice to governmental and non-governmental actors could be based. In the broader social science debate, it seems that a new scientific framework "Science II" (Hollingsworth and Müller, 2008) is slowly emerging. This places a great deal of emphasis on evolution, dynamism, chance and/or pattern recognition, nesting phenomena simultaneously in multiple levels of reality as well as in the recognition of relationships between micro and macro phenomena. The first step towards employing this new science paradigm in the field of women in science and technology would be focused integration of various research efforts involving: a) at least closer collaboration between sociology, political science and organisational science; b) combining micro, meso and macro levels of analysis, while taking into account the multi-level character of investigated phenomena; and c) a combination of quantitative and qualitative research methods (including studying careers) while comparing case studies and carrying out "variable oriented" longitudinal and international comparisons. 
Table 2. Research experience in Slovenia regarding level of analysis and main research experiences

\begin{tabular}{|c|c|c|}
\hline Theories & Level of analysis & Main research experiences \\
\hline Modernisation theory & macro level & $\begin{array}{l}\text { relatively developed islands of } \\
\text { research into many social aspects }\end{array}$ \\
\hline $\begin{array}{l}\text { Theories explaining European } \\
\text { integration processes }\end{array}$ & meso level & \\
\hline - multi-level governance & policy processes & $\begin{array}{l}\text { some scattered research into the } \\
\text { implementation of EU policies } \\
\text { under the important influence } \\
\text { of EU institutions and European } \\
\text { expert networks; the lack of } \\
\text { complex research taking both the } \\
\text { top-down and bottom-up views } \\
\text { into account }\end{array}$ \\
\hline - (social) constructivism & $\begin{array}{l}\text { multi-level interactions } \\
\text { between organisations } \\
\text { and/ or individuals }\end{array}$ & lack of research \\
\hline Organisational theories & micro level & $\begin{array}{l}\text { limited research on organisational } \\
\text { learning, social networking and } \\
\text { social capital in enterprises; a } \\
\text { lack of systematic research within } \\
\text { research organisation units }\end{array}$ \\
\hline Combining approaches & $\begin{array}{l}\text { Macro and meso } \\
\text { and micro }\end{array}$ & $\begin{array}{l}\text { some research into the national } \\
\text { implementation of EU policies, } \\
\text { e.g. specific mechanisms (like } \\
\text { "family-friendly enterprise" } \\
\text { certificates ); the lack of a } \\
\text { combined research approach } \\
\text { in the field of research and } \\
\text { development }\end{array}$ \\
\hline
\end{tabular}

All of this not only means that gender studies need to "take the EU seriously" (Hoskyins, 2004). It also means that: a) gender studies need to take globalisation in all its aspects (economic, social and political) seriously; b) general theoretical approaches in social science disciplines need to be "gendered"; while c) additional gender-sensitive theoretical and conceptual approaches need to be harnessed and further developed. 


\section{References}

ANTIĆ, Milica G. (1991). Democracy between tyranny and liberty: Women in post"socialist" Slovenia. Feminist Review, 39, 149-154.

BAYKAN, Ayşegül (1990). Women between fundamentalism and modernity. In B. S. Turner (Ed.), Theories of Modernity and Postmodernity (pp. 136-146). London, Newbury Park, California, New Delhi: Sage.

BÖRZEL, Tanja A. (1997). What's so special about policy networks? An exploration of the concept and its usefulness in studying European governance. European Integration Online Papers, 1(16). Retrieved on 11 November 2005 from <http:// eiop.or.at/eiop/texte/1997-016a.htm>

CAPPELLI, Peter, \& HAMORI, Monika (2004). The Path to the top: Changes in the attributes and careers of corporate executives, 1980-2001. Cambridge, MA, USA: National Bureau of Economic Research, NBER Program. Retrieved on 10 December 2007 from <http://www.nber.org/papers/w10507>

CHRYSSOCHOOU, Dimitris N., TSINISIZELIS, Michael J., STAVRIDIS, Stelios, \& IFANTIS, Kostas (2003). Theory and Reform in the European Union (2nd ed.). Manchester and New York: Manchester University Press.

CHRISTIANSEN, Thomas, JØRGENSEN, Knud Erik, \& WIENER, Antje (Eds.) (1999). Special issue 4 on the social construction of Europe. Journal of European Public Policy, 6, 527-720.

CROMPTON, Rosemary (2001). Gender, comparative research and biographical matching. European Societies, 3, 167-190.

DAHLERUP, Drude (1988). From a small to a large minority: Women in Scandinavian politics. Scandinavian Political Studies, 11, 275-298.

DIEZ, Thomas (1999). Riding the AM-track through Europe; Or the pitfalls of a rationalist's journey through European integration. Millennium: Journal of International Studies, 28, 355-369.

ELGSTRÖM, Ole (2000). Norm negotiations. The construction of new norms regarding gender and development in EU foreign aid policy. Journal of European Public Policy, 7, 457-76.

FINK-HAFNER, Danica (2005). Evropske volitve 2004 v Sloveniji - Učinkovitost volilnega inženirstva v korist bolj uravnotežene zastopanosti spolov. In A. Krašovec (Ed.), Volitve v evropski parlament: Res drugorazredne volitve (pp. 107-129). Ljubljana: Fakulteta za družbene vede.

FINK-HAFNER, Danica, \& KRAŠOVEC, Alenka (2004). Vpliv volilnega sistema na delež žensk v nacionalnem in lokalnih predstavniških telesih. In M. Brezovšek, M. Haček, \& A. Krašovec (Eds.), Lokalna demokracija I. Analiza lokalnih volitev 2002 (pp. 102-124.) Ljubljana: Fakulteta za družbene vede.

FINK-HAFNER, Danica, DEŽELAN, Tomaž, \& TOPOLINJAK, Simona (2005). Kandidatke na evropskih volitvah 2004 v Sloveniji: Strankocentričnost volilnega sistema in medijskega poročanja. In S. Kustec Lipicer (Ed.), Politološki vidiki volilne kampanje: Analiza volilne kampanje za volitve v Evropski parlament 2004 (pp. 128-146). Ljubljana: Fakulteta za družbene vede. 
FRIEDMAN, Stewart D., CHRISTINESEN, Perry \& DEGROOT, Jessica (2005). Work and life. The end of the zero-sum game. In Harvard business review on women in business (pp. 95-123). USA: Harvard Business School Press.

GALLIGAN, Yvonne, CLAVERO, Sara, \& CALLONI, Marina (2007). Gender politics and democracy in post-socialist Europe. Opladen \& Farmington Hills: Barbara Budrich Publishers.

HAJER, Maarten (2003). Policy without polity? Policy analysis and the institutional void. Policy Sciences, 36, 175-195.

HANSEN, Lene (2000). Gendered communities. The ambiguous attraction of Europe. In M. Kelstrup \& M. C. Williams (Eds.), International relations theory and the politics of European integration (pp. 131-170). London and New York: Routledge.

HARVARD BUSINESS SCHOOL PRESS (Ed.) (2005). Harvard business review on women in business. Ideas with impact series. USA: Harvard Business School Press.

HEWLETT, Sylvia Ann, LUCE, Carolin Buck, \& SOUTHWELL, Sandra (2005). The hidden brain drain: Off-ramps and on-ramps in women's careers. Center for Work-life Policy and Harvard business review. Retrieved on 10 December 2007 from < http://harvardbusinessonline.hbsp.harvard.edu/email/pdfs/9491p4_rev_ Alias_URL.pdf;jsessionid=PHD3KTNFE3MF0AKRGWDR5VQBKE0YIISW>

HOLLINGSWORTH, Rogers, \& MÜLLER, Karl (2008). Transforming socio-economics with a new epistemology. Socio-Economic Review, 6, 1-32.

HOOGHE, Liesbet, \& MARKS, Garry (2001a). Multi-level governance and European integration. Lanham, Boulder, New York, Oxford: Rowman \& Littlefield Publishers Inc.

HOOGHE, Liesbet \& MARKS, Garry (2001b). Types of multi-level governance. European Integration online Papers, 5(11). Retrieved on 24 May 2004 from $<$ http:// eiop.or.at/eiop/texte/2001-011a.htm>

HOSKYNS, Catherine (2004). Gender perspectives. In A. Wiener \& T. Diez (Eds.), European integration theory (pp. 217-236). Oxford and New York: Oxford University Press.

INGLEHART, Ronald \& NORRIS, Pippa (2003). Rising tide. Gender equality and cultural change. Cambridge University Press.

JOGAN, Maca (1990). Družbena konstrukcija hierarhije med spoloma. Ljubljana: Fakulteta za sociologijo, politične vede in novinarstvo.

JOGAN, Maca (2001). Seksizem v vsakdanjem življenju. Ljubljana: Znanstvena knjižnica.

JOGAN, Maca (2006). Ženske v znanosti: Od izključenosti do (popolne) vključenosti. Časopis za kritiko znanosti, domišljijo in novo antropologijo, 34, 152-167.

JONES, Candace, HESTERLY, William S., \& BORGATTI, Stephen P. (1997). A general theory of network governance. Exchange conditions and social mechanisms. Available at <http://www.analytictech.com/borgatti/oppamr6z.htm>

KANJUO-MRČELA, Aleksandra (1996). Ženska v menedžmentu. Ljubljana: Enotnost.

KANJUO-MRČELA, Aleksandra (2000). Spolna konstrukcija menedžerskih vlog: Stekleni organizacijski stropovi v devetdesetih. Družboslovne razprave, 16, 5378. 
KANJUO-MRČELA, Aleksandra, \& ČERNIGOJ-SADAR, Nevenka, (Eds.) (2007). Delo in družina - s partnerstvom do družini prijaznega delovnega okolja. Ljubljana: Založba FDV.

KOHLER-KOCH, Beate (2002). European networks and ideas: Changing national policies? European Integration Online Papers, (6)6. Retrieved on 24 May 2004 from <http://eiop.or.at/eiop/texte/2002-006a.htm>

KOMAC, Nataša (2000). Ženske/znanstvenice na UL. Vestnik, No. 6-7. Retrieved on 13 May 2004 from <http://www.vestnik.uni-lj.si/Objave/Vestnik/6-7-2000/ razno4.asp>

KRAŠOVEC, Alenka, \& FINK-HAFNER, Danica (2004). Politične izkušnje in volitve: Posredna diskriminacija žensk. In M. Brezovšek, M. Haček, \& A. Krašovec (Eds.), Lokalna demokracija I. Analiza lokalnih volitev 2002 (pp. 75-101). Ljubljana: Fakulteta za družbene vede.

KUMP, Sonja (2001). Hierarhična razmerja moči na univerzi. Družboslovne razprave, 37-38, 109-115.

LUTHAR, Breda, \& ŠADL, Zdenka (2002). Skriti traskripti moči: Dominacija in emocije v akademski instituciji. Teorija in Praksa, 39, 170-195.

MARKS, Garry (1996). Exploring and explaining variation in EU cohesion policy. In L. Hooghe (Ed.), Cohesion policy and European integration: Building multi-level governance (pp. 388-422). Oxford University Press.

MAZEY, Sonia (1988). European Community action on behalf of women: The limits of legislation. Journal of Common Market Studies, 27, 63-84.

MAZEY, Sonia (Ed.) (2000). Special issue on women, power and public policy in Europe. Journal of European Public Policy, 7, 333-476.

MLADENIĆ, Dunja (2006). Enakost žensk and moških v znanosti in raziskovanju: (Pri)poročila Evropske komisije. Časopis za kritiko znanosti, domišljijo in novo antropologijo, 34, 142-151.

MLADENIĆ, Dunja (Ed.) (2006). Enakost žensk in moških v znanosti in raziskovanju v Sloveniji. Ljubljana: Central European Centre for Women and Youth in Science.

NORRIS, Pippa (2004). Electoral engineering. Voting rules and political behavior. Cambridge University Press.

NOVAK, Polona (2006). Ali ženske v Sloveniji prejemajo nižje plače od moških za enako znanstveno-raziskovalno delo? Časopis za kritiko znanosti, domišljijo in novo antropologijo, 34, 168-181.

OEO (2005). Analiza stanja/Analysis of the current situation. The basis for the Resolution on the National Programme of Equal Opportunities for Women and Men (2005-2013). Office for Equal Opportunities, Government of the Republic Of Slovenia: Ljubljana.

PETERSON, John (1995). Decision-making in the European Union: Towards a framework for analysis. Journal of European Public Policy, 2, 69-93.

PETERSON, John, \& BOMBERG, Emilie (1999). Decision-making in the European Union. Houndmills: Macmillan Press, New York: St. Martin's Press.

POLLACK, Mark A., \& HAFNER-BURTON, Emilie (2000). Mainstreaming gender in the European Union. Journal of European Public Policy, 7, 432-456. 
RAMET, Sabrina P., \& FINK-HAFNER, Danica (Eds.) (2006). Democratic transition in Slovenia. College Station: Texas A\&M University Press.

RISSE, Thomas (2004). Social constructivism and European integration. In A. Wiener, \& T. Diez (Eds.), European integration theory (pp. 159-76). Oxford University Press.

RHODES, R. A. W., BACHE Ian, \& GEORGE, Stephen (1996). Policy networks and policy-making in the European Union: A critical appraisal. In L. Hooghe (Ed.), Cohesion policy and European integration: Building multi-level governance (pp. 367-387). Oxford University Press.

ROSAMOND, Ben (2000). Theories of European integration. Palgrave, Macmillan.

SCHMIDT, Verena (2005). Gender mainstreaming - an innovation in Europe? The institutionalisation of gender mainstreaming in the European Commission. Opladen: Barbara Budrich Publishers.

SIEMIEŃSKA, Renata, \& ZIMMER, Annette (Eds.) (2007). Gendered career trajectories in academia in cross-national perspective. Warsaw: Wydawnictwo Naukowe Scholar.

ŠADL, Zdenka (2006). Iluzija inkluzije. Znanstvenice v homosocialnem okolju. Časopis za kritiko znanosti, domišljijo in novo antropologijo, 34, 182-194.

THOMAS, David A., \& ELY, Robin J. (2005). Making differences matter. A new paradigm for managing diversity. In Harvard business review on women in business (pp. 125-157). USA: Harvard Business School Press.

TURNER, Bryan S. (1990). Periodization and politics in the postmodern. In B. S. Turner (Ed.), Theories of modernity and postmodernity (pp. 1-13). London, Newbury Park, California, New Delhi: Sage.

VAN DER VLEUTEN, Anna (2007). The price of gender equality. Member states and governance in the European Union. Hampshire, England and Berlington, USA: Ashgate.

VAN VUHT TIJSSEN, Lieteke (1990). Women between modernity and postmodernity. In S. B. Turner (Ed.), Theories of modernity and postmodernity (pp. 147-163). London, Newbury Park, California, New Delhi: Sage.

\section{Other sources:}

MHEST, Ministry of Higher Education, Science And Technology of the Republic of Slovenia. Special subpage on women in science. <http://www.mvzt.gov.si/si/ delovna_podrocja/znanost_in_visoko_solstvo/znanost/dejavnost/zenske_v_ znanosti/>

OEO, Office for Equal Opportunities, Government of the Republic Of Slovenia, $<$ http://www.uem.gov.si>

SORS, Statistical Office of the Republic of Slovenia, <http://www.stat.si> 


\section{Anke Reinhardt}

\section{Third party funding agencies and their role in advancing women in science: the case of the DFG in Germany*}

\section{Introduction}

The situation of women in science is one of the most important topics in research policy today. The insufficient participation of women in academia raises concern among decision makers in the scientific and research policy community. Policy makers fear a deficit of efficiency and excellence in the science system if women leave academia in disproportionate numbers because this limits the "pool" of talents. Raising the number of women in science can also increase the diversity of research perspectives.

Compared with the situation in the rest of Europe, the lack of female scientists in Germany is especially severe. Taking all levels together, $13.6 \%$ of professorships in 2004 were held by women. The number of female professors varies significantly among the disciplines. In the humanities and social sciences, the share of women in all professorships is more than $20 \%$, and in engineering it is less than $5 \%$ (Destatis, 2006). While the number of female professors at the highest level was only $9.2 \%$ in Germany in 2004, in the United Kingdom the share was 15.9\%, and in France 16.1\% (EC, 2006). Countries like Finland, Poland or Portugal have even more women in high academic ranks. Change will come, but slowly. The number of professors is rising in Germany, and the proportion of women newly appointed to professorships was $22 \%$ in 2005 (BLK, 2006).

As a first step in a scientific career, the number of women pursuing a doctorate is of high relevance for the proportion of women in high levels of academia. While in 2004 almost $50 \%$ of university degrees in Germany were obtained by women, the proportion of young female researchers working on their doctorate was only $40 \%$. In contrast, in

* The views expressed herein are the personal views of the author and are not intended to reflect the views of the DFG. 
Portugal, Finland, Italy, and Lithuania about half of the graduates pursuing a $\mathrm{PhD}$ were female (EC, 2006). The proportion of women that had successfully completed their "habilitation" in Germany amounted to $23 \%$ in 2004 .

At high levels of scientific administration and in executive ranks, women are also underrepresented. In the leadership of universities, only $15.5 \%$ are women. At the top level (president of a university), only $6.0 \%$ are women (BLK, 2006).

In the 1990s, the question of women in science was discussed in many fora. Fuchs et al. (2001: 175) found that "at the highest level, political and scientific commissions, committees, program and work groups have been formed to determine the causes for women's underrepresentation in science" (e.g. EC, 1999; BLK, 2006; Wissenschaftsrat, 2007). These efforts were accompanied by academic research into the topic and the funding of programmes to promote women in science.

The main empirical studies concerning women in science tend to focus on the percentage of women in different status groups. The subject matters of studies are mostly only higher education institutions (mainly universities), and few studies look at the science system as a whole, including, for example, non-university research institutions (Fuchs et al., 2001). One aspect is often overlooked: what role does third party funding play in the career of women in science? Concerning the methodology, very few authors analyse qualitative information. Therefore, policies that aim to promote women in science in the German research system are only seldom systematically studied. This is especially true for the policies of a third party funding agency.

Third party funding is becoming increasingly important for the success of an academic career. It is not merely a means of additional resources which allows the scientist to pursue his or her research interest on a broader financial basis. It is also evidence of the scientific productivity of a researcher. More and more, it is additionally seen as a sign of quality and - because of the peer-review mechanism - as a means of quality assurance. It therefore becomes a source of reputation and a prerequisite for career advancement. Allmendinger and Hinz (2002) point to the fact that recently many universities in Germany have started to link the personal income of researchers and the budget of research institutions to the acquisition of third party funding.

The Deutsche Forschungsgemeinschaft (DFG, German Research Foundation) is the main funding agency for basic research in Germany. 
One-third of all third party funding in Germany is distributed by the DFG. It therefore has an important role in both shaping research policy issues and in the day-to-day lives of scientists. Because of its high profile and ever more important role in the science system in Germany, its functions and its policies on gender equality deserve special attention.

Beyond ministries or universities, third party funding agencies also set research policies concerning gender equality and shape the working conditions of men and women in academia. In this chapter, I therefore want to focus on the role of the DFG as a research policy player in Germany and on the measures it takes to address the issue of women in science. This paper describes the DFG's concerns and practices related to gender discrimination in science and its efforts to work towards a more egalitarian situation. The focus is on the logic of a funding agency and its internal mechanisms (especially peer review), and on the policies it formulates to address some of the hurdles for women in a scientific career.

The chapter begins by presenting the main fields of research on gender equality in academia (section 2). It goes on to describe the research policy players in Germany and their contributions to the promotion of women. This is followed by a perspective on third party funding institutions, including their main driving mechanism: peer review (section 3). Empirical results concerning the representation of women in the DFG and the view women hold of the process (section 4) will provide the basis on which to present policies which the DFG has recently adopted to promote women in science (section 5).

The main point is that the analysis of gender issues in the research system can also give insights into the mechanisms at play in funding agencies. On the basis of these findings, the DFG creates its policies to promote women in science.

\section{Gender equality in science policy studies}

Two aspects are at the centre of attention of science policy studies on gender equality. First, becoming a scientist is seen as a career choice. In this view, women leaving the research system are leaving the labour market, or rather one specific labour market. Therefore, studies on career patterns and the specific effects of academic working life on women can give useful insights. Second, the research system as such is under scrutiny. The drop-out or lower success of female scientists is 
then explained by either the organisational structures of single institutions or by the research system as a whole.

The study of academic careers gives many insights into the reasons why women are underrepresented in science. The literature in this field has coined terms that have been widely used and are now "common wisdom" in the debate. One of the main concepts is the "leaking pipeline" (White, 2004). It describes the phenomenon of women leaving the research system early in their academic career and especially at certain career steps, such as the completion of a $\mathrm{PhD}$ or the "habilitation" in Germany. This leads to the increasing underrepresentation of women in higher ranks. White (2004: 231) finds that women are "discouraged from enrolling or completing higher research degrees". The reasons for the "leaking pipeline" are not yet clear. The completion of a $\mathrm{PhD}$ is seen as a "critical tipping point" by Bell and Bentley (2005: 18), at which women decide on the basis of competing priorities or a lack of confidence to give up their academic career. Another explanation, put forward by Allen and Castleman (2001), is that women are less likely to have continuing employment, which is important to build a career. Doherty and Manfredi (2005) find that women display less explicit career planning and are also less confident in their abilities and achievements.

Finding a work-life balance and combining work and family life are especially difficult at universities (Forster, 2000). Johnson and Stafford (1974) argue from a human capital perspective that women have less incentives to invest in their careers than men because the (possible) efforts of child rearing means that they will most likely not have enough time to see a return on their investment. Instead, they focus on teaching jobs that will give them the opportunity for short-term economic gains. However, Colander and Woos (1997) argue that "emphasis on differences between men's and women's human capital diverts attention from demand-side discrimination against women" (cited from Bentley and Adamson, 2003). Gender bias, as Bentley and Adamson (2003: 3) point out, "can either limit the set of job opportunities available to women or make some jobs less attractive because of lower pay or reduced promotion possibilities". Cole (1987) gives an overview of the influence of gender on career success, and on the accumulation of advantages and scientific merits. Most likely, the underrepresentation of women at higher levels of academia is, according to Bentley and Adamson (2003: 5), a result of "combined selection forces of human capital accumulation, job preferences, and limited opportunities". 
Besides the individual perspective of the female scientist working at university, a study of the structure of the scientific system can help to understand the under-representation of women. Merton's work on the social organisation of science (1973) describes the norms and organisation of the scientific community. From this starting point, science policy studies have focused on the organisation of science and the conditions for the production and quality assurance of knowledge (Joas, 1990). However, "as a social field and profession, science has been found to be patterned by a 'male scientific ethos', with negative consequences for women's aspirations, perceptions and participation" (Fuchs et al., 2001: 183f, referring to Etzkowitz et al., 1994). The gender of a scientist has an effect on the opportunities and choices that he or she has and his or her reaction to these (Sonnert, 1995). Bagilhole and Goode (2001) argue that "the reward of individual merit" is merely a myth, while in fact male dominance, networking and subtle discrimination hinder women from advancing in the scientific system. Lind (2006) underlines that a view on the gender-specific outcomes of organisations shows that structural factors are stronger than individual factors in determining a woman's career in the sciences. These gendered structures in scientific organisations are manifest in seemingly neutral rules that are in fact designed for male biographies (e.g. informal age limits, attribution of performance and accomplishments measured by availability and presence).

Therefore, the study of organisations from a gendered perspective, as put forward by Acker (1990), gives insights that go beyond individual career choices and provide explanations for existing organisational structures and cultures and also for the careers and knowledge system they produce:

To say that an organization, or any other analytic unit, is gendered means that advantage and disadvantage, exploitation and control, action and emotion, meaning and identity, are patterned through and in terms of a distinction between male and female, masculine and feminine. Gender is not an addition to ongoing processes, conceived as gender neutral. Rather, it is an integral part of those processes, which cannot be understood without an analysis of gender.

(Acker, 1990: 146)

Acker's theory of gendered dynamics and processes in organisations can shed light on "gendered divisions, gendered symbols, gendered interaction and individuals' internal mental processing of them" (Husu, 
2004: 74). Applied to the study of science systems, it offers the chance to better understand the specificities that make research organisations a place that women tend to leave. The ones remaining have to find a way of dealing with the gendered structures of the organisations.

The challenges that a woman working in academia faces are manifold and are based on the structure of the system. Many empirically oriented studies in this field have found the following factors to be crucial (see Bentley and Adamson, 2003; and Fuchs et al., 2001 for literature):

- women feel marginalised and excluded in their departments;

- female scientists have fewer networks in their field;

- women have less straightforward careers and experience interruptions in their careers from bearing and raising children;

- female scientists perceive academic careers as insecure; compared to their male colleagues, they are disproportionately employed on fixed-term contracts;

- women receive less support and mentoring than their male colleagues;

- female academics are rarely represented in influential commissions and committees;

- female scientists are more frustrated than men by the publishing review process;

- women perceive the male dominance in academic and scientific environments to be hostile, and anticipate huge efforts to make the necessary adjustments.

Such a list may also include the point that women report having less access to material resources than their male counterparts (Lind, 2006; Krimmer and Zimmer, 2003; Macfarlane and Luzzadder-Beach, 1998). This directly addresses the activity of funding agencies.

\section{Equal opportunities as a research policy issue}

The empirical studies and analyses that science policy studies have conducted have not only broadened understanding of the problems that women face in academia, but have also informed the debate of research policy players on this topic.

In European science policy, gender equality in scientific organisations is seen not only as an important goal to promote individual female researchers and to give them opportunities to use their potential. It is also more generally viewed as a way to promote excellence 
in scientific research by enlarging the pool of researchers and getting new perspectives (ETAN, 2000). The same holds true for the debate in Germany. The small number of women in science is not only a topic for academic studies. Many public bodies perceive the need to increase the number of female scientists and to better integrate female researchers into the research world. Science, politics, and research organisations discuss what "science as a female profession" (Allmendinger and Hinz, 2002: 2) does and what it should mean. Below, we present some of the most important players in the field in Germany and outline the gender equality policies they put forward.

\subsection{Research policy players in Germany for women in science}

After the private sector, the universities are the main employers of women in research. Since the number of women in science, as well as their working conditions, depends on the human resources policies of the universities, such policies are the most influential factor for the promotion of women in science. Of course, general employment regulations that address the discrimination of women also apply to universities. In addition, many universities have special mentoring programmes for women, and offer childcare facilities, among other things.

As a policy player, the German Rectors' Conference (HRK) is the voice of the universities. In November 2006, the Rectors' Conference put forward its policy recommendations, entitled Promoting Women (German Rectors' Conference, 2006), which include suggestions to enable work-life-balance at universities, and proposals to use performancebased allocation of funds to increase the number of women at universities. The Länder (states) in Germany, which finance the universities, also have human resources plans for the universities and many have implemented specific programmes to promote women. Changes in the Framework Act for Higher Education (Hochschulrahmengesetz) integrated equal opportunities into the steering tools at universities. The distribution of financial means and the evaluation of universities must now take into account the accomplishments of universities in achieving gender equality (Lind, 2006).

The Federal Ministry of Research and Education (BMBF) has several programmes to promote women. In the 1990s, the Special Programmes for Universities I and II helped to increase the number of women at universities. While the first programme focused on in- 
creasing the numbers of women with required qualifications by giving scholarships, the second programme created positions at universities: this time they took into account the results of organisational studies and the structural impediments they found. It proved to be the more successful strategy to integrate women into the scientific system (Lind, 2006). In 2008, the BMBF started a new Female Professor's Programme that aims to reserve the positions of professors who retire for women. The BMBF also supports the Centre of Excellence Women and Science (CEWS), which was opened in 2000, and serves as a national centre for coordination, consulting and gender mainstreaming. The centre distributes information and scientific results on gender-related issues in research, publishes the "Gender Ranking of Universities" every third year, and conducts projects to increase the proportion of women in executive positions in science.

The Joint Science Conference (GWK, before 2008: Bund-Länder Commission for Educational Planning and Research Promotion/BLK) coordinates policies of the Länder which are the main actors responsible for higher education and universities in Germany. In 1989, it presented its first report on the position of women in science, which gave an overview of instruments in the Länder and showed possibilities for improving the situation. In 2000, a subsequent report drew conclusions on the previous analysis. It recommends that:

Structures must be created which enable the free development of women and men's potential regardless of traditional roles. The dimension of equal opportunities must be included in the discussion on the reform of higher education institutions and non-university research institutions and applied as a pervasive guiding principle to all plans, legislative projects and measures by taking into account the different implications for women and men in all areas and on all levels (gender mainstreaming) (Hadulla-Kuhlmann and Hartung, 2002: 6).

The Research Council (Wissenschaftsrat) advises the federal and state governments on research policy matters and evaluates institutions. In July 2007, the Research Council published its Recommendations on the Gender Equality of Researchers, in which it asked for acceptance of the scientifically established fact that gender discrimination exists in research, and proposed, among other things, a cascade model for all hierarchical levels and the formalisation of recruitment procedures, so that they would depend less on personal recommendations. 
With the "Offensive for Equal Opportunities of Male and Female Scientists", all major research organisations (Max-Planck-Society, Fraunhofer Society, DFG, etc.) have committed themselves to take measures and devote resources to increase considerably the proportion of women within five years. Each research organisation had to develop a strategy according to their specific tasks and profile.

Furthermore, there are a number of awards and certificates, including the Robert Bosch-Foundation award for family friendly universities (in 2008 awarded to eight universities), the "Total E-Quality award" which is sponsored by the Federal Ministry of Research and Education, and the Hertie Foundation certificate for "family friendly workplaces", which some universities have obtained.

This overview of the main research policy actors shows that every relevant organisation in the field has taken up the issue of women in science. While universities have the most practical impact on the situation of women in academia, the federal and state governments have established programmes to promote women and try to offer direction through financial incentives. Some institutions can only act on an advisory basis or provide examples of best practice. They have an important discursive power, however, which shapes the strategy and reflects the thinking of the research policy scene. We now turn to a type of organisation that has both advisory and operational functions.

\subsection{The role of third party funding agencies in promoting gender equality}

The scientific system and its impact on the position of women in academia are mostly looked at from the point of view of universities. However, as Fuchs et al. (2001) highlight, universities represent only a part of the scientific system. The political and advisory bodies described above influence the scientific system by setting research policies and goals. Third party funding agencies have a twin function. First, they have an important operational role in the scientific system by distributing money. Financial resources enable researchers to realise their ideas beyond the means they already receive from their university. Additionally, third party funded projects (which means they are externally evaluated) are often seen as an important performance indicator, since funding is awarded only to those researchers whose projects succeed in the competition for the best ideas. Third party funding, there- 
fore, is not only regarded as a source of money, but also as a source of reputation. Second, precisely because of their important position in the system, funding agencies themselves can formulate research policies.

Looking at funding organisations' research policy and their funding practices sheds light on an area that is often overlooked in science studies. Most of the science policy studies presented above look at the question of why women drop out of science or what problems they have to face in the academic world. The policies that ministries or advisory bodies put forward mostly address the career prospects of women. Another point of view that Allmendinger and Hinz (2002) point to is the performance of women within the scientific system. How active are female professors? Can they successfully secure resources? Because funding agencies distribute resources and serve as a proof of quality, whether they "tend to conform to discrimination procedures or not is a crucial question in determining strategies for policies on scientific excellence in Europe. The complex problem of gender bias is a cornerstone in that discussion" (Sandström and Hällsten, 2004: 77). In Germany, the role of third party funding organisations in this matter has so far been neglected in many science studies.

When applying for third party funding, a researcher submits a proposal for his or her project which is then evaluated by peers. Depending on the result of the evaluation, it will be rejected or funded. This gives the funding agency the power to "let people into the system", or to keep them out.

Husu points out the importance of gatekeeping, a concept that was introduced by Kurt Lewin (1943): "The dual nature of gate-keeping is important to emphasise, that gate-keeping can function as exclusion and control on the one hand and facilitation, on the other" (Husu, 2004). While editors of scientific journals were the "classical" gatekeepers in science (de Grazia, 1963; Crane, 1967), Merton (1973) also applied this concept to institutions that allocate human and financial resources.

Referring to Acker's concept of gendered organisations, one can look at funding organisations as gatekeepers in research. According to Husu (2004: 71, 74):

gate-keeping in research funding is fundamental not only to the definition of scientific excellence but more generally to the construction of scientific knowledge... When exploring gate-keeping policies, the analysis focuses on the rules and regulations concerning the recruitment of gate-keepers (including referees), the construction of the criteria (eligibility and excellence) 
on which funding is allocated to the applicants and on explicit published policies and statements overtly or covertly related to gender (for example policies related to parental leave or encouraging women in particular to apply for grants, age limits, and use of generic masculine language in communication).

The mechanisms of third party funding can be analysed according to their effect on women.

The debate on women in science in the 1990s throughout the European Union has also informed the practices of research funding agencies. The European Commission publishes women's success rates when applying to funding agencies (EC, 2006). From a total of 26 countries, in 17 countries men have higher success rates, with the highest discrepancy in Cyprus (13.5 percentage points difference) and Austria (11.0 percentage points difference). In nine countries, women have better chances of securing funds from funding agencies, with Slovakia being the most favourable country for women $(-4.7$ percentage points difference). The success rates are calculated in relation to the numbers who apply, and do not speak about the representation of women among the applicants. Therefore, for a complete picture one has to take into account the size of the pool of potential applicants.

Studies have shown that the proportion of women who apply for research funding is less than their proportion in the pool of scientists. Grant et al. (1997) stated this problem of self-selection in applications for the British Medical Research Council. Research Councils were especially under scrutiny because of the differing success of men and women in securing research funds. A study by Wenneras and Wold (1997) found gender bias in the evaluation of postdoctoral fellowships, therefore within the procedures of a funding agency itself. This is why funding agencies have come into focus. The expectation is that "a critical analysis of the dynamics of gate-keeping in research funding and its gendered aspects can inform science policy and the policies and practices of funding organizations towards greater gender awareness and fairness" (Husu, 2004: 75).

\subsection{The DFG and its role in research policy issues}

The German Research Foundation (DFG) is the central funding agency for basic research in Germany and the largest in Europe (Allmendinger and Hinz, 2002). It promotes research at universities 
and other publicly financed research institutions. The DFG is a membership organisation (its members are universities and academies) and it is therefore close to the scientific community. Its importance in the science system stems from its role in distributing resources, while its dominant position as the self-governing organisation of science in Germany also gives it a mandate for positioning itself in research policy debates. According to its statutes, the DFG advises parliaments and public authorities on questions relating to science and research. This role of the DFG has therefore become increasingly important over recent years. The DFG also reaches into the member organisations and can trigger changes within them.

With an annual budget of approximately EUR 1.8 billion, the DFG funds more than 20,000 research projects in all areas of science and the humanities each year. The projects are funded within different funding schemes. The most important is the Individual Grants Programme, although in financial terms the Coordinated Programmes have taken the lead. In the Individual Grants Programme and the Direct Funding of Young Researchers, individuals apply for grants or for funding for a position in a project. In Coordinated Programmes, a group of researchers write an application which is then submitted by the university. The university is also asked to contribute to the financing of the project. Therefore, the DFG has a direct influence on the thematic profile and on the infrastructure of universities. Because of this power to decide on projects and positions, it can be described as a gatekeeper in the science system.

Since 2002, gender equality has been a statutory goal of the DFG. To begin with, the senate, the main decision making body of the DFG, installed a Senate Committee on Women in Science. Its final report, submitted during April 2008, put forward several recommendations regarding how the DFG could improve its funding schemes to better meet the interests of women. As a follow-up, in December 2007, the Executive Committee set up a commission to propose "research-oriented standards on gender equality" which were to be agreed on by the member universities at the general assembly in July 2008.

The DFG wants to contribute to equal opportunities in accordance with its role in the research policy landscape. First, it seeks to ensure that the proportion of applications submitted by women to the DFG is at least as high as the proportion of women among researchers at universities, so that the process of applying to the DFG for project fund- 
ing is not an additional hurdle in the scientific career of women. Then, the funding success should not depend on the gender of the applicant. Second, it wants to design its funding schemes in a way that encourages more women to pursue an academic career. Finally, it encourages universities to employ more women and provide better working conditions for them, either directly by requiring corresponding measures when funding projects, or indirectly by giving universities directions through their membership.

What has been lacking so far is a sound knowledge of the current position in quantitative and qualitative terms.

\section{DFG's procedures: empirical results}

The results of studies in the field of science policy and gender studies, more generally of women in science, inform the policy decisions of the DFG. Two of the cornerstones of the policies of the DFG are therefore:

- women should participate in the funding schemes in numbers that correspond to their representation at the respective scientific level;

- the processes within the DFG should not be gender biased, so that women should have an equal chance of a proportionate share of the money distributed.

It is important both for symbolic reasons ("role models"), for reasons of fairness in the process and for the success of women in securing awards that women are represented at every level and in every process in proportionate numbers.

To pick up on the last point, the number of women in the decisionmaking bodies of the DFG is comparatively high. In the two bodies responsible for decisions on scientific policy, the Executive Committee and the Senate, $25 \%$ of members are female. At the last election for review board members in 2007, the proportion of women rose from $11.6 \%$ to $16.8 \%$

However, funding agencies cannot act guided only by political considerations. They are in the middle position between the scientific system and the political system. In many countries it is not programme officers but scientific committees that are "in command of the work" (Sandström and Hällsten, 2004: 77, for the case of Sweden). This is true of the DFG in Germany, too. They cannot directly influence procedures 
and priorities in distributing grants. The cornerstone of the DFG's procedures in deciding on the distribution of research grants is the peer review. Therefore, the gender aspect of the peer review is crucial in understanding what an agency that relies on scientific decision making can do to ensure equal opportunities.

The DFG depends on an independent multi-tiered peer review system. The DFG Head Office manages the review process. It selects the reviewers, drafts funding recommendations, and notifies the applicants about the decision and about the comments of the reviewers.

The peer reviewers, who are selected by the DFG's Head Office to review a proposal on account of their subject-specific expertise, carry out either written reviews for funding schemes such as the Individual Grants Programmes and the Direct Funding of Young Researchers, or oral reviews, as is often the case for Coordinated Programmes. The criteria they apply include the quality of the proposal, the qualifications of the principal investigator, the originality and innovativeness of the project, the feasibility of the working programme, the existing and requested resources and infrastructure, and the funding requirements. The peer reviewers make a suggestion to fund a project, which is checked by review boards, ${ }^{1}$ and is then decided on by the Joint Committee.

\subsection{Functioning of peer review processes}

In the research system, peer review has an important role to ensure quality and to secure trust in scientific results. It has a central role in scientific communication (Hirschauer, 2004) and has - in publishing and in funding decisions - the role of a central gatekeeping mechanism. Therefore, peer review is under scrutiny. If criteria other than the scientific determine the review of scientific results, the production of knowledge is in danger (Hull, 1990, as cited by Bornmann, 2007). The main focus of studies on the peer review process is the validity

\footnotetext{
${ }^{1}$ Elected, honorary members of the review board meet on a quarterly basis and evaluate the quality of the review process. They ensure adherence to quality standards across programmes and monitor the selection of reviewers. They evaluate and compare reviews and participate in on-site visits. This is intended to ensure a clear separation of the peer review and the evaluation of this review (quality assurance). The review boards have an additional advisory function to the DFG in matters regarding strategic planning. Recently, a survey of review board members has given some insights into the functioning of the DFG's new review board system, which was established in 2004 (Hornbostel and Olbrecht, 2007).
} 
of peer review. Concern was raised when studies on the peer review procedure in the National Foundation showed that the evaluation of research grants depended on contingent factors (Cole et al., 1978). Not only the validity, but also the gender equality aspect have been criticised recently (for an overview, see Bornmann, 2004).

The functioning of the peer review system and the potential for gender bias within it are important issues to determine whether women are disadvantaged in science. The results of potential gender bias are contradictory. One influential study on this question is the work of Wenneras and Wold, which suggests that women have to publish more to be treated equally to men when applying for postdoctoral grants at the Swedish Medical Research Council (Wenneras and Wold, 1997). Nervik has also found gender bias, most striking in coordinated programmes (Nervik, 2006, as cited by Melin, 2007). Bornmann et al. (2007) conducted a meta-study on this topic, drawing the conclusion that even though the gender effects vary from study to study, men generally have a greater chance of receiving funding than women.

Regarding the causes of this gender bias, Melin (2006) distinguishes between additive and reasoning evaluation methods in peer review, the former with strict rating scales and rather transparent evaluation criteria, the latter with a more intuitive procedure. According to Melin, reasoning evaluation methods, which are often used in coordinated programmes, are less favourable for women. An often cited study of the peer review processes in the National Science Foundation (NSF) showed for the discipline of economics that the success of a proposal is not only dependent on the gender of the applicant, but also on the gender of the reviewer. Female reviewers tend to rate proposals by female applicants more severely than their male colleagues (Broder, 1993).

A detailed look at the involvement of women in the DFG's peer review system shows that of all researchers who wrote reviews for the DFG in 2007, 12.0\% were women. The peer reviewers are predominantly professors. However, compared to the proportion of female professors at German universities, which was $13.6 \%$ in 2006, women are still underrepresented among DFG peer reviewers (see Hinz et al., 2008). Women are also asked less frequently to carry out reviews than men. While men wrote 3.4 reviews on average in the 3-year period from 2005 to 2007, women wrote only 2.7 reviews (DFG, 2008).

A study commissioned by the DFG on the subsequent career development of former DFG fellows who had participated in postdoctoral 
programmes (Enders and Mugabushaka, 2004) included an analysis of the prevalence of certain opinions regarding the peer review process used in the DFG. Comparing the answers given by male and female respondents, it is evident that women are more sceptical when it comes to the question of whether women and men are treated equally by peer reviewers.

Table 1. Opinion of the peer review process by gender ${ }^{\star}$

\begin{tabular}{lccc}
\hline & Men & Women & Total \\
\hline $\begin{array}{l}\text { Men and women are treated equally by peer } \\
\text { reviewers }\end{array}$ & 72.1 & 38.2 & 65.1 \\
$\begin{array}{l}\text { Younger and established researchers and } \\
\text { scientists are treated equally by peer reviewers }\end{array}$ & 22.7 & 13.5 & 20.8 \\
$\begin{array}{l}\text { There are mechanisms in place to ensure that } \\
\text { the best funding proposals are granted }\end{array}$ & 24.7 & 18.3 & 23.3 \\
$\begin{array}{l}\text { Peer reviewers are open to unconventional ideas } \\
\text { Peer reviewers are objective and neutral in spite } \\
\text { of the competitive situation }\end{array}$ & 14.0 & 8.7 & 12.9 \\
\hline Number & 39.5 & 27.9 & 37.1 \\
\hline
\end{tabular}

Answer categories 1 and 2 , in percentages ${ }^{2}$

This scepticism can also be observed, albeit less strongly, when the respondents are asked whether the peer review process guarantees equal opportunities for young and established researchers and scientists, and when questions are posed about the selection of the best funding proposals, the objectivity and neutrality of the peer reviewers, and openness to unconventional ideas.

The fact that female scientists have the impression that gender bias exists corresponds to the results of a study on leaders in social arenas. Skjeie and Teigen (2003, as cited by Husu, 2004: 72) found gender differences in how elite groups "explained the persistent male dominance in top positions either in their own arena or more generally". While every fourth woman agreed that direct discrimination in appointments was an important explanation for male dominance in their own activ-

${ }^{2}$ Question: What is your opinion of the "peer review process" (on a scale of $1=$ agree completely to $5=$ disagree completely). Based on a survey of applicants who had been granted research funding. Source: Enders and Mugabushaka, 2004. 
ity area, the male elite rejected this explanation nearly unanimously. It seems to be quite common for male and female professionals to hold quite different views on the gender neutrality of the system they are working in.

\subsection{Distribution of resources: applications for and success with research grants}

Empirical studies show that women have fewer resources at their disposal to conduct their research than men (Lind, 2006, and see there for literature). Grant et al. (1997) argue that this is a result of self-selection mechanisms. This could either imply that women have to turn to external (third party) funding to realise their projects. Alternatively, they are also underrepresented when it comes to securing project grants. What is the situation with the DFG?

In 2007 , the share of project applications by women in the Individual Grants Programme was only $17.0 \%$. How well does this reflect the proportion of women at German universities? The proportion of women funded under the Individual Grants Programme is more or less in line with the proportion of female professors, and from 2000 onwards it is generally slightly higher. However, compared to the pool of people eligible to apply, which is not only professors but all researchers with a $\mathrm{PhD}$, women are underrepresented among applicants.

Figure 1. Share of applications by women in all applications in the Individual Grants Programme (2007)

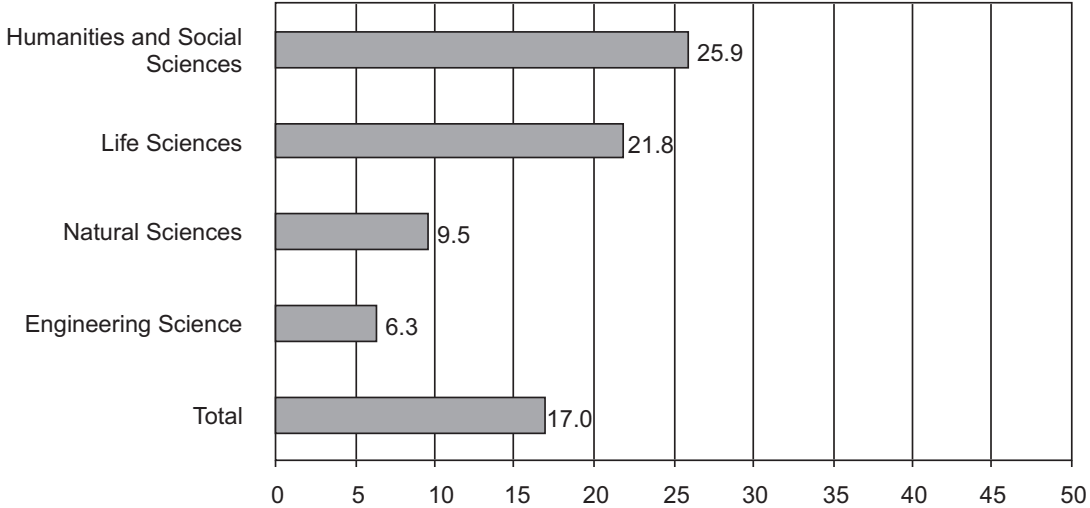


The decision on research grants is, as described above, the result of a peer review process. Looking at the outcome of this process in the case of the DFG, the success of women in securing project funding in the Individual Grants Programme was 5.1 percentage points lower in 2007 than the funding success of men.

However, the reasons for this are not clear. Gender bias in DFG's peer review processes could only be diagnosed if all proposals were equal in every respect but in the gender of the applicant. This is, of course, not true. Hinz et al. (2008) analysed the funding success in the Individual Grants Programme of the DFG for 14 years (1991-2004). Keeping other factors (year of application, discipline, money applied for, etc.) constant, the funding success of women is less than 1 percentage point lower than that of men. Nevertheless, there is still a unidirectional discrepancy, for which the reasons are not yet known. More studies are needed to analyse this result.

Figure 2. Success of female and male applicants in securing research grants in the Individual Grants Programme (2007)

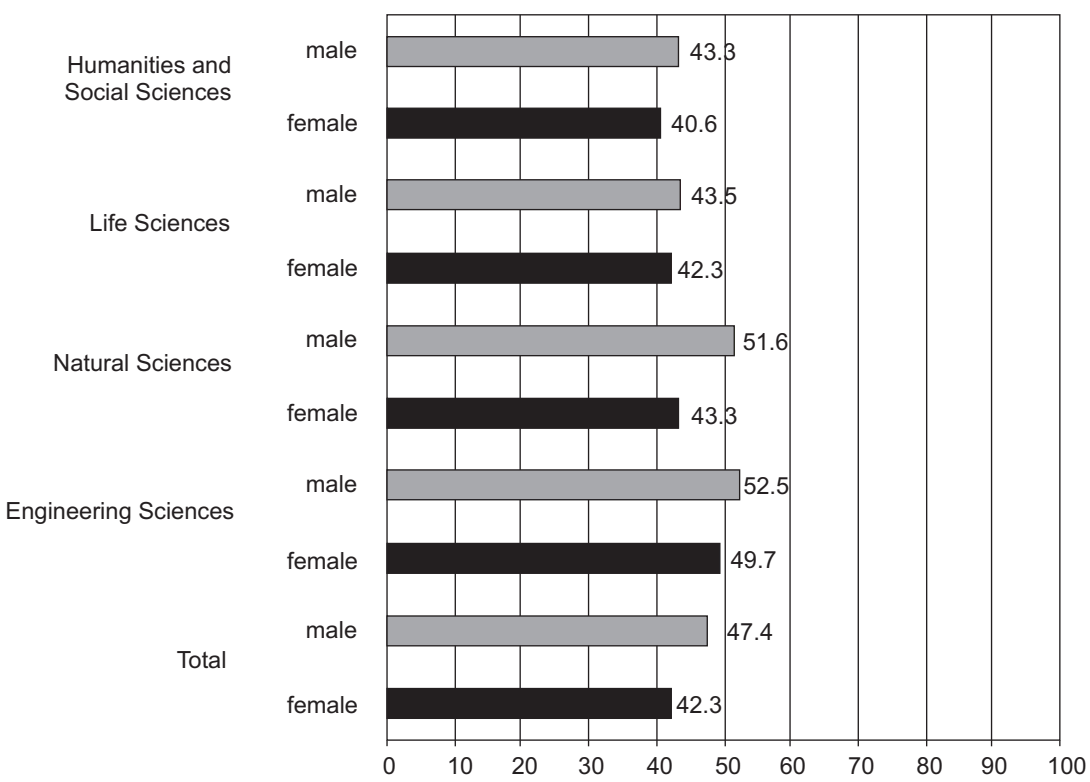

The selection and promotion of young researchers is one of the key ways of directing long-term improvements in gender-specific oppor- 
tunities in academia. Participation in DFG-funded research projects offers young scientists a start to their research career (so-called "indirect promotion of young researchers"). Moreover, the DFG also offers programmes directly targeting young scientist in their postdoctoral phase, including research fellowships, temporary positions for principal investigators, the Emmy Noether Programme and the Heisenberg Programme ("direct promotion of young researchers").

The share of young women applying for all young researchers programmes was $30.1 \%$ in 2007 (the funding quota was 1.8\% lower than that of men). In comparison, the share of women obtaining a $\mathrm{PhD}$ is approximately $40 \%$ in Germany.

Figure 3. Share of female applicants in all applicants for Programmes for Young Researchers (2007)

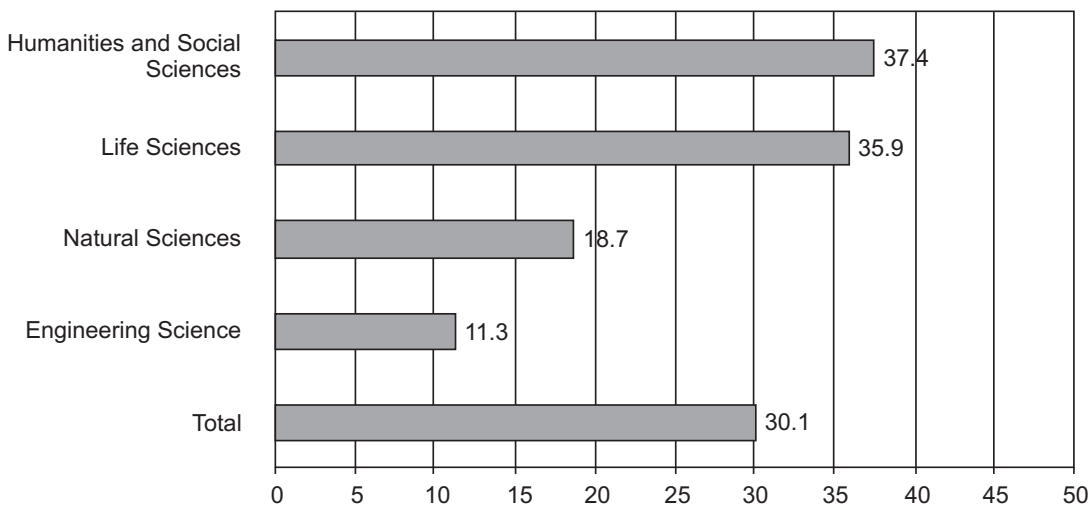

The lower proportion of women applying for Programmes for Young Researchers compared to the number of women obtaining a $\mathrm{PhD}$ is an indicator that this is the stage of a scientific career where the "leaking pipeline" loses many women. Surveys conducted among DFG applicants underline that women are less confident in their career planning than their male counterparts.

\subsection{Career planning}

That there are so few women at the upper levels of the hierarchy is most likely due to a mix of self-selection and selection by others. Women have to make a decision on whether to proceed in their scientific career 
based on subjective judgements, first on their career prospects, and second on the possibility to pursue both a career and have a family (von Stebut, 2003). Often, it seems that institutions and professors are hesitant to invest in the career of women and to support them as much as men because of the fear they might leave academia (Beaufays, 2003; von Stebut, 2003). In addition to the raw factual data generated by an analysis of the DFG's funding data, it is particularly revealing to compare the expectations that young DFG funding recipients have of their own career and how these expectations vary between men and women.

Women seem to be less persuaded to pursue an academic career. In the DFG survey of research funding applicants (2002), $24 \%$ of male project staff employed in DFG funded projects, but only $16 \%$ of female project staff, said that they hoped to become university lecturers. Female respondents more often have ambitions of pursuing a research career outside academia.

Table 2. Career goal by gender*

\begin{tabular}{lrrr}
\hline & Men & Women & Total \\
\hline A career as a university lecturer & 23.8 & 15.7 & 21.0 \\
Another scientific career & 29.9 & 37.9 & 32.7 \\
A non-scientific career & 9.3 & 4.9 & 7.8 \\
As yet undecided & 36.9 & 41.6 & 38.5 \\
Total & 100.0 & 100.0 & 100.0 \\
\hline Number & 815 & 428 & 1.243 \\
\hline
\end{tabular}

${ }^{*}$ in percentages ${ }^{3}$

The DFG's surveys of research funding applicants also show that, in comparison to their male counterparts, female project staff consider it more important to establish themselves in the scientific community by means of publications, participation in scientific conferences, and contact with other researchers and scientists. This also comes from the view that in Germany a scientific career is decisively dependent on the support of scientific mentors (Lind, 2006; Krimmer and Zimmer, 2003). However, the chances of actually being able to

\footnotetext{
${ }^{3}$ Question: What is your main career goal? Source: DFG survey of research funding applicants, 2002.
} 
obtain this support are perceived less optimistically by women. Even though the differences between men and women are not that great, the overall outcome for women is the consistently greater discrepancy between the priority given to certain aspects of further scientific accomplishment and the chances of achieving this than is the case for men (DFG, 2002).

Table 3. Aspects of further scientific accomplishment by gender ${ }^{*}$

\begin{tabular}{lllll}
\hline & & Men & Women & Total \\
\hline $\begin{array}{lllll}\text { Publication of the (interim) results of my } \\
\text { research work }\end{array}$ & Importance & 85.3 & 87.2 & 85.9 \\
\cline { 2 - 5 } & Chances of achieving & 77.2 & 70.3 & 74.8 \\
\hline \multirow{2}{*}{\begin{tabular}{llll} 
Participation in scientific conferences \\
\cline { 2 - 5 }
\end{tabular}} & Importance & 70.3 & 79.1 & 73.3 \\
\hline $\begin{array}{lllll}\text { Contact to researchers and scientists from } \\
\text { other universities or research institutes }\end{array}$ & Importance & 75.4 & 82.7 & 77.9 \\
\cline { 2 - 5 } & Chances of achieving & 64.0 & 57.3 & 61.7 \\
\hline Number & & 809 & 421 & 1.230 \\
\hline
\end{tabular}

* Answers to categories 5 (important) and 6 (very important) in percentages ${ }^{4}$

\section{Instruments of a funding agency}

As seen above, the empirical data relating to the DFG mirrors findings from other studies on women in science: women tend to drop out of the system at an early stage. They are sceptical of the system with regard to their career prospects, as well as in terms of the fairness of the processes within funding agencies. In addition, there is, in fact, a small disadvantage in funding success.

The DFG reacts to such empirical data in two ways. On the one hand, it uses the information to adapt its policies and internal processes. On the other hand, it tracks developments and makes informa-

${ }^{4}$ Question: How important are the following activities in terms of their relevance to your scientific work in this research project to you personally (on a scale of $1=$ unimportant to $6=$ very important)? Question: Does your scientific work on this research project give you the opportunity to achieve these activities (on a scale of $1=$ not at all to $6=$ very important)? Source: DFG survey of research funding applicants, 2002. 
tion available, thus assuming responsibility for the influence it has on the scientific world.

At the general assembly in July 2008, the DFG adopted "Research oriented standards on gender equality". These standards will target processes within the DFG's member institutions, but also processes within the DFG itself. The DFG commits itself to organising its processes in a transparent, structured and formalised manner. As opposed to relying on votes originating from ties to individual persons, it always requires external votes. Review processes must focus on the scientific accomplishments of the person and the merit of the project without prejudice towards the people involved.

The member organisations will be asked to commit themselves to standards in their institutional structures, making gender equality a permanent goal at all levels of their organisation. They should facilitate work-life-balance and commit themselves to transparency and to standards for gender equality in human resources. A "tool box" containing ideas and examples for the implementation of these standards will be offered by the DFG, and rounds off the new standards. The responsibility for implementing the "research oriented standards on gender equality" rests with every single member organisation. Many of these suggestions concern the human resources policy of an organisation, which is not within the DFG's area of influence. The DFG's position can only be to provide best practice examples and to encourage its member organisations to adhere to the standards by making its goals explicit and setting incentives for its members to adhere to them.

Apart from the "standards on gender equality", there are also other very practical conclusions that the DFG has already drawn from the results of the analysis of the situation (see also Brennecke-Schröder and Koch, 2007), where the most important field of activity is raising awareness within its own bodies, as well as in the scientific community:

- for 2009, the DFG plans an extensive information campaign which addresses female scientists and universities and includes information on its programmes and the specific support it offers women;

- at the initial meetings of the newly elected review boards at the beginning of 2008, in each committee there was a special section on equal opportunities. This will be expanded into a gender sensitivity training programme; 
- the DFG now requires a discipline-specific representation of women in review groups (at least one woman per group);

- the gender equality concepts of the universities are part of the review process of Coordinated Programmes (when universities apply);

- in the last election of review board members in 2007, a target was set for the proportion of female candidates. The organisations eligible to propose candidates were explicitly asked to propose women. The plan was for the candidate list to contain $18 \%$ women (a 50\% increase from the last election which saw 11.3\% women on the list). The target was not met, although the share did increase to $16.8 \%$.

- for the most prestigious scientific award of the DFG, the Gottfried Wilhelm Leibniz prize, to the value of EUR 2.5 million, the DFG explicitly and repeatedly asked the eligible parties to nominate women. As a result, the number of female candidates increased considerably. Three women won the prize in 2008 (out of 11 prize winners in total).

That young female researchers feel only little encouragement, support and integration into the scientific community in Germany (for further studies, see Lind 2006) is a problem that can only very indirectly be tackled by the DFG:

Career reliability has to be established early on, and [that] the distribution of support, as well as the rationale for its provision, must be agreed on the basis of formalised procedures within the scientific organization itself. Support, mentoring and advice are important inputs to careers in science

(Fuchs et al., 2001: 198).

While in some coordinated programmes like research training groups the DFG suggests formalised agreements between $\mathrm{PhD}$ students and their professors, it has no means of enforcing these. However, the DFG wants to send out signals to young women that they can apply for assistance in the difficult phase of founding a family, when traditionally many of them leave the system. Therefore, in 2008, the DFG also changed the regulations in its programmes to better meet the interests of women:

- both male and female research grant receivers can extend their research grants for a maximum of one year when a child is born; 
- in all Coordinated Programmes (most notably Collaborative Research Centres and Research Training Groups), the applicants can apply for a lump sum of EUR 15,000 to EUR 50,000 per year to promote gender equality (e.g. mentoring programmes, childcare facilities, additional staff to help project leaders with children in routine activities).

In addition to implementing these changes in its procedures, there needs to be a continuous process to check whether the measures taken have actually resulted in change for women in science. Therefore, the DFG will regularly carry out an analysis based on more information and a broader set of indicators (Güdler and Reinhardt, 2007). A monitoring system is an important steering instrument for the DFG. It provides information for every single project officer in the Head Office dealing with proposals on a day-to-day basis. It is of particular importance for the decision-making bodies within the DFG, including the Executive Committee and the review boards that are responsible for shaping the research policy of the DFG. The monitoring system will serve as a starting point for further analysis. Increasing knowledge on the effects of the programmes and implementing more effective policy action go hand in hand.

All these changes have been quite new. Their effects will be the subject of future analysis.

\section{Conclusion and future prospects}

For about two decades, gender equality has been a prominent topic in the science policy scene in Europe. Many empirical studies have shown different impediments for the scientific careers of women, and the gendered dimension of the scientific field has also been analysed. These studies have helped to gain an understanding of the problems faced by women working in academia. Taking the example of Germany, many policy makers are conscious of these questions and try to formulate policies that address them.

In the research policy scene, third party funding agencies have an intermediary role. Because of their proximity to the scientific community, they are important consultants for ministries and, as member organisations, they have the authority to formulate science policy recommendations. At the same time, they act as gatekeepers for financial resources and for scientific reputation, and are therefore part of the 
(gendered) scientific field. Given this, a closer look at the peer review processes underlying the funding operations can help to find potential gender bias within funding agencies.

In studies of the peer review processes, there is no clear result on how strong the bias is and from where it stems. The same is true of the DFG's peer review process. While there is (small) bias, the reasons for it are yet unknown. One important but open question is whether, how much, and in what way the scientific output of women and men differs. It can be shown that women apply in smaller numbers for third party funding than their actual proportion in the pool of researchers. This might be a result of distrust in the fairness of the peer review procedure. If women at an early stage in their careers report subjective experience, or even just a subjective sense, of being at a disadvantage to their male counterparts, then this calls not only for individual measures but for policy action.

The DFG has made gender equality one of its statutory goals and has recently decided on many policies intended to promote women. The results of these efforts, which were agreed upon mainly during the past year, naturally cannot be evaluated yet. However, all this calls for cautious optimism at least. The number of women in science has risen steadily in Germany over the past years, but they are still underrepresented. While more programmes and measures to promote the longterm integration of women are certainly needed (von Stebut, 2003), as has been shown, many actors in research policy have already started programmes. Their success also depends on the right analysis of the problem. Studies on the careers of female scientists can help in formulating the appropriate policy answers, as can the study on gendered dynamics that exists in organisations within the scientific system. Instead of just calling for improvements in the system in general, every organisation has to look at its own processes and their gender-specific outcomes.

This chapter has focused on the role of the DFG in the scientific system in Germany and on some of the gender-specific outcomes of the DFG's processes. The DFG is moving towards a paradigm shift in its women's policy by acknowledging the gender dimension of its action and by monitoring the gender-specific results of its activities.

Further consideration of these efforts will give more insights into the processes at play within the science system. Gender equality is a field where many more questions about the science system arise. One 
topic for further exploration is the role of different actors in the research policy scene and the effectiveness and impact of their policies. Science policy studies could profit from an analysis of the programmes geared to women to find answers to questions of efficient policy making in research. When the number of women in higher positions increases, an analysis of their performance and their success with third party funding will become even more revealing. Studies on the mechanisms and gendered outcomes of the peer review system can be another important contribution to the discussion of the gender dimension of the scientific system. The case of the equal opportunities policy of the DFG in Germany could therefore serve as a starting point for exploring more questions in science policy studies.

\section{References}

ACKER, Joan (1990). Hierarchies, jobs, bodies: A theory of gendered organizations. Gender \& Society, 4 (2), 139-158.

ALLEN, Margaret, \& CASTLEMAN, Tanya (2001). Fighting the pipeline theory. In Ann Brooks and Alison Mackinnon (Eds.), Gender and the restructured university: Changing management and culture in higher education (pp. 151-165). Buckingham: Open University Press.

ALLMENDINGER, Jutta, \& HINZ, Thomas (2002). Programmierte (Un-) Gleichheit? Zeitschrift für Soziologie, 4, 275-293.

BAGILHOLE, Barbara, \& GOODE, Jackie (2001). The contradiction of the myth of individual merit, and the reality of a patriarchal support system in academic careers: A feminist investigation. European Journal of Women's Studies, 8 (2), 161180.

BEAUFAYS, Sandra (2003). Wie werden Wissenschaftler gemacht? Beobachtungen zur wechselseitigen Konstruktion von Geschlecht und Wissenschaft. Bielefeld: Transcript Verlag.

BELL, Sharon, \& BENTLEY, Rhonda (2005). Women in research. Discussion Paper. AVCC National Colloquium of Senior Women Executives.

BENTLEY, Jerome T. \& ADAMSON, Rebecca (2003). Gender differences in the careers of academic scientists and engineers: A literature review. Washington: NSF 03322.

BLK (2006). Frauen in Führungspositionen an Hochschulen und außerhochschulischen Forschungseinrichtungen. Bonn: Bund-Länder-Kommission.

BORNMANN, Lutz (2004). Stiftungspropheten der Wissenschaft. Zuverlässigkeit, Fairness und Erfolg des Peer-Review. Münster: Waxmann Verlag.

BORNMANN, Lutz (2007). Grundlegende Kommunikationsprozesse und stabilisierte Mechanismen für die Erzeugung gesicherter Erkenntnisse. Eine Übersicht über den Theoriestand in der Wissenschaftssoziologie. Sociologia Internationalis, 45 $(1 / 2), 177-200$. 
BORNMANN, Lutz, MUTZ, Rüdiger \& DANIEL, Hans-Dieter (2007). Gender differences in grant peer review: A meta-analysis. Journal of Informetrics, 1, 226-238.

BRENNECKE-SCHRÖDER, Doris, \& KOCH, Stefan (2007). Die Förderung der Gleichstellung von Männern und Frauen durch die DFG - Stellungnahme zur Studie "Wissenschaftlerinnen in der DFG -Antragsaktivitäten, Förderchancen und Funktionen”. Bonn: Deutsche Forschungsgemeinschaft.

BRODER, Ivy E. (1993). Professional achievements and gender differences among academic economists. Economic Inquiry, 31, 116-127.

CEWS (2007). Hochschulranking nach Gleichstellungsaspekten, Bonn.

COLANDER, David, \& WOOS, Joanna Wayland (1997). Institutional demandside discrimination against women and the human capital model. Feminist Economics, 3 (1), 53-64.

COLE, Jonathan R. (1987). Women in science. In Douglas N. Jackson and J. Phillippe Rushton (Eds.), Scientific excellence, origins and assessment. Newsbury Park: Sage Publications, 359-375.

COLE, Stephen, RUBIN, Leonard \& COLE, Jonathan R. (1978). Peer review in the National Science Foundation. Phase one of a study. Washington: National Academy Press.

CRANE, Diana (1967). The gate-keepers of science. Some factors affecting the selection of articles in scientific journals. American Sociologist, 2, 195-201.

DFG (2002). DFG survey on research funding applicants. Bonn (unpublished): Deutsche Forschungsgemeinschaft.

DFG (2004). Annual survey of research training groups. Bonn (unpublished): Deutsche Forschungsgemeinschaft.

DFG (2006). Funding ranking 2006. Bonn: Deutsche Forschungsgemeinschaft.

DFG (2008). Gutachterinneneinsatz. Bonn (not published): Deutsche Forschungsgemeinschaft.

DEVER, Maryanne, BOREMAN, Paul, LAFFAN, Warren, BEHRENS, Karin, HAYNES, Michele, WESTERN, Mark \& KUBLER, Matthias (2008). Gender differences in post PhD employment and the influence of PhD experience and family circumstances. University of Queensland.

DOHERTY, Liz, \& MANFREDI, Simonetta (2005). Improving women's representation in senior positions in the higher education sector. Stage I: Findings. Oxford: Centre for Diversity Policy Research, Oxford Brookes University.

EC (2004). Gender and excellence in the making. Luxembourg: European Commission.

EC (2006). She figures 2006: Women and sciences - statistics and indicators. Luxembourg: European Commission.

ENDERS, Jürgen, \& MUGABUSHAKA, Alexis-Michel (2004). Wissenschaft und Karriere - Erfahrungen und Werdegänge ehemaliger Stipendiaten der Deutschen Forschungsgemeinschaft. Bonn: Deutsche Forschungsgemeinschaft.

ETZKOWITZ, Henry, KEMELGOR, Carol, NEUSCHATZ, Michael and UZZI, Brian (1994). Barriers to women's participation in academic science and engineering. In Willie Pearson and Alan Fechter (Eds.), Who will do science? Educating the next generation (pp. 43-67). Baltimore/London: Johns Hopkins University Press. 
ETAN (2000). Science policies in the European Union. Promoting excellence through mainstreaming gender equality. A Report from the ETAN Network on Women in Science. Brussels: European Technology Assessment Network.

BUKOF (2007). Chancengleichheit an Medizinischen Fakultäten und Universitätsklinika in Deutschland 2001/2005. Berlin: Federal Conference of Gender Equality Officers in Higher Education in Germany.

DESTATIS (2006). Hauptberuflich tätiges wissenschaftliches und künstlerisches Personal nach organisatorischer Zuordnung und Geschlecht (Sonderauswertung). Wiesbaden: Federal Statistical Office.

FORSTER, Nick (2000). A case study on women academics' view on equal opportunities, career prospects and work-family conflicts in a British university. Women in Management Review, 15 (7), 316-330.

FUCHS, Stefan, VON STEBUT, Janina \& ALLMENDINGER, Jutta. (2001). Gender, science, and scientific organizations in Germany. Minerva, 39, 175-201.

HRK (2006). Empfehlungen des 209. Plenums der Hochschulrektorenkonferenz "Frauen Fördern" vom 14. 11. 2006. Bonn: German Rector's Conference.

GRANT, Jonathan, BURDEN, Simon \& BREEN, Gilian (1997). No evidence of sexism in peer review. Nature, 390, 438.

de GRAZIA, Alfred (1963). The scientific reception system and Dr Vellkovsky. American Behavioural Scientist, 7, 38-56.

GÜDLER, Jürgen (2006). CRIS as a management tool: Experiences and perspectives at the German Research Foundation (DFG). Conference on Current Research Information Systems CRIS 2006. Bergen, 10-13 May 2006.

GÜDLER, Jürgen, \& HAHNEN, Holger (2008). Quality is the product is the quality information management as a closed-loop process. Conference on Current Research Information Systems CRIS2008. Maribor, 5-6 June 2008.

GÜDLER, Jürgen, \& REINHARDT, Anke (2007). Gender equality in DFG research funding - facts and assessment. Bonn: Deutsche Forschungsgemeinschaft.

HADULLA-KUHLMANN, Christina, \& HARTUNG, Barbara (2002). Women in science. Review of the situation in Germany. In EC. Women in science. Luxembourg: European Commission.

HINZ, Thomas, AUSPURG, Katrin \& FINDEISEN, Ina (2008). Wissenschaftlerinnen in der DFG. Antragsaktivitäten, Förderchancen und Funktionen. Bonn: Deutsche Forschungsgemeinschaft.

HIRSCHAUER, Stefan (2004). Peer Review Verfahren auf dem Prüfstand. Zum Soziologiedefizit der Wissenschaftsevaluation. Zeitschrift für Soziologie, 33 (1), 62-83.

HORNBOSTEL, Stefan, \& OLBRECHT, Meike (2007). Peer Review in der DFG: Die Fachkollegiaten. Bonn: iFQ-Working Paper No. 2.

HULL, David (1990). Particularism in science. Criticism - A Quarterly for Literature and the Arts, 32 (3), 343-359.

HUSU, Liisa (2004). Gate-keeping, Gender equality and scientific excellence. In EC. Gender and excellence in the making. Luxembourg: European Commission, 6976. 
INTERNATIONALE KOMMISSION (1999). Forschungsförderung in Deutschland. Bericht der internationalen Kommission zur Systemevaluation der Deutschen Forschungsgemeinschaft und der Max-Planck-Gesellschaft, Hannover.

JOAS, Hans (1990). Die Benachteiligung der Frauen in der Wissenschaft. Die Neue Gesellschaft Frankfurter Hefte, 239-244.

JOHNSON, George E., \& STAFFORD, Frank P. (1974). The earnings and promotion of women faculty. The American Economic Review, 64 (6), 888-903.

$\mathrm{KOCH}$, Stefan (2006). Die Deutsche Forschungsgemeinschaft und die Reform ihres Begutachtungssystems: Zur Einführung der Fachkollegien. Wissenschaftsrecht, 39, 25-47.

KRIMMER, Holger, \& ZIMMER, Annette (2003). Karrierewege von Professorinnen an Hochschulen in Deutschland. Zeitschrift für Frauenforschung und Geschlechterstudien, 21 (4), 18-33.

LEWIN, Kurt (1943). Forces behind food habits and methods of change. Bulletin of the National Research Council, 108, 65.

LIND, Inken (2006). Kurzexpertise zum Themenfeld Frauen in Wissenschaft und Forschung. Bonn: Informationszentrum Sozialwissenschaften.

MacFARLANE, Allison, \& LUZZADDER-BEACH, Sheryl (1998). Achieving equity between women and men in the geosciences. GSA Bulletin 110 (12), 1590-1614.

MELIN, Göran (2007). Reviewing applications by women: Critical use of additive and reasoning evaluation methods. SISTER Working Paper 2007-68. Stockholm: Swedish Institute for Studies in Education and Research.

MERTON, Robert (1973). The Sociology of science: Theoretical and empirical investigations. Chicago: University of Chicago Press.

NERVIK, Beata (2006). Ansökningar till strategiska forskningscentra. En jämförande undersökning av könsförderlningen i ansökningarna till strategiska centra respektive traditionella projektbidrag" Power-Point-Presentation. Retrieved on 25 May 2008 from <http://www.idas.nu/filer/Strategiska_centra_okt-06.ppt>

SANDSTRÖM, Ulf, \& HÄLLSTEN, Martin (2004). Springboard or stumbling block - can research councils promote scientific excellence without gender bias? EC: Gender and excellence in the making. Luxembourg: European Commission, 77-89.

SKJEIE, Hege, \& TEIGEN, Mari (2003). Men imellom, Mansdominans og likestillingspolitikk (Between men, male dominance and gender equality policies). Oslo: Gyldendal Akademisk.

SONNERT, Gerhard (1995). Who succeeds in science? The Gender Dimension. New Brunswick: Rutgers University Press.

VON STEBUT, Janina (2003). Eine Frage der Zeit? Zur Integration von Frauen in die Wissenschaft. Eine empirische Untersuchung der Max-Planck-Gesellschaft. Opladen: Leske und Budrich.

WELLER, Christoph (2004). Beobachtungen wissenschaftlicher Selbstkontrolle. Qualität, Schwächen und die Zukunft des Peer Review- Verfahrens. Zeitschrift für Internationale Beziehungen, 11 (2), 365-394.

WENNERAS, Christine, \& WOLD, Agnes (1997). Nepotism and sexism in peer-review. Nature, 387, 341-343. 
WHITE, Kate (2004). The leaking pipeline: Women postgraduate and early career researchers in Australia. Tertiary Education and Management, 10, 227-241.

WISSENSCHAFTSRAT (2007). Empfehlungen zur Chancengleichheit von Wissenschaftlerinnen und Wissenschaftlern des Wissenschaftsrates vom 13. Juli 2007 (Drs. 8036-07). Köln: Wissenschaftsrat. 
Appendix 



\section{List of figures}

- Proportion of researchers per thousand labour force by country (2003)

- Proportion of scientists and engineers in the total labour force by country (2004)

- Proportion of $\mathrm{R} \& \mathrm{D}$ expenditure in purchasing power standards (PPS) per capita researcher by country (2003)

- The segmentation of the European S\&T space

- Hierarchy of European countries according to S\&T development indicators

- Segmentation of the European S\&T space: clustering the countries

- Indicators of gender discrimination by S\&T segment

- Patterns of gender discrimination in the European S\&T space

- Correspondence Analysis Map for S\&T segments and patterns of gender discrimination in the European Space

- Countries within gender discrimination indicators

- Mentoring and career outcomes

- Male and female scientific personnel by sector 1998 - 2006

- Researchers by position in all Austrian universities

- Career-scripts as link between social institutions and individual acting

- Share of female professors without child/ren

- The average number of publications by natural scientists according to their gender and scientific field

- The average number of citations received by natural scientists according to their gender and scientific field

- Number of citations per publication according to the gender and field of natural scientists

- The average number of publications by social scientists according to their gender and scientific field

- The average number of citations received by social scientists according to their gender and scientific field

- Number of citations per publication according to the gender and field of social scientists

- Positioning the Digital Content Industry (DCI) sectors

- SCT model (Bandura, 2001) 
- Authors' concept to illustrate women's range of participation in the DCI

- The initial areas of interest emerging from the data as relevant to Bandura's model

- An early representation of the "Sphere of Influence" model

- An expansion of the "environment" category from the "Sphere of Influence" model

- Share of applications by women of all applications in the Individual Grants Program (2007)

- Success of female and male applicants in securing research grants in the Individual Grants Program (2007)

- Share of applications by women of all applications in Programs for Young Researchers (2007) 


\section{List of tables}

- Measures of S\&T segments

- S\&T systems and organisational academic culture in gender discrimination

- Associations between S\&T segmentation and gender discrimination indicators

- Sample mentoring programmes

- Productivity and work satisfaction for assistant and associate level faculty (difference of means)

- Identification of and initiation with primary mentor by field

- Types of collaboration with primary mentor (past two years) (mean responses by rank and gender: $0=$ no, $1=$ yes)

- Advice sought and resources received from primary mentor and other workplace relationships (mean responses: $0=$ no, $1=y e s$ )

- R\&D in Austria - employment by sector and sex

- Glass Ceiling Index in selected countries

- Employment structure in non-university research institutions in Austria

- Researchers in management positions and on boards at non-university research institutions in Austria, 2006

- Researchers in Austrian non-university research institutions

- Form of employment in non-university research institutions in Austria

- Gender arrangement of researchers with child/ren under 16 years

- Effects on career after child-birth (multiple responses)

- Reconciliation barriers (open question, answers ranked)

- Motivation aspects after child-birth

- Researchers' publications and citations (means and standard deviations) in the natural and social sciences from 1996 to 2005 (with ttests results)

- Comparison between lowly productive and highly productive men and women in the natural and social sciences - key indicators

- Significant predictors of the quantity and visibility of natural scientists' productivity

- Significant predictors of the quantity and visibility of social scientists' productivity

- Summary of empirical research explaining influences on women's participation in ICT 
APPENDIX

- Summary of the "types" of theory used as a scaffold for analytic generalisability

- How initial research findings help answer the research questions

- Theories, concepts and levels of analysis

- Research experience in Slovenia regarding level of analysis and main research experiences

- Opinion of the peer review process by gender

- Career goal by gender

- Aspects of further scientific accomplishment by gender 


\section{Contributors}

Helena Carvalho is an associate professor in the Department of Quantitative Methods at Lisbon University Institute (ISCTE), and senior researcher at the Centre for the Research and Study of Sociology (CIES/ISCTE) in Lisbon. Her research focuses on quantitative and multivariate methods for categorical variables, mainly interdependence and dependence methods using optimal scaling (Leiden school). She is the author of a recent methodological book and co-author of several other books, and has published articles in national and international scientific journals. She is a member of several local and international scientific associations.

Ruth Christie is an associate professor in the School of Information Technology and course co-ordinator for the Bachelor of Games and Interactive Entertainment at QUT, Brisbane. She has been teaching and researching in computer graphics and programming for twentyfive years, showing her support for women in computer science for much of this time. She has published papers in this area and received a number of outstanding achievement awards at state and university level for her work in this area, including the inaugural Office of Women and Women In Technology Outstanding Achievement Award, the QUT Equity Award, and the QUT Award for Outstanding Academic Contribution.

Danica Fink-Hafner is professor of political parties, interest groups and policy analysis at the University of Ljubljana and head of the Centre for Political Science Research at the Faculty of Social Sciences. She has taught in the USA (as a Fulbright scholar) and been a visiting researcher in the UK (including as a PECO grant recipient) and Norway. Her articles have appeared in Public Administration, Journal of European Public Policy, Journal of Communist Studies, Electoral Studies, Sociological Review and Journal of Southern Europe and the Balkans. Besides her other publications, she is the co-editor of the book Democratization in Slovenia: Value transformation, education, and media.

Anitza Geneve has been a vocational trainer, receiving a TAFE Unisys Award (Equity Outcomes) for her work with the Diploma of Multimedia for Women at Southbank Institute of Technology. She is an active volun- 
teer in initiatives that encourage women to enter the ICT field, recently featuring as a role model in the book Tech girls are chic: not just geek. Currently a PhD candidate and sessional lecturer in the Faculty of Science and Technology at the Queensland University of Technology, her $\mathrm{PhD}$ research topic explores influences on women's participation in the multimedia and games sector of the Australian Digital Content Industry.

Sven Hemlin is associate professor in psychology, senior researcher at the Gothenburg Research Institute (GRI), and senior lecturer at the Department of Psychology at the University of Gothenburg. He has been a visiting professor at Copenhagen Business School, and visiting research fellow at SPRU at the University of Sussex, TaSTI at the University of Tampere, and the School of Engineering and Applied Science at the University of Virginia. His interests are in scientific quality, creative knowledge environments and creative leadership. Sven Hemlin has published in Creativity Research Journal, Science, Technology \& Human Values, Scientometrics, Work, and other journals.

Agrita Kiopa is a doctoral student in public policy at the Georgia Institute of Technology and also holds the position of assistant professor at Vidzeme University College, Valmiera, Latvia, where she teaches policy analysis. In 2005, she was awarded a US Fulbright fellowship that allowed her to earn a Master of Public Administration from the Maxwell School of Citizenship and Public Affairs at Syracuse University, Syracuse, New York. Her research interests are related to the science and technology workforce, public management, understanding the benefits of social capital, and the application of social network analysis in policy research.

Julia Melkers is associate professor of public policy at the Georgia Institute of Technology, where she teaches research methods, programme evaluation and public policy. Her work addresses collaboration and outcomes in STEM fields and performance measures in public organisations, with a special emphasis on publicly-funded science and technology-based institutions. She is currently co-principal investigator on a large national US study of the social and professional networks of women in science. She has published articles in a number of public policy and public administration journals and serves on the editorial boards of Research Evaluation, Evaluation and Program Planning, State and Local Government Review, and Economic Development Quarterly. 
Karen Nelson is an associate professor in the School of Information Technology and director of first year experience at Queensland University of Technology, Brisbane, Australia. She teaches undergraduate and postgraduate students in information systems management and manages a large group of higher degree research students as well as pursuing research in the areas of knowledge management and organisational and social IT issues. She is a member of three professional organisations and contributes to ICT education through curriculum design and modelling. Recently her attention has been focused on the process of transition to higher education. She has published a monograph and received a national teaching award.

Luísa Oliveira is associate professor of sociology at Lisbon University Institute (ISCTE) and senior researcher at the Centre for the Research and Study of Sociology (CIES/ISCTE) in Lisbon. She has been a visiting professor at the École des Hautes Études en Sciences Sociales in Paris. Engaged in the research of science and technology, she has lately focused on gender discrimination in S\&T and on innovation studies. She has published two books, including a recent one on the sociology of innovation, and numerous works in national and international scientific journals. She is a member of several local and international scientific associations and scientific journal editorial boards.

Nikola Petrović graduated in sociology from the Faculty of Philosophy at the University of Zagreb, where he is also engaged in postgraduate doctoral studies in sociology. He is a research assistant at the Institute for Social Research in Zagreb. His special interests in science and technology studies include science policy research and the relationship between science and ideology.

Katarina Prpić is a tenured research advisor at the Institute for Social Research in Zagreb. Her research interests focus on the social organisation of science, scientific productivity and ethics, and marginal groups of scientists - especially women. Her scientific publications, both local and international, include thirteen authored, co-authored and edited books (three of which are in English). She has conducted graduate courses on the sociology of science at Zagreb University. In addition, she is a member of several local and international scientific associations and scientific journal editorial boards, and is also a winner of the Croatian Academy of Sciences and Arts Award for Social Sciences (2001). 
Anke Reinhardt graduated in social sciences from the University of Goettingen in Germany. After her studies, she worked as a research assistant at the University of Bremen but also integrated practical and scientific work in the field of labour market policy at a consultancy in Bremen and at the European Foundation in Dublin. Since 2006, she has worked as a programme officer for evaluation and statistics at the Deutsche Forschungsgemeinschaft (DFG, German Research Foundation), and is also a member of the DFG-internal working group for gender equality in academia. Her fields of interest include political sociology, labour market policy and research policy.

Helene Schiffbänker is a senior scientist at Joanneum Research in Vienna and head of FEMtech's scientific department. Her research in the fields of science and technology and creative industries focuses on working conditions in general and on gender-specific career aspects such as the reconciliation of work and private life, part-time work, and research culture. Basing counselling on empirical research, she advises and supports policymakers on the design and implementation of gender-mainstreaming and equality measures. She has published numerous empirical studies and national and international publications (both papers and a co-authored book) in German and English.

Adrijana Šuljok graduated in sociology from the Faculty of Philosophy at the University of Zagreb, where she is also currently engaged in postgraduate doctoral studies in sociology. She is a research assistant at the Institute for Social Research in Zagreb. Her fields of interest include social studies of science, science communication and bibliometric studies of scientific productivity.

Zeynep Esra Tanyildiz is a clinical assistant professor at the Andrew Young School of Policy Studies at Georgia State University, where she teaches courses on public policy, urban policy, and research methodology. Her research interest is in science and technology policy and urban policy, with a focus on scientific human capital, and the mobility of highly-skilled immigrants. She holds a bachelor's degree in city and regional planning, a master's degree in urban policy planning, and a doctorate in public policy. She is the co-author of a book on urban development (in Turkish), and the author of journal articles on foreign student mobility. 



\title{
Institute for Social Research - Zagreb (ISRZ) \\ Zagreb, Amruševa 11 \\ Tel. +38514810 264; fax: +38514810263 \\ e-mail: idiz@idi.hr
}

\author{
Cover design \\ Marko Šesnić \& Goran Turković \\ Proofreader \\ Stjepan Tribuson \\ Computer layout \\ TERCIJA d. o. o., Zagreb \\ Printed and bound by \\ M.A.K. GOLDEN d. o. o., Zagreb
}

\section{Other recent ISRZ publications in English}

Katarina Prpić (Ed.) Beyond the Myths about the Natural and Social Sciences: A Sociological View. ISRZ, 2009

Vlasta Ilišin (Ed.) Croatian Youth and European Integration. ISRZ, 2007

Dinka Marinović Jerolimov, Siniša Zrinščak \& Irena Borowik (Eds.) Religion and Patterns of Social Transformation. ISRZ, 2004

Vlasta Ilišin \& Furio Radin (Eds.) Youth and Transition in Croatia. ISRZ, 2002 